Dimy Nanclares Fernandes Sanches

\title{
Nanotubos de hidróxidos lamelares: composição, estrutura e luminescência
}

Orientador: Prof. Dr. Danilo Mustafa

Instituto de Física - Universidade de São Paulo 2021 



\author{
Universidade de São Paulo \\ Instituto de Física
}

\title{
Nanotubos de hidróxidos lamelares: composição, estrutura e luminescência
}

\author{
Dimy Nanclares Fernandes Sanches
}

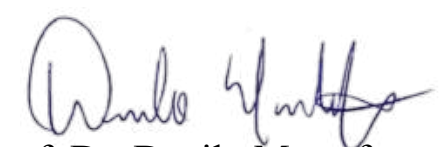

Orientador: Prof. Dr. Danilo Mustafa

Tese de doutorado apresentada ao Instituto de Física como requisito parcial para a obtenção do título de Doutor em Ciências.

Banca Examinadora:

Prof. Dr. Danilo Mustafa (IFUSP)

Profa. Dra. Helena Maria Petrilli (IFUSP)

Profa. Dra. Vera Regina Leopoldo Constantino (IQUSP)

Prof. Dr. Paulo Cesar de Sousa Filho (UNICAMP)

Profa. Dra. Verônica de Carvalho Teixeira (LNLS) 
FICHA CATALOGRÁFICA

Preparada pelo Serviço de Biblioteca e Informação do Instituto de Física da Universidade de São Paulo

\section{Sanches, Dimy Nanclares Fernandes}

Nanotubos de hidróxidos lamelares: composição, estrutura e luminescência. São Paulo, 2021.

Tese (Doutorado) - Universidade de São Paulo. Instituto de Física. Depto. de Física dos Materiais e Mecânica.

Orientador: Prof. Dr. Danilo Mustafa

Área de Concentração: Física

Unitermos: 1. Nanotubos; 2. Nanopartículas; 3. Espectroscopia óptica; 4. Fotoluminescência; 5 . Terras raras. 


\author{
Universidade de São Paulo \\ Instituto de Física
}

\title{
Layered hydroxides nanotubes: composition, structure and luminescence
}

\author{
Dimy Nanclares Fernandes Sanches
}

Supervisor: Prof. Dr. Danilo Mustafa

Examining Committee:

Prof. Dr. Danilo Mustafa

Profa. Dra. Helena Maria Petrilli

Profa. Dra. Vera Regina Leopoldo Constantino

Prof. Dr. Paulo Cesar de Sousa Filho

Profa. Dra. Verônica de Carvalho Teixeira

Thesis submitted to the Physics Institute of the University of São Paulo in partial fulfillment of the requirements for the degree of Doctor of Science. 

Ao meu irmão Gabriel Nanclares, futuro cientista. 



\section{Agradecimentos}

Não é por mera formalidade que inicio esta seção agradecendo ao meu grupo de pesquisa. Sem eles, nem uma página desta tese seria possível. Foi no Laboratório de Nanomateriais e Aplicações que reorientei minha carreira e desenvolvi todas as ferramentas que me tornaram uma física experimental.

Agradeço ao Prof. Danilo Mustafa pela orientação e pela sugestão do tema de pesquisa.

Agradeço ao meu químico preferido, Dr. Ivan Guide Nunes da Silva, por tudo que me ensinou. Nossas discussões permeiam todo meu trabalho. Agradeço também por ser minha melhor companhia pelas manhãs e nos experimentos sem horário para terminar.

Agradeço ao Dr. Alysson F. Morais, por quem nutro profunda admiração como cientista e como pessoa, por toda a generosidade e aprendizado. Você me deu os melhores conselhos, mesmo quando não os segui.

Agradeço ao Prof. Hermi Felinto de Brito por ter mantido seu laboratório de portas abertas para que eu fizesse todas as medidas preliminares de luminescência deste trabalho. Agradeço também à Profa. Maria Claudia F. C. Felinto por ter me recebido no IPEN para que eu pudesse finalizar minhas medidas de difração de raios X em plena pandemia. Agradeço ao Laboratório de Cristalografia do IFUSP, em especial aos técnicos Tarsis e Antônio Carlos, pelo apoio nas medidas de difração de raios X. Agradeço imensamente ao Alfredo Duarte, cuja experiência tornou possível as medidas de microscopia eletrônica deste material tão sensível. Agradeço à Mariana Freitas por trazer dos Estados Unidos os filtros necessários para minhas medidas no fluorímetro do LNA.

Agradeço ao Rafael por todo amor, carinho e companheirismo, por transgredir regras não ditas e permanecer ao meu lado. Eu poderia preencher muitas páginas com as razões que tenho para te agradecer, pessoais e acadêmicas, mas você gosta de concisão. Obrigada por não saber ler datas de validade.

Agradeço à Clara - minha companheira de pandemia - pelos finais de semana na USP, por ficar atrás na trilha e sobreviver, por sua câmera sempre alerta, prestes a captar nossos melhores momentos, e por ter me acolhido tão bem na sua família. Agradeço à Mari, com sua independência, humor e senso crítico, por me lembrar a todo momento de uma Dimy de muitos anos atrás. 
Agradeço à Mariana Cipolla por todo apoio, amizade e inspiração. Você esteve presente em momentos muito importantes desta jornada. Caminhar ao lado da pessoa mais sensata e acolhedora que já conheci certamente me fez aprender muito e chegar mais longe.

Agradeço à Marcela Babini, minha companheira de caverna e de trabalhos concluídos nas madrugadas, pela afinidade instantânea que tornou melhores meus dias no departamento.

Agradeço aos amigos Bruna, Renata, Tutuga, Cata, Zeca, Luisa, Baldi, Xavier, Adolfo, Ipaves, Thainá, Barbra e Morgana. Impossível mensurar a importância de cada um de vocês na minha vida e na minha carreira.

Agradeço aos meus pais, tios e primos, que sempre me apoiaram e estiveram comigo mesmo em minha eterna ausência, nesses anos em que fiz da Universidade o meu lar. Agradeço aos meus avós Alcides e Cida, que me criaram com muito carinho. Obrigada pelo exemplo de parceria. Vocês sempre foram meu porto seguro.

Escrevo esta tese em memória do meu avô Simeão, de quem herdei a curiosidade e o amor pelo conhecimento. Ele me ensinou tudo o que sabia sobre letras, números, ferramentas, motores e o mundo. Se cheguei até aqui numa área dominada por homens, foi porque aprendi com meu avô que isso era irrelevante. Escrevo também em memória da minha avó Maria del Carmo, de quem herdei a dedicação e o cuidado. Ela sempre acobertou minhas experiências científicas domésticas, que frequentemente não terminavam bem. Sou incapaz de superar a sua falta.

Agradeço a todos os docentes e funcionários do Instituto de Física, que constroem todos os dias, cada um a seu modo, uma Universidade melhor. O IFUSP foi minha casa nos últimos 11 anos e eu certamente sentirei saudades. Agradeço particularmente ao Prof. Luis Gregório G. V. Dias da Silva pelos 7 anos de trabalho e aprendizado.

Por fim, agradeço a todos os brasileiros e brasileiras que financiaram esta pesquisa (CNPq 140196/2017-0), em especial àqueles que defendem a ciência e a Universidade pública, gratuita e de qualidade. 
Todos esses que aí estão Atravancando o meu caminho, Eles passarão... Eu passarinho! (Mario Quintana) 



\section{Resumo}

Hidróxidos duplos lamelares (HDL) são uma importante classe de materiais sintéticos dados pela fórmula química $\left[\mathrm{M}_{2}^{I I} \mathrm{M}^{I I I}(\mathrm{OH})_{6}\right]^{1+}\left[\left(\mathrm{A}_{1 / n}^{n-}\right) \cdot \mathrm{yH}_{2} \mathrm{O}\right]^{1-}$. Devido à intrínseca porosidade e variedade de composições, distintas propriedades físicas e químicas foram obtidas para esse tipo de matriz inorgânica, levando à sua aplicação em diversas áreas da indústria e do conhecimento. Embora naturalmente planos, novas morfologias podem ser impostas a esses materiais em laboratório. O presente trabalho tem por objetivo estudar a influência de íons terras raras (TR) na formação de nanotubos de hidróxidos lamelares. A síntese dos materiais $\mathrm{Zn}_{2} \mathrm{Al}_{1-x} \mathrm{TR}_{x}(\mathrm{OH})_{6} \mathrm{~A}_{1 / n}^{n-} \cdot \mathrm{yH}_{2} \mathrm{O}$, com os ânions intercalantes $\mathrm{NO}_{3}^{-}$ou benzeno1,3,5-tricarboxilatos (BTC) em sua forma desprotonada, foi realizada pelo método de coprecipatação de cátions metálicos sobre uma solução de micelas cilíndricas do surfactante P123. Produzimos, com sucesso, amostras com concentrações de terras raras variando entre $\mathrm{x}=0$ e 15\%. Devido à diminuição da constante de solubilidade dos hidróxidos de terras raras ao longo da série lantanídica, os elementos de menor número atômico apresentaram tendência à formação de fases laterais. Fases puras dos hidróxidos lamelares pretendidos apenas foram obtidas para os metais com raio atômico menor que o samário. A estratégia de indução da auto-organização dos hidróxidos lamelares ao redor de micelas surfactantes cilíndricas se mostrou eficiente, gerando, com a inclusão de uma concentração ótima de $\mathrm{TR}^{3+}$ na amostra, aglomerados de nanotubos de hidróxidos lamelares com os íons $\mathrm{La}^{3+}, \mathrm{Nd}^{3+}, \mathrm{Sm}^{3+}, \mathrm{Eu}^{3+}$, $\mathrm{Gd}^{3+}, \mathrm{Tb}^{3+}$ ou $\mathrm{Dy}^{3+}$. A formação pontual de nanotubos em meio a amostras com morfologia predominantemente plana foi observada com a inclusão dos terras raras de número atômico maior que o disprósio. Em consonância com resultados reportados anteriormente para o európio, somente a adição conjunta de micelas cilíndricas de P123, BTC e lantanídeos na produção dos hidróxidos lamelares foi capaz de permitir curvaturas no material, induzindo a auto organização do sistema na morfologia de nanotubos. As propriedades espectroscópicas das amostras foram analisadas a fim de caracterizar o ambiente químico na região dos átomos lantanídeos, onde verificou-se que a intercalação de BTC nos hidróxidos lamelares reduz as simetrias dos sítios ocupados pelos TR, característica necessária para a formação dos nanotubos. A presença de BTC também se mostrou eficiente como forma de sensibilizar os íons $\mathrm{Eu}^{3+}, \mathrm{Tb}^{3+}, \mathrm{Sm}^{3+}$ e $\mathrm{Dy}^{3+}$, gerando uma nova classe de nanotubos fotoluminescentes. 



\section{Abstract}

Layered double hydroxides (LDH) are an important class of synthetic materials given by the chemical formula $\left[\mathrm{M}_{2}^{I I} \mathrm{M}^{I I I}(\mathrm{OH})_{6}\right]^{1+}\left[\left(\mathrm{A}_{1 / n}^{n-}\right) \cdot \mathrm{yH}_{2} \mathrm{O}\right]^{1-}$. Due to its intrinsic porosity and diversity of compositions, different physical and chemical properties were obtained for this type of inorganic matrix, leading to its application in several areas of industry and knowledge. Although naturally flat, new morphologies can be imposed on these materials in the laboratory. The present work aims to study the influence of rare earth ions (RE) in the formation of layered hydroxides nanotubes. The synthesis of $\mathrm{Zn}_{2} \mathrm{Al}_{1-x} \mathrm{RE}_{x}(\mathrm{OH})_{6} \mathrm{~A}_{1 / n}^{n-} \cdot \mathrm{yH}_{2} \mathrm{O}$ were performed by the method of co-precipation of metallic cations on a cylindrical micelles' solution of the surfactant P123. We have successfully produced samples with rare earth concentrations ranging from $\mathrm{x}=0$ to $30 \%$. Due to the decrease in the solubility constant of rare earth hydroxides along the lanthanide series, the elements with the lowest atomic number tended to form lateral phases. Pure phases of the intended layered hydroxides were only obtained for metals with an atomic radius smaller than samarium. The strategy of inducing the self-assembly of lamellar hydroxides around cylindrical surfactant micelles proved to be efficient, yielding, with the inclusion of an optimal concentration of $\mathrm{RE}^{3+}$ in the sample, agglomerates of layered hydroxide nanotubes with the ions $\mathrm{La}^{3+}, \mathrm{Nd}^{3+}, \mathrm{Sm}^{3+}$, $\mathrm{Eu}^{3+}, \mathrm{Gd}^{3+}, \mathrm{Tb}^{3+}$ or $\mathrm{Dy}^{3+}$. Some localized nanotubes among samples with predominantly flat morphology was observed with the inclusion of rare earths smaller than dysprosium. In line with previously reported results for europium, only the combined addition of cylindrical micelles of P123, benzene-1,3,5-tricarboxylates (BTC) and lanthanides in the production of layered hydroxides was able to allow curvatures in the material, inducing the self-assembly of the system in the morphology of nanotubes. The spectroscopic properties of the samples were analyzed in order to characterize the chemical environment in the region of the lanthanide ions, where it was found that the intercalation of BTC reduces the symmetries of the sites occupied by the RE, a necessary characteristic for the formation of nanotubes. The presence of BTC was also efficient as a way to sensitize the ions $\mathrm{Eu}^{3+}, \mathrm{Tb}^{3+}, \mathrm{Sm}^{3+}$ and $\mathrm{Dy}^{3+}$, yielding a new class of photoluminescent nanotubes. 



\section{Lista de ilustrações}

Figura 1 - Estrutura cristalina da brucita . . . . . . . . . . . . . . . . . 27

Figura 2 - Estrutura cristalina de um HDL . . . . . . . . . . . . . . . . 28

Figura 3 - Rede cristalina de uma lamela de HDL . . . . . . . . . . . . . . . . . . 29

Figura $4-$ Polímero Plurônico ${ }^{\circledR} \mathrm{P} 123 \ldots \ldots$. . . . . . . . . . . . . . 30

Figura 5 - Micelas de P123. . . . . . . . . . . . . . . . . . . 30

Figura 6 - Representação das lamelas de um HDL e de um TR $(\mathrm{OH})_{2.5} \ldots$. . . . . 31

Figura 7 - Diagrama esquemático dos orbitais . . . . . . . . . . . . . . 34

Figura 8 - Diagrama de configurações eletrônicas . . . . . . . . . . . . . . 35

Figura $9-$ Diagrama de Dieke . . . . . . . . . . . . . . . . . 39

Figura 10 - Diagrama esquemático das energias de um lantanídeo com as correções de cada interação . . . . . . . . . . . . . . . . . . . . . . . . 40 40

Figura 11 - Espectro de absorção do óxido de holmio . . . . . . . . . . . . . . . . . 47

Figura 12 - Efeito antena . . . . . . . . . . . . . . . . . . 51

Figura 13 - Difração de raios X . . . . . . . . . . . . . . . . . . 54

Figura 14 - Análise termogravimétrica . . . . . . . . . . . . . . . . . 55

Figura $15-$ Análise elementar $-\mathrm{CHN}$. . . . . . . . . . . . . . . . . 56

Figura 16 - Análise elementar - ICP . . . . . . . . . . . . . . . . . 57

Figura 17 - Diagrama esquemático de um microscópio eletrônico de transmissão . . . 59

Figura 18 - Diagrama esquemático de um fluorímetro . . . . . . . . . . . . . . . 60

Figura 19 - Diagrama esquemático do processo de síntese . . . . . . . . . . . . . . 62

Figura 20 - Difração de raios X das amostras ZnAl-NO ${ }_{3}-\mathrm{P} 123$ e ZnAl-BTC-P123 . . 67

Figura 21 - Difração de raios X das amostras ZnAlTR5\%-BTC-P123 . . . . . . . . . 69

Figura 22 - Difração de raios X para diferentes concentrações de TR . . . . . . . . . 71

Figura 23 - Termogravimetria das amostras contendo Dy e Er . . . . . . . . . . . 73

Figura 24 - Termogravimetria das amostras contendo Sm, Eu, Gd e Tb. . . . . . . . 74

Figura 25 - Termogravimetria das amostras contendo La e Nd . . . . . . . . . . . 75

Figura 26 - Termogravimetria com diferentes concentrações de TR . . . . . . . . . 76

Figura 27 - Microscopia eletrônica de transmissão das principais amostras . . . . . . 79 
Figura 28 - Microscopia eletrônica da amostra ZnAl-BTC-P123 . . . . . . . . . . . . 81

Figura 29 - Microscopia eletrônica das amostras com La ou Nd (x $\leq 5 \%)$. . . . . . . 82

Figura 30 - Diâmetro dos nanotubos contendo La e Nd - histograma . . . . . . . . . 83

Figura 31 - Microscopia eletrônica das amostras com La e Nd $(\mathrm{x}=15 \%)$. . . . . . . 84

Figura 32 - Microscopia eletrônica das amostras com Sm . . . . . . . . . . . . . . . 85

Figura 33 - Diâmetro dos nanotubos contendo Sm - histograma . . . . . . . . . . . . 86

Figura 34 - Microscopia eletrônica das amostras com Eu . . . . . . . . . . . . . . . 87

Figura 35 - Diâmetro dos nanotubos contendo Eu - histograma . . . . . . . . . . . . 88

Figura 36 - Perfil de um nanotubo . . . . . . . . . . . . . . . . . . . . 88

Figura 37 - Microscopia eletrônica das amostras com Gd ou Tb . . . . . . . . . . . . 90

Figura 38 - Diâmetro dos nanotubos contendo Gd - histograma . . . . . . . . . . . . 91

Figura 39 - Diâmetro dos nanotubos contendo Tb-histograma . . . . . . . . . . . . 91

Figura 40 - Microscopia eletrônica das amostras com Dy . . . . . . . . . . . . . . . . 92

Figura 41 - Diâmetro dos nanotubos contendo Dy - histograma . . . . . . . . . . . . 93

Figura 42 - Microscopia eletrônica das amostras com Ho, Er, Tm ou Lu . . . . . . . 94

Figura 43 - Microscopia eletrônica das amostras com Y ou Pr . . . . . . . . . . . . . 95

Figura 44 - Diâmetro dos nanotubos contendo Y ou Pr - histogramas . . . . . . . . . 96

Figura 45 - Microscopia eletrônica das amostras com Y e Pr . . . . . . . . . . . . 96

Figura 46 - Diâmetro dos nanotubos mistos de YPr- histograma . . . . . . . . . . . 97

Figura 47 - Dimensões médias dos nanotubos sintetizados para cada TR . . . . . . . 98

Figura 48 - Foto das amostras expostas a radiação UV . . . . . . . . . . . . . . . . 102

Figura 49 - Espectros de excitação e emissão do BTC . . . . . . . . . . . . . . . . 103

Figura 50 - BTC e Diagrama de Dieke . . . . . . . . . . . . . . . . . . 104

Figura 51 - Espectro de emissão do $\mathrm{Eu}^{3+}$ em escala logarítmica $\ldots . . .106$

Figura 52 - Espectros de excitação e emissão da amostra $\mathrm{Zn}_{2} \mathrm{Al}_{0.95} \mathrm{Eu}_{0.05}$-BTC-P123 107

Figura 53 - Ajuste do tempo de vida do estado $\left(\mathrm{Eu}^{3+}\right)^{7} \mathrm{~F}_{0} \ldots \ldots$. . . . . . . . . . 110

Figura 54 - Espectros de excitação e emissão da amostra $\mathrm{Zn}_{2} \mathrm{Al}_{0.95} \mathrm{Sm}_{0.05}$-BTC-P123 111

Figura 55 - Espectro de emissão da amostra ZnAlSm15\%-BTC-P123 . . . . . . . . . 112

Figura 56 - Ajuste do tempo de vida do estado $\left(\mathrm{Sm}^{3+}\right)^{6} \mathrm{H}_{9 / 2}$. . . . . . . . . . . . . . 114

Figura 57 - Espectros de excitação e emissão da amostra $\mathrm{Zn}_{2} \mathrm{Al}_{0.95} \mathrm{~Tb}_{0.05}$-BTC-P123. 115

Figura 58 - Ajuste do tempo de vida do estado $\left(\mathrm{Tb}^{3+}\right)^{7} \mathrm{~F}_{5} \ldots \ldots \ldots$. . . . . . . . . 119 
Figura 59 - Espectros de excitação e emissão da amostra ZnAlDy5\%-BTC-P123 . . . 120

Figura 60 - Ajuste do tempo de vida do estado $\left(\mathrm{Dy}^{3+}\right)^{6} \mathrm{H}_{13 / 2} \ldots \ldots \ldots . . \ldots 121$

Figura A.1-XRD das amostras contendo 5\% de Y, Pr, Ho, Tm, Yb e Lu . . . . . . . 135

Figura A.2-XRD das amostras contendo 15\% de TRs . . . . . . . . . . . 136

Figura B.1-Termogravimetria das amostras contendo Y, Pr, Ho, Tm e Lu . . . . . . 137 



\section{Lista de tabelas}

Tabela 1 - Regras de seleção do íon livre . . . . . . . . . . . . . . . . . 38

Tabela 2 - Regras de seleção de Judd-Ofelt . . . . . . . . . . . . . . . . 45

Tabela 3 - Materiais e compostos . . . . . . . . . . . . . . . . . . . . 61

Tabela 4 - Propriedades cristalográficas . . . . . . . . . . . . . . . . 68

Tabela 5 - Composição das amostras e fórmula empírica . . . . . . . . . . . 77

Tabela 6 - Características dos nanotubos . . . . . . . . . . . . . . . . 97

Tabela 7 - Ajuste da primeira esfera de coordenação para os dados de EXAFS da borda LIII do Eu nas amostras ZnAlEux\%-BTC-P123. . . . . . . . . . . 99

Tabela 8 - Características das micrografias analisadas . . . . . . . . . . . . . . 101

Tabela 9 - Propriedades das emissões ${ }^{5} \mathrm{D}_{0} \rightarrow{ }^{7} \mathrm{~F}_{J}$ do íon $\mathrm{Eu}^{3+} \ldots \ldots \ldots \ldots$

Tabela 10 - Termos de matriz reduzida $\mathrm{U}_{\lambda}^{2}$ do 1 on $\mathrm{Eu}^{3+} \ldots \ldots \ldots$. . . . . . 108

Tabela 11 - Parâmetros fenomenológicos de Judd Ofelt do íon $\mathrm{Eu}^{3+}$. . . . . . . . . . 109

Tabela 12 - Taxas de transição e eficiência quântica das amostras contendo európio . 109

Tabela 13 - Propriedades das emissões ${ }^{4} \mathrm{G}_{5 / 2} \rightarrow{ }^{6} \mathrm{H}_{J}$ do íon $\mathrm{Sm}^{3+} \ldots \ldots$. . . . . 111

Tabela 14 - Termos de matriz reduzida $\mathrm{U}_{\lambda}^{2}$ do íon $\mathrm{Sm}^{3+} \ldots$. . . . . . . . . . . 113

Tabela 15 - Parâmetros fenomenológicos de Judd Ofelt do íon $\mathrm{Sm}^{3+}$. . . . . . . . 113

Tabela 16 - Taxas de transição e eficiência quântica das amostras contendo samário . 114

Tabela 17 - Propriedades das emissões ${ }^{5} \mathrm{D}_{4} \rightarrow{ }^{7} \mathrm{~F}_{J}$ do íon $\mathrm{Tb}^{3+} \ldots \ldots \ldots$. . . . 116

Tabela 18 - Termos de matriz reduzida $\mathrm{U}_{\lambda}^{2}$ do íon $\mathrm{Tb}^{3+} \ldots \ldots \ldots 116$

Tabela 19 - Parâmetros fenomenológicos de Judd Ofelt do íon $\mathrm{Tb}^{3+}$. . . . . . . . . . 118

Tabela 20 - Taxas de transição e eficiência quântica das amostras contendo térbio . . 119

Tabela 21 - Propriedades das emissões ${ }^{4} \mathrm{~F}_{9 / 2} \rightarrow{ }^{2 S+1} \mathrm{~L}_{J}$ do íon Dy ${ }^{3+} \ldots$. . . . . . 120

Tabela 22 - Parâmetros fenomenológicos de Judd Ofelt do íon Dy ${ }^{3+}$. . . . . . . . . . 121

Tabela 23 - Taxas de transição e eficiência quântica das amostras contendo disprósio 121 



\section{Sumário}

$1 \quad$ Introdução . . . . . . . . . . . . . . . . . . . . . 25

2 Hidróxidos lamelares . . . . . . . . . . . . . . . . . . . . 27

2.1 Estrutura cristalina e composição . . . . . . . . . . . . . . . . . 27

$2.2 \quad$ Morfologias . . . . . . . . . . . . . . . . . . . . . . . . . . . . . 29

3 Elementos terras raras $\ldots \ldots \ldots \ldots \ldots$

3.1 Níveis eletrônicos de íons lantanídeos livres . . . . . . . . . . . . . . . . . . 34

3.2 Propriedades espectroscópicas $\ldots \ldots \ldots \ldots \ldots \ldots$

$3.2 .1 \quad$ Diagrama de Dieke . . . . . . . . . . . . . . . . . . . . 38

3.2 .2 Teoria de Judd-Ofelt $\ldots \ldots \ldots$. . . . . . . . . . . . . . 40

3.3 Relacionando resultados experimentais à teoria $\ldots \ldots \ldots \ldots$

3.4 Efeito antena . . . . . . . . . . . . . . . . . . . . . . 50

4 Técnicas de caracterização $\ldots \ldots \ldots \ldots$. . . . . . . . . . . . . 53

4.1 Difração de raios $\mathrm{X}$. . . . . . . . . . . . . . . . . . . . . . . . 53

4.2 Termogravimetria $\ldots \ldots \ldots \ldots \ldots \ldots \ldots \ldots$

4.3 Análise elementar: CHN . . . . . . . . . . . . . . . . . . . 56

4.4 Análise elementar: ICP-OES . . . . . . . . . . . . . . . . . 56

4.5 Microscopia eletrônica de transmissão $\ldots \ldots \ldots \ldots$. . . . . . . . . 57

4.6 Fotoluminescência . . . . . . . . . . . . . . . . . . . . . . . . . . . . . . . . . . 59

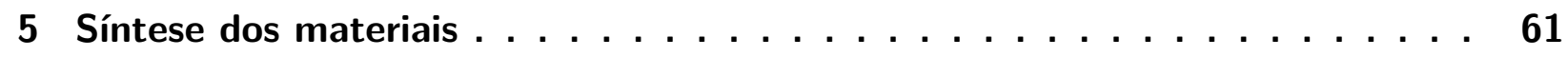

$5.1 \quad$ Materiais e compostos utilizados $\ldots \ldots \ldots \ldots \ldots$. . . . . . . . 61

5.2 Procedimentos . . . . . . . . . . . . . . . . . . . . . . 61

6 Resultados . . . . . . . . . . . . . . . . . . . . . 65

6.1 Caracterização estrutural . . . . . . . . . . . . . . . . . . . . . 65

6.2 Estabilidade térmica $\ldots \ldots \ldots \ldots \ldots \ldots \ldots$

6.3 Análise elementar . . . . . . . . . . . . . . . . . . 76

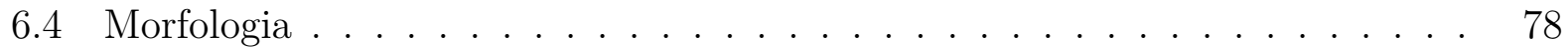

6.5 Propriedades espectroscópicas $\ldots \ldots \ldots \ldots$

6.5 .1 BTC: fluorescência, fosforescência e o efeito antena . . . . . . . . . 102 
6.5 .2 Európio . . . . . . . . . . . . . . . . . . . . . 105

6.5 .3 Samário . . . . . . . . . . . . . . . . . . . 110

6.5 .4 Térbio . . . . . . . . . . . . . . . . . . . . . . . . . . . . . 114

6.5 .5 Disprósio $\ldots \ldots \ldots \ldots \ldots$

6.5.6 Considerações gerais sobre a luminescência das amostras estudadas . 121

7 Conclusão . . . . . . . . . . . . . . . . . . . . . . . . . 123

Bibliografia . . . . . . . . . . . . . . . . . . . . 125

ANEXO A Medidas complementares de PXRD . . . . . . . . . . . . . . . . . 135

ANEXO B Medidas complementares de estabilidade térmica . . . . . . . . . . 137

ANEXO C Código para cálculo dos parâmetros fenomenológicos de Judd Ofelt 139 


\section{Introdução}

A descoberta dos hidróxidos duplos lamelares (HDL) remonta ao século XIX, quando mineralogistas encontraram a hidrotalcita, sua forma natural mais conhecida. [1] Sua estrutura é formada por lamelas de hidróxidos positivamente carregadas, compostas pelos metais magnésio e alumínio cercados por hidroxilas e centrados em unidades octaédricas justapostas. Entre as camadas positivas, são intercalados carbonatos e moléculas de água fracamente ligados às camadas de hidróxidos, que tendem a se empilhar, dando origem ao sólido lamelar observado: $\mathrm{Mg}_{6} \mathrm{Al}_{2} \mathrm{CO}_{3}(\mathrm{OH})_{16} \cdot 4 \mathrm{H}_{2} \mathrm{O}$. 22

Apenas em meados do século XX foram reportadas as primeiras sínteses desta classe de materiais, com a produção de HDLs de magnésio e alumínio em laboratório. 3] Desde então, diversas composições foram testadas na literatura considerando-se diferentes metais divalentes $(\mathrm{Zn}, \mathrm{Fe}, \mathrm{Mg}, \mathrm{Ni}, \ldots)$ e trivalentes $(\mathrm{Al}, \mathrm{Fe}, \mathrm{Mg}, \ldots)$, bem como um grande leque de ânions ligantes na intercalação das camadas. 4, 5] Devido à intrínseca porosidade do material e variedade de composições, distintas propriedades físicas e químicas foram obtidas para esse tipo de matriz inorgânica, levando à sua aplicação na forma de eletrólitos sólidos, catalisadores, adsorventes e liberadores de fármacos. 6 - 14

A alta demanda por novos materiais funcionais em áreas como catálise, cromatografia, nanomedicina, sensores e armazenamento de energia, [15 21 torna tais materiais, ainda hoje, tema de grande interesse científico e comercial. 22, 23] Apesar do sucesso de sua aplicação em diversas áreas devido principalmente à facilidade de síntese e baixo custo de produção, algumas limitações como baixa área superficial e restritas distâncias interlamelares, geralmente da ordem de 1 a $3 \mathrm{~nm}$, 24] são entraves a serem superados para que as potencialidades dos hidróxidos lamelares possam ser alcançadas.

Uma estratégia emergente na literatura para a criação de mesoporos e aumento das áreas superficiais nesses sistemas é dada por sua nanoestruturação. 25] Nanotubos de carbono, nanofios de $\mathrm{NiCO}_{2} \mathrm{O}_{4}$ e microesferas de $\mathrm{Fe}_{3} \mathrm{O}_{4}$ foram utilizados como suporte de nanopartículas de HDL, impondo com sucesso uma ordem tridimensional ao material. 26 29] Esta abordagem, no entanto, mantém inacessíveis os mesoporos, limitando as propriedades difusivas do sistema e suas possíveis aplicações. Poucos HDLs autossuportados foram relatados 
até o momento na literatura, possuindo morfologia de poliedros, [30 nanoesferas, [26] microesferas, [26, 31], nanocones [19, 32], nanoflores [33] e enrolamentos. [34] Enquanto os três primeiros possuem propriedades difusivas limitadas e potenciais aplicações como hospedeiros, carregadores ou liberadores de substâncias maiores que aquelas presentes em suas galerias, o oposto ocorre no caso dos nanocones, nanoflores e enrolamentos.

A primeira síntese auto-organizada de nanotubos ocos de hidróxidos lamelares autossuportados foi relatada por nosso grupo de pesquisa, [35] sendo tema de uma tese de doutorado [36] e resultando em uma patente aos pesquisadores envolvidos. 37] Os materiais, produzidos pelo método de coprecipitação de cátions metálicos sobre uma solução de micelas surfactantes, resultavam em nanotubos ocos após a remoção dos moldes poliméricos. Foi demonstrado que a cristalização das lamelas em cascas cilíndricas só era possível na presença de íons $\mathrm{Eu}^{3+}$, que eram incorporados nas camadas de hidróxidos, relaxando a estrutura plana usualmente rígida dos HDLs e permitindo curvaturas. Comparando materiais com a mesma composição, mas morfologias distintas, os nanotubos produzidos apresentaram áreas superficiais 5 vezes maiores que seus equivalentes planos, além de manifestar a presença conjunta de micro e mesoporos nas amostras. 38

Neste contexto, o objetivo deste trabalho de doutorado é generalizar o processo de síntese dos nanotubos de hidróxidos lamelares para outras composições com diferentes terras raras e investigar o papel desses elementos na estrutura e luminescência dos materiais produzidos, ampliando o leque de potenciais aplicações e melhorando o entendimento, a caracterização e o controle do sistema.

Uma introdução teórica sobre a estrutura cristalina e morfologia dos hidróxidos lamelares descritos na literatura é apresentada no Capítulo 2. Em seguida (Cap. 3), estudamos os metais terras raras e suas propriedades espectroscópicas, modeladas pela Teoria de JuddOfelt. As técnicas de caracterização empregadas e os procedimentos de síntese dos materiais são descritos nos Capítulos 4 e 5 , respectivamente. Por fim, os resultados deste trabalho, organizados no Capítulo 6, são divididos entre a caracterização estrutural dos materiais, sua estabilidade térmica, composição, morfologia e propriedades espectroscópicas. 


\section{Hidróxidos lamelares}

\subsection{Estrutura cristalina e composição}

A estrutura básica dos hidróxidos lamelares pode ser entendida em termos da brucita, um mineral composto de hidróxido de magnésio, cuja estrutura cristalina está representada na Figura 1. Nesse composto, o magnésio se posiciona no centro de um poliedro distorcido de coordenação octaédrica, cujas arestas são compartilhadas com as unidades vizinhas, de modo a formar uma camada bidimensional [4]. As hidroxilas se posicionam perpendicularmente ao plano formado pelos íons magnésio. Hidróxidos do tipo $\mathrm{M}^{I I}(\mathrm{OH})_{2}$, formados por outros metais com estado de oxidação II, possuem a mesma estrutura cristalina da brucita.

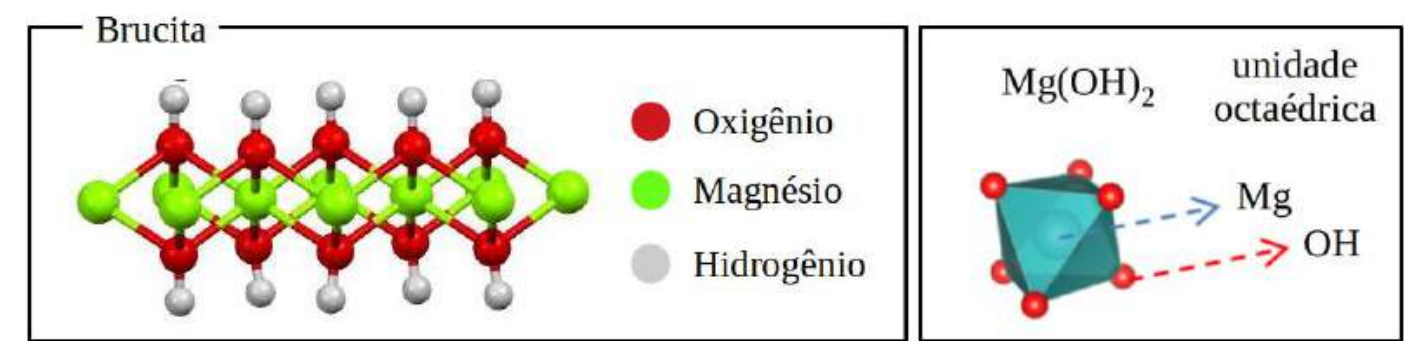

Figura 1 - Estrutura cristalina da brucita - $\mathrm{Mg}(\mathrm{OH})_{2}$. Os magnésios permanecem centrados em unidades octaédricas, que compartilham as bordas entre si, de modo a formar um plano. Adaptado de Smokefoot - Own work, CC BY-SA 4.0, Wikimedia / Alysson Morais [36.

Se alguns íons da camada $\mathrm{M}^{I I}(\mathrm{OH})_{2}$ são substituídos por metais com estado de oxidação III, a estrutura cristalina é mantida, restando uma lamela positivamente carregada. Neste cenário, a tendência é que ânions disponíveis no meio se aproximem do sistema de forma a balancear a carga, induzindo, por sua vez, outra lamela positivamente carregada a se aproximar, e assim sucessivamente. A estrutura formada desta maneira é o hidróxido duplo lamelar (HDL), cuja fórmula geral é dada por $\left[\mathrm{M}_{1-x}^{I I} \mathrm{M}_{x}^{I I I}\left(\mathrm{OH}^{-}\right)_{2}\right]^{x+} \mathrm{A}_{x / n}^{n-}$. A estrutura cristalina desses materiais, formados pelo empilhamento de hidróxidos, está ilustrada na Figura 2.

O espaço entre as camadas de hidróxidos, onde ficam os ligantes aniônicos, é chamado de região interlamelar. O tamanho desta região é normalmente definido pelo comprimento 


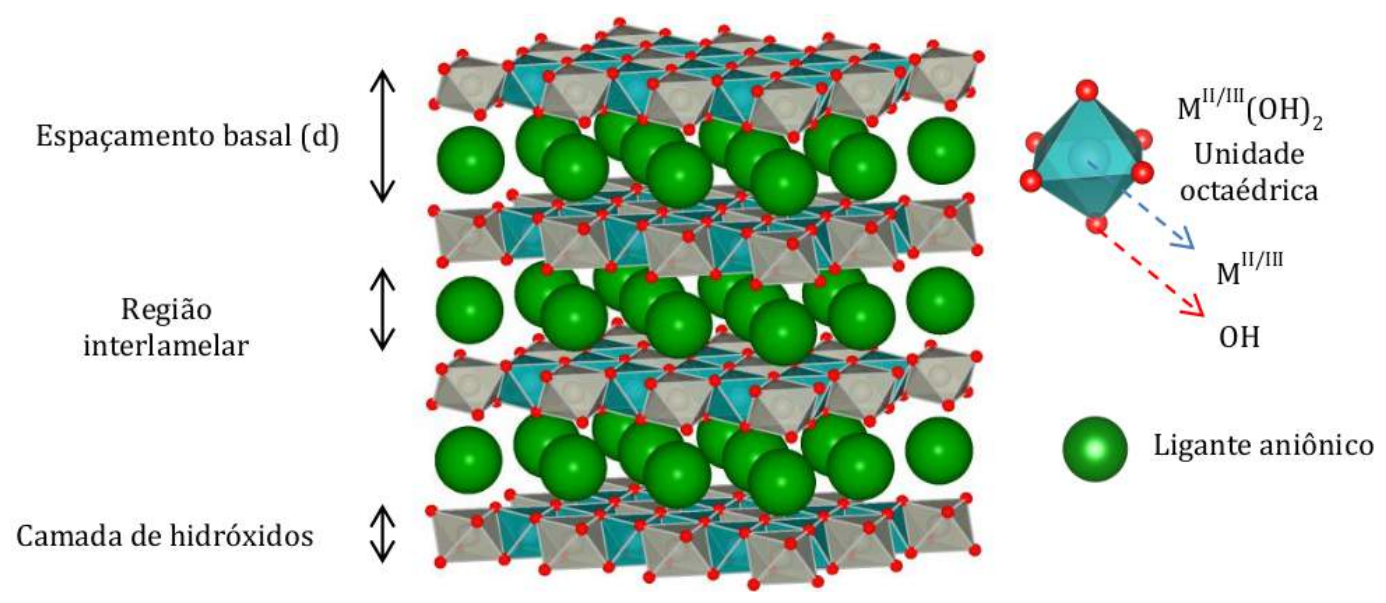

Figura 2 - Estrutura cristalina de um HDL. Camadas de hidróxidos são intercaladas por ligantes aniônicos na região interlamelar. A composição de cada camada é dada por metais com números de oxidação II e III, centrados em unidades octaédricas. [39].

e posicionamento dos ligantes. Podemos caracteriza-lo pelo espaçamento basal, dado pela distância entre uma camada e sua subsequente. Por conta da interação fraca entre as camadas metálicas, dentro de um certo intervalo onde a atração é suficiente para garantir o empilhamento das lamelas, é possível variar o espaçamento basal livremente em função dos ânions intercalados.

O plano constituído pelos metais possui rede triangular, com vetores $\vec{e}_{1}$ e $\vec{e}_{2}$ formando um ângulo de $120^{\circ}$ entre si no plano xy, como ilustrado na Figura 3 . O vetor $\vec{e}_{3}$ liga uma camada de hidróxidos à camada imediatamente superior, isto é, chamando "d" o espaçamento basal, $\overrightarrow{e_{3}}=\mathrm{d} \hat{k}+\vec{Q}$, onde $\vec{Q}$ é um possível deslocamento no plano xy entre camadas subsequentes. O empilhamento perfeito das lamelas só ocorre para $\mathrm{Q}_{x}$ e $\mathrm{Q}_{y}$ racionais, após a repetição de um dado número de camadas. Esta característica é denominada polimorfismo.

Quando a proporção entre metais com estado de oxidação II e metais com estado de oxidação III é muito maior que o dobro $\left(\mathrm{M}^{I I}: \mathrm{M}^{I I I} \gg 2: 1\right)$, os cátions mais positivos se distribuem de maneira aleatória na rede. À medida que a proporção se aproxima de $\mathrm{M}^{I I}: \mathrm{M}^{I I I}$ $=2: 1$, a repulsão entre os metais $\mathrm{M}^{I I I}$ faz com que eles se organizem para permitir apenas cátions $\mathrm{M}^{I I}$ ao seu redor, resultando no quadro da direita na Figura 3.

A formação de HDL é desfavorável para $\mathrm{M}^{I I}: \mathrm{M}^{I I}<2: 1$, uma vez que o excesso de metais com estado de oxidação III implicaria na ocupação sítios vizinhos. Sem terem a carga compensada pelas hidroxilas, a repulsão entre os cátions $\mathrm{M}^{I I I}-\mathrm{M}^{I I I}$ não permite que 


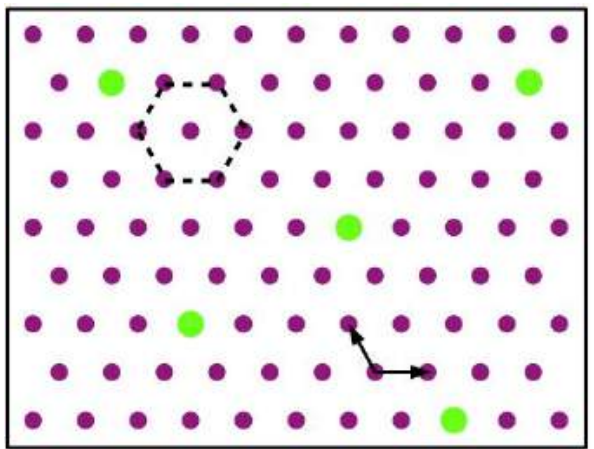

$\mathrm{M}^{\mathrm{II}}: \mathrm{M}^{\mathrm{III}}>2: 1$

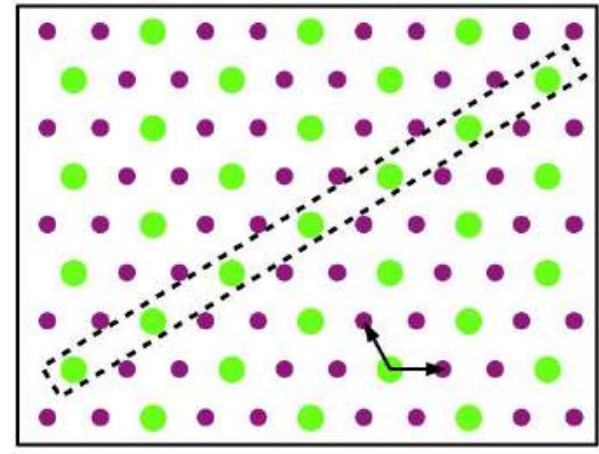

$\mathrm{M}^{\mathrm{II}}: \mathrm{M}^{\mathrm{III}}=2: 1$
- $\mathrm{M}^{\mathrm{II}}$

$\mathrm{M}^{\mathrm{III}}$

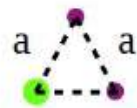

a

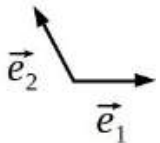

Figura 3 - Rede triangular do plano formado pelos metais em uma lamela de HDL. No quadro da esquerda, a proporção $\mathrm{M}^{I I}: \mathrm{M}^{I I I}$ é maior que $2: 1$, resultando no posicionamento aleatório dos íons $\mathrm{M}^{I I I}$, enquanto para $\mathrm{M}^{I I}: \mathrm{M}^{I I I}=2: 1$, os metais $\mathrm{M}^{I I I}$ formam uma sub-rede organizada.

as ligações eletrônicas sejam formadas. Esse tipo de estrutura apenas foi reportado em algumas composições para valores de temperatura e pressão maiores que o ambiente, forçando sua estabilidade pela diminuição da solubilidade dos metais. Temos em condições normais, portanto, a lamela com maior carga positiva para a proporção $\mathrm{M}^{I I}: \mathrm{M}^{I I I}=2: 1[40,42]$.

\subsection{Morfologias}

Em sua forma natural, devido à estrutura cristalina plana das lamelas, hidróxidos duplos lamelares possuem morfologia de placas 4,43 . Ainda que seja de grande utilidade para diversas aplicações, poucos estudos são encontrados explorando diferentes morfologias nesses materiais. Em especial, a imposição de morfologias tridimensionais foi relatada apenas recentemente pela deposição de placas de HDL em outros sistemas que permanecem de suporte para a estruturação atípica. Nanocones [44], nanoesferas [26] e enrolamentos 34] autossuportados também foram produzidos.

A síntese de HDL autossuportado com morfologia nanotubular foi reportada pela primeira vez por nosso grupo [35]. Como estratégia para a estruturação do HDL em forma de nanotubos, foram utilizados surfactantes para a produção de micelas cilíndricas que foram posteriormente utilizadas como moldes, induzindo a formação do material em sua superfície.

Surfactantes são compostos capazes de reduzir a tensão interfacial entre duas substâncias. Usualmente, são polímeros ou outras moléculas orgânicas de comportamento anfifílico, con- 
tendo uma região polar (hidrofílica) e outra apolar (hidrofóbica). O polímero P123, ilustrado na Figura 4, é um exemplo de surfactante. Ele possui dois blocos polares polietilenoglicol (PEG) em suas extremidades, com um bloco apolar polipropilenoglicol (PPG) entre ambos.
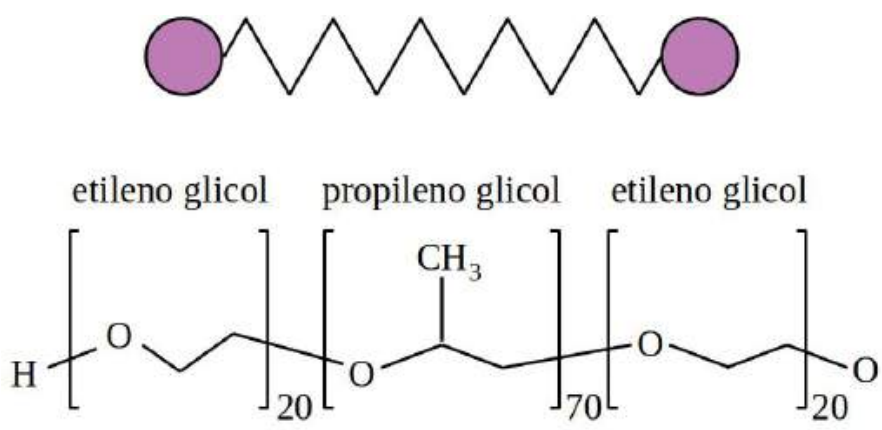

Figura 4 - Diagrama e fórmula estrutural do polímero Plurônic ${ }^{\circledR}$ P123, que possui em seus extremos os blocos polares polietilenoglicol (PEG) e na região central a cadeia apolar polipropilenoglicol (PPG).

Em solução aquosa, a região polar é capaz de interagir com a água, permitindo a dissolução do surfactante. A região apolar, por outro lado, tende a afastar as moléculas de $\mathrm{H}_{2} \mathrm{O}$, e na presença de outra substância de caráter apolar, tende a se aproximar da mesma, reduzindo a tensão superficial entre os compostos. Na ausência de substância apolar, a existência de uma cadeia do surfactante com este caráter faz com que as moléculas de água ao seu redor fiquem em um estado mais energético que as demais moléculas do solvente, que realizaram ligações de hidrogênio nas regiões polares. Para minimizar a energia do sistema, os surfactantes tendem a se organizar em micelas, porções de material onde as partes apolares se agregam protegidas pela região polar da molécula, como ilustrado na Figura 5.
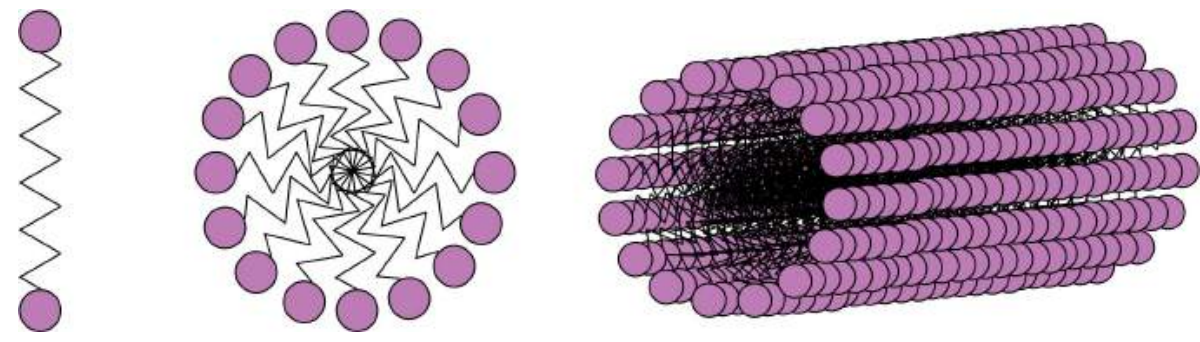

Figura 5 - À esquerda, observa-se a representação esquemática da molécula P123. Ao aumentar a disponibilidade de surfactante em meio aquoso, as moléculas se agregam formando uma micela esférica, cuja secção transversal está ilustrada ao centro. Elevando ainda mais a concentração, há formação de micelas do tipo bastão, como a figura da direita.

As configurações das micelas são determinadas pela temperatura e concentração de sur- 
factante no solvente. No caso do P123, com a elevação gradual da concentração em meio aquoso, o polímero se organiza em micelas esféricas. Inicialmente, tais micelas possuem diâmetro reduzido, da ordem de nanômetros, com as cadeias apolares enoveladas entre as regiões polares. Aumentando a disponibilidade das moléculas no solvente, o diâmetro dessas micelas aumenta até o limite de $20 \mathrm{~nm}$, correspondente ao comprimento da cadeia apolar. A partir deste momento, se a concentração de P123 é aumentada, as esferas começam a se unir de modo a formar bastões de diâmetro $20 \mathrm{~nm}$. Tais bastões são usados como moldes na síntese dos HDL com morfologia de nanotubos. [45, 46]

Entretanto, a simples produção de hidróxidos duplos lamelares em solução contendo micelas cilíndricas não é suficiente para impor a estruturação do material em forma de tubo. A rede formada pelas lamelas possui configuração bidimensional e é rígida, de modo que a camada fica impedida de se curvar, permitindo apenas a formação de placas.

Foi demonstrado por Ma e Sasaki [47] que hidróxidos lamelares formados por metais terras raras, ao contrário do que é observado para cátions $\mathrm{M}^{I I}$ e $\mathrm{M}^{I I I}$ mais leves, não possuem uma estrutura plana regular. Enquanto metais como zinco, alumínio, magnésio ou ferro apresentam número de coordenação igual a 6, os íons terras raras apresentam número de coordenação superior, usualmente variando entre 8 e 12. A lamela de hidróxido sintetizada dessa forma tem a aparência de uma folha amassada, como ilustrado na Figura 6rB.
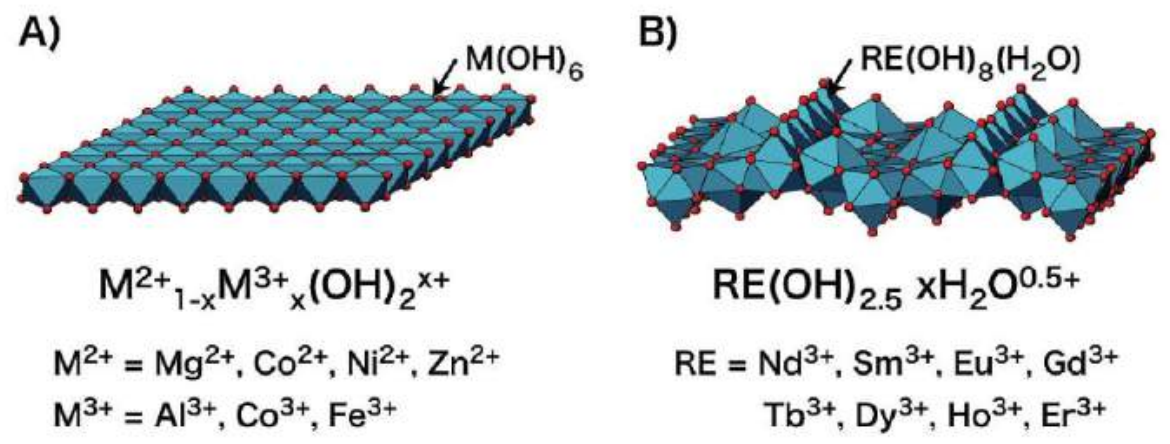

Figura 6 - A) Lamela plana formada por hidróxidos $\mathrm{M}_{1-x}^{I I} \mathrm{M}_{x}^{I I I}(\mathrm{OH})_{2}^{x+}$, cujos metais possuem número de coordenação 6 e estão centrados em unidades $\mathrm{M}(\mathrm{OH})_{6}$. B) Lamela "amassada" formada por hidróxidos de terras raras com número de coordenação 8 [47].

Essa flexibilização da estrutura cristalina permite que as lamelas se curvem, possibilitando a imposição de morfologias 3D aos hidróxidos duplos lamelares. Para viabilizar a síntese dos nanotubos, realizamos dopagem com íons terras raras em substituição aos metais 
$\mathrm{M}^{I I I}$. Além deste efeito desejável quanto à morfologia, os terras raras possuem características espectroscópicas importantes, permitindo a formação de materiais luminescentes e fornecendo informações a respeito do ambiente químico ao seu redor, como será discutido no capítulo seguinte. 


\section{Elementos terras raras}

Os elementos terras raras (TR) são um conjunto de 17 metais constituído pelo escândio, ítrio e lantanídeos, que constituem parte do grupo 3 da tabela periódica. Lantanídeos são os elementos de número atômico entre 57 e 71. Possuem orbital $4 \mathrm{f}^{n}$ parcialmente preenchido, cujos elétrons são blindados eletrostaticamente do ambiente externo pelas camadas 5 e 6 , preferencialmente envolvidas em ligações químicas ou ionização. Por esta razão, mesmo quando os lantanídeos são inseridos em ambiente cristalino, seus níveis energéticos 4f não sofrem grandes alterações. Esta característica confere aos lantanídeos transições eletrônicas finas, algumas posicionadas na região do visível, dando origem ao efeito de luminescência com propriedades espectroscópicas muito bem definidas.

A absorção e emissão de fótons com tais características é responsável por inspirar pesquisas com a aplicação de terras raras no campo da fotônica e materiais luminescentes em geral. O európio, por exemplo, é utilizado como marca de segurança contra falsificações nas notas de euro, na produção de vidros flourescentes e em telas, por conta de sua emissão fina na região do vermelho. Outros terras raras, além de explorados por suas propriedades magnéticas, vêm sendo estudados em dispositivos fotônicos para armazenamento de memória quântica [48], conversão de informação quântica [49] e conversão de energia de fótons 50 54.

Apesar de algumas especificidades de cada um desses elementos, eles possuem características fisico-químicas muito similares. Em especial, todos admitem estado de oxidação $3+$, possuem raios iônicos próximos e propriedades termodinâmicas parecidas. Nas seções seguintes, são discutidas em detalhes a estrutura eletrônica dos TR e as propriedades que permitem a emissão das linhas finas observadas na espectroscopia desses materiais. 


\subsection{Níveis eletrônicos de íons lantanídeos livres}

A descrição apresentada nesta seção pode ser revisada nas referências 55, 56]. Partindo do Hamiltoniano do átomo livre, temos

$$
H_{F}=-\frac{\hbar^{2}}{2 m} \sum_{i}^{N_{E}} \nabla_{i}^{2}-\sum_{i}^{N_{E}} \frac{k Z e^{2}}{r_{i}}+\sum_{i<j}^{N_{E}} \frac{k e^{2}}{r_{i j}}+\sum_{i}^{N_{E}} \xi\left(r_{i}\right)\left(\vec{s}_{i} \cdot \vec{l}_{i}\right),
$$

onde o somatório em $i$ se dá sobre todos os $N_{E}$ elétrons do átomo.

Naturalmente, o primeiro termo refere-se à energia cinética do sistema. O segundo, proporcional à carga $Z e^{2}$ do núcleo, é o potencial de atração entre os prótons e a eletrosfera. Juntos, dão origem à configuração de orbitais eletrônicos, onde a energia do sistema depende apenas do número de elétrons em cada orbital. As soluções são dadas em termos de uma função radial e dos harmônicos esféricos:

$$
\psi_{n l m}(r, \theta, \phi)=R_{n l}(r) Y_{l}^{m}(\theta, \phi) .
$$

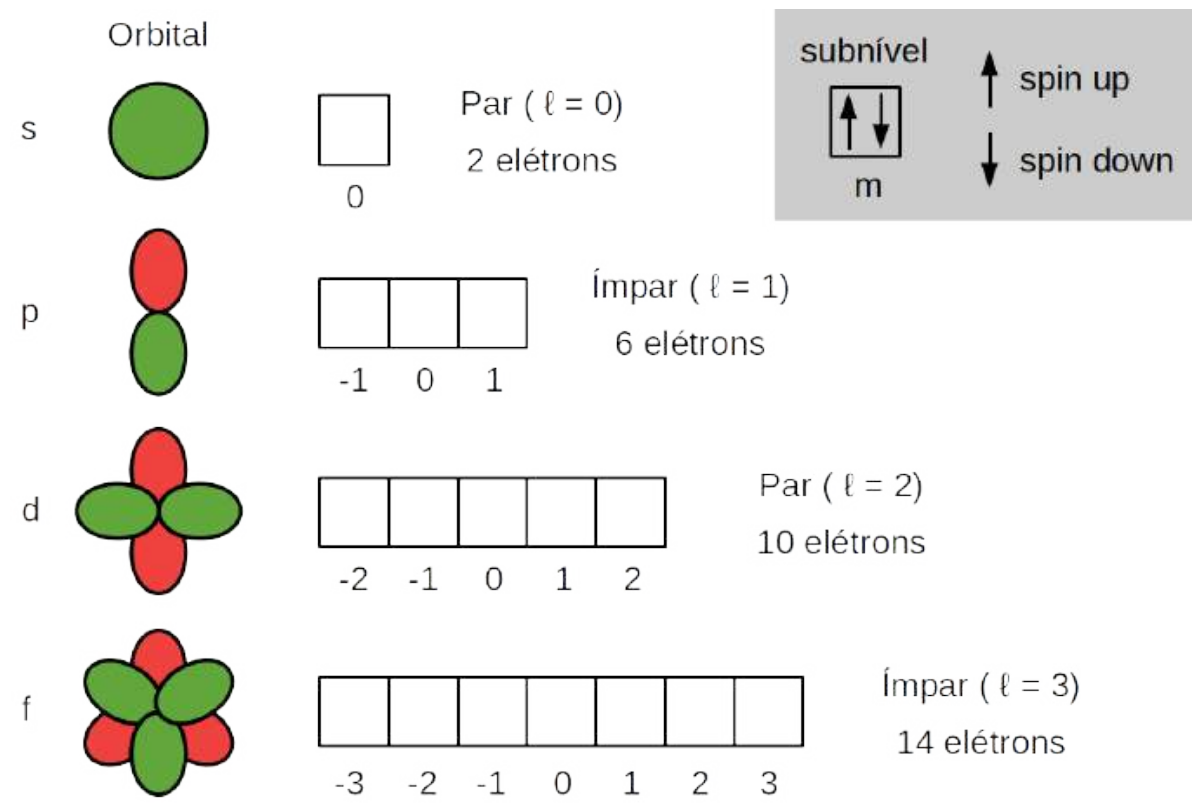

Figura 7 - Diagrama esquemático dos orbitais, caracterizados pelo número quântico $\ell$, e seus subníveis, caracterizados pelo número quântico $m$. Obedecendo ao princípio de exclusão de Pauli, cada subnível comporta 2 elétrons: um de spin up e outro de spin down.

Na Figura 7, há um diagrama esquemático dos orbitais e seus subníveis. As funções eletrônicas $\psi_{n l m s}$ neste cenário podem ser descritas em termo dos números quânticos $n$ (1, 
$2,3, \ldots)$, que caracteriza a camada eletrônica, $\ell$, referente ao orbital (s, p, d, f...), $m$ de cada subnível (com $|\mathrm{m}| \leq \ell)$ e $s$, relativo às projeções do spin. Embora o Hamiltoniano composto apenas pelos primeiros dois termos não seja uma boa aproximação para os lantanídeos, as funções $\psi_{n l m s}$ compõem uma base completa que descreve satisfatoriamente as simetrias em sistemas atômicos. Os cálculos que seguem, portanto, podem ser entendidos como combinações lineares da base $|n l m s\rangle$ para descrever outros efeitos presentes no sistema.

A repulsão elétron-elétron é contabilizada no terceiro termo da expressão 3.1. Chegamos à solução do sistema dada pelos termos eletrônicos ${ }^{2 S+1} L$, onde $S$ é o spin total e $L$ é o momento angular orbital total dos $N$ elétrons presentes no orbital:

$$
S=\left|\sum_{i}^{N_{E}} s_{i}\right|, \quad L=\left|\sum_{i}^{N_{E}} m_{i}\right| .
$$

Caracterizamos os níveis por $n \ell^{N}\left({ }^{2 S+1} \mathrm{~L}\right)$. Por exemplo, para a camada 4 com orbital $\mathrm{f}$ semipreenchido, poderíamos ter $4 \mathrm{f}^{3}\left({ }^{4} \mathrm{~F}\right)$, para $S=3 / 2$ e $L=3$, como ilustrado na Figura 8. Os valores $m$ e $s$ deixam de ser bons números quânticos, uma vez que há mistura de subníveis e spin no estado final.

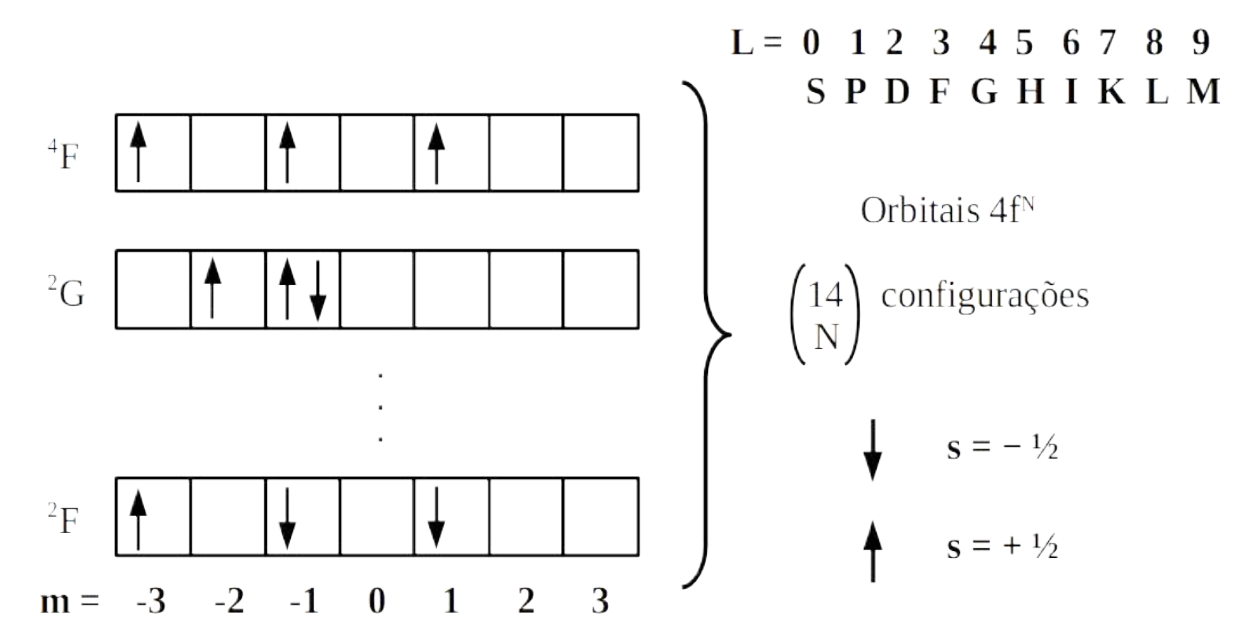

Figura 8 - Exemplo de configurações para 3 elétrons no orbital 4f $(n=4, \ell=3)$, como o íon $\mathrm{Nd}^{3+}$. Na aproximação de elétrons não interagentes, as diferentes configurações são degeneradas. Incluindo a repulsão elétron-elétron, a energia de cada nível depende do spin total e do momento angular orbital total, sendo a configuração identificada pelo termo ${ }^{2 S+1} \mathrm{~L}$.

Quando uma partícula com spin se movimenta em um potencial, o momento angular devido a este movimento é acoplado a seu spin, criando um efeito relativístico no sistema. Este efeito é conhecido como acoplamento spin-órbita, e no caso de elétrons em um átomo 
pode ser caracterizado pelo quarto termo da expressão 3.1. Configurações de diferentes spins, anteriormente possuindo a mesma energia, têm sua degenerescência quebrada por essas correções.

Em átomos leves $(Z<30)$, o efeito de repulsão entre os elétrons é muito maior que alterações devidas ao acoplamento spin-órbita. Os spins dos diferentes elétrons interagem entre si, resultando no spin total $S$, de forma análoga aos momentos angulas orbitais dos diferentes elétrons, que resultam no momento orbital total $L$. Neste cenário, é possível descrever os níveis de energia em termos do esquema de Russel-Saunders, também conhecido como acoplamento LS. As novas configurações são escritas em termos do momento angular total dado por

$$
\vec{J}=\vec{L}+\vec{S}
$$

Por outro lado, em átomos pesados, o acoplamento spin órbita é muito maior que a repulsão eletrônica. Cada elétron tem momento angular total dado por $j=s+\ell$, e são os momentos totais de cada elétron que se relacionam entre si, interação conhecida como acoplamento jj:

$$
J=\left|\sum_{i}^{N_{E}} j_{i}\right|
$$

Em ambos os casos, os termos espectroscópicos são bem descritos pelos números quânticos $S, L$ e $J$, dando origem às configurações ${ }^{2 S+1} L_{J}$. Cada uma das configurações é $2 J+1$ degenerada, por conta das diferentes projeções do momento angular total.

Em especial para os íons lantanídeos, temos a camada $4 \mathrm{f}^{N}$ parcialmente preenchida. Respeitando o princípio de exclusão de Pauli, há 14 posições possíveis no orbital 4f. O número de estados é dado pelas diferentes combinações dos elétrons dentro do orbital:

$$
\left(\begin{array}{c}
14 \\
N_{E}
\end{array}\right)=\frac{14 !}{N_{E} !\left(14-N_{E}\right) !}
$$

A correção dada pelo campo coulombiano para os TR é da mesma ordem que o termo spin-órbita $\left(H_{C} \approx H_{S O}\right)$. Os acoplamentos LS e jj não descrevem satisfatoriamente o sistema, sendo necessária uma nova abordagem. Os novos níveis de energia são agora descritos como 
uma combinação linear entre termos LS de mesmo momento angular total [57]:

$$
\psi_{n \ell J}=\sum_{S, L}^{2 S+1} L_{J}
$$

Temos para o európio, por exemplo, que o estado fundamental sofre a correção ${ }^{7} \mathrm{~F}_{0} \rightarrow$ $0,9680{ }^{7} \mathrm{~F}_{0}+0,0016{ }^{5} \mathrm{D}(2)_{0}+0,1659{ }^{5} \mathrm{D}(3)_{0}-0,1815{ }^{5} \mathrm{D}(1)_{0}$ [58. Os valores $L$ e $S$ deixam de ser, portanto, bons números quânticos. Este cenário é conhecido como acoplamento intermediário. Apesar desta correção ser conhecida, usualmente as configurações são identificadas pelo termo LS de maior peso na combinação linear (no exemplo, ${ }^{7} \mathrm{~F}_{0}$ ) como forma de simplificar a notação.

\subsection{Propriedades espectroscópicas}

As emissões e absorções de fótons por átomos são entendidas como transições eletrônicas causadas por um campo eletromagnético oscilante sobre os autoestados do sistema [59]. Utilizando a expansão em multipolos [60], é possível computar as taxas de transição entre os níveis em termos do dipolo elétrico, do dipolo magnético e do quadrupolo elétrico, dados por $\vec{P}, \vec{M}$ e $\vec{Q}$, respectivamente:

$$
\begin{gathered}
\vec{P}=-e \sum_{i} \vec{r}_{i}, \\
\vec{M}=-\frac{e \hbar}{2 m c} \sum_{i}\left(\vec{\ell}_{i}+2 \vec{s}_{i}\right), \\
\vec{Q}=-\frac{1}{2} \sum_{i}\left(\vec{k} \cdot \vec{r}_{i}\right) \vec{r}_{i} .
\end{gathered}
$$

A paridade dos estados de íons livres no espaço das configurações é dada pelo número quântico $\ell$, que caracteriza o orbital atômico. Se calcularmos as grandezas $\left\langle n \ell|\vec{P}| n^{\prime} \ell^{\prime}\right\rangle$, $\left\langle n \ell|\vec{M}| n^{\prime} \ell^{\prime}\right\rangle$ e $\left\langle n \ell|\vec{Q}| n^{\prime} \ell^{\prime}\right\rangle$, vemos que para o dipolo elétrico, um operador ímpar em $\vec{r}$, haverá transição induzida caso os estados inicial e final tenham paridade oposta. Isto é, não seria possível, dado o Hamiltoniano 3.1, obter transições intraconfiguracionais por dipolo elétrico. Ao contrário, o dipolo magnético e quadrupolo elétrico são operadores pares, apenas permitindo transições quando os estados inicial e final possuírem mesma paridade. As regras 
de seleção do sistema estão descritas na Tabela 1 .

Tabela 1 - Regras de seleção do íon livre para os operadores de dipolo elétrico, dipolo magnético e quadrupolo elétrico, considerando os níveis atômicos ${ }^{2 S+1} \mathrm{~L}_{J}$. Transições entre níveis de energia só ocorrem se tais condições forem satisfeitas. 61

\begin{tabular}{lcllc}
\hline \multicolumn{1}{c}{ Operador } & $S$ & \multicolumn{1}{c}{$L$} & \multicolumn{1}{c}{$J(0 \nrightarrow 0)$} & Paridade \\
\hline \hline Dipolo elétrico & $\Delta S=0$ & $\Delta L=0, \pm 1$ & $\Delta J=0, \pm 1$ & oposta \\
Dipolo magnético & $\Delta S=0$ & $\Delta L=0$ & $\Delta J=0, \pm 1$ & igual \\
Quadrupolo elétrico & $\Delta S=0$ & $\Delta L=0, \pm 1, \pm 2$ & $\Delta J=0, \pm 1, \pm 2$ & igual \\
\hline
\end{tabular}

\subsubsection{Diagrama de Dieke}

No diagrama da Figura 9 são apresentados os níveis de energia observados para todos os lantanídeos, obtidos por análises espectroscópicas dos íons com estado de oxidação $3+$ e publicadas por Dieke em 1963.

Por terem o orbital 4 f vazio ou completamente preenchido, o lantânio e o lutécio apresentam, respectivamente, nenhuma e apenas uma energia nesta configuração, correspondente ao nível ${ }^{1} \mathrm{~S}_{0}$. Por esta razão, não apresentam emissões intraconfiguracionais e não constam no diagrama. Para os demais lantanídeos, foram observadas linhas finas com energias entre 0 e $40000 \mathrm{~cm}^{-1}$.

Até o início da década de 60 a luminescência dos íons lantanídeos não era bem compreendida, dados os níveis de energia exibidos para tais elementos. As emissões finas na região do visível são decorrentes de transições intraconfiguracionais, isto é, ocorrem entre níveis 4f-4f, e a maior parte delas não poderia ter origem em transições por dipolo magnético. Entretanto, tais transições são proibidas também para dipolo elétrico segundo as regras de Laporte, discutidas na seção anterior. Deveria haver, então, algum mecanismo de quebra de simetria, alterando as regras de seleção para o sistema. Em 1962, Judd [58] e Ofelt 63] desenvolveram, independentemente, o modelo que leva seus nomes e explica os espectros de absorção e emissão medidos para os lantanídeos. Essa descrição será apresentada em detalhes na seção seguinte. 


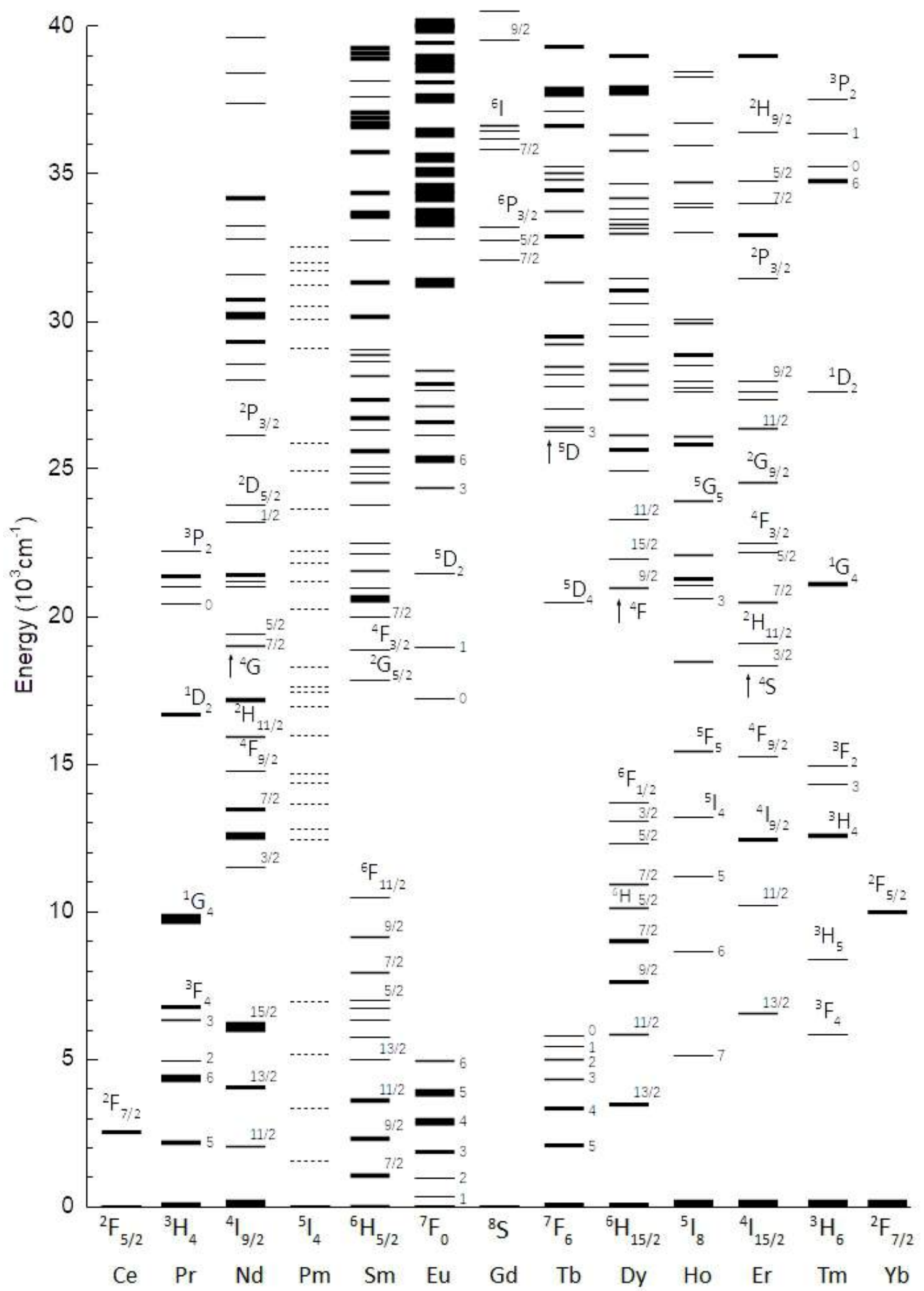

Figura 9 - Diagrama de Dieke dos níveis de energia dos lantanídeos. Adaptado de 62 


\subsubsection{Teoria de Judd-Ofelt}

Quando íons são inseridos em uma matriz, seja uma molécula, um sólido cristalino ou vidro, sofrem uma interação devida ao campo eletromagnético dos diversos átomos do ambiente que os rodeia. O Hamiltoniano total do sistema é, portanto, corrigido pelo potencial deste campo cristalino, $V_{C F}$ :

$$
H=H_{F}+V_{C F} \text {. }
$$

Se o campo cristalino quebra alguma simetria no espaço, há a mistura entre níveis do orbital 4f e estados de energia mais excitados e paridade oposta, relaxando as regras de seleção de Laporte de forma a permitir transições por dipolo elétrico. A degenerescência em $J$ é quebrada, gerando até $2 J+1$ desdobramentos em energia conhecidos como níveis de Stark. As sucessivas correções em energia para os lantanídeos estão ilustradas no diagrama da Figura 10.

\section{Interação:}

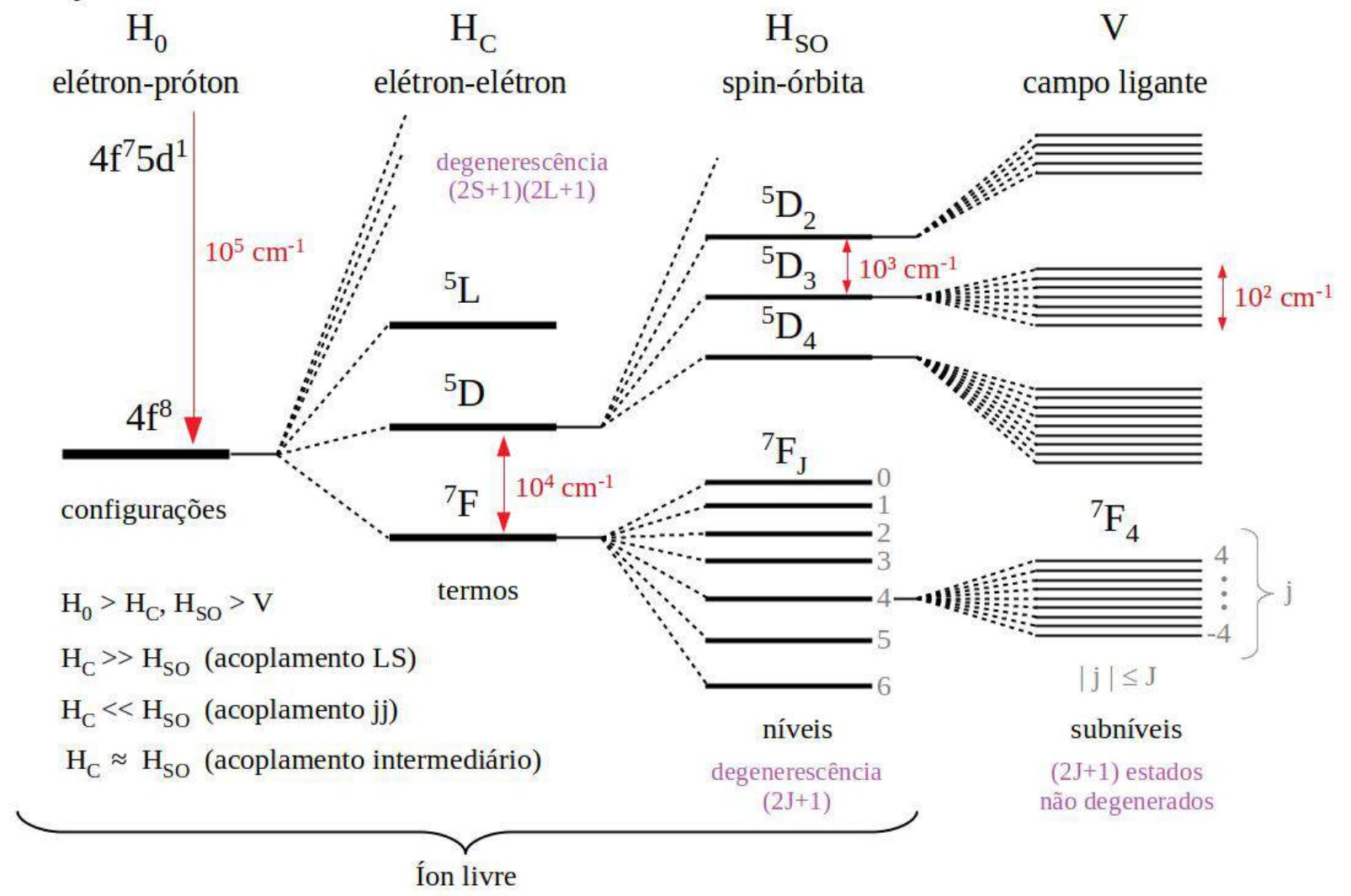

Figura 10 - Diagrama esquemático das energias dos lantanídeos levando em consideração as correções para cada uma das interações. As distâncias em energia estão fora de escala, a ordem de grandeza dos desdobramentos está representada em vermelho. A configuração $4 f^{8}$ corresponde ao $\mathrm{Tb}^{3+}$. 
Para calcular as correções dos níveis eletrônicos devidas ao ambiente químico, escrevemos o campo cristalino como uma expansão em termos dos harmônicos esféricos:

$$
\begin{gathered}
V_{C F}=\sum_{k q} A_{k q} \sum_{i} r_{i}^{k} Y_{k q}\left(\theta_{i}, \phi_{i}\right), \\
A_{k q}=-q_{e} \sum_{i} \frac{z_{i} Y_{k q}\left(\theta_{i}, \phi_{i}\right)}{R_{i}^{k+1}},
\end{gathered}
$$

onde $\mathrm{A}_{k q}$ são parâmetros estruturais e dependem somente do ambiente. 61

Primeiramente, consideramos a hipótese de íon livre, onde o campo cristalino é apenas uma perturbação no Hamiltoniano $H_{F}$. Desta forma, é possível realizar os cálculos pela teoria de perturbação de um sistema em $1^{\mathrm{a}}$ ordem. Levamos em conta também que o campo cristalino não varia com o tempo, tratando a perturbação como um modelo estático. Por fim, trataremos o sistema como uma configuração única, onde serão desprezadas as interações entre elétrons de orbitais distintos, isto é, todas as interações são intraconfiguracionais. As três hipóteses, juntas, descrevem satisfatoriamente íons lantanídeos e actnideos em meios materiais.

Por utilizarmos o modelo estático e uma matriz não magnética, as correções devidas ao campo cristalino são de natureza elétrica. Estamos interessados, portanto, em descrever a transição de dipolo elétrico dos estados perturbados do sistema. Os elementos de matriz do operador dipolo elétrico $\vec{P}$ são dados por

$$
\vec{D}=\left\langle\psi_{a}|\vec{P}| \psi_{b}\right\rangle
$$

onde $\psi_{a}$ e $\psi_{b}$ são os estados inicial e final perturbados em primeira ordem sobre os estados de mais alta energia e paridade oposta $\varphi_{\beta}$ :

$$
\begin{aligned}
& \left\langle\psi_{a}\right|=\left\langle\varphi_{a}\right|+\sum_{\beta} \frac{\left\langle\varphi_{a}|V| \varphi_{\beta}\right\rangle}{E_{a}-E_{\beta}}\left\langle\varphi_{\beta}\right|, \\
& \left|\psi_{b}\right\rangle=\left|\varphi_{b}\right\rangle+\sum_{\beta} \frac{\left\langle\varphi_{\beta}|V| \varphi_{b}\right\rangle}{E_{b}-E_{\beta}}\left|\varphi_{\beta}\right\rangle .
\end{aligned}
$$


Substituindo 3.13 e 3.14 na expressão para o dipolo elétrico 3.12 , temos:

$$
\vec{D}=\left(\left\langle\varphi_{a}\left|+\sum_{\beta} \frac{\left\langle\varphi_{a}|V| \varphi_{\beta}\right\rangle}{E_{a}-E_{\beta}}\left\langle\varphi_{\beta}\right|\right) \vec{P}\left(\left|\varphi_{b}\right\rangle+\sum_{\beta^{\prime}} \frac{\left\langle\varphi_{\beta^{\prime}}|V| \varphi_{b}\right\rangle}{E_{b}-E_{\beta^{\prime}}}\left|\varphi_{\beta^{\prime}}\right\rangle\right)\right.\right.
$$

Para os lantanídeos, os estados $a$ e $b$ pertencem ao orbital 4f e possuem mesma paridade. Uma vez que os estados $\beta$ e $\beta^{\prime}$ possuem paridade oposta aos níveis $a$ e $b$, respectivamente, $\psi_{\beta}$ e $\psi_{\beta^{\prime}}$ têm mesma paridade entre si. Desta forma, a componente do dipolo elétrico se anula para essas transições:

$$
\begin{aligned}
& \vec{D}=\left\langle\varphi_{a}|\vec{P}| \varphi_{b}\right\rangle+\sum_{\beta^{\prime}} \frac{\left\langle\varphi_{\beta^{\prime}}|V| \varphi_{b}\right\rangle}{E_{b}-E_{\beta^{\prime}}}\left\langle\varphi_{a}|\vec{P}| \varphi_{\beta^{\prime}}\right\rangle \\
&+\sum_{\beta} \frac{\left\langle\varphi_{a}|V| \varphi_{\beta}\right\rangle}{E_{a}-E_{\beta}}\left\langle\varphi_{\beta}|\vec{P}| \varphi_{b}\right\rangle \\
&+\sum_{\beta} \sum_{\beta^{\prime}} \frac{\left\langle\varphi_{a}|V| \varphi_{\beta}\right\rangle\left\langle\varphi_{\beta^{\prime}}|V| \varphi_{b}\right\rangle}{\left(E_{a}-E_{\beta}\right)\left(E_{b}-E_{\beta^{\prime}}\right)}\left\langle\varphi_{\beta}|\vec{P}| \varphi_{\beta^{\prime}}\right\rangle \\
& \Longrightarrow \vec{D}=\sum_{\beta}\left(\frac{\left\langle\varphi_{a}|\vec{P}| \varphi_{\beta}\right\rangle\left\langle\varphi_{\beta}|V| \varphi_{b}\right\rangle}{E_{b}-E_{\beta}}+\frac{\left\langle\varphi_{a}|V| \varphi_{\beta}\right\rangle\left\langle\varphi_{\beta}|\vec{P}| \varphi_{b}\right\rangle}{E_{a}-E_{\beta}}\right) .
\end{aligned}
$$

Utilizando a relação de completeza $\sum_{\beta}\left|\varphi_{\beta}\right\rangle\left\langle\varphi_{\beta}\right|=1$, a equação 3.17 é simplificada como

$$
\vec{D}=\sum_{\beta}\left(\frac{\left\langle\varphi_{a}|\vec{P} V| \varphi_{b}\right\rangle}{E_{b}-E_{\beta}}+\frac{\left\langle\varphi_{a}|V \vec{P}| \varphi_{b}\right\rangle}{E_{a}-E_{\beta}}\right)
$$

Para realizar estes cálculos numericamente, a soma sobre todos os estados $\beta$ considerando os diferentes valores de $J$ possíveis para $\beta, a$ e $b$ se torna um impeditivo. Duas simplificações devem ser feitas para prosseguirmos com a computação dos valores: a primeira é assumir que os níveis excitados $\beta$ são degenerados em $J$. Em seguida, assumimos também que a diferença de energia entre estados de orbitais diferentes é muito maior que as diferenças entre estados dentro de um mesmo orbital, de forma que $E_{a}-E_{\beta} \approx E_{b}-E_{\beta}$. Chamamos a diferença de energia entre o orbital $4 \mathrm{f}$ e seu estado excitado $n \ell$ de $\Delta E_{n \ell}$ :

$$
\vec{D}=\sum_{n \ell} \frac{\left\langle\varphi_{a}|(\vec{P} V+V \vec{P})| \varphi_{b}\right\rangle}{\Delta E_{n \ell}}
$$

Como $\vec{P}$ e $V$ comutam, já que ambos podem ser escritos em termos de potências da 
posição $|\vec{r}|$, a equação é simplificada:

$$
\vec{D}=\sum_{n \ell} \frac{2\left\langle\varphi_{a}|\vec{P} V| \varphi_{b}\right\rangle}{\Delta E_{n \ell}}
$$

Para obter as regras de seleção do operador $\vec{P} V$, é conveniente escrever o dipolo elétrico e o campo cristalino em termos dos tensores esféricos $\vec{C}_{q}^{(k)}$ :

$$
\begin{gathered}
\vec{C}_{q}^{(k)}=\left(\frac{4 \pi}{2 k+1}\right)^{1 / 2} \vec{Y}_{k q}, \\
\vec{P}=-e \sum_{i} r_{i}\left[\vec{C}_{q}^{(1)}\right]_{i}, \\
V=\sum_{t p} A_{t p} \sum_{i} r_{i}^{t}\left[\vec{C}_{p}^{(t)}\right]_{i},
\end{gathered}
$$

de forma que o produto dos operadores resulta

$$
\vec{P} V=-e \sum_{t p} A_{t p} \sum_{i} \sum_{j} r_{j} r_{i}^{t}\left[C_{q}^{(1)}\right]_{j}\left[C_{p}^{(t)}\right]_{i}
$$

Se $i \neq j$, o termo $r_{j} r_{i}^{t}$ é ímpar e portanto $\left\langle\varphi_{a}|\vec{P} V| \varphi_{b}\right\rangle=0$, uma vez que $\varphi_{a}$ e $\varphi_{b}$ possuem mesma paridade. Para $i=j$,

$$
\vec{P} V=-e \sum_{t p} A_{t p} \sum_{i} r_{i}^{t+1}\left[C_{q}^{(1)} C_{p}^{(t)}\right]_{i}
$$

Sendo $\vec{C}_{p}^{(t)}=\left\langle\ell|| \vec{C}^{(t)}|| \ell^{\prime}\right\rangle \vec{U}_{p}^{(t)}$, o produto de tensores esféricos pode ser transformado em um operador tensorial efetivo segundo a relação:

$$
\vec{U}_{q}^{(1)} \vec{U}_{p}^{(t)}=\sum_{\lambda Q}(-1)^{1+t+\lambda+Q}(2 \lambda+1)\left\{\begin{array}{lll}
1 & t & \lambda \\
\ell & \ell & \ell^{\prime}
\end{array}\right\}\left(\begin{array}{lll}
1 & t & \lambda \\
q & p & Q
\end{array}\right) \vec{U}_{Q}^{(\lambda)}
$$

onde $Q=-(p+q), \lambda=1+\mathrm{t}$ e os símbolos $3 \mathrm{j}(\mathrm{)}$ e $6 \mathrm{j}\{\}$ de Wigner são relacionados aos coeficientes de Clebsch-Gordon para o acoplamento de dois e três momentos angulares, respectivamente.

Pelo teorema de Wigner-Eckart, os elementos de matriz do operador tensorial efetivo 
dependem apenas dos símbolos $3 \mathrm{j}$ e da norma de $\vec{U}^{(\lambda)}$, segundo a relação

$$
\left\langle J M\left|\vec{U}_{Q}^{(\lambda)}\right| J^{\prime} M^{\prime}\right\rangle=(-1)^{J-M}\left(\begin{array}{ccc}
J & \lambda & J^{\prime} \\
-M & Q & M^{\prime}
\end{array}\right)\left\langle J|| \vec{U}^{(\lambda)}|| J^{\prime}\right\rangle .
$$

Apesar do teorema de Wigner-Eckart não fornecer um modo simples de calcular a grandeza $\left\langle J|| \vec{U}^{(\lambda)}|| J^{\prime}\right\rangle$, sendo necessário realizar as integrais para os estados $a$ e $b$ no cenário de acoplamento intermediário - como derivado na seção 2.1-, o resultado mostra que essas integrais dependem apenas do momento angular total $J$, restando para os demais números quânticos algumas regras de seleção verificáveis. A simples aplicação de tais regras de seleção reduz significativamente o número de integrais a serem calculadas, tornando factível o processamento computacional.

Substituindo os resultados obtidos em 3.26 e 3.27 na equação 3.20 , chegamos à solução final para os elementos de matriz do dipolo elétrico para um átomo

$$
\begin{gathered}
D=-e \sum_{t p} \sum_{\lambda Q}(-1)^{J-M-Q}(2 \lambda+1) A_{t p} Y_{t \lambda}\left(\begin{array}{ccc}
1 & t & \lambda \\
q & p & Q
\end{array}\right)\left(\begin{array}{ccc}
J & \lambda & J^{\prime} \\
-M & Q & M^{\prime}
\end{array}\right)\left\langle\varphi_{a}|| \vec{U}^{(\lambda)}|| \varphi_{b}\right\rangle, \\
Y_{t \lambda}=2 \sum_{n \ell} \frac{\langle 4 f|r| n \ell\rangle\left\langle n \ell\left|r^{t}\right| 4 f\right\rangle}{\Delta E_{n \ell}}\left\langle f|| \vec{C}^{(1)}|| \ell\right\rangle\left\langle\ell|| \vec{C}^{(t)}|| f\right\rangle\left\{\begin{array}{lll}
1 & t & \lambda \\
\ell & \ell & \ell
\end{array}\right\},
\end{gathered}
$$

onde a parte angular do campo cristalino é dada em termos do símbolo 3j:

$$
\left\langle\ell_{1}|| \vec{C}^{(t)}|| \ell_{2}\right\rangle=(-1)^{\ell_{2}}\left(2 \ell_{2}+1\right)^{\frac{1}{2}}\left(2 \ell_{1}+1\right)^{\frac{1}{2}}\left(\begin{array}{ccc}
\ell_{1} & 1 & \ell_{2} \\
0 & 0 & 0
\end{array}\right) .
$$

Na Tabela 2 são traduzidas em termos de $\Delta L$ e $\Delta J$ as novas regras de seleção do sistema originadas pelos símbolos 3j e 6j de Wigner.

Para interpretar os resultados de transição entre níveis eletrônicos, usualmente é definida a grandeza conhecida como força de oscilador. Ela pode ser entendida como a razão entre a probabilidade de uma transição ocorrer no sistema quântico e o equivalente clássico de um elétron oscilando com frequência igual ao comprimento de onda do fóton emitido. 59 Matematicamente:

$$
f=\frac{4 \pi m c}{h \lambda e^{2}} n\left(\frac{n^{2}+2}{3 n}\right)^{2} \sum_{M M^{\prime}}\left|\left\langle\alpha J M|\vec{P}| \alpha^{\prime} J^{\prime} M^{\prime}\right\rangle\right|^{2}
$$


Tabela 2 - Regras de seleção de Judd-Ofelt para os operadores de dipolo elétrico, dipolo magnético e quadrupolo elétrico, considerando os níveis atômicos no cenário de acoplamento intermediário. 61

\begin{tabular}{lcllr}
\hline \multicolumn{1}{c}{ Operador } & ${ }^{*} S$ & \multicolumn{1}{c}{${ }^{*} L$} & $J(0 \nrightarrow 0)$ & Paridade $^{\dagger}$ \\
\hline \hline Dipolo elétrico & $\Delta S=0$ & $\Delta L \leq 6\left(J\right.$ e $\left.J^{\prime} \neq 0\right)$ & $\Delta J \leq 6$ & oposta \\
& & $\Delta L=2,4,6 \quad\left(J\right.$ ou $\left.J^{\prime}=0\right)$ & & \\
Dipolo magnético & $\Delta S=0$ & $\Delta L=0$ & $\Delta J=0, \pm 1$ & igual \\
Quadrupolo elétrico & $\Delta S=0$ & $\Delta L=0, \pm 1, \pm 2$ & $\Delta J=0, \pm 1, \pm 2$ & igual \\
\hline
\end{tabular}

*No cenário de acoplamento intermediário, $S$ e $L$ não são bons números quânticos.

É necessário conhecer as correções de cada termo para utilizar as regras de seleção adequadamente. ${ }^{\dagger}$ Os estados $|\psi\rangle$ do sistema são misturas entre níveis do orbital 4f e estados de energia mais excitados, possivelmente com paridade oposta.

Utilizando a expressão 3.28 e considerando as regras de seleção para os símbolos 3j, a força de oscilador para os lantanídeos é dada por

$$
f=\frac{4 \pi m c}{3 h \lambda(2 J+1)} n\left(\frac{n^{2}+2}{3 n}\right)^{2} \sum_{\lambda=2,4,6} \sum_{p} \sum_{t=1,3,5}(2 \lambda+1) \frac{\left|A_{t p}\right|^{2}}{2 t+1} Y_{t \lambda}^{2}\left|\left\langle\varphi_{a}|| \vec{U}^{(\lambda)}|| \varphi_{b}\right\rangle\right|^{2} .
$$

Por fim, definindo como parâmetros de Judd-Ofelt os valores $\Omega_{\lambda}$, chegamos à equação simplificada para $f$ :

$$
\begin{gathered}
\Omega_{\lambda}=(2 \lambda+1) \sum_{p} \sum_{t=1,3,5} \frac{\left|A_{t p}\right|^{2}}{2 t+1} Y_{t \lambda}^{2}, \\
f=\frac{4 \pi m c}{3 h \lambda(2 J+1)} n\left(\frac{n^{2}+2}{3 n}\right)^{2} \sum_{\lambda=2,4,6} \Omega_{\lambda}\left|\left\langle\varphi_{a}|| \vec{U}^{(\lambda)}|| \varphi_{b}\right\rangle\right|^{2} .
\end{gathered}
$$

Os termos $\mathrm{U}_{\lambda}^{2}=\left|\left\langle\varphi_{a}|| \vec{U}^{(\lambda)}|| \varphi_{b}\right\rangle\right|^{2}$ podem ser calculados pela integração do tensor esférico entre os níveis $\varphi_{a}$ e $\varphi_{b}$ no cenário de acoplamento intermediário. Como os valores absolutos em energia dentro do orbital $4 \mathrm{f}$ variam pouco com o ambiente cristalino, o resultado da integração é aproximadamente independente do meio material. Há vasta literatura tabelando os resultados dessas integrais 64.

Os parâmetros de Judd-Ofelt guardam toda a informação relativa ao campo cristalino e podem ser obtidos por primeiros princípios. Com os resultados de $\Omega_{\lambda}$ e $U_{\lambda}^{2}$, além das taxas de transição calculadas para o dipolo magnético $\mathrm{A}_{M D}$ e quadrupolo elétrico $\mathrm{A}_{E Q}$, é possível construir os espectros teóricos de emissão e absorção dos lantanídeos. Usualmente, este processo é utilizado de maneira inversa: conhecido o espectro experimental de um material, as intensidades das transições eletrônicas são ajustadas aos $\mathrm{U}_{\lambda}^{2}$, de forma a obter o valor dos 
parâmetros de Judd-Ofelt e inferir, a partir disso, informações acerca da simetria do sítio dos íons $\mathrm{TR}^{3+}$ e do campo ligante. Apesar da energia dos níveis permanecer aproximadamente inalterada, são as pequenas distorções criadas pelo campo cristalino que relaxam as regras de seleção e alteram as intensidades das linhas observadas - que permacem, aproximadamente, numa mesma posição do espectro.

A análise direta da equação 3.33 em busca de significados físicos para os parâmetros $\Omega_{2}$, $\Omega_{6}$ e $\Omega_{6}$ não é intuitiva. Os três parâmetros são dados por combinações dos componentes ímpares da expansão do campo cristalino em termos de harmônicos esféricos. São essas componentes as responsáveis por quebrar as simetrias de inversão do sistema, alterando as regras de seleção. O parâmetro $\Omega_{2}$ é mais sensível a mudanças angulares na geometria de coordenação, aumentando quando este efeito está presente no sistema. Por sua vez, os parâmetros $\Omega_{4}$ e $\Omega_{6}$ são sensíveis a mudanças na distância entre os íons TR e os ligantes e à polarizabilidade. 65, 66. Conhecendo os valores $\Omega_{\gamma}$, é possível relacionar os parâmetros fenomenológicos às grandezas teóricas e calcular a eficiência quântica $\eta$ do sistema, tema que será discutido na seção seguinte.

\subsection{Relacionando resultados experimentais à teoria}

Por conveniência, as discussões que seguem serão feitas para o espectro de absorção dos íons lantanídeos, mas também são válidas para a emissão de fótons. O somatório da equação 3.34 é denominado linestrength. Esta grandeza é proporcional à intensidade de absorção do material, contabilizando a contribuição da transição por dipolo elétrico entre os estados perturbados $\psi_{a}$ e $\psi_{b}$. No cenário de acoplamento intermediário, discutido na seção 2.1, o estado inicial $\psi_{a}$ pode ser escrito em termos dos números quânticos $S, L$ e $J$, representando o spin total, o momento orbital total e o momento angular total, respectivamente. $\psi_{b}$ é escrito de forma análoga para os índices do estado final $S^{\prime}, L^{\prime}$ e $J^{\prime}$. Ambos os estados, inicial e final, são níveis da configuração 4f, com $N$ elétrons no orbital:

$$
S_{E D}\left(J ; J^{\prime}\right)=\sum_{\gamma=2,4,6} \Omega_{\gamma}\left|\left\langle f^{N}[S L] J\left\|U^{(\gamma)}\right\| f^{N}\left[S^{\prime} L^{\prime}\right] J^{\prime}\right\rangle\right|^{2}
$$

Por outro lado, os espectros de absorção experimentais são dados em termos da seção 
transversal, que é proporcional à probabilidade de que ocorra, mediada por um fóton, a interação entre dois níveis de um centro absorvedor em um dado comprimento de onda. A seção transversal possui unidade de área, e em uma abordagem semi-clássica pode ser entendida como a região em torno do átomo que o fóton deve atravessar para que seja absorvido. Quanto maior a área, maior a probabilidade de correr a absorção e portanto maior a intensidade da transição no espectro.

As correções dos níveis de energia que dão origem aos subníveis - caracterizados pelas projeções $j$ do momento angular total - são muito pequenas. Desta forma, as transições entre diferentes subníveis acabam sobrepostas nos espectros de absorção dos materiais, como retratado na Figura 11, que ilustra o espectro de absorção do óxido de holmio. No exemplo do $\mathrm{Ho}_{2} \mathrm{O}_{3}$, podemos avaliar a transição ${ }^{5} \mathrm{I}_{8} \rightarrow{ }^{5} \mathrm{~F}_{5}$ : no estado inicial, temos $J=8$, que corresponde a 17 possíveis projeções $j$, enquanto no estado final temos $J=5$, correspondendo a 11 projeções. Se o campo cristalino suprimir todas as simetrias do sistema, há 17 subníveis não degenerados que podem decair para outros 11 subníveis, emitindo fótons com energias ligeiramente diferentes uns dos outros. No total, há a superposição de até $17 \times 11=187$ picos.

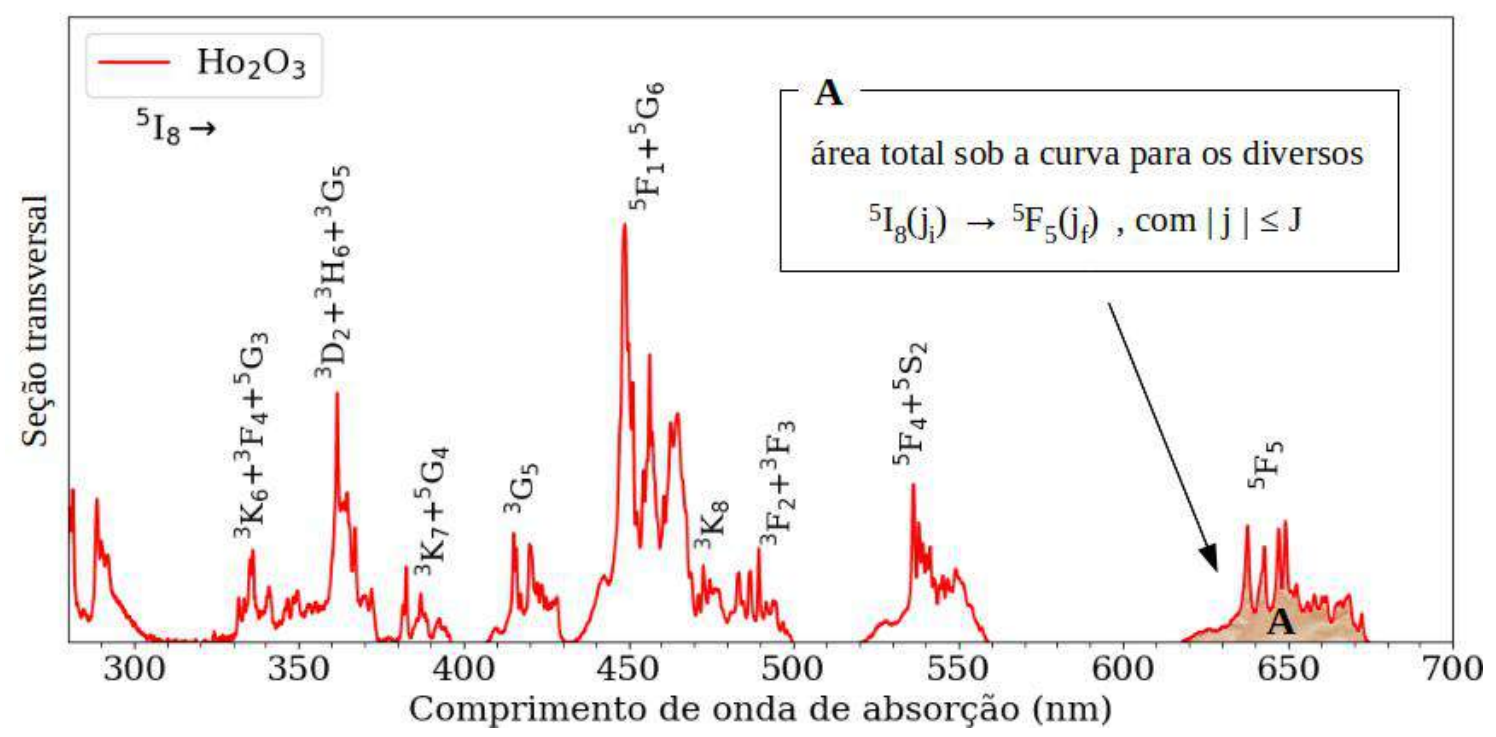

Figura 11 - Espectro de absorção do óxido de holmio. O estado fundamental do sistema é o ${ }^{5} \mathrm{I}_{8}$, a partir do qual ocorrem as transições para os estados excitados, identificados no gráfico.

Neste caso, os cálculos para a intensidade da absorção devem ser feitos considerando a transição do conjunto de subníveis que compõem o nível inicial ${ }^{2 S+1} L_{J}$ para o conjunto de subníveis que compõem o nível final ${ }^{2 S^{\prime}+1} L_{J^{\prime}}^{\prime}$. O linestrength de uma transição entre os 
estados inicial $a$ e final $b\left(\psi_{b_{i}} \rightarrow \psi_{a_{i}}\right)$ relativo ao pico $i$ de um espectro se relaciona à seção transversal por

$$
S_{i}=\frac{3 \operatorname{ch}\left(2 J_{i}+1\right)}{2 \pi^{2} e^{2} \bar{\lambda}_{i}} n\left(\frac{3}{n^{2}+2}\right)^{2} \int_{\Delta \lambda_{i}} \sigma(\lambda) d \lambda,
$$

onde $J_{i}$ é o o momento angular total do estado inicial para o pico $i, n$ é o índice de refração do meio, $\sigma$ é a seção transversal, $\bar{\lambda}_{i}$ é o comprimento de onda médio do pico e $\Delta \lambda_{i}$ é a região em comprimento de onda dos fótons mediadores das transições entre os múltiplos subníveis ${ }^{2 S+1} L_{J}(j=-J,-J+1, \ldots, J)$.

Combinando 3.35 e 3.36 , encontramos $i$ equações para os parâmetros de Judd-Ofelt fenomenológicos a partir do espectro de absorção experimental:

$$
\sum_{\gamma=2,4,6} \Omega_{\gamma} U_{i \gamma}^{2}=\frac{3 c \epsilon_{0} h\left(2 J_{i}+1\right)}{2 \pi^{2} e^{2} \bar{\lambda}_{i}} n\left(\frac{3}{n^{2}+2}\right)^{2} \int_{\Delta \lambda_{i}} \sigma(\lambda) d \lambda .
$$

Segundo as regras de seleção (Tabela 2), transições com $\Delta S=0, \Delta L=0$ e $\Delta J=0$, \pm 1 também possuem contribuição do dipolo magnético para a absorção. Neste caso, o linestrength magnético $S_{M D}$ deve ser contabilizado:

$$
\sum_{\gamma=2,4,6} \Omega_{\gamma} U_{i \gamma}^{2}+S_{M D}^{(i)}=\frac{3 c \epsilon_{0} h\left(2 J_{i}+1\right)}{2 \pi^{2} e^{2} \bar{\lambda}_{i}} n\left(\frac{3}{n^{2}+2}\right)^{2} \int_{\Delta \lambda_{i}} \sigma(\lambda) d \lambda .
$$

Na literatura são encontrados valores tabelados para as probabilidades de transição por dipolo magnético $\mathrm{A}_{M D}$ 67, se relacionando aos linestrength por

$$
A_{M D}=\frac{16 \pi^{3} e^{2} n^{2}}{3 \epsilon_{0} h(2 J+1) \bar{\lambda}^{3}} S_{M D}
$$

Por serem 3 os parâmetros de Judd-Ofelt $\left(\Omega_{2}, \Omega_{4}\right.$ e $\left.\Omega_{6}\right)$, seriam necessárias também 3 equações para obtê-los se todas as outras variáveis fossem conhecidas e houvesse a possibilidade de resolver o sistema exatamente. Veremos adiante que isso é possível apenas para o íon $\mathrm{Eu}^{3+}$. O itérbio e o cério, por sua vez, apresentam apenas uma transição, de forma que a teoria não pode ser aplicada a eles. Para os demais lantanídeos, os parâmetros fenomenológicos são determinados pelos melhores valores possíveis de $\Omega_{\gamma}$ de forma que o lado esquerdo e o lado direito da equação 3.38 coincidam. 
Definindo $\eta^{2}$ o erro quadrático total:

$$
\eta^{2}=\sum_{i}\left(\sum_{\gamma=2,4,6} \Omega_{\gamma} U_{i \gamma}^{2}+S_{M D}^{(i)}-\frac{3 c \epsilon_{0} h\left(2 J_{i}+1\right)}{2 \pi^{2} e^{2} \bar{\lambda}_{i}} n\left(\frac{3}{n^{2}+2}\right)^{2} \int_{\Delta \lambda_{i}} \sigma(\lambda) d \lambda\right)
$$

podemos obter os melhores valores para $\Omega_{\gamma}$ minimizando o erro. Assim,

$$
\frac{\partial\left(\eta^{2}\right)}{\partial \Omega_{\gamma}}=0
$$

Este procedimento é conhecido como método dos mínimos quadrados. Escrevendo de outra forma, temos o sistema de equações

$$
\begin{aligned}
S_{E D}^{e x p}(1) & =U_{12}^{2} \Omega_{2}+U_{14}^{2} \Omega_{4}+U_{16}^{2} \Omega_{6}, \\
S_{E D}^{\exp }(2) & =U_{22}^{2} \Omega_{2}+U_{24}^{2} \Omega_{4}+U_{26}^{2} \Omega_{6}, \\
\vdots & \\
S_{E D}^{\exp }(i) & =U_{i 2}^{2} \Omega_{2}+U_{i 4}^{2} \Omega_{4}+U_{i 6}^{2} \Omega_{6}, \\
\vdots & \\
S_{E D}^{\exp }(N) & =U_{N 2}^{2} \Omega_{2}+U_{N 4}^{2} \Omega_{4}+U_{N 6}^{2} \Omega_{6},
\end{aligned}
$$

onde $S_{E D}^{e x p}$ é o linestrength experimental, dado pela integral direta do espectro de absorção menos eventuais contribuições por dipolo magnético:

$$
S_{E D}^{e x p}(i)=\frac{3 c \epsilon_{0} h\left(2 J_{i}+1\right)}{2 \pi^{2} e^{2} \bar{\lambda}_{i}} n\left(\frac{3}{n^{2}+2}\right)^{2} \int_{\Delta \lambda_{i}} \sigma(\lambda) d \lambda-S_{M D}
$$

Definindo as matrizes

$$
\Omega=\left(\begin{array}{c}
\Omega_{2} \\
\Omega_{4} \\
\Omega_{6}
\end{array}\right), \quad S=\left(\begin{array}{c}
S_{E D}^{\exp }(1) \\
S_{E D}^{\exp }(2) \\
\vdots \\
S_{E D}^{\exp }(N)
\end{array}\right), \quad U=\left(\begin{array}{ccc}
U_{12}^{2} & U_{14}^{2} & U_{16}^{2} \\
U_{22}^{2} & U_{24}^{2} & U_{26}^{2} \\
\vdots & \vdots & \vdots \\
U_{N 2}^{2} & U_{N 4}^{2} & U_{N 6}^{2}
\end{array}\right)
$$


é possível mostrar que $\Omega$ satisfaz 3.41 quando

$$
\Omega=\left(U^{T} U\right)^{-1} U^{T} S
$$

Para o estudo de espectros de emissão, é conveniente utilizarmos o coeficiente $A$ de Einstein para descrever o sistema.

$$
A_{n}=\chi_{E D}^{e m} A_{E D}^{(n)}+\chi_{M D}^{e m} A_{M D}^{(n)}=\delta \frac{4 \pi \lambda}{h c} I_{n}
$$

onde $I_{n}$ é a radiância total da transição $n$ e $\delta$ é um coeficiente dependente do ângulo sólido do feixe efetivamente observado e do número de centros emissores excitados. Na prática, para a maioria das medidas experimentais não é possível calcular $\delta$ diretamente utilizando-se da geometria do aparato e da concentração de íons lantanídeos na amostra. Esta inviabilidade se dá pela dificuldade de determinar a porção da emissão detectada pelo instrumento e a penetração dos fótons na amostra. Por outro lado, as contribuições dadas pelas transições induzidas por dipolo magnético podem ser utilizadas para uma estimativa empírica de $\delta$, devido a sua pouca sensibilidade a variações no campo cristalino.

Foi escrito um código em linguagem Python (Anexo C) para o cálculo das grandezas físicas associadas à análise espectroscópica e realizar os ajustes dos parâmetros fenomenológicos aos dados experimentais.

\subsection{Efeito antena}

A teoria de Judd-Ofelt demonstra o relaxamento das regras de seleção de Laporte para os íons lantanídeos. Embora nessa nova perspectiva transições 4f-4f sejam permitidas, deve-se ter em mente que a probabilidade de ocorrência dessas transições é baixa e depende das amplitudes obtidas no cenário de acoplamento intermediário para cada termo de correção dos autoestados de energia. Deste modo, a absorção de energia pela excitação direta dos $\mathrm{Ln}^{3+}$ é pouco eficaz, resultando em baixas eficiências para a luminescência desses íons.

Uma técnica utilizada para contornar esta questão é conhecida como efeito antena, onde uma molécula sensibilizadora é utilizada para absorver energia do meio, a transferindo posteriormente aos íons $\mathrm{Ln}^{3+}$ e populando seus estados excitados, que emitem fótons eficiente- 
mente para retornar ao estado fundamental.

A molécula sensibilizadoraé excitada no ultravioleta, absorvendo eficientemente os fótons fornecidos por uma fonte de luz. Esta absorção leva elétrons do estado fundamental singleto $\mathrm{S}_{0}$ para um estado singleto excitado $\mathrm{S}_{n}$. A partir de então, diversos processos de relaxamento podem ocorrer dentro da molécula, como ilustrado na Figura 12.

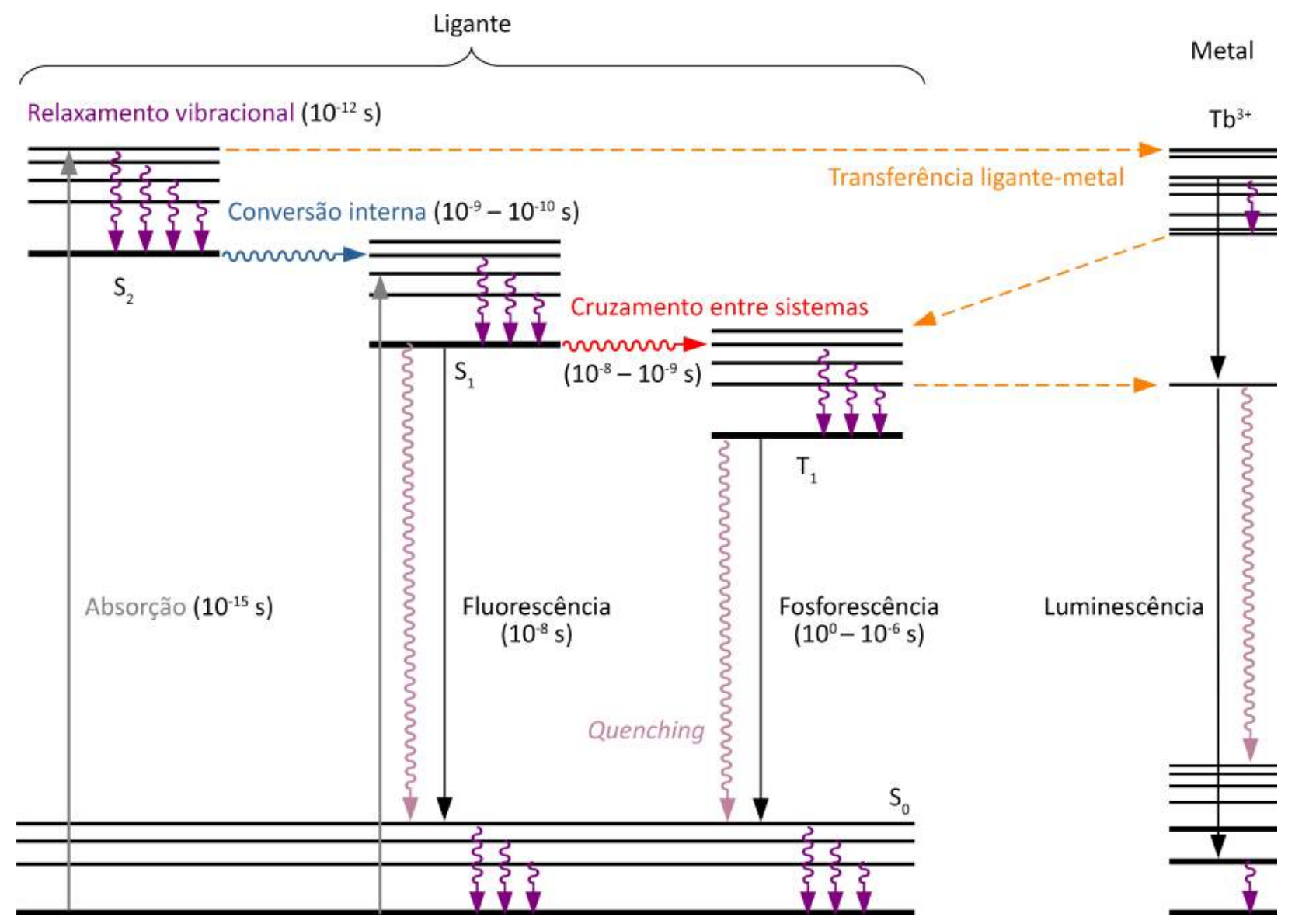

Figura 12 - Diagrama esquemático do efeito antena. Uma molécula sensibilizadora é utilizada para absorver energia do meio, transferindo-a posteriormente aos íons $\mathrm{Ln}^{3+}$. As setas indicam rotas de transferência de energia. Entre parênteses, o tempo característico de cada fenômeno. As linhas onduladas representam modos não radiativos, enquanto as tracejadas envolvem transferência de elétrons.

Em um primeiro momento, ocorre o relaxamento vibracional, com tempos característicos de $10^{-12} \mathrm{~s}$. Elétrons decaem de modos vibracionais mais excitados para o de menor nível energético dentro de um mesmo estado. Por conversão interna, um estado singleto pode ir para outro singleto degenerado ou com energia ligeiramente menor, até chegar em $\mathrm{S}_{1}$. Dois processos podem, então, ocorrer: a fluorescência, onde a molécula emite um fóton para retornar a seu estado fundamental ou, alternativemente, em moléculas nas proximi- 
dades de metais pesados e com forte acoplamento spin-órbita, as regras de seleção podem ser relaxadas ocorrendo um cruzamento entre sistemas, isto é, a transferência de energia de um estado singleto para um estado tripleto da molécula. Ambas as rotas possuem tempos característicos similares e costumam ocorrer concomitantemente. Após um eventual processo de conversão interna o relaxamento radiativo do estado tripleto $\mathrm{T}_{1}$ para o singleto $\mathrm{S}_{0}$, conhecido como fosforescência, pode ocorrer com tempos característicos longos e fraca intensidade, por se tratar de uma transição originalmente proibida.

Durante todo o processo de relaxamento da molécula pode ocorrer a transferência de energia do ligante para o metal (e vice-versa). É possível que um estado singleto $S_{n}$ transfira diretamente energia para um estado degenerado do lantanídeo, como indicado pela seta laranja na Figura 12 , seguido do relaxamento radiativo ou não radiativo do íon $\mathrm{Ln}^{3+}$ até um nível emissor. A retrotransferência de energia do metal para o ligante, por exemplo, é uma rota viável para popular seu nível tripleto. Entretanto, alguns estudos demonstram que a rota mais provável, por conta dos tempos característicos envolvidos, é que a molécula sensibilizadora relaxe por conversão interna seguida do cruzamento entre sistemas. Como o relaxamento por fosforescência é lento, antes que ele ocorra há uma eficiente transferência de energia entre o estado tripleto $\mathrm{T}_{1}$ e o nível emissor do lantanídeo. Por fim, o íon $\operatorname{Ln}^{3+}$ luminesce emitindo um fóton característico de suas transições $4 \mathrm{f}-4 \mathrm{f}$. 


\section{Técnicas de caracterização}

\subsection{Difração de raios $X$}

A difração é um fenômeno tipicamente ondulatório, observado quando ondas contornam obstáculos ou interferem com objetos cujas dimensões são da mesma ordem de grandeza de seu comprimento de onda. Em sólidos, as separações típicas entre átomos na rede cristalina são da ordem de ângstrons. Os raios X, por sua vez, são ondas eletromagnéticas que possuem comprimentos de onda entre 0,01 nm e $10 \mathrm{~nm}$, tornando-se ideais para a determinação das propriedades cristalográficas de materiais, como distâncias entre seus constituintes, rede cristalina ou polimorfismo. Cada tipo de arranjo cristalino origina de forma unívoca um padrão de difração.

A técnica de caracterização de materiais por difração de raios X (DRX) utiliza feixes desta radiação incidindo sobre a amostra. Os átomos da rede cristalina espalham as ondas em todas as direções, formando padrões de interferência que podem ser medidos em todo o espaço. Na geometria Bragg-Brentano, utilizada nas caracterizações apresentadas neste trabalho, o detector é posicionado a uma distância fixa do porta amostras, com ângulo $\theta$ com relação ao plano de reflexão sempre igual à fonte de raios $\mathrm{X}$, como ilustrado na Figura 13. À medida que $\theta$ varia, um difratograma formado de máximos e mínimos é coletado.

O padrão medido depende da diferença de caminho óptico entre os feixes superpostos, isto é, a diferença de distância percorrida pelos diferentes feixes espalhados pela amostra. No exemplo da Figura 13, a diferença de caminho óptico entre o feixe 1 e o feixe 2 é dada por $2 x$, onde $x=d \cdot \sin \theta$. O máximo de interferência será medido pelo detector quando a superposição for totalmente construtiva. Ou seja, considerando que as ondas possuem a mesma fase ao deixarem a fonte, os máximos estão presentes quando a diferença de caminho óptico for igual a múltiplos inteiros do comprimento de onda. Esta relação entre o ângulo $\theta$ medido e a distância d entre dois planos atômicos é conhecida como Lei de Bragg:

$$
\sin \theta=\frac{n \lambda}{2 d},(n=1,2,3, \ldots)
$$



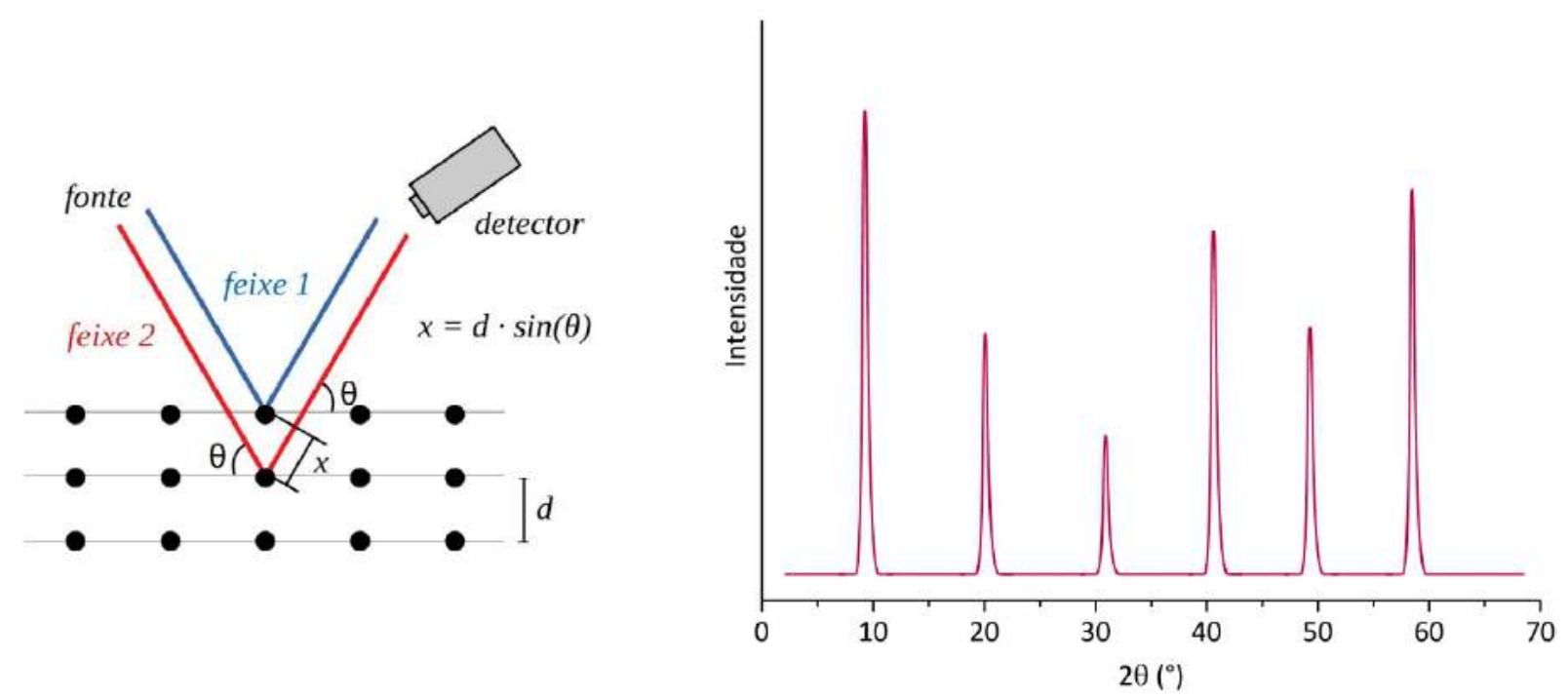

Figura 13 - Representação esquemática de um difratômetro. O sólido recebe e espalha ondas de raios X provenientes de uma fonte. A superposição resultante é medida pelo detector.

onde $\lambda$ é o comprimento de onda da radiação.

Nas caracterizações apresentadas neste trabalho, utilizamos o difratômetro multiusuário Bruker D8 Disover do Laboratório de Cristalografia do IFUSP. Sua fonte de radiação produz ondas com $\lambda=1,5418 \AA$, provenientes da linha de emissão $K_{\alpha}$ de um filamento de cobre submetido a diferença de potencial de $40 \mathrm{kV}$ e corrente de $30 \mathrm{~mA}$. Utilizamos um detector Lynxeye de 193 canais. As medidas foram realizadas para $2 \theta$ na faixa de $4^{\circ}$ a $70^{\circ}$, com passos de $0,05^{\circ}$ e tempo de integração do detector $\Delta \mathrm{t}=1,5 \mathrm{~s}$. Todas as amostras foram maceradas com o intuito de garantir a aleatoriedade de orientações dos cristalitos, possibilitando a medida de todos os comprimentos característicos do material. Neste sentido, o suporte também foi mantido sob rotação constante de $20 \mathrm{rpm}$. O pó foi cuidadosamente nivelado no porta-amostras para que o plano superior de incidência fosse bem definido.

\subsection{Termogravimetria}

A termogravimetria é uma técnica que consiste no monitoramento da massa de uma amostra em função da temperatura aplicada sobre a mesma. Além da análise de estabilidade térmica do material estudado, eventos de perda ou agregação de massa podem ser correlacionados com resultados de análises elementares para melhor determinar a composição 
de uma amostra.

O equipamento utilizado para as medidas apresentadas neste trabalho foi o TA Instruments TGA Q500, da Central Analítica do IQUSP. Um diagrama simplificado de seu funcionamento pode ser observado na Figura 14. O sistema é composto por um forno com atmosfera de nitrogênio ou ar sintético, inseridos no ambiente com vazão ajustável, e controle de temperatura até $1000^{\circ} \mathrm{C}$. As rampas de temperatura podem ser ajustadas para taxas de variação partindo de 0.01 a $100{ }^{\circ} \mathrm{C} / \mathrm{min}$. Dentro do forno é inserido o porta amostras acoplado a uma balança de precisão com sensibilidade de $1 \mu \mathrm{g}$ e capaz de medir variações de $\pm 0.01 \%$ de massa. 68,69
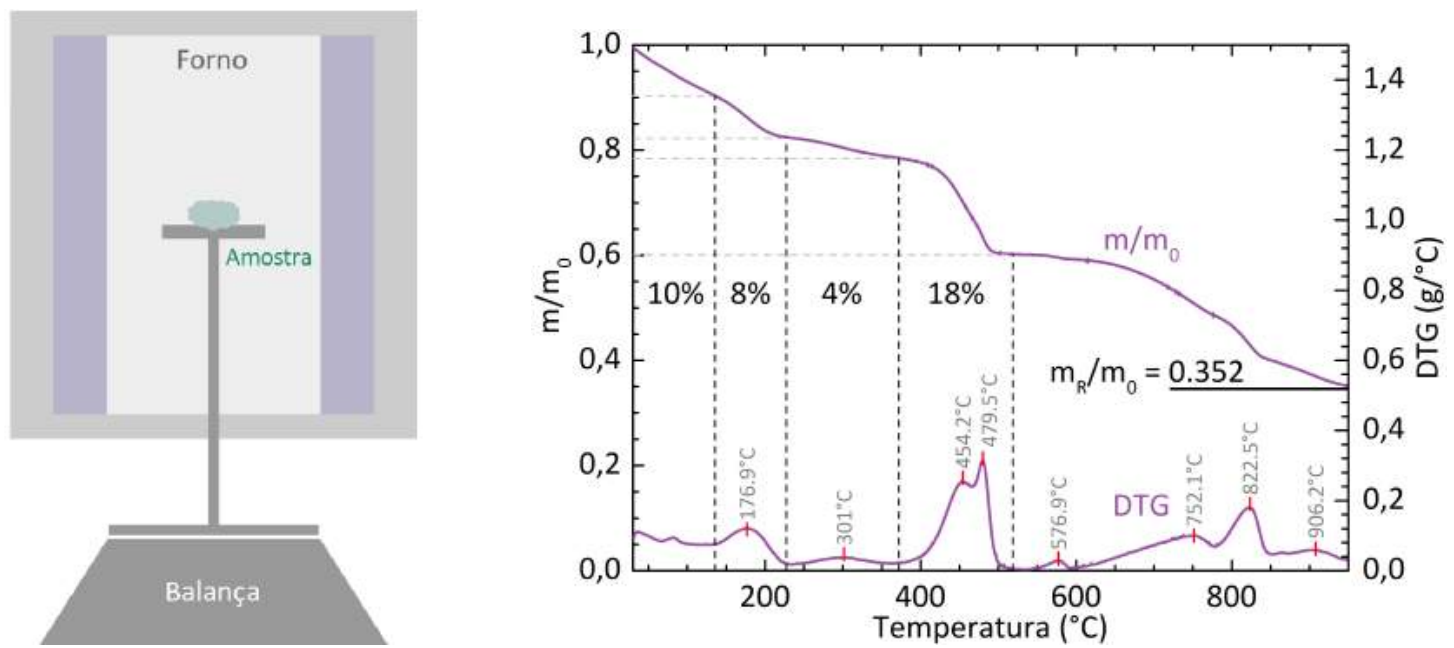

Figura 14 - Representação esquemática de uma análise termogravimétrica. A massa da amostra e sua variação são monitoradas em função da temperatura em um ambiente controlado de ar sintético.

Nossas amostras foram introduzidas no instrumento com atmosfera controlada de ar sintético, fluindo pelo sistema a uma vazão de $60 \mathrm{ml} / \mathrm{min}$. A temperatura foi variada com taxa de $5{ }^{\circ} \mathrm{C} / \mathrm{min}$, partindo da temperatura ambiente até $950{ }^{\circ} \mathrm{C}$. Tempo decorrido, massa, variação da massa e temperatura foram medidos cerca de 100 vezes por minuto, gerando resultados como o ilustrado na Figura 14 A curva $\mathrm{m} / \mathrm{m}_{0}$ indica a fração de massa no porta amostras, enquanto a curva DTG mostra a variação da massa em função da temperatura. São indicados na imagem os centros dos eventos de perda de massa e suas respectivas perdas percentuais, além da fração de massa residual $\mathrm{m}_{R} / \mathrm{m}_{0}$. 


\subsection{Análise elementar: CHN}

Para investigar a composição química dos materiais sintetizados, foram realizadas análises capazes de aferir a quantidade de cada elemento presente nas amostras.

A determinação da concentração de carbono, hidrogênio e nitrogênio foi baseada no método de Pregl-Dumas, ilustrado na Figura 15. Em uma atmosfera pura de gás oxigênio, as amostras passam por um processo de combustão completa, onde decompõem-se para os gases elementares $\mathrm{CO}_{2}, \mathrm{H}_{2} \mathrm{O}, \mathrm{N}_{2}$ e $\mathrm{SO}_{2}$. Tais gases resultantes da combustão são então misturados e estabilizados a condições controladas de temperatura, pressão e volume. Pelo método de cromatografia frontal, a mistura é separada de forma que cada um dos gases possa ser quantificado por um detector de condutividade térmica.

As análises elementares de CHN apresentadas neste trabalho foram realizadas no analisador Perkin Elmer 2400 Series II da Central Analítica do IQUSP, que possui acurácia de $0.3 \%$ e precisão nominal de $0.2 \%$ em suas medidas, segundo o fabricante. [70]

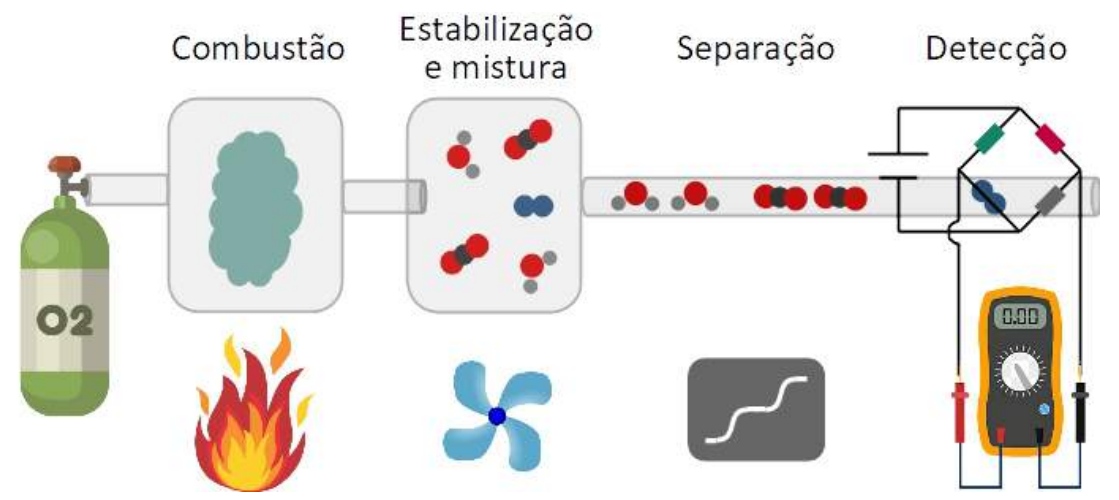

Figura 15 - Representação esquemática de uma análise elementar de CHN.

\subsection{Análise elementar: ICP-OES}

A determinação da quantidade de metais constituintes de cada amostra foi feita pela espectrometria de emissão óptica por plasma acoplado indutivamente (ICP-OES, do inglês Inductively Coupled Plasma Optical Emission Spectrometry). Nesta técnica, um plasma de argônio com temperaturas típicas de 7000 a 10000 K é utilizado para excitar os átomos e íons analisados. As emissões características do relaxamento dessas partículas são medidas por um espectroscópio óptico, tendo suas intensidades traduzidas em termos de concentrações. 
Para serem submetidas ao ICP-OES, as amostras precisam primeiramente passar por um processo de digestão ácida (ou abertura) para remover eventuais compostos orgânicos presentes no material.

O equipamento Spectro Arcos ICP-OES da Central Analítica do IQUSP foi utilizado para as medidas apresentadas nestre trabalho. Um diagrama esquemático de seu funcionamento pode ser visualizado na Figura 16, [71] Uma bobina transportando corrente alternada de radio frequência 27.12 MHz envolve o tubo por onde flui gás argônio. Os intensos campos eletromagnéticos gerados ionizam completamente o argônio, formando um plasma estável. A amostra é nebulizada no sistema e excitada na região do plasma em razão das altas temperaturas. Os íons passam a emitir a energia absorvida em forma de fótons, relaxando de níveis mais energéticos até atingir o estado fundamental.

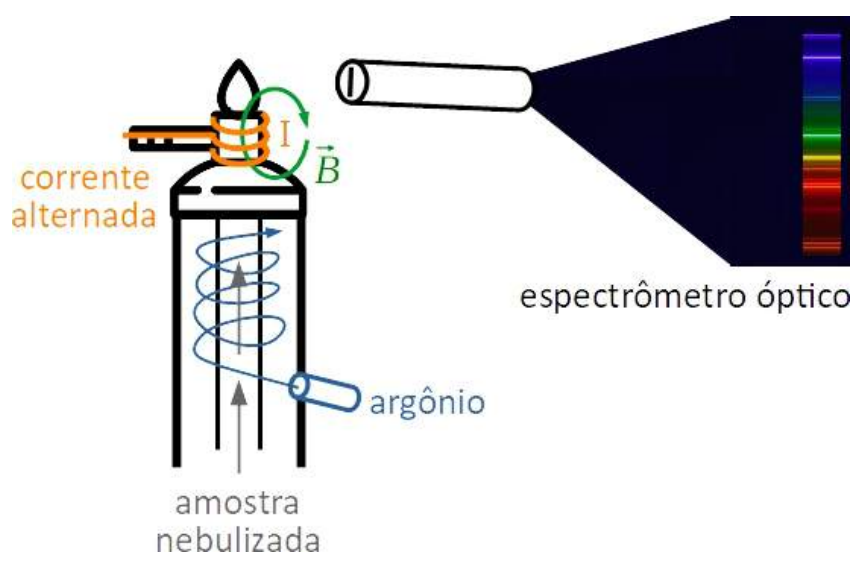

Figura 16 - Representação esquemática de uma análise elementar por ICP-OES.

As intensidades das emissões características de cada elemento são medidas por um espectrômetro óptico capaz de detectar fótons na região do ultravioleta e espectro visível, entre 130 e $770 \mathrm{~nm}$. Tais intensidades são posteriormente comparadas com as emissões padrão desses elementos em concentrações conhecidas, possibilitando o cálculo do teor daquele metal na amostra analisada.

\subsection{Microscopia eletrônica de transmissão}

Devido ao comprimento de onda dos fótons visíveis, na faixa de 400 a $750 \mathrm{~nm}$, a microscopia óptica possui uma limitação de resolução em cerca de $200 \mathrm{~nm}$. Para observar objetos 
menores que este limite, como é o caso de nosso interesse, torna-se necessário recorrer a outras técnicas.

De forma análoga à microscopia óptica usual, que se utiliza de conjuntos de lentes para ampliar as amostras iluminadas por fótons, a microscopia eletrônica utiliza elétrons para formar a imagem analisada, permitindo o aumento da resolução à medida que o momento linear dos elétrons aumenta. Na microscopia eletrônica de transmissão (TEM), um feixe de elétrons altamente energético incide sobre a amostra, sendo transmitido através da mesma. Esta parte transmitida é ampliada com o auxílio de lentes magnéticas para então colidir contra um anteparo, gerando a imagem. 72

As micrografias apresentadas no Capítulo 6 foram geradas no equipamento Jeol JEM 2100 da Central Analítica do IQUSP, ilustrado na Figura 17. Em seu funcionamento, um feixe é gerado pelo canhão de elétrons contendo um filamento do cristal hexaboreto de lantânio $\left(\mathrm{LaB}_{6}\right)$. Os elétrons são acelerados podendo chegar à energia de $200 \mathrm{keV}$. Conjuntos de lentes eletrônicas operadas por campos elétricos e magnéticos são acionadas para controlar o feixe, e podem ser divididos em três funções principais: condensador, objetiva e projetora. O primeiro deles é utilizado para colimar e direcionar o feixe. As objetivas, que podem aparecer acima e abaixo da amostra, realizam ajuste fino da posição do feixe e focalizam os elétrons. Por fim, a projetora é responsável por ampliar a imagem que será formada no anteparo. É possível observá-la diretamente em uma tela fluorescente com auxílio de binóculos ou em computadores ligados ao sistema.

O material a ser analisado é inserido no porta amostras após ser depositado em grades de cobre recobertas de resina (formvar), próprias para este fim. Para a preparação das amostras, primeiramente uma pequena massa do pó era dispersado em etanol, com auxílio de um sistema de ultrassom. A solução era dissolvida em etanol até que perdesse a opacidade, obtendo concentrações típicas de $0,1 \mathrm{mg} / \mathrm{mL}$ ou inferiores. A seguir, uma gota de $3 \mu \mathrm{L}$ da mistura era depositada nas grades (Formvar/Carbon 200 Mesh Copper TEM Grid, Electron Microscopy Sciences, USA). Os suportes utilizados possuíam cerca de $3 \mathrm{~mm}$ de diâmetro e malha contendo 200 poços. Esperava-se o etanol evaporar completamente de modo que apenas as amostras ficavam depositadas sobre a grade. 

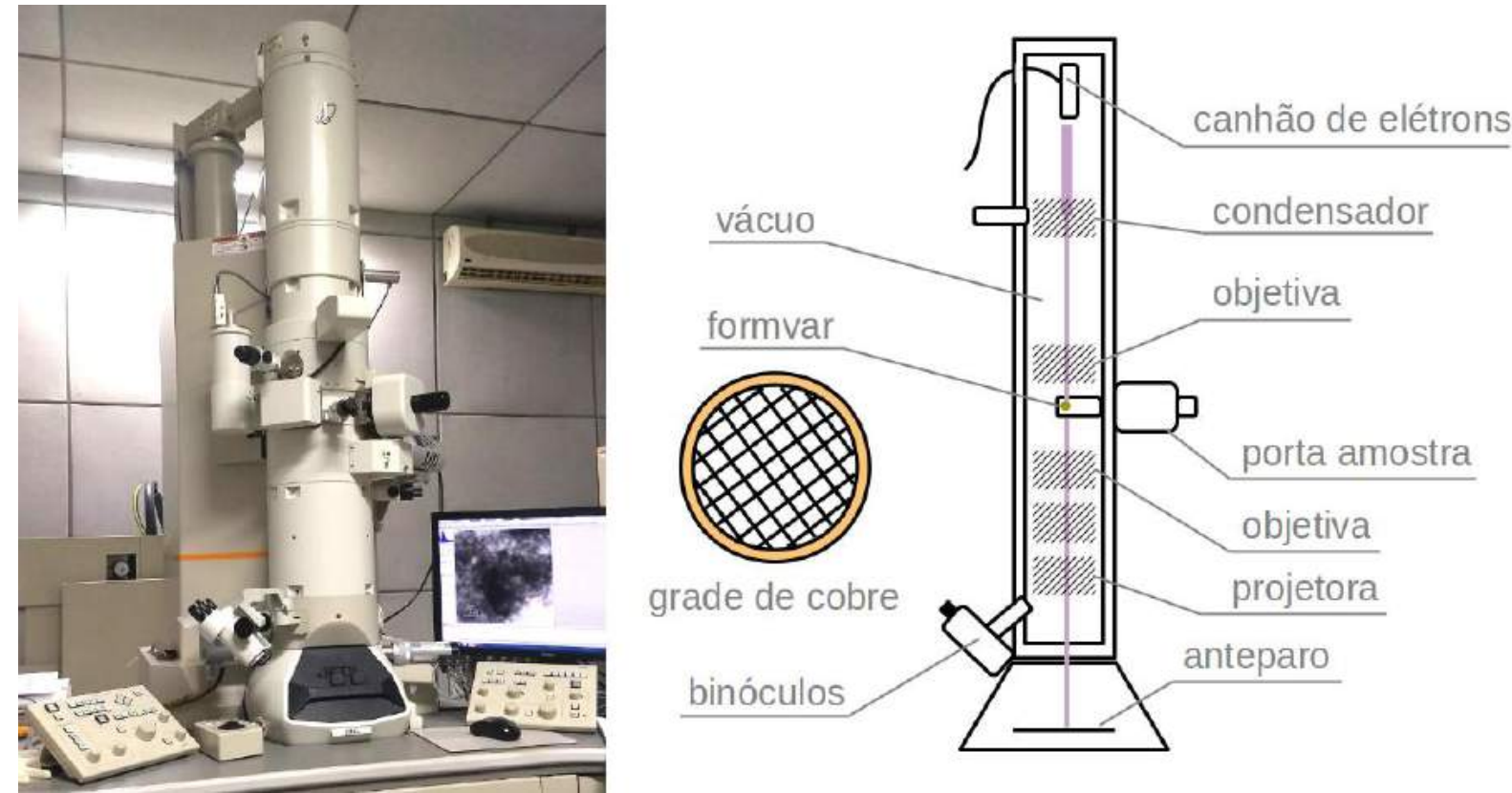

Figura 17 - Fotografia do microscópio eletrônico de transmissão Jeol JEM 2100 da Central Analítica do IQUSP. O diagrama ilustra as partes básicas para o funcionamento de um TEM.

\subsection{Fotoluminescência}

As propriedades espectroscópicas dos íons terras raras foram abordadas em detalhes no Capítulo 3. Como discutido, transições entre níveis de energia dos átomos podem ocorrer induzidas por dipolo elétrico ou dipolo magnético. Quando uma transição ocorre, é emitido ou absorvido um fóton com energia equivalente à diferença entre os níveis inicial e final. Uma forma de induzir tais transições é excitar os elétrons do material com fótons, fazendo com que ocupem níveis mais energéticos que o estado fundamental. O sistema tende a voltar para o estado de menor energia, liberando outros fótons no processo. Este efeito, denominado fotoluminescência, é realizado experimentalmente no equipamento da Figura 18.

As análises podem ser realizadas para os espectros de excitação e emissão do material estudado. No espectro de excitação, é monitorado um comprimento de onda $\lambda_{\text {em }}$ fixo para os fótons emitidos, enquanto a excitação é realizada por fótons em um intervalo de $\lambda_{e x}$ definido pelo usuário. Ao contrário, o espectro de emissão é realizado ao excitar a amostra em um comprimento de onda $\lambda_{e x}$ monocromático fixo, enquanto é medida a intensidade da emissão dos fótons com diferentes energias.

Os resultados espectroscópicos apresentados neste trabalho foram obtidos pelos espectros 


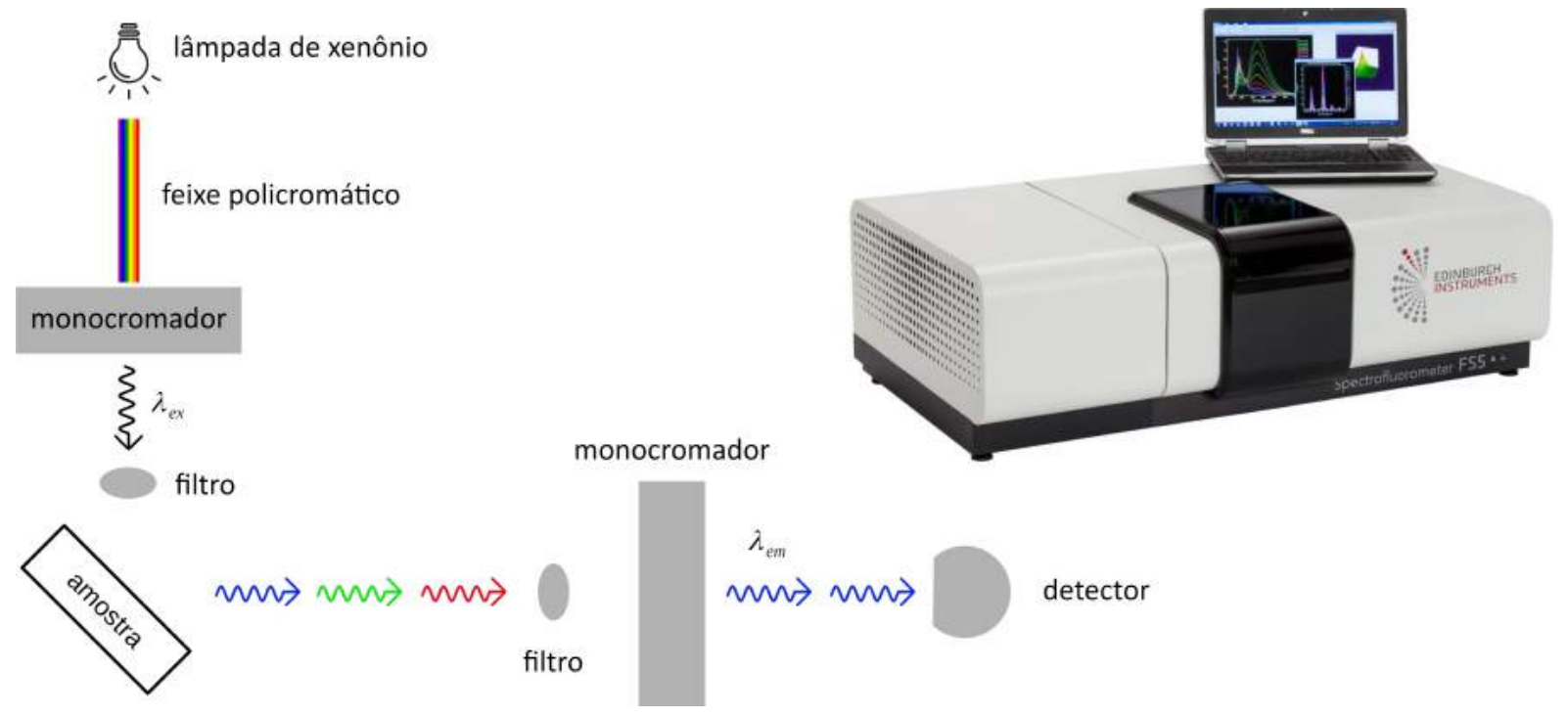

Figura 18 - Edinburgh Instruments FS5 e diagrama esquemático de funcionamento de um fluorímetro.

de excitação e emissão medidos no fluorímetro Edinburgh Instruments FS5 do Laboratório de Nanomateriais e Aplicações (IFUSP). Sua fonte policromática é uma lâmpada de xenônio de $450 \mathrm{~W}$, cujo feixe de luz colimado passa por um monocromador, de forma a selecionar o comprimento de onda de excitação $\lambda_{e x}$. 


\section{Síntese dos materiais}

\subsection{Materiais e compostos utilizados}

Neste trabalho foram sintetizadas amostras de hidróxidos lamelares de zinco, alumínio e terras raras do tipo $\mathrm{Zn}_{2} \mathrm{Al}_{1-x} \mathrm{TR}_{x}(\mathrm{OH})_{6}\left[\mathrm{C}_{6} \mathrm{H}_{3}\left(\mathrm{CO}_{2} \mathrm{H}\right)_{3}^{3-}\right]$. A escolha pelos metais zinco e alumínio se deve à sua relativa abundância e também ao fato de apresentarem baixa toxicidade, permitindo, por exemplo, seu uso para aplicações biológicas. Como precursores dos íons $\mathrm{Zn}^{2+}, \mathrm{Al}^{3+}$ e $\mathrm{TR}^{3+}$ utilizamos seus respectivos nitratos $\mathrm{M}\left(\mathrm{NO}_{3}\right)_{n} \cdot \mathrm{yH}_{2} \mathrm{O}$. Para o controle de pH durante o procedimento, empregamos o titulador 848 Titrino Plus da Metrohm preenchido com solução aquosa de hidróxido de sódio $1 \mathrm{~mol} / \mathrm{L}$. Micelas cilíndricas do sufactante Plurônic ${ }^{\circledR} \mathrm{P}_{123}$ foram preparadas em solução. A relação dos compostos utilizados e suas especificações consta na Tabela 3 .

Tabela 3 - Relação de produtos utilizados na síntese de nanotubos de hidróxidos duplos lamelares de zinco-alumínio.

\begin{tabular}{cc}
\hline Composto & Especificações \\
\hline \hline Nitrato de Zinco: $\mathrm{Zn}\left(\mathrm{NO}_{3}\right)_{2} \cdot 6 \mathrm{H}_{2} \mathrm{O}$ & teor $\geq 96,0 \%$, marca: Synth \\
Nitrato de Alumínio: $\mathrm{Al}\left(\mathrm{NO}_{3}\right)_{3} \cdot 9 \mathrm{H}_{2} \mathrm{O}$ & teor $\geq 98,0 \%$, marca: Synth \\
Nitrato de $\mathrm{TR}^{3+}: \mathrm{TR}\left(\mathrm{NO}_{3}\right)_{3} \cdot 6 \mathrm{H}_{2} \mathrm{O}$ & produzido no LNA a partir do óxido \\
Polímero $\mathrm{P}_{123}$ : PEG-PPG-PEG & Plurônic, marca: Sigma-Aldrich \\
Ácido Benzeno-1,3,5-Tricarboxílico: BTC & teor $\geq 95,0 \%$, marca: Sigma-Aldrich \\
Hidróxido de Sódio: $\mathrm{NaOH}$ & solução 1 mol/L \\
\hline
\end{tabular}

\subsection{Procedimentos}

A síntese dos materiais, desenvolvida por pesquisadores do nosso laboratório, tem como base o tradicional método de coprecipitação de cátions metálicos sobre uma solução alcalina.

Os procedimentos experimentais são divididos em quatro etapas: preparação das micelas cilíndricas, coprecipitação, cristalização e lavagem. 


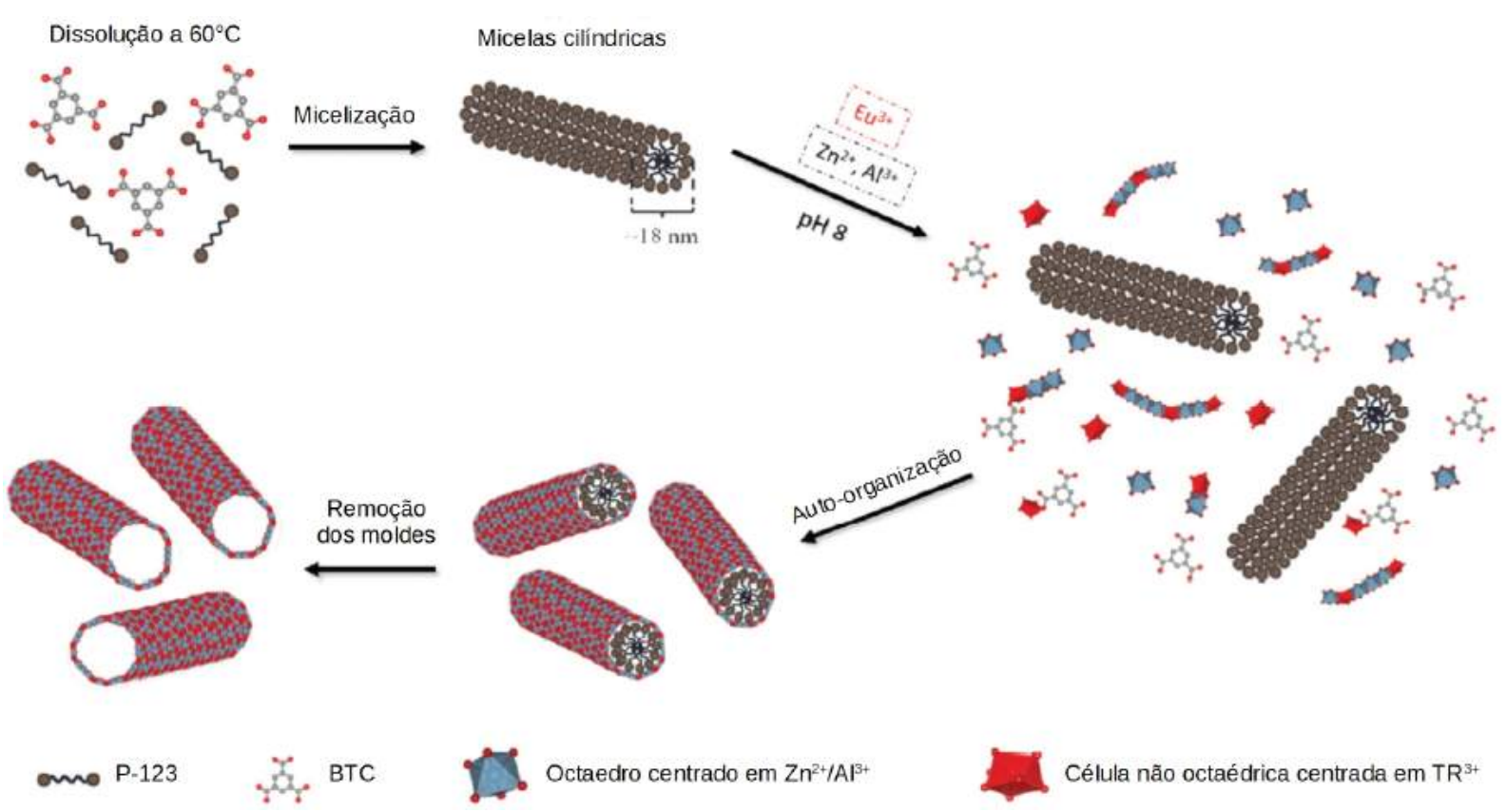

Figura 19 - Diagrama esquemático do processo de síntese dos nanotubos. Créditos: Alysson F. Morais (adaptado de [38]).

\section{Parte 1 - Preparação das micelas cilíndricas}

O polímero $\mathrm{P}_{123}$ foi escolhido como surfactante devido à possibilidade de formação de micelas cilíndricas com diâmetros da ordem de $20 \mathrm{~nm}$, ideal para a produção de mesoporos.

A preparação das micelas é iniciada, dissolvendo $0,30 \mathrm{~g}$ de $\mathrm{P}_{123}$ com o auxílio de um agitador magnético em $200 \mathrm{~mL}$ de água desionizada a $60{ }^{\circ} \mathrm{C}$, tomando-se o cuidado para que a temperatura não se alterasse por mais de $2{ }^{\circ} \mathrm{C}$ do desejado. Quando o polímero é completamente disperso nesta temperatura a mistura atinge o cloud point, momento em que adquire aparência de nuvem, tornando-se turva e esbranquiçada. A adição de sais a sistemas micelares de $\mathrm{P}_{123}$ induz a formação de cilindros e mantém o sistema estável mesmo após seu resfriamento 73. Adicionamos 0,490 g de BTC, que realiza esta função de indução e atua posteriormente como ligante entre as lamelas de hidróxidos. Para que a dissolução do BTC se complete, desprotonamos suas carboxilas titulando a solução a pH 5,0.

Após este procedimento, espera-se que a mistura esfrie até $25^{\circ} \mathrm{C}$. Um ciclo é realizado aquecendo-se novamente a mistura a $60{ }^{\circ} \mathrm{C}$ e aguardando que retorne ao equilíbrio térmico com o ambiente. 


\section{Parte 2 - Coprecipitação}

Uma solução $1 \mathrm{~mol} / \mathrm{L}$ é preparada com os sais dos precursores metálicos para a formação de hidróxidos lamelares do tipo $\left[\mathrm{M}_{2}^{I I} \mathrm{M}_{1-x}^{I I I} \mathrm{TR}_{x}^{3+}(\mathrm{OH})_{6}\right]^{1+}\left[\left(\mathrm{A}_{1 / n}^{n-}\right) \cdot \mathrm{yH}_{2} \mathrm{O}\right]^{1-}$.

Em $10 \mathrm{~mL}$ de água desionizada, os cátions di e tri-valentes são adicionados na proporção $\mathrm{M}^{I I}: \mathrm{M}^{I I I}=2: 1$. Para a formação de hidróxidos lamelares com terras raras, uma porcentagem dos íons $\mathrm{M}^{I I I}$ é substituída pelos $\mathrm{TR}^{3+}$. À temperatura ambiente e com auxílio de uma seringa, a mistura é gotejada sobre a solução contendo as micelas na taxa de $10 \mathrm{~mL} / \mathrm{h}$, enquanto o sistema tem seu pH regulado a 8,0 com a injeção de $\mathrm{NaOH} 1 \mathrm{~mol} / \mathrm{L}$. Durante todo o procedimento, a mistura é mantida agitada por um sistema magnético.

\section{Parte 3 - Cristalização}

Finalizada a síntese dos hidróxidos, a suspensão é inserida imediatamente em uma estufa a $60{ }^{\circ} \mathrm{C}$ durante o período de dois dias. A permanência do material sob tais condições otimiza sua cristalização.

\section{Parte 4 - Lavagem}

Após o tempo de estufa, a amostra é retirada e centrifugada, para separar o material, em forma de pó, do líquido excedente. O pó é lavado por três vezes em $30 \mathrm{~mL}$ de água destilada e centrifugado, para que nitratos remanescentes sejam retirados do sistema. Em seguida, o material resultante é lavado por duas vezes em $20 \mathrm{~mL}$ de metanol, deixando no banho ultrassom por 15 minutos e centrifugando para retirar o solvente. Este procedimento é realizado para dissolver as micelas de $\mathrm{P}_{123}$, restando apenas os nanotubos de hidróxidos nanoporosos. Após seca, a amostra é macerada e pode ser submetida às caracterizações necessárias ou armazenada. 



\section{Resultados}

O método de síntese para produção de nanotubos de hidróxidos lamelares foi testado para diversas composições, utilizando nas diferentes amostras cada um dos lantanídeos estáveis entre o praseodímio (Pr) e lutécio (Lu), além do lantânio (La) e do ítrio (Y).

Todos os materiais produzidos foram submetidos a caracterização estrutural, morfológica e espectroscópica. A fim de simplificar a nomenclatura dos materiais e diferenciar amostras sintetizadas pelo método descrito na seção 5.2 e pelo método usual de coprecipitação (realizado com a omissão "Parte 1"), neste trabalho nos referimos às amostras $\mathrm{Zn}_{2} \mathrm{Al}_{1-x} \mathrm{TR}_{x}(\mathrm{OH})_{6} \mathrm{~A}_{1 / n}^{n-}$ como ZnAlTRx\%-A, onde $\mathrm{A}=\mathrm{NO}_{3}^{-}$ou $\mathrm{BTC}^{3-}$, adicionando-P123 para aquelas produzidas na presença de micelas deste polímero.

As seções 6.1, 6.2 e 6.3 concernem à investigação da composição e da estrutura cristalina dos materiais sintetizados, independente de sua morfologia. Em seguida, exploramos os resultados obtidos por microscopia eletrônica para identificar os sistemas que formam nanotubos e caracterizá-los quanto a suas dimensões e prevalência na amostra. Abordamos a possibilidade de produção dos nanotubos com mais de um íon TR, importante ferramenta para ajustar a funcionalidade dos materiais em pesquisas futuras. Por fim, discutimos as propriedades luminescentes das amostras apresentadas neste trabalho e informações sobre o ambiente químico dos íons terras raras a partir de sua análise espectroscópica.

\subsection{Caracterização estrutural}

Há quatro principais informações que podem ser aferidas das medidas de DRX:

1) Os primeiros picos do difratograma, em geral os mais intensos, dizem respeito às reflexões (00n) ao longo do eixo de empilhamento das lamelas, definindo pela Lei de Bragg (4.1) o espaçamento basal $\mathbf{c}_{0}$ da amostra.

2) A equação de Scherrer, dada por

$$
D=\frac{k \lambda}{\cos \theta \sqrt{\Delta^{2}-\delta^{2}}}
$$


relaciona a largura destes picos com o tamanho $\mathbf{D}$ do cristalito analisado, determinando um limite inferior para o número de lamelas empilhadas. Nesta relação, $\lambda=1.5418 \AA$ é o comprimento de onda da radiação $\mathrm{K}_{\alpha}$ do cobre, $\delta=0.14^{\circ}$ é a largura a meia altura intrínseca do equipamento utilizado, $\Delta$ é a largura a meia altura medida no pico gaussiano e k é uma constante dependente da estrutura do cristalito.

3) Na região de $2 \theta=60^{\circ}$ a posição do pico (110) determina o parâmetro de rede $\mathbf{a}_{0}$, relativo à distância metal-metal nas lamelas do HDL, uma vez que $\mathrm{a}_{0}=2 \mathrm{~d}(110)$.

4) As posições de eventuais picos (011) e (10l) podem determinar o polimorfismo da estrutura cristalina. Utilizando a seguinte relação para (011) e (101):

$$
\frac{1}{d^{2}(h k l)}=4 \frac{h^{2}+h k+k^{2}}{3 a_{0}^{2}}+\frac{l^{2}}{c^{2}},
$$

onde $d(h k l)$ é a distância entre os planos de reflexão $(\mathrm{hkl})$ e $c=n c_{0}$, o valor verdadeiro do número inteiro $n$ é dado quando os picos simulados coincidem com aqueles do difratograma medido. Sistemas romboédricos (3R), cuja estrutura cristalina se repete após o empilhamento de 3 camadas de hidróxidos $(\mathrm{n}=3)$, apresentam em seu difratograma apenas os picos (011) e (10l) com $-h+k+l=3 m$, para $m$ inteiro. Sistemas hexagonais $(\mathbf{n H})$, por sua vez, apresentam intensas reflexões para $-h+k+l \neq 3 m$.

Os HDLs planos de zinco e alumínio ZnAl-NO $\mathrm{N}_{3}$-P123 e ZnAl-BTC-P123, intercalados de nitrato e trimesato, respectivamente, foram sintetizados na presença de micelas cilíndricas de P123. Essas amostras serviram como referência para posteriores análises comparativas entre hidróxidos lamelares com diferentes morfologias.

A amostra ZnAl-NO $\mathbf{Z}_{3} \mathbf{- P 1 2 3}$ apresentou espaçamento basal $\mathrm{c}_{0}=(0.886 \pm 0.013) \mathrm{nm}$. Descontando a espessura típica das camadas de hidróxidos, da ordem de $0.48 \mathrm{~nm}$, o espaço interlamelar de $0.40 \mathrm{~nm}$ é compatível com a presença de nitratos intercalados entre as lamelas. 74 77. A estimativa para o tamanho do cristalito obtida pela equação de Scherrer foi de 29.2 nm, indicando um empilhamento mínimo de 33 camadas no material. O parâmetro de rede correspondente à distância metal-metal foi $\mathrm{a}_{0}=(0,3071 \pm 0,0008) \mathrm{nm}$, compatível com outros HDLs de Zn/Al. 74 Com a repetição da estrutura cristalina após o empilhamento de três camadas $(\mathrm{n}=3)$, foram observadas as reflexões (101), (012), (015), (018) e (0 1 11) com a intensidade dos picos (011) maior que (101), como ilustrado na Figura 20, caracterizando 
um sistema de simetria romboédrica $3 \mathbf{R}_{1}$. [78] A reflexão assinalada com asterisco indica uma pequena presença da fase $\mathrm{ZnAl}-\mathrm{CO}_{3}-\mathrm{P} 123$, um HDL de zinco e alumínio intercalado de carbonatos, possivelmente adsorvidos do ar atmosférico durante o processo de síntese. Trata-se de uma contaminação comum já reportada em trabalhos anteriores. 38

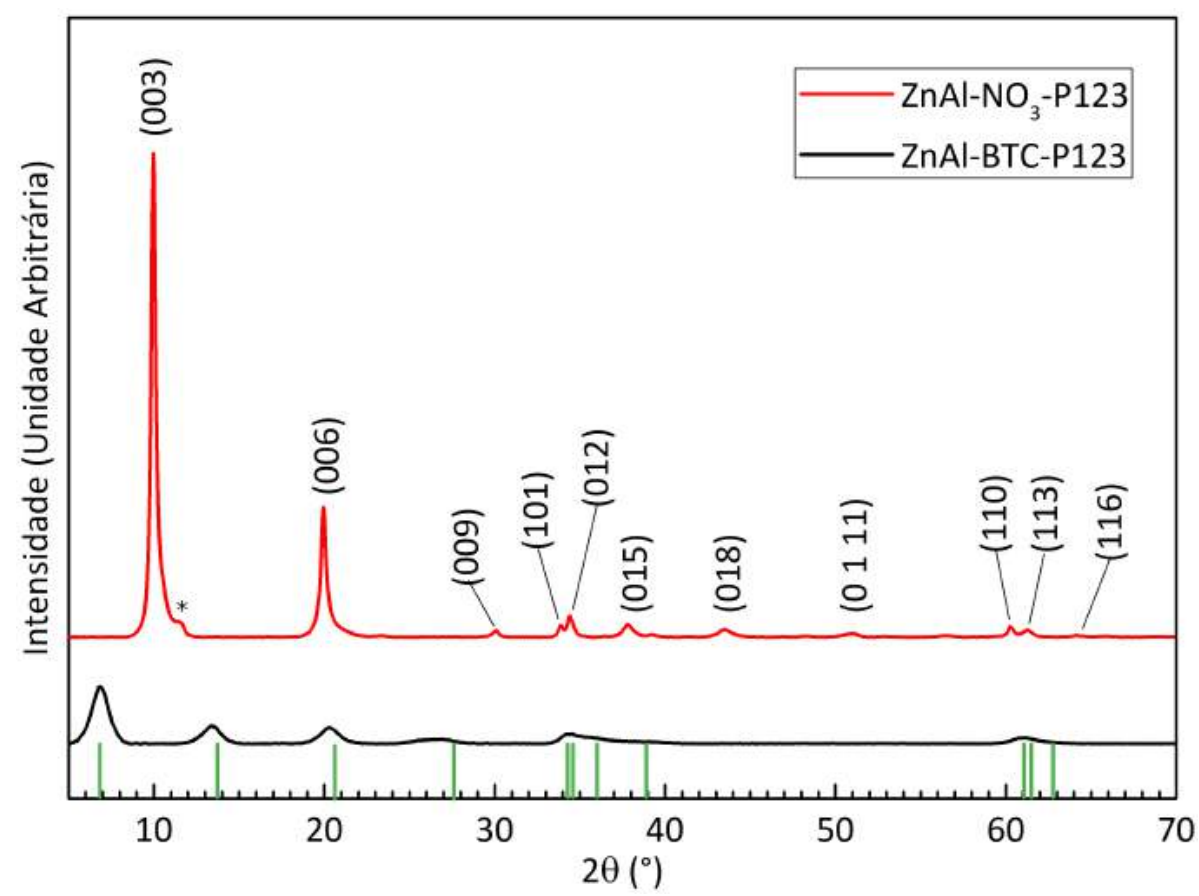

Figura 20 - Difração de raios X das amostras ZnAl-NO ${ }_{3}$-P123 (vermelho) e ZnAl-BTC-P123 (preto). Em verde estão as posições simuladas de um HDL de Zn/Al com parâmetros de rede $\mathrm{a}_{0}=3.038 \AA, \mathrm{c}_{0}=12.92 \AA$ e simetria romboédrica $3 \mathrm{R}$.

A intercalação de trimesatos no hidróxido de zinco e alumínio reduziu consideravelmente a cristalinidade da amostra ZnAl-BTC-P123 em comparação ao HDL intercalado com nitratos. Com primeiro pico de difração na região de $2 \theta=6.8^{\circ}$, seu espaçamento basal foi $\mathrm{c}_{0}=(1.29 \pm 0.09) \mathrm{nm}$. Este valor é compatível com a intercalação de $\mathrm{BTC}^{2-}$ em orientação vertical com relação às lamelas, como reportado por Shao et al [77] para hidróxidos lamelares de európio ( $\mathrm{LEuH})$. O tamanho mínimo do cristalito estimado para esta amostra foi de 6.6 nm, indicando empilhamento de apenas 5 camadas de hidróxidos. A redução da cristalinidade da amostra causa o alargamento dos picos e consequente sobreposição das reflexões (110) e (113) na região de $2 \theta=60^{\circ}$. Embora esta característica aumente a incerteza da medida, foi possível estimar a distância metal-metal $\mathrm{a}_{0}=(0.303 \pm 0.003) \mathrm{nm}$, compatível dentro de uma incerteza com o valor obtido para o HDL intercalado de nitratos.

A Figura 20 mostra o difratograma do HDL intercalado de trimesatos em comparação 
aos picos esperados para um sistema com parâmetros de rede $\mathrm{a}_{0}=3.038 \AA, \mathrm{c}_{0}=12.92 \AA \mathrm{e}$ simetria romboédrica 3R. Devido à baixa cristalinidade do sistema, não é possível identificar o polimorfismo da amostra. Na região $30^{\circ}<2 \theta<40^{\circ}$, onde estariam presentes as reflexões (011) e (101), surge um perfil descrito na literatura como "barbatana de tubarão". [79 Este efeito é atribuído à falta de periodicidade no empilhamento das lamelas. O consequente alargamento dos picos combinado à atenuação das reflexões (101) dá origem ao envelope assimétrico observado no sinal de raios X. Na impossibilidade de determinar com exatidão a simetria da amostra, a escolha da célula unitária se torna arbitrária. Utilizamos $n=3$ para facilitar eventuais comparações entre os hidróxidos lamelares sintetizados com BTC e $\mathrm{NO}_{3}$.

Os padrões de DRX das amostras ZnAlTR5\%-BTC-P123 são apresentados nas Figuras 21(a) e A.1. Para caracterizar as amostras quanto a seu espaçamento basal, ajustes gaussianos foram feitos nos picos de reflexão (003), determinando sua posição média e largura a meia altura, como ilustrado no exemplo da Figura 21b para o hidróxido lamelar ZnAlEu5\%-BTC-P123. As posições dos picos (003) para todas as composições de hidróxidos sintetizados com terras raras são compatíveis entre si e não apresentam qualquer tendência com o raio ou número atômico dos diferentes íons $\mathrm{TR}^{3+}$. Conforme evidenciado pela comparação com a amostra ZnAl-BTC-P123, o espaçamento basal é coerente com a intercalação de $\mathrm{BTC}^{2-}$ em orientação transversal às lamelas.

Tabela 4 - Propriedades cristalográficas das amostras ZnAlTR5\%-BTC-P123.

\begin{tabular}{cccccc}
\hline TR & $\begin{array}{c}\text { Espaçamento } \\
\text { basal }(\mathrm{nm})\end{array}$ & $\begin{array}{c}\text { FWHM } \\
(003)\left({ }^{\circ}\right)\end{array}$ & $\begin{array}{c}\text { Cristalito }^{\dagger} \\
(\mathrm{nm})\end{array}$ & $\begin{array}{c}\text { Empilhamento } \\
\text { médio }\end{array}$ & $\begin{array}{c}\mathrm{d}_{M M} \\
(\mathrm{~nm})\end{array}$ \\
\hline- & $1.29(9)$ & 1.21 & 6.6 & 5.1 & $0.303(3)$ \\
$\mathrm{La}$ & $1.30(11)$ & 1.51 & 5.3 & 4.1 & $0.304(3)$ \\
$\mathrm{Pr}$ & $1.32(11)$ & 1.45 & 5.5 & 4.2 & $0.304(3)$ \\
$\mathrm{Nd}$ & $1.35(14)$ & 1.75 & 4.6 & 3.4 & $0.3046(24)$ \\
$\mathrm{Sm}$ & $1.35(14)$ & 1.73 & 4.6 & 3.4 & $0.304(3)$ \\
$\mathrm{Eu}$ & $1.34(11)$ & 1.33 & 6.0 & 4.5 & $0.305(3)$ \\
$\mathrm{Gd}$ & $1.32(13)$ & 1.79 & 4.5 & 3.4 & $0.304(3)$ \\
$\mathrm{Tb}$ & $1.32(13)$ & 1.75 & 4.6 & 3.4 & $0.305(3)$ \\
$\mathrm{Dy}$ & $1.30(10)$ & 1.34 & 6.0 & 4.6 & $0.304(3)$ \\
$\mathrm{Ho}$ & $1.28(12)$ & 1.74 & 4.6 & 3.6 & $0.304(3)$ \\
$\mathrm{Er}$ & $1.30(10)$ & 1.34 & 6.0 & 4.6 & $0.304(3)$ \\
$\mathrm{Tm}$ & $1.30(11)$ & 1.43 & 5.6 & 4.3 & $0.305(3)$ \\
$\mathrm{Yb}$ & $1.30(12)$ & 1.60 & 5.0 & 3.8 & $0.305(3)$ \\
$\mathrm{Lu}$ & $1.25(11)$ & 1.58 & 5.1 & 4.1 & $0.304(3)$ \\
\hline
\end{tabular}

† Tamanho mínimo do cristalito, obtido pela equação de Scherrer. Utilizamos k $=0.9$, que é o valor esperado para um conjunto unidimensional de planos cristalinos. 
(a)

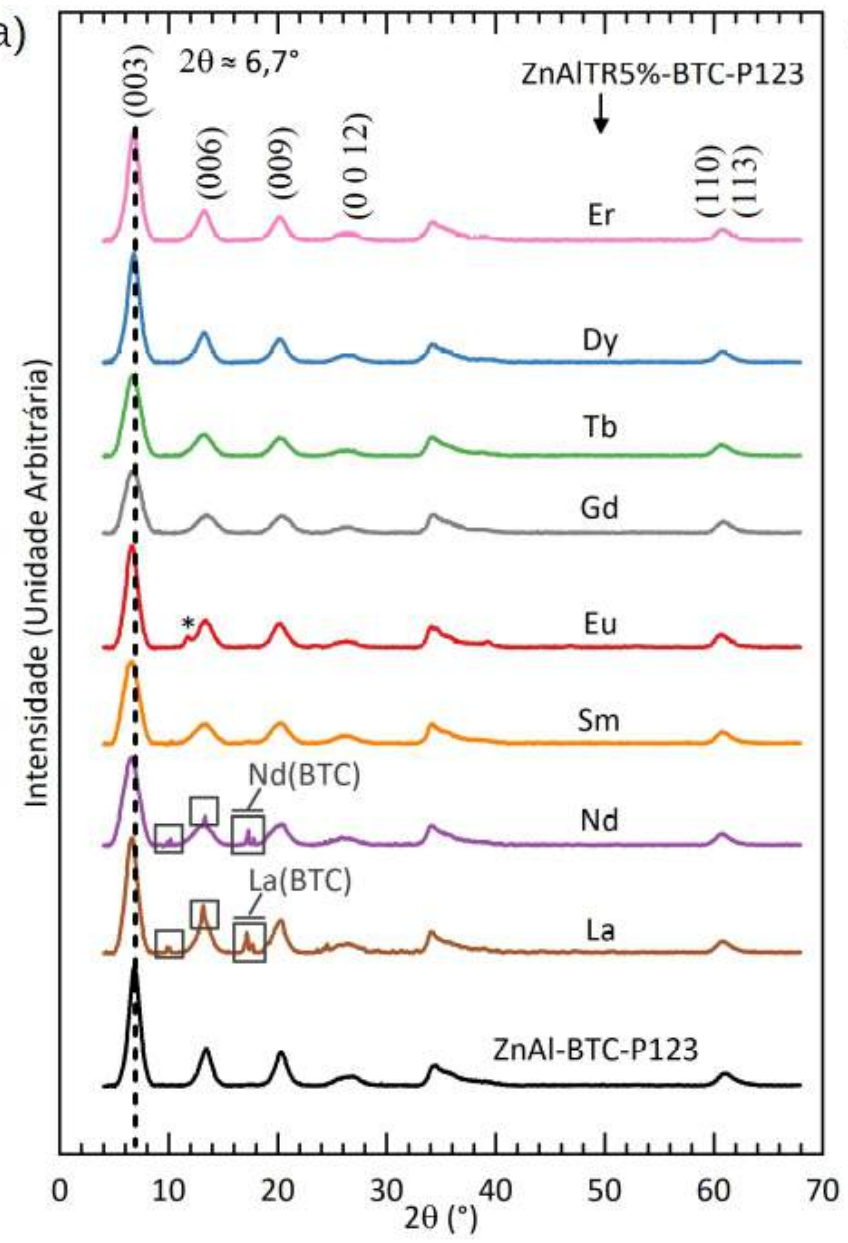

(b)

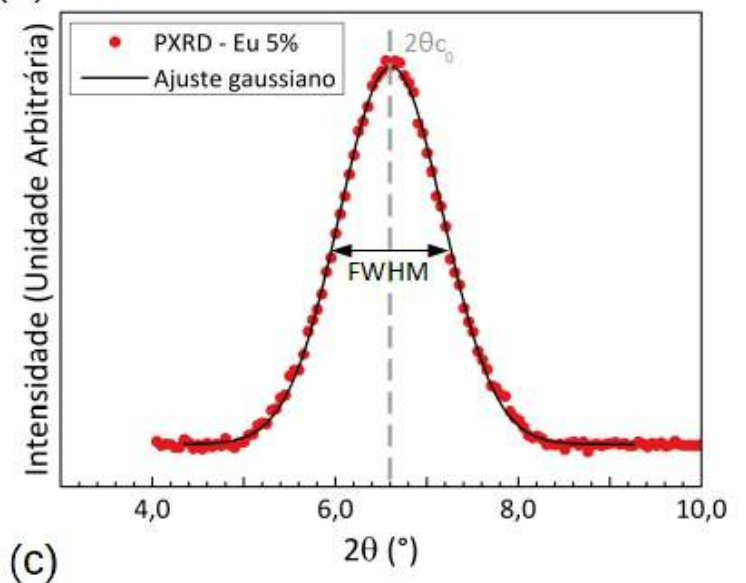

(c)

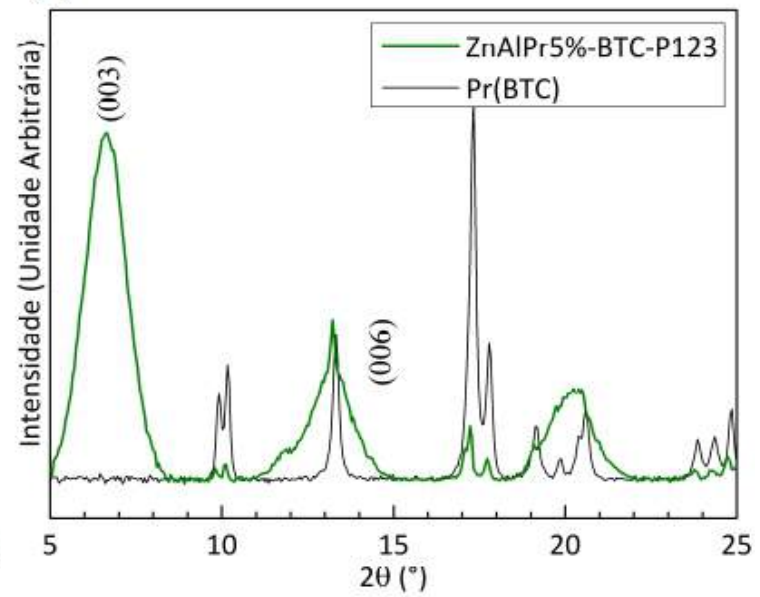

Figura 21 - (a) Difração de raios X das amostras ZnAlTR5\%-BTC-P123 (cores) e ZnAlBTC-P123 (preto); (b) Exemplo de ajuste gaussiano sobre o pico (003) de difração; (c) Comparação entre os compostos ZnAlPr5\%-BTC-P123 e Pr(BTC).

Uma ligeira diminuição na cristalinidade foi observada nas amostras dopadas de terras raras se comparadas com o HDL não dopado. O consequente alargamento dos picos de difração é refletido nas propriedades cristalográficas das amostras (Tabela 4), que indicam uma redução no empilhamento médio de lamelas para valores entre 3.4 e 4.6 camadas. Esta redução de cristalinidade se deve às distorções causadas pela introdução dos íons $\mathrm{TR}^{3+}$ na camada de hidróxidos. A diferença de raio iônico entre os lantanídeos e os metais $\mathrm{Zn} / \mathrm{Al}$ e seus elevados números de coordenação interferem na regularidade da rede formada por sítios octaédricos do HDL comum, como relatado em trabalhos anteriores com a incorporação de Tb nesses materiais. 80 Foi observado por Gago et al. 81 que a presença de lantanídeos na região interlamelar aumenta a densidade eletrônica da galeria de modo que a contribuição para a intensidade I das reflexões ao longo do eixo de empilhamento é construtiva para o pico 
(006) e destrutiva para (003). Neste caso, é comum obter padrões invertidos de difração, onde $\mathrm{I}(003)<\mathrm{I}(006)$. A inexistência deste efeito para todas as amostras ZnAlTR5\%-BTCP123 sintetizadas indica que os íons terras raras foram de fato incorporados às camadas de hidróxidos.

A distância metal-metal nos hidróxidos é dependente do raio iônico dos metais que compõem suas camadas. O valor de $\mathrm{a}_{0}$ observado nas amostras ZnAlTR5\%-BTC-P123 é da ordem de $\mathrm{a}_{0} \approx 0.304 \mathrm{~nm}$. A Lei de Vegard,

$$
a_{A_{1-x} B_{x}}=(1-x) a_{A}+x a_{B},
$$

é uma lei empírica que relaciona o parâmetro de rede $a_{A B}$ de uma solução sólida aos parâmetros de rede $a_{A}$ e $a_{B}$ individuais de seus constituintes e suas respectivas concentrações $x$ na mistura. Se aplicarmos para o caso estudado, temos que a distância metal-metal das amostras de hidróxidos lamelares com terras raras pode ser estimada a partir dos valores de $\mathrm{a}_{0}$ para o HDL puro e do hidróxido lamelar do respectivo íon terra rara. Usando como exemplo o Európio,

$$
a_{\mathrm{ZnAlEux} \%}=(1-x) a_{\mathrm{ZnAl}}+x a_{\mathrm{LEuH}}
$$

dado $\left.a_{\mathrm{LEuH}}=3.7 \AA 82\right]$ e $x=\mathrm{Eu} /(\mathrm{Zn}+\mathrm{Al}+\mathrm{Eu})=1.6 \%$ para a amostra ZnAlEu5\%-BTCP123, temos a distância metal-metal corrigida de $\mathrm{a}_{0}=0.30407 \mathrm{~nm}$. Devido à sobreposição das reflexões $(110)$ e $(113)$, a incerteza propagada para os valores $a_{0} \approx(0.304 \pm 0.003) \mathrm{nm}$ (Tabela 4) é maior que as mudanças previstas para o parâmetro de rede pela substituição de diferentes terras raras, tornando todos os valores compatíveis entre si e sem nenhuma tendência perceptível de aumento de $\mathrm{a}_{0}$ em função de seus raios iônicos.

Dois tipos de fases laterais foram observadas em algumas composições dos materiais sintetizados. Para os terras raras com raio atômico maior que o európio, houve a formação do complexo $\mathrm{TR}(\mathrm{BTC})$, caracterizado por picos estreitos na região entre $10^{\circ} \leq 2 \theta \leq 25^{\circ}$. 83 85 Figura 21 mostra a correspondência entre o DRX da amostra sintetizada com 5\% de praseodímio e o respectivo complexo $\operatorname{Pr}(\mathrm{BTC})$. A constante de formação dos complexos TR-benzenocarboxilatos é aproximadamente constante para toda a série dos lantanídeos, enquanto a constante de solubilidade de seus hidróxidos decresce à medida que aumentamos o número atômico. [86, 87] Essas propriedades favorecem a formação de complexo para 
os terras raras com maior raio atômico, mesmo quando em pequenas concentrações. A Figura 22 mostra que mesmo com a substituição de apenas 3\% de alumínio por lantânio há a formação da fase lateral La(BTC), enquanto não é possível identificar complexos nas amostras ZnAlTmx\%-BTC-P123 para concentrações até 30\%. Como evidenciado no DRX das amostras com túlio, um aumento na concentração do íon TR implica na redução da cristalinidade da amostra em sistemas que não apresentam fases laterais, devido ao aumento de desordens locais causadas na rede cristalina pela incorporação de mais terras raras.
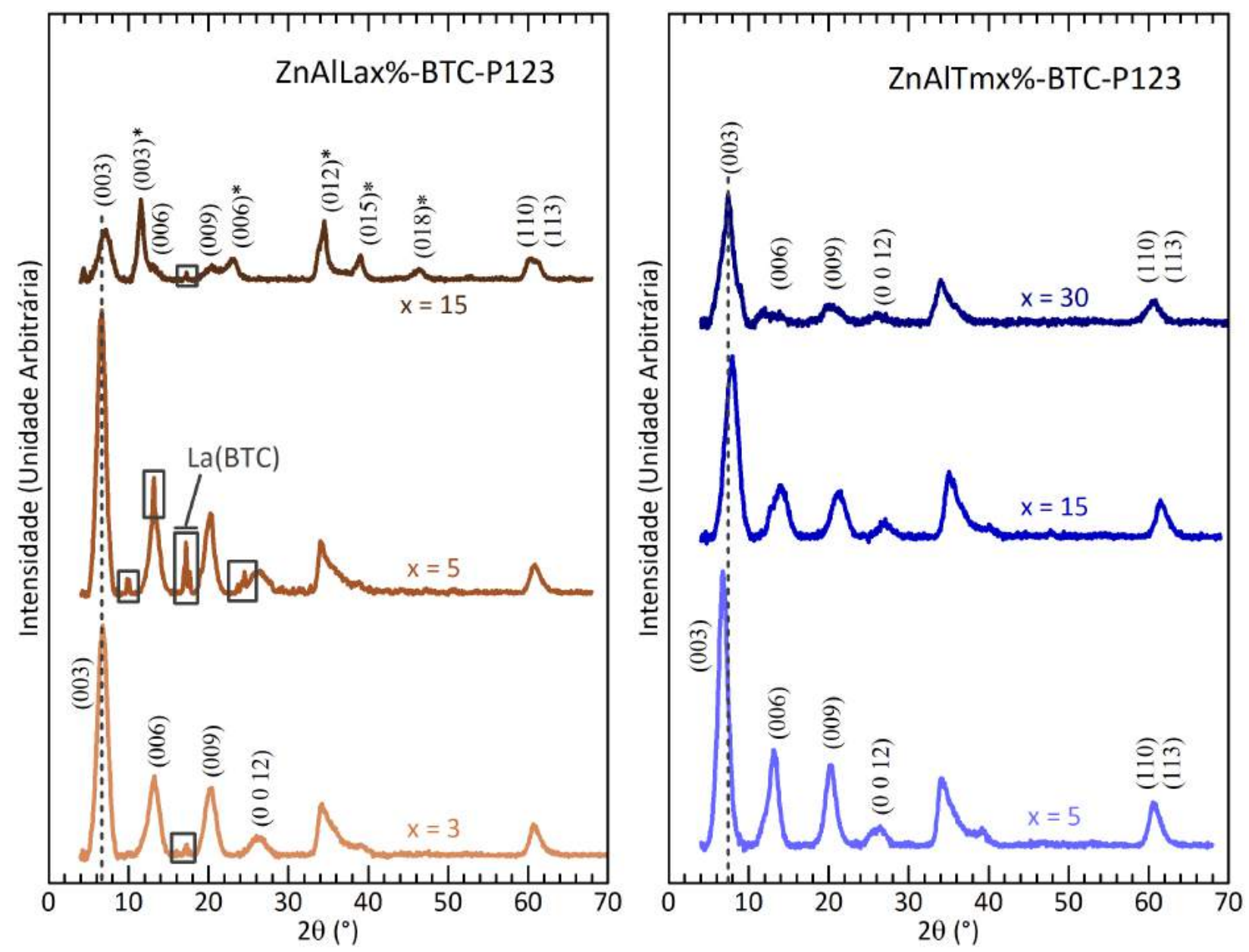

Figura 22 - Difração de raios $\mathrm{X}$ das amostras ZnAlLax\%-BTC-P123 (marrom) e ZnAlTmx\%-BTC-P123 (azul). O aumento da concentração de lantânio durante a síntese induz a formação de fases laterais, como complexo TR(BTC). Para o túlio, o aumento da concentração até $30 \%$ causa gradual diminuição na cristalinidade do sistema.

O segundo tipo de fase lateral observada nos materiais sintetizados com terras raras é caracterizado por uma reflexão na região de $2 \theta \approx 11.5^{\circ}$, similar à contaminação por carbonatos relatada anteriormente para o $\mathrm{ZnAl}-\mathrm{NO}_{3}-\mathrm{P} 123$. Esta fase está presente, por exemplo, 
na amostra ZnAlEu5\%-BTC-P123 (Figura 21), mas apresenta maior intensidade e picos característicos quando a concentração do íon terra rara aumenta (Figuras 22 e A.2). Três hipóteses foram consideradas: a primeira estabelece relação direta entre tais reflexões e o pico observado na amostra intercalada de nitratos. Uma vez que os parâmetros de rede $a_{0}$ são compatíveis entre si, é plausível que eventuais contaminações de carbonato surjam na mesma região do difratograma, sugerindo uma fase lateral ZnAlTR5\%-CO3-P123. O espaçamento basal de $7.66 \AA$ calculado para o sistema é compatível com a presença dos ânions $\mathrm{CO}_{3}^{2-}$ entre as lamelas. 88

Por outro lado, a intensidade relativa desta nova fase presente na DRX para concentrações com 15\% de terras raras, como observado para o lantânio na Figura 22, abre margem para outras interpretações. A despeito do aumento na concentração dos terras raras, a redução do complexo TR(BTC) nas amostras com intensos picos na região de $11.5^{\circ}$ indica que ou o BTC ou o íon lantanídeo deve estar sendo consumido na formação de outros compostos. A intercalação da molécula $\mathrm{BTC}^{3-}$ em posição horizontal, paralela às lamelas, também é compatível com o espaçamento basal observado de 7.66 A. [77] É possível, portanto, que os hidróxidos lamelares ZnAlTR15\%-BTC-P123 estejam intercalando os trimesatos em duas fases distintas, com diferentes orientações da molécula.

A terceira hipótese é que uma fase segregada $\mathrm{TR}(\mathrm{OH})_{3}$ esteja sendo formada para altas concentrações de terras raras. Devido à diferença de raios iônicos entre os lantanídeos e os metais $\mathrm{Zn} / \mathrm{Al}$ originalmente presentes nas camadas de hidróxidos, há uma limitação na quantidade de terras raras possíveis de serem acomodados nesta estrutura. É natural que lantanídeos com raios maiores apresentem fases segregadas para concentrações menores, como observado no surgimento da suposta fase $\mathrm{TR}(\mathrm{OH})_{3}$ para $\mathrm{x}=15 \%$ com os terras raras de raio iônico $r<r_{E u}$. Neste caso, os ânions ligantes são substituídos por ligações - $(\mathrm{OH})$, dando origem ao espaçamento basal reduzido observado. Na literatura, onde esses compostos também foram reportados como fase lateral na síntese de HDLs dopados de terras raras, o espaçamento basal atribuído ao empilhamento das lamelas é da ordem de $7.5 \AA$. 89,90

Devido à limitação de resolução dada pela baixa cristalinidade do sistema, não é possível definir apenas pela análise da difração de raios X qual das hipóteses é mais viável para cada amostra. O estudo da estabilidade térmica e análises elementares, discutidos nas seções que seguem, são complementares ao DRX para o estabelecimento da composição dos materiais. 


\subsection{Estabilidade térmica}

As amostras ZnAlTRx\%-BTC-P123 foram submetidas a análise termogravimétrica para o estudo de suas estabilidades térmicas. Os principais resultados para as amostras com 5\% de terras raras podem ser separados em três grupos, cujas características estão relacionadas aos íons de menores $\left(r<r_{T b}\right)$, médios $\left(r_{P m}>r \geq r_{T b}\right)$ e maiores $\left(r>r_{P m}\right)$ raios atômicos.

O primeiro grupo, ilustrado na Figura 23, apresenta em suas curvas termogravimétricas perdas de massa da ordem de $10-12 \%$ para temperaturas até $150{ }^{\circ} \mathrm{C}$. Esta perda é atribuída primeiramente às águas superficiais do material, seguida das águas presentes em suas galerias. Após os $150{ }^{\circ} \mathrm{C}$, tem início o processo de desidroxilação, que tem seu pico na região dos 220 ${ }^{\circ} \mathrm{C}$. Neste momento, parte dos hidróxidos que compõem as lamelas passam a se desligar dos metais, formando moléculas de água para evaporar em sequência. 91 A perda máxima de massa esperada neste evento é da ordem de 13\%, correspondente à formação de uma molécula de água para cada duas hidroxilas, onde um oxigênio permanece no sólido dando origem ao óxido de zinco, alumínio e terra rara. A perda de $19 \%$ de massa na região entre 150 e $350{ }^{\circ} \mathrm{C}$ indica que, além deste efeito, há outro constituinte da amostra se decompondo. É provável que a remoção do polímero P123 não tenha sido completa nesses materiais mesmo após os dois ciclos de lavagem com metanol anidro, resultando em um evento de perda de 6-10\% de massa superposto à desidroxilação. 92 Em seguida, entre 400 e $450{ }^{\circ} \mathrm{C}$, há à decomposição do benzenotricarboxilato intercalado no hidróxido lamelar. 93] A redução entre 19 e $21 \%$ de massa neste evento indica a presença de aproximadamente uma molécula de BTC para cada duas cargas excedentes nas lamelas, sugerindo a carga $\mathrm{BTC}^{2-}$.
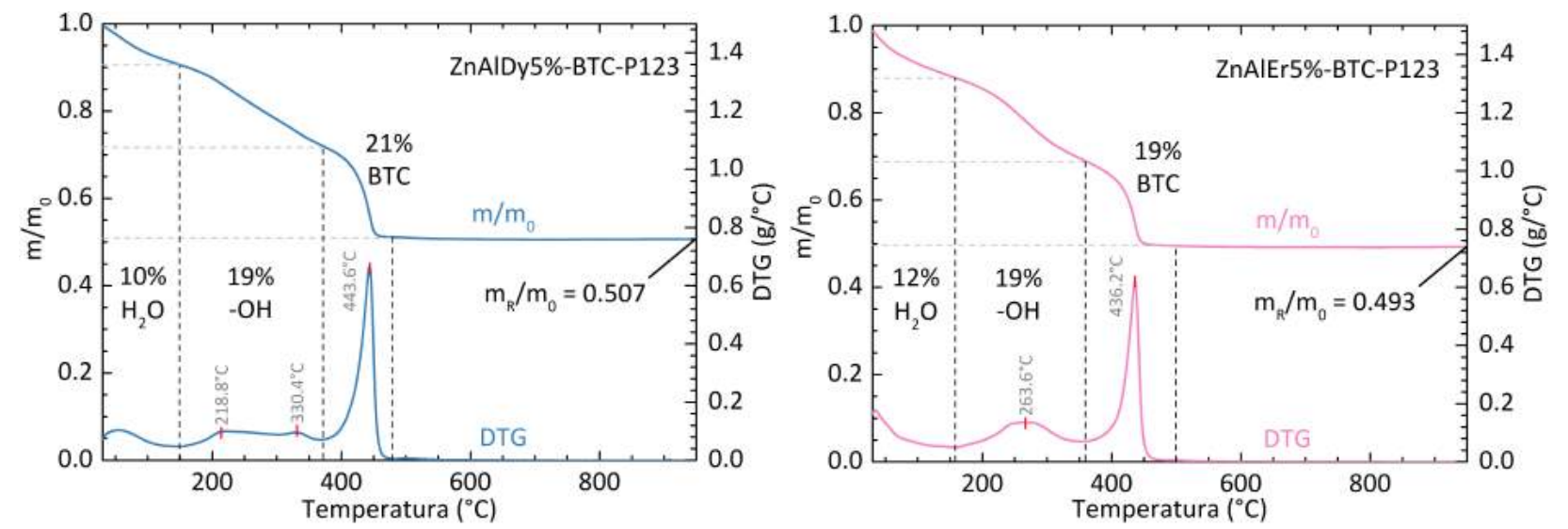

Figura 23 - Termogravimetria das amostras ZnAlTR5\%-BTC-P123 para o grupo de terras raras com menores raios atômicos $\left(r<r_{T b}\right)$. 
As curvas da análise termogravimétrica para os materiais contendo terras raras de raio atômico médio $\left(\mathrm{r}_{P m}>\mathrm{r} \geq \mathrm{r}_{T b}\right)$ estão ilustradas nos gráficos da Figura 24. Assim como observado anteriormente, há três principais eventos de perda de massa. Até a região dos 150 ${ }^{\circ} \mathrm{C}$ ocorre a perda de $12 \%$ de massa relativas às águas superficiais e intercaladas no material. Em seguida, há o processo de desidroxilação, que neste caso tem seu pico em temperaturas mais baixas, da ordem de $200{ }^{\circ} \mathrm{C}$. A redução de $10 \%$ da massa da amostra está dentro do esperado, e não há sinal da decomposição de micelas residuais do polímero, indicando que a lavagem com metanol foi efetiva nessas amostras. Por fim, a redução entre 19 e $21 \%$ de massa entre 400 e $450{ }^{\circ} \mathrm{C}$ é atribuída ao BTC e indica novamente a presença do estado de oxidação $\mathrm{BTC}^{2-}$. A decomposição do benzenotricarboxilato em dois picos, o que acontece de forma mais evidente para a amostra ZnAlEu5\%-BTC-P123, indica a presença de pelo menos dois ambientes químicos distintos para este composto.
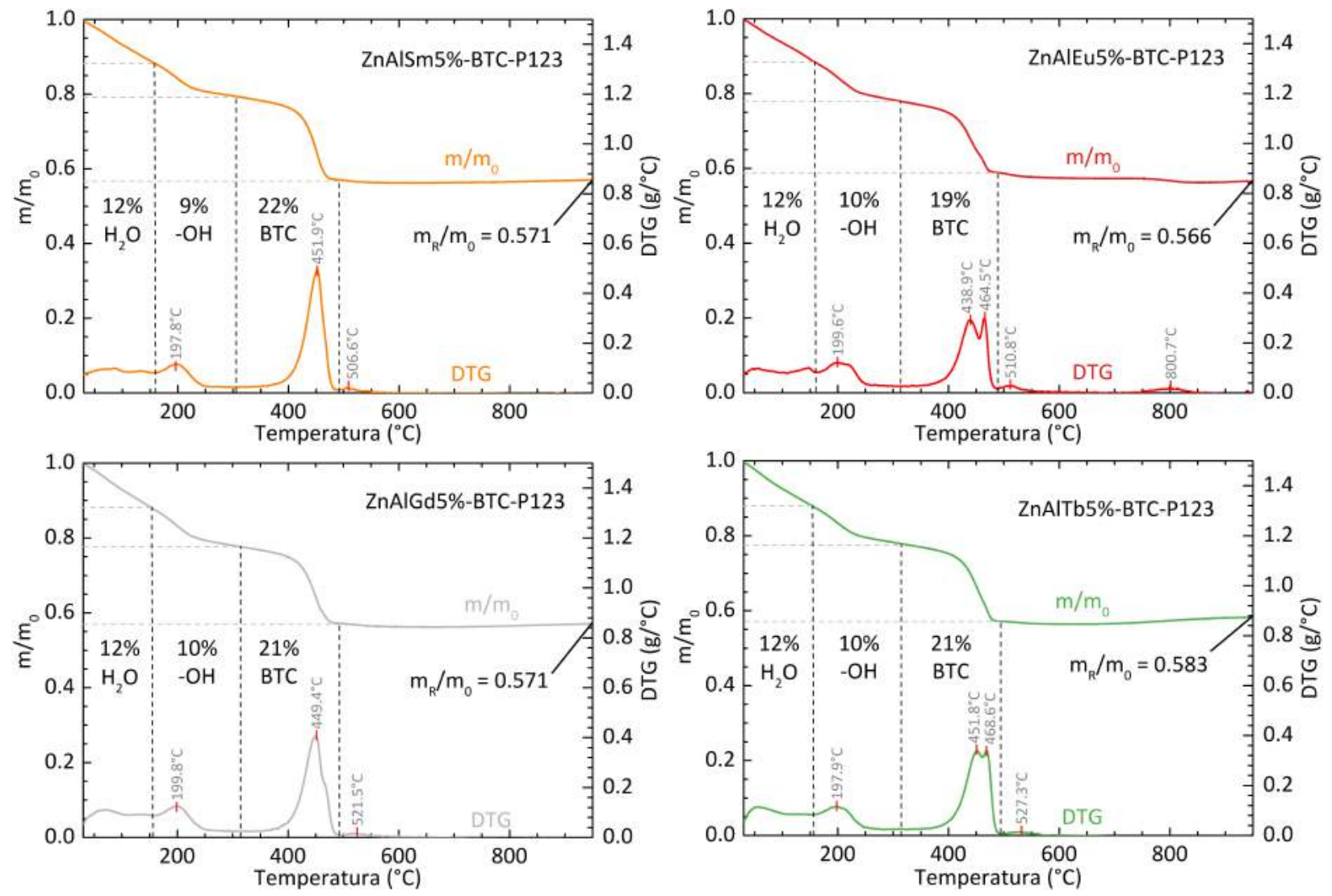

Figura 24 - Termogravimetria das amostras ZnAlTR5\%-BTC-P123 para o grupo de terras raras com raios atômicos médios $\left(\mathrm{r}_{P m}>\mathrm{r} \geq \mathrm{r}_{T b}\right)$.

O último grupo, ilustrado na Figura 25, é formado pelos materiais que apresentaram o complexo TR(BTC) como fase lateral após o processo de síntese. As curvas termogravimé- 

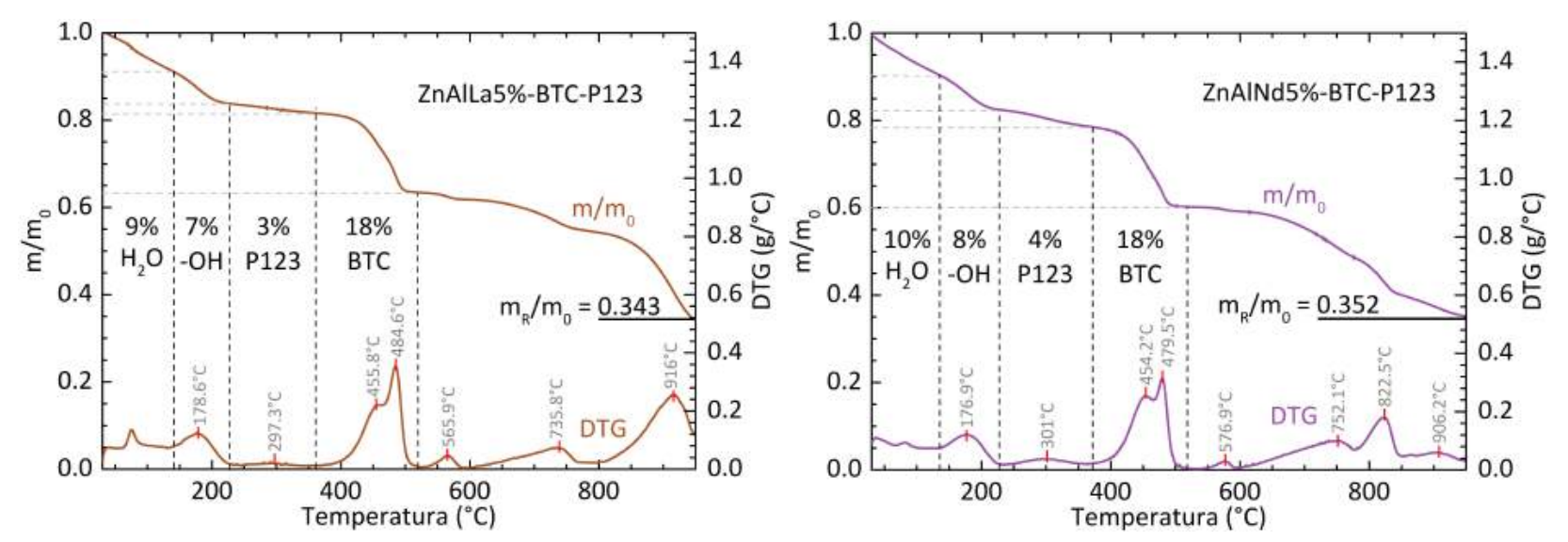

Figura 25 - Termogravimetria das amostras ZnAlTR5\%-BTC-P123 para o grupo de terras raras com maiores raios atômicos $\left(r>r_{P m}\right)$.

tricas indicam perda de massa atribuída às águas da ordem de 9-10\% para temperaturas até $140{ }^{\circ} \mathrm{C}$. Após os $140{ }^{\circ} \mathrm{C}$, tem início o processo de desidroxilação, que tem seu pico na região dos $177^{\circ} \mathrm{C}$ - temperatura ainda mais baixa que a observada nos materiais com terras raras de raio médio. Uma ligeira perda de massa na região dos $300{ }^{\circ} \mathrm{C}$ indica que a remoção do polímero P123 não foi completa nesses materiais mesmo após os dois ciclos de lavagem com metanol anidro. O evento típico de perda de massa pela decomposição do BTC ocorre entre 400 e $500{ }^{\circ} \mathrm{C}$, dividido em dois picos. Por haver complexo TR(BTC) além do hidróxido lamelar, eram esperados pelo menos dois ambientes químicos para o benzenotricarboxilato, coerente com o resultado obtido. Os eventos de desidroxilação ocorridos nessas amostras para temperaturas inferiores a $200{ }^{\circ} \mathrm{C}$ deixam ligações disponíveis com os metais da lamela que podem ser preenchidas pelos carboxilatos dos compostos intercalados ou por aqueles presentes nos complexos formados como fases laterais. Esta nova ligação estabiliza o BTC, elevando as temperaturas para ocorrência de decarboxilação. 34, 94 Apenas para temperaturas superiores a $600{ }^{\circ} \mathrm{C}$ tais compostos orgânicos começam a se decompor neste cenário, dando origem aos eventos de perda de até $25 \%$ de massa observados. A queima não foi completa mesmo na temperatura máxima de $950{ }^{\circ} \mathrm{C}$ atingida durante as medidas.

Ao comparar as curvas termogravimétricas de materiais dopados do mesmo elemento terra rara com diferentes concentrações (Figura 26), nota-se que o aumento da concentração de terra rara diminui a estabilidade térmica do material, reduzindo a temperatura do evento de desidroxilação. Este fato indica que a introdução de desordens no sistema devido ao elevado número de coordenação e diferentes raios atômicos dos dopantes com relação ao zinco e 
ao alumínio torna o material menos estável com o aumento da temperatura. As demais diferenças observadas se devem a existência ou não de fases laterais no sistema induzidas pelo aumento na concentração de terras raras. Por esta razão, as curvas são distintas acima de $600{ }^{\circ} \mathrm{C}$ para as amostras com lantânio, que apresentam formação de complexo La(BTC), e similares para o érbio 5 e 15\%, que não apresentam fases laterais.
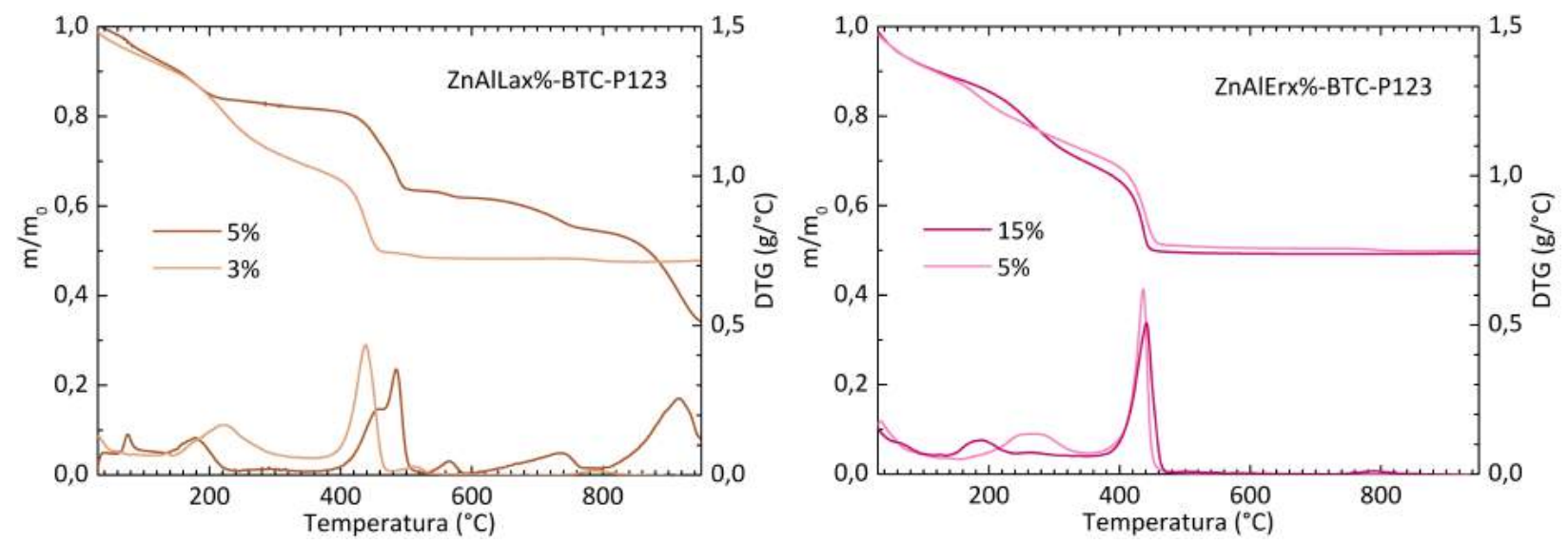

Figura 26 - Termogravimetria das amostras ZnAlTRx\%-BTC-P123 de Lantânio e Érbio com diferentes concentrações.

\subsection{Análise elementar}

A Tabela 5 apresenta os resultados das análises elementares de CHN e ICP-OES realizadas para determinação da composição dos materiais sintetizados.

As duas técnicas determinaram o teor de carbono, hidrogênio, nitrogênio, zinco, alumínio e terra rara de cada amostra, como apresentado, onde os resultados são dados em porcentagem de massa. Como critério para determinação das fórmulas empíricas exibidas, impusemos que a massa molar do composto e o teor calculado para cada elemento apresentassem erro relativo inferior a 5\%, se comparadas aos valores experimentais. Devido à existência conjunta de fases laterais em alguns materiais - como complexos de terras raras - e de resíduos do polímero P123, não foi possível determinar a composição de todas as amostras analisadas. O teor de nitrogênio medido determinou a quantidade de nitrato intercalado entre as lamelas de hidróxidos. Apesar do BTC possuir maior afinidade química com as lamelas, a presença de nitratos é verificada em quase todas as amostras, representando até 35\% da quantidade de ânions intercalados, como no caso da amostra ZnAlEr5\%-BTC-P123. A hidratação dos 
Tabela 5 - Composição das amostras ZnAlTRx\%-BTC-P123 e fórmula empírica derivada pelas análises de ICP-OES, CHN e TG.

\begin{tabular}{|c|c|c|c|c|c|c|c|c|c|}
\hline TRx & & $\begin{array}{c}\mathrm{C} \\
(\%)\end{array}$ & $\begin{array}{c}\mathrm{H} \\
(\%)\end{array}$ & $\begin{array}{l}\mathrm{N} \\
(\%)\end{array}$ & $\begin{array}{l}\mathrm{Zn} \\
(\%)\end{array}$ & $\begin{array}{c}\mathrm{Al} \\
(\%)\end{array}$ & $\begin{array}{l}\mathrm{TR} \\
(\%)\end{array}$ & $\begin{array}{c}\mathrm{M} \\
(\mathrm{g} / \mathrm{mol})\end{array}$ & Fórmula empírica \\
\hline \multirow{2}{*}{ La3 } & Teo. & 19.0 & 3.8 & 0.5 & 29.1 & 5.9 & 0.9 & 449.9 & \multirow{2}{*}{$\begin{array}{c}{\left[\mathrm{Zn}_{2} \mathrm{Al}_{0.98} \mathrm{La}_{0.02}(\mathrm{OH})_{6}\right]\left[\left(\mathrm{NO}_{3}\right)_{0.16} \mathrm{BTC}_{0.45}\right] \cdot 1.1 \mathrm{H}_{2} \mathrm{O}} \\
+0.01 \mathrm{La}(\mathrm{BTC})\end{array}$} \\
\hline & Exp. & 18.6 & 3.7 & 0.5 & 28.5 & 5.8 & 0.9 & 436.5 & \\
\hline \multirow{2}{*}{ La15 } & Calc. & 14.1 & 3.6 & 0.3 & 30.0 & 4.6 & 4.9 & 435.8 & \multirow{2}{*}[\mathrm{Zn}_{2}\mathrm{Al}_{0.75}\mathrm{La}_{0.15}(\mathrm{OH})_{6}]{$\left[\left(\mathrm{NO}_{3}\right)_{0.11} \mathrm{BTC}_{0.45}\right] \cdot 2.2 \mathrm{H}_{2} \mathrm{O}$} \\
\hline & Exp. & 14.4 & 3.7 & 0.3 & 30.4 & 4.7 & 5.0 & 430.3 & \\
\hline \multirow{2}{*}{$\operatorname{Pr} 15$} & Calc. & 15.1 & 3.6 & 0.1 & 29.8 & 4.7 & 4.3 & 439.5 & \multirow{2}{*}[\mathrm{Zn}_{2}\mathrm{Al}_{0.76}\operatorname{Pr}_{0.13}(\mathrm{OH})_{6}]{$\left[\left(\mathrm{NO}_{3}\right)_{0.04} \mathrm{BTC}_{0.45}\right] \cdot 2.2 \mathrm{H}_{2} \mathrm{O}$} \\
\hline & Exp. & 15.4 & 3.3 & 0.1 & 30.2 & 4.8 & 4.4 & 448.3 & \\
\hline \multirow{2}{*}{ Nd15 } & Calc. & 12.0 & 3.4 & 0.4 & 30.2 & 5.3 & 6.2 & 433.7 & \multirow{2}{*}[\mathrm{Zn}_{2}\mathrm{Al}_{0.85}\mathrm{Nd}_{0.19}(\mathrm{OH})_{6}]{$\left[\left(\mathrm{NO}_{3}\right)_{0.11} \mathrm{BTC}_{0.38}\right] \cdot 2.5 \mathrm{H}_{2} \mathrm{O}$} \\
\hline & Exp. & 12.3 & 3.3 & 0.4 & 29.3 & 5.1 & 6.3 & 445.6 & \\
\hline \multirow{2}{*}{ Sm5 } & Calc. & 13.6 & 3.8 & 0.0 & 30.5 & 6.0 & 1.7 & 428.3 & \multirow{2}{*}[\mathrm{Zn}_{2}\mathrm{Al}_{0.96}\mathrm{Sm}_{0.05}(\mathrm{OH})_{6}]{$\left[\mathrm{BTC}_{0.46}\right] \cdot 2.8 \mathrm{H}_{2} \mathrm{O}$} \\
\hline & Exp. & 13.6 & 3.0 & 0.0 & 30.1 & 5.9 & 1.9 & 420.9 & \\
\hline \multirow{2}{*}{$\operatorname{Sm} 15$} & Calc. & 13.8 & 3.5 & 0.7 & 26.8 & 4.9 & 4.8 & 488.2 & \multirow{2}{*}[\mathrm{Zn}_{2}\mathrm{Al}_{0.88}\mathrm{Sm}_{0.17}(\mathrm{OH})_{6}]{$\left[\left(\mathrm{NO}_{3}\right)_{0.26} \mathrm{BTC}_{0.52}\right] \cdot 3.5 \mathrm{H}_{2} \mathrm{O}$} \\
\hline & Exp. & 13.7 & 3.5 & 0.7 & 26.4 & 4.8 & 5.2 & 519.7 & \\
\hline \multirow{2}{*}{ Eu5 } & Calc. & 11.5 & 3.7 & 0.0 & 32.5 & 6.3 & 1.9 & 402.0 & \multirow{2}{*}[\mathrm{Zn}_{2}\mathrm{Al}_{0.94}\mathrm{Eu}_{0.05}(\mathrm{OH})_{6}]{$\left[\left(\mathrm{NO}_{3}\right)_{0.01} \mathrm{BTC}_{0.36}\right] \cdot 2.6 \mathrm{H}_{2} \mathrm{O}$} \\
\hline & Exp. & 12.2 & 3.0 & 0.0 & 32.7 & 6.4 & 2.1 & 392.7 & \\
\hline \multirow{2}{*}{ Gd5 } & Calc. & 12.8 & 3.7 & 0.0 & 30.9 & 6.1 & 1.8 & 422.9 & \multirow{2}{*}[\mathrm{Zn}_{2}\mathrm{Al}_{0.96}\mathrm{Gd}_{0.06}(\mathrm{OH})_{6}]{$\left[\left(\mathrm{NO}_{3}\right)_{0.02} \mathrm{BTC}_{0.42}\right] \cdot 2.9 \mathrm{H}_{2} \mathrm{O}$} \\
\hline & Exp. & 12.9 & 3.3 & 0.1 & 30.9 & 6.1 & 2.1 & 429.1 & \\
\hline \multirow{2}{*}{ Gd15 } & Calc. & 14.1 & 3.8 & 0.1 & 28.2 & 5.0 & 5.1 & 464.6 & \multirow{2}{*}[\mathrm{Zn}_{2}\mathrm{Al}_{0.86}\mathrm{Gd}_{0.17}(\mathrm{OH})_{6}]{$\left[\left(\mathrm{NO}_{3}\right)_{0.04} \mathrm{BTC}_{0.46}\right] \cdot 3.1 \mathrm{H}_{2} \mathrm{O}$} \\
\hline & Exp. & 14.2 & 3.4 & 0.1 & 28.3 & 5.0 & 5.9 & 466.5 & \\
\hline \multirow{2}{*}{ Tb5 } & Calc. & 13.3 & 3.6 & 0.1 & 30.2 & 6.0 & 1.6 & 433.0 & \multirow{2}{*}[\mathrm{Zn}_{2}\mathrm{Al}_{0.96}\mathrm{Tb}_{0.05}(\mathrm{OH})_{6}]{$\left[\left(\mathrm{NO}_{3}\right)_{0.04} \mathrm{BTC}_{0.45}\right] \cdot 3.0 \mathrm{H}_{2} \mathrm{O}$} \\
\hline & Exp. & 13.0 & 3.0 & 0.1 & 29.3 & 5.8 & - & 453.3 & \\
\hline \multirow{2}{*}{ Tb15 } & Calc. & 14.3 & 3.7 & 0.1 & 28.1 & 5.0 & 4.5 & 465.1 & \multirow{2}{*}[\mathrm{Zn}_{2}\mathrm{Al}_{0.86}\mathrm{Tb}_{0.15}(\mathrm{OH})_{6}]{$\left[\left(\mathrm{NO}_{3}\right)_{0.03} \mathrm{BTC}_{0.48}\right] \cdot 3.2 \mathrm{H}_{2} \mathrm{O}$} \\
\hline & Exp. & 14.0 & 3.1 & 0.1 & 27.4 & 4.9 & - & 486.5 & \\
\hline \multirow{2}{*}{ Dy5 } & Calc. & 15.8 & 3.8 & 0.5 & 28.6 & 5.7 & 1.6 & 458.1 & \multirow{2}{*}[\mathrm{Zn}_{2}\mathrm{Al}_{0.96}\mathrm{Dy}_{0.05}(\mathrm{OH})_{6}]{$\left[\left(\mathrm{NO}_{3}\right)_{0.16} \mathrm{BTC}_{0.46}\right] \cdot 2.6 \mathrm{H}_{2} \mathrm{O}$} \\
\hline & Exp. & 15.8 & 3.6 & 0.5 & 28.4 & 5.6 & 1.8 & 465.7 & \\
\hline \multirow{2}{*}{ Dy15 } & Calc. & 14.5 & 3.6 & 0.0 & 28.7 & 5.5 & 5.0 & 455.4 & \multirow{2}{*}[\mathrm{Zn}_{2}\mathrm{Al}_{0.92}\mathrm{Dy}_{0.17}(\mathrm{OH})_{6}]{$\left[\left(\mathrm{NO}_{3}\right)_{0.01} \mathrm{BTC}_{0.47}\right] \cdot 2.6 \mathrm{H}_{2} \mathrm{O}$} \\
\hline & Exp. & 14.1 & 3.1 & 0.0 & 28.0 & 5.3 & 5.8 & 465.4 & \\
\hline & Calc. & 15.8 & 4.0 & 0.7 & 27.0 & 5.5 & 1.6 & 484.9 & $\left.\mathrm{Al}_{0.99} \mathrm{Er}_{0.05}(\mathrm{OH})_{6}\right]\left[\left(\mathrm{NO}_{3}\right)_{0.24} \mathrm{BTC}_{0.45}\right] \cdot 3.4 \mathrm{H}_{2} \mathrm{O}$ \\
\hline & Exp. & 15.4 & 3.6 & 0.7 & 26.0 & 5.3 & 1.8 & 504.1 & \\
\hline Er15 & Calc. & 17.1 & 3.9 & 0.2 & 25.7 & 4.7 & 4.7 & 509.4 & $.25 \mathrm{H}_{2} \mathrm{O}$ \\
\hline & Exp. & 16.9 & 3.5 & 0.2 & 25.3 & 4.6 & 5.6 & 524.3 & $1 H_{2}$ \\
\hline Tm5 & Calc. & 12.0 & 3.9 & 0.2 & 32.2 & 5.7 & 1.5 & 406.8 & $\left.{ }_{5}(\mathrm{OH})_{6}\right]\left[\left(\mathrm{NO}_{3}\right)_{0.07} \mathrm{BTC}_{0.34}\right] \cdot 2.6 \mathrm{H}_{2} \mathrm{O}$ \\
\hline $1 \mathrm{~m} 2$ & Exp. & 14.1 & 3.3 & 0.3 & 34.3 & 6.1 & 2.0 & 389.7 & $5(011) 6][(1 \times 3) 0.07 D+0.34] \cdot 2.01120$ \\
\hline $\operatorname{Tm} 15$ & Calc. & 17.1 & 3.9 & 0.7 & 25.2 & 4.2 & 3.7 & 518.3 & ] $.2 .5 \mathrm{H}_{2} \mathrm{O}$ \\
\hline & Exp. & 17.4 & 3.7 & 0.7 & 25.6 & 4.3 & 4.6 & 543.7 & $10.81+110.14(\mathrm{~V} 11) 6]\left[\left(\mathrm{N}_{0} \mathrm{U}_{3}\right)\right.$ \\
\hline & Teo. & 12.7 & 3.8 & 0.4 & 31.4 & 5.5 & 0.9 & 417.0 & \\
\hline & Exp. & 13.4 & 3.1 & 0.4 & 31.8 & 5.6 & 1.1 & 416.5 & \\
\hline
\end{tabular}

materiais foi estimada com base no primeiro evento de perda de massa das termogravimetrias. O carbono, por sua vez, poderia ter como origem o BTC ou resíduos do polímero P123 utilizado para formar as micelas no processo de síntese. Utilizamos a porcentagem 
de massa atribuída a cada um na análise termogravimétrica para separar as duas componentes. Observou-se boa concordância entre as composições observadas e as concentrações pretendidas no processo de síntese.

\subsection{Morfologia}

Imagens de microscopia eletrônica de transmissão foram utilizadas para a análise morfológica dos materiais sintetizados. Devido à sensibilidade das amostras ao aumento de temperatura, a exposição delas ao feixe de elétrons e a consequente dispersão de energia por efeito Joule causava a decomposição do material em uma escala de tempo de dezenas de segundos. Este fator dificultou a coleta de imagens focalizadas ou de alta resolução, sobretudo para as amostras contendo nantubos.

A Figura 27 ilustra os resultados obtidos para cada um dos terras raras testados nas amostras ZnAlTRx\%-BTC-P123, em comparação com os HDLs intercalados de nitratos e trimesatos sintetizados na ausência de terras raras. Assim como amplamente relatado na literatura para os HDLs comuns de zinco e alumínio, 95, 96] a amostra ZnAl- $\mathrm{NO}_{3}$ apresentou morfologia plana, sendo formada por placas com dimensões variando entre $50 \mathrm{~nm}$ e $1 \mu \mathrm{m}$. A intercalação do BTC nas amostras ZnAl-BTC-P123 reduziu o tamanho das folhas com relação ao nitrato, em consonância com a redução de cristalinidade observada na difração de raios $\mathrm{X}$.

Foi possível observar para todos os terras raras testados nas amostras ZnAlTRx\%-BTCP123 regiões similares a nanotubos, como ilustrado nos quadros C-P da Figura 27. Em comum, a introdução desses elementos na estrutura reduziu o tamanho das nanopartículas observadas com relação às amostras de zinco e alumínio puras, além de flexibilizar a curvatura das folhas suficientemente para a formação de nanotubos, nanocones e enrolamentos. Enquanto a introdução de alguns terras raras induziram à formação de aglomerados de nanotubos, outros deram origem a amostras que apresentam majoritariamente nanofolhas em suas micrografias.

Quando uma captura com grande ampliação e bom foco é realizada, como no quadro L da Figura 27, é possível distinguir cada lamela do material e obter a distância basal da amostra. Neste tipo de imagem, as regiões mais escuras são aquelas que apresentam maior densidade, 


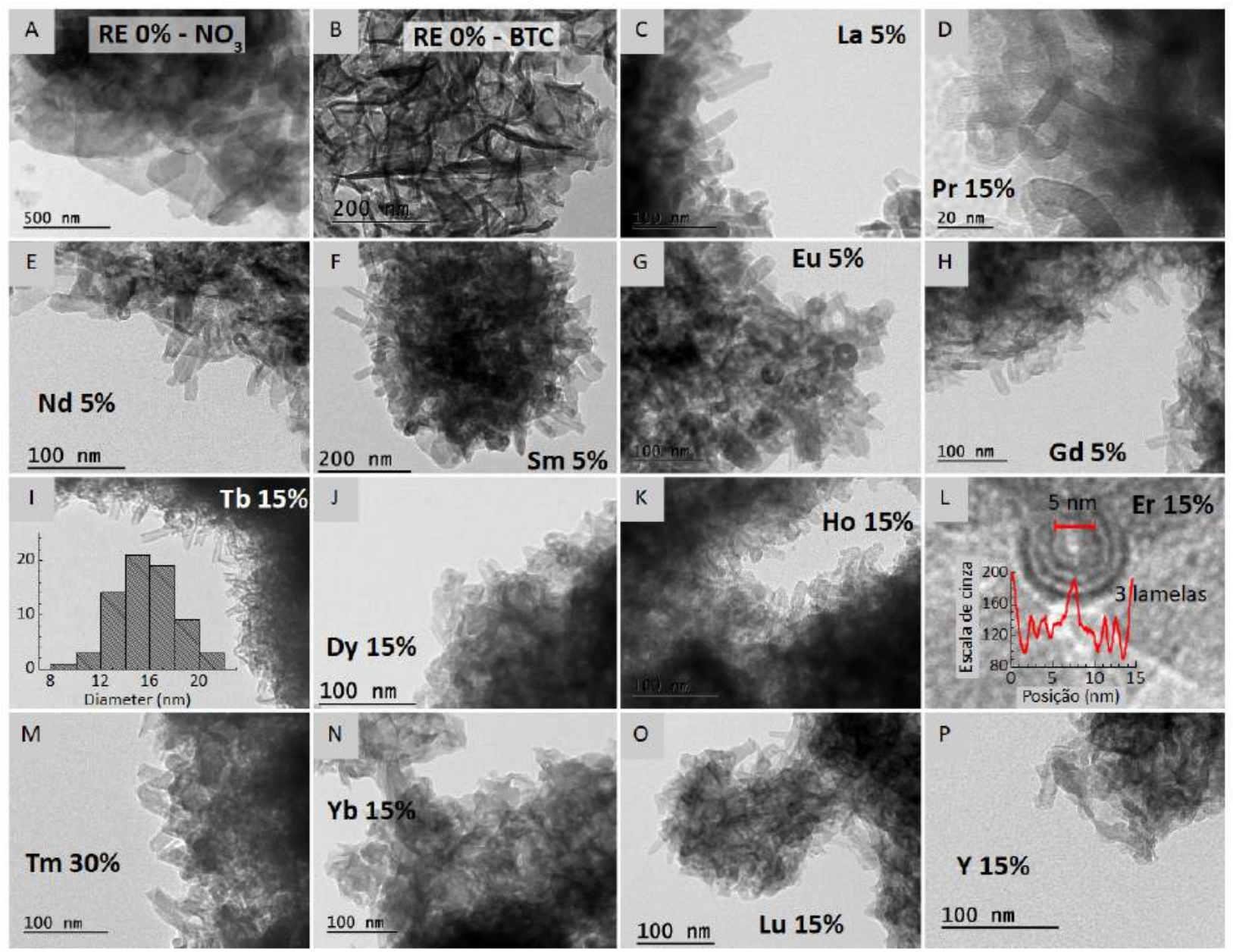

Figura 27 - Microscopia eletrônica de transmissão.

e correspondem às camadas de hidróxidos que contêm os metais Zn, Al e TR. As regiões mais claras equivalem a espaços vazios ou matéria orgânica, de baixa densidade eletrônica, como o BTC. O gráfico do quadro L mostra o perfil de um nanotubo bem focalizado em escala de cinza. Fazendo uso do programa ImageJ, a imagem pôde ser tratada em computador e foi atribuído um valor entre 0 e 255 para cada pixel ao longo do diâmetro do nanotubo, sendo 0 equivalente ao preto e 255 equivalente ao branco. O perfil resultante evidencia em seus vales a posição central da camada de hidróxidos, permitindo uma medida mais acurada do espaçamento basal.

Medidas sistemáticas dos diâmetros externos e internos foram realizadas para os nanotubos identificáveis nas micrografias. Analisamos com o programa ImageJ o número de pixels nos diâmetros aparentes dos diversos tubos, utilizando a escala da imagem para conversão em nanômetros. As medidas realizadas dos diâmetros internos devem ser entendidas como um 
limite inferior para a largura dos mesoporos. A existência de material no plano de fundo dos tubos ou até mesmo adsorvido no mesoporo reduz o contraste da imagem, impossibilitando uma determinação inequívoca dos limites internos à lamela. Desta forma, a região central mais brilhante pode ser por vezes subestimada. Embora fosse possível o efeito análogo de superestimar os diâmetros externos devido a moléculas superficiais, o perfil exposto no quadro L indica que este segundo efeito não é importante. Ao contrário do que acontece na região central do tubo, a escala de cinza não revela um platô ou um alargamento perceptível na lamela mais externa, resultado que se repete para todos os nanotubos bem focalizados.

Para materiais aglomerados ou com grande número de tubos visíveis, realizamos uma análise estatística dos diâmetros. Nota-se que a distribuição dos valores para todos os terras raras nessas condições é aproximadamente gaussiana (Fig. 27. I), de modo que a média e o desvio padrão da média podem ser utilizados como uma estimativa para o diâmetro médio medido e sua incerteza. Nas seções subsequentes serão apresentados os resultados detalhados de cada sistema.

\section{Análise morfológica das amostras ZnAl-BTC-P123}

O HDL intercalado de trimesatos é formado por folhas sem orientação preferencial aparente, em contraste com o empilhamento paralelo às lamelas observado para a amostra intercalada de nitratos. As amostras ZnAl-BTC-P123 apresentam folhas com dimensões variando de 20 a $200 \mathrm{~nm}$ (Fig. 28B) e espessuras de 7 a 15 nm (Fig. 28D), compatível com o tamanho mínimo do cristalito de $6.6 \mathrm{~nm}$ obtido pela equação de Scherrer. Esta alteração no sistema também foi capaz de relaxar a rigidez do material, que apresentou folhas com curvaturas suaves no lugar de superfícies estritamente planas.

\section{Análise morfológica - ZnAlLax\%-BTC-P123 e ZnAINdx\%-BTC-P123}

As micrografias de transmissão das amostras contendo lantânio ou neodímio mostram que a incorporação desses terras raras nas lamelas dos hidróxidos em baixas concentrações $(\mathrm{x} \leq 5 \%)$ induz a formação de aglomerados de nanotubos, como ilustrado na Figura 29 .

Embora a fase lateral TR(BTC) tenha sido formada para ambos os terras raras La e Nd nas concentrações analisadas, não observamos os típicos bastões microscópicos atribuídos a 

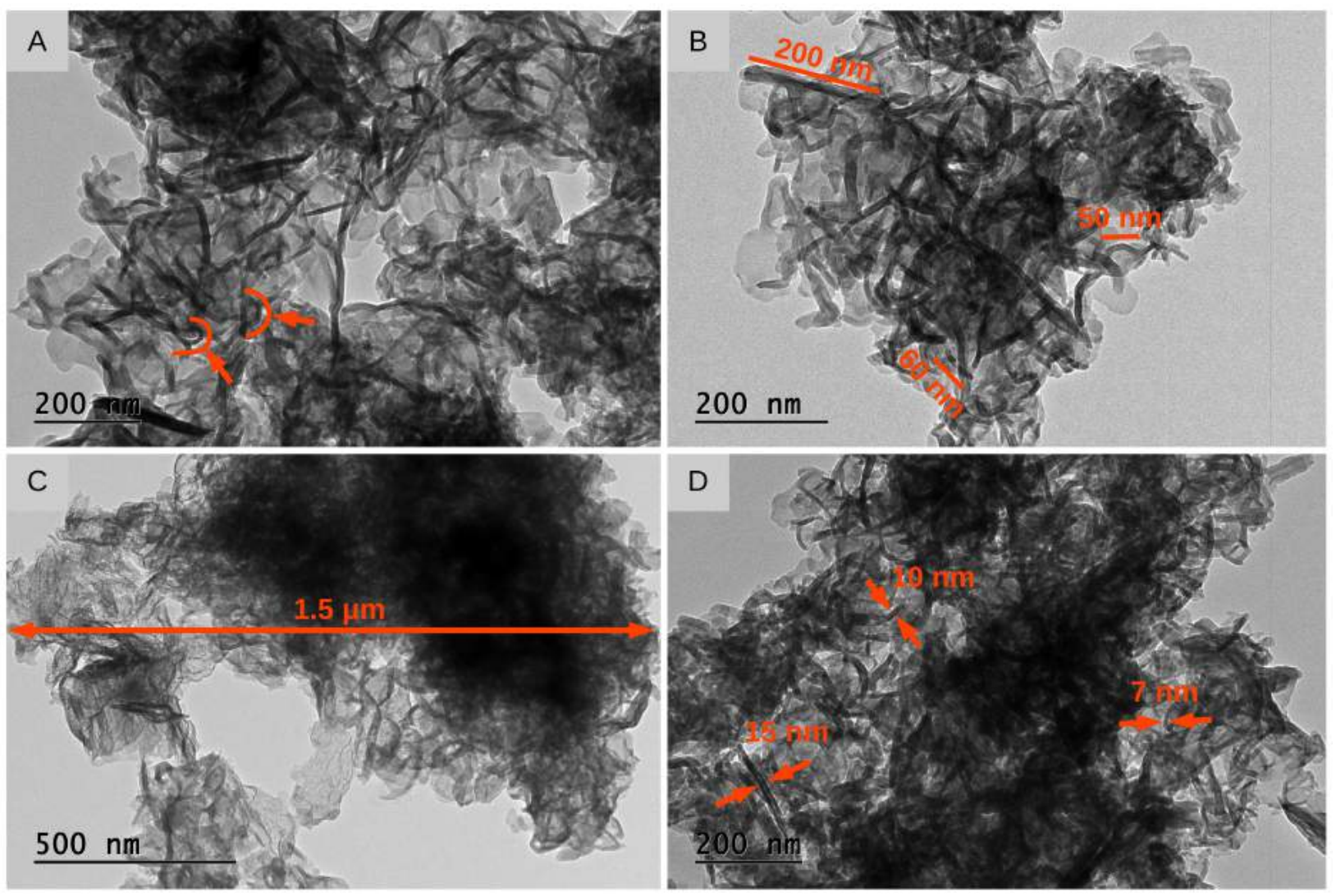

Figura 28 - Microscopia eletrônica de transmissão da amostra ZnAl-BTC-P123.

este material nas medidas de microscopia. Trata-se de um indicativo de que a presença de hidróxidos lamelares é predominante nessas amostras.

Em contraste com os resultados obtidos na ausência de terras raras, a substituição de apenas 3\% do alumínio do HDL por lantânio foi suficiente para permitir curvaturas nas lamelas de hidróxidos de modo que o material se formasse sobre a superfície das micelas cilíndricas de P123. O resultado foi uma rede de nanotubos entrelaçados com diâmetro médio $\Phi_{L a 3 \%}=21.8 \pm 0.6 \mathrm{~nm}$. Resultados similares foram obtidos para a concentração de $5 \%$ de lantânio, onde os nanotubos observados tinham diâmetro médio $\Phi_{L a 5 \%}=19.4 \pm 0.9$ nm, valor compatível com $\Phi_{L a 3 \%}$.

Os nanotubos formados com a substituição de $5 \%$ de neodímio, por sua vez, apresentaram diâmetro médio $\Phi_{N d 5 \%}=15.1 \pm 0.3 \mathrm{~nm}$, menores que os observados nas amostras com lantânio. As medidas dos diâmetros dos nanotubos apresentadas nos histogramas da Figura 30 mostra que para cada um dos terras raras há uma distribuição aproximadamente normal dos dados em torno do valor médio $\Phi_{T R}$. 

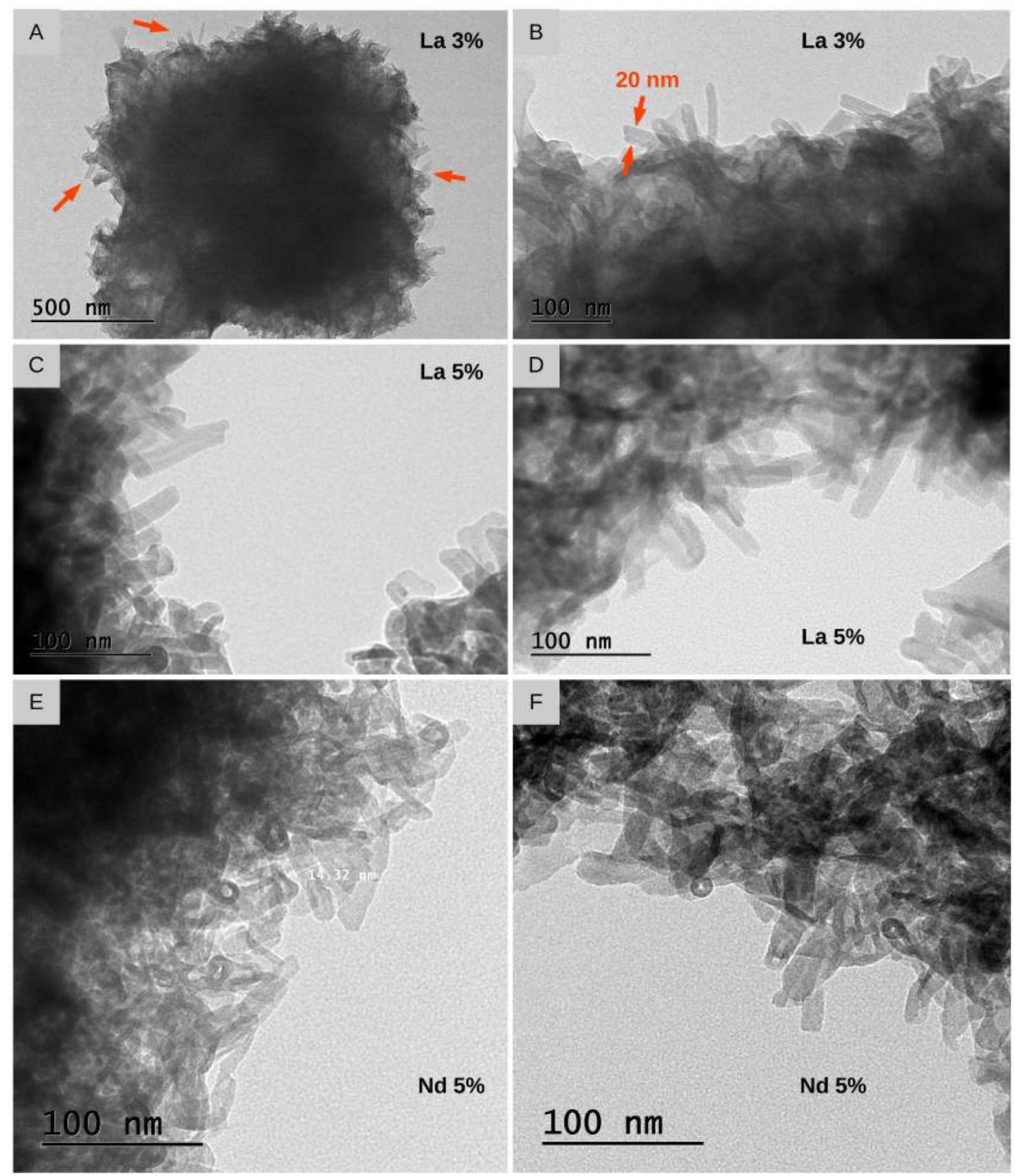

Figura 29 - Microscopia eletrônica de transmissão das amostras ZnAlLax\%-BTC-P123 e ZnAlNd5\%-BTC-P123.

Uma vez que os espaçamentos basais das amostras são compatíveis entre si para todos os terras raras, eventuais diferenças no diâmetro dos nanotubos podem ter origem apenas em diferentes tamanhos da cavidade central ou no número de camadas empilhadas. A diferença no diâmetro médio observado para os nanotubos de lantânio e neodímio é coerente com os tamanhos de cristalito obtidos pela equação de Scherrer para cada um dos metais (Tab. 4), que indica maior empilhamento médio para o lantânio. 

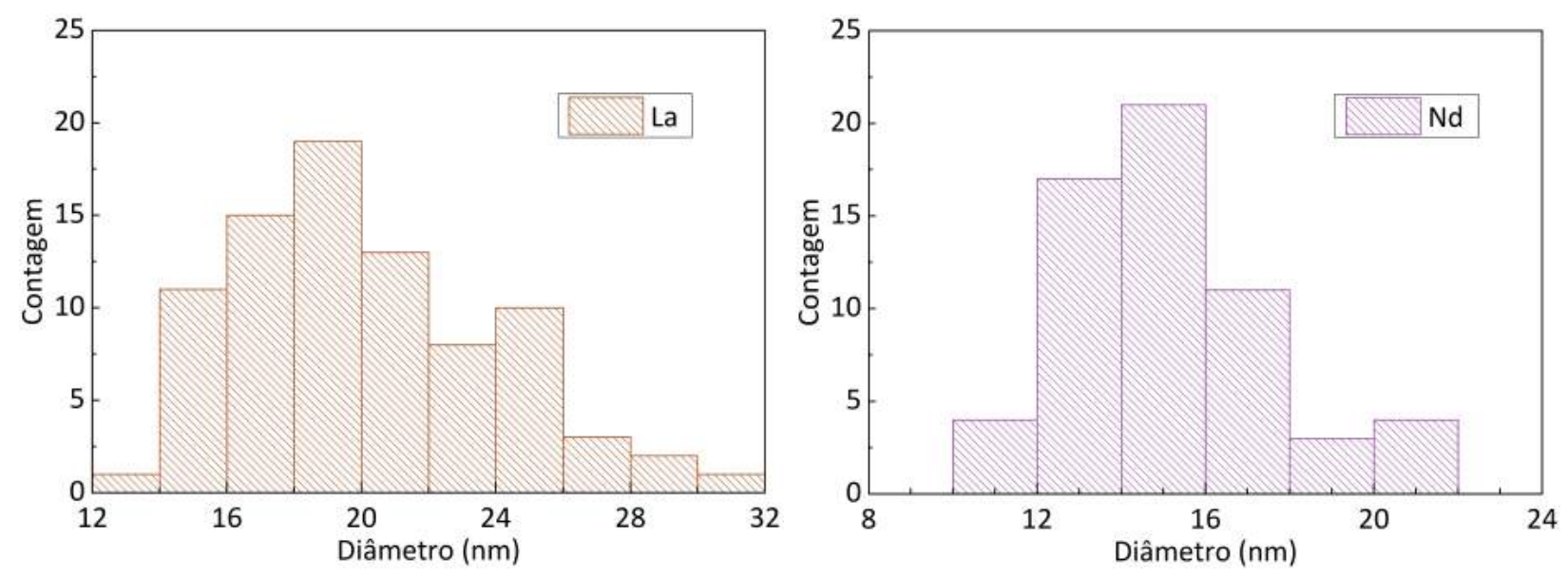

Figura 30 - Diâmetro dos nanotubos presentes nas amostras ZnAlLax\%-BTC-P123 (esq.) e ZnAlNd5\%-BTC-P123 (dir.).

O diâmetro interno relativo à cavidade dos nanotubos, inferido diretamente das micrografias, foi de $\phi_{L a}=5.5 \pm 0.4 \mathrm{~nm}$ para o lantânio e $\phi_{N d}=4.30 \pm 0.19 \mathrm{~nm}$ para o neodímio. Embora os valores não sejam compatíveis entre si, não é possível afirmar que existam diferenças no tamanho das cavidades para cada terra rara. Como discutido anteriormente, a medida do diâmetro interno é severamente comprometida pela presença de material superficial ou no fundo das imagens. Com poucas medidas e pela indefinição dos limites internos da primeira camada, o valor inferido pode ser utilizado apenas como um limite inferior.

A concentrações de 15\%, foi observada na difração de raios X das amostras contendo La e Nd a mudança de orientação da molécula de BTC nas galerias do material ou a intercalação de carbonatos entre as lamelas. As micrografias desses materiais, ilustradas na Figura 31. indicam que não há formação de nanotubos nesta configuração. As amostras ZnAlLa15\%BTC-P123 e ZnAlNd15\%-BTC-P123 apresentaram morfologia plana, similares às nanofolhas verificadas na ausência de terras raras.

\section{Análise morfológica - ZnAISmx\%-BTC-P123}

Similarmente aos resultados obtidos para os materiais contendo lantânio ou neodímio, as micrografias de transmissão das amostras ZnAlSmx\%-BTC-P123 mostram que a incorporação de samário na concentração de $5 \%$ em substituição ao alumínio das lamelas induz a formação de aglomerados de nanotubos, como ilustrado nos quadros A-D da Figura 32.

Foi possível analisar a distribuição de diâmetros externos $\left(\Phi_{S m}\right)$ e internos $\left(\phi_{S m}\right)$ dos na- 

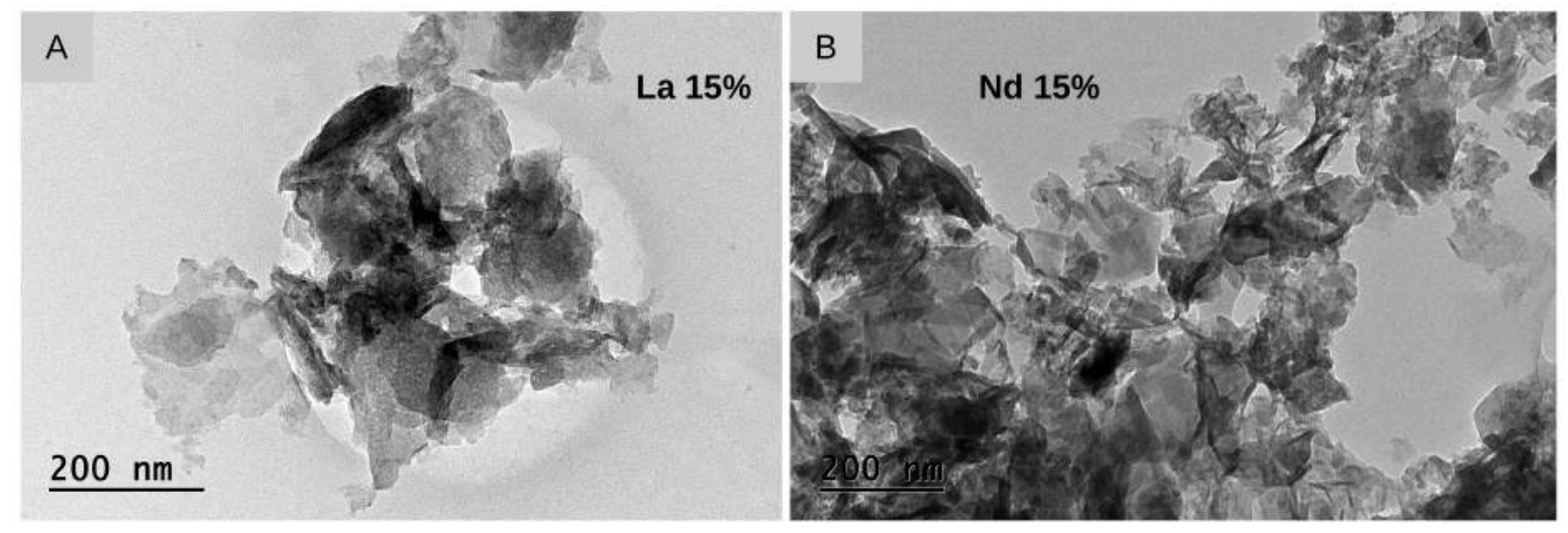

Figura 31 - Microscopia eletrônica de transmissão das amostras ZnAlTR15\%-BTC-P123, $\mathrm{TR}=\mathrm{La}, \mathrm{Nd}$.

notubos visíveis nas micrografias, resultando nos valores médios $\Phi_{S m}=16.2 \pm 0.3 \mathrm{~nm}$ e $\phi_{S m}$ $=4.13 \pm 0.14 \mathrm{~nm}$. Estes resultados são compatíveis com aqueles obtidos para o neodímio, e coerentes com o fato de ambos os terras raras terem apresentado cristalitos e espaçamentos basais idênticos, evidenciando a correlação entre o número de camadas empilhadas nos hidróxidos e o diâmetro dos nanotubos. Os dados apresentam distribuição normal em torno dos valores médios $\Phi_{S m}$ e $\phi_{S m}$, como verificado nos histogramas da Figura 33.

Aumentando a concentração de Sm na síntese da amostra para 15\%, há a inibição da formação dos nanotubos, em consonância com o observado para os terras raras com raios maiores que o samário. As micrografias presentes nos quadros E-F da Figura 32 mostram um material de morfologia plana, formado por pequenas folhas com dimensões da ordem de dezenas de nanômetros.

\section{Análise morfológica - ZnAIEux\%-BTC-P123}

A Figura 34 apresenta micrografia dos hidróxidos dopados com 5 e $15 \%$ de európio. Deferente do observado com terras raras de raio maior, ambas as concentrações induzem a formação de aglomerados micrométricos de nanotubos, dispostos sem orientação preferencial. Este resultado é coerente com o obtido em trabalhos anteriores, que reportaram a presença de nanotubos nas amostras para concentrações a partir de 1\% de európio e aglomerados se forem utilizadas concentrações entre 5 e $15 \%$. 38

Tubos individuais, como visualizado no quarto painel C da Figura 34, são raramente encontrados, mas possibilitam uma estimativa dos comprimentos dessas partículas. Por se 


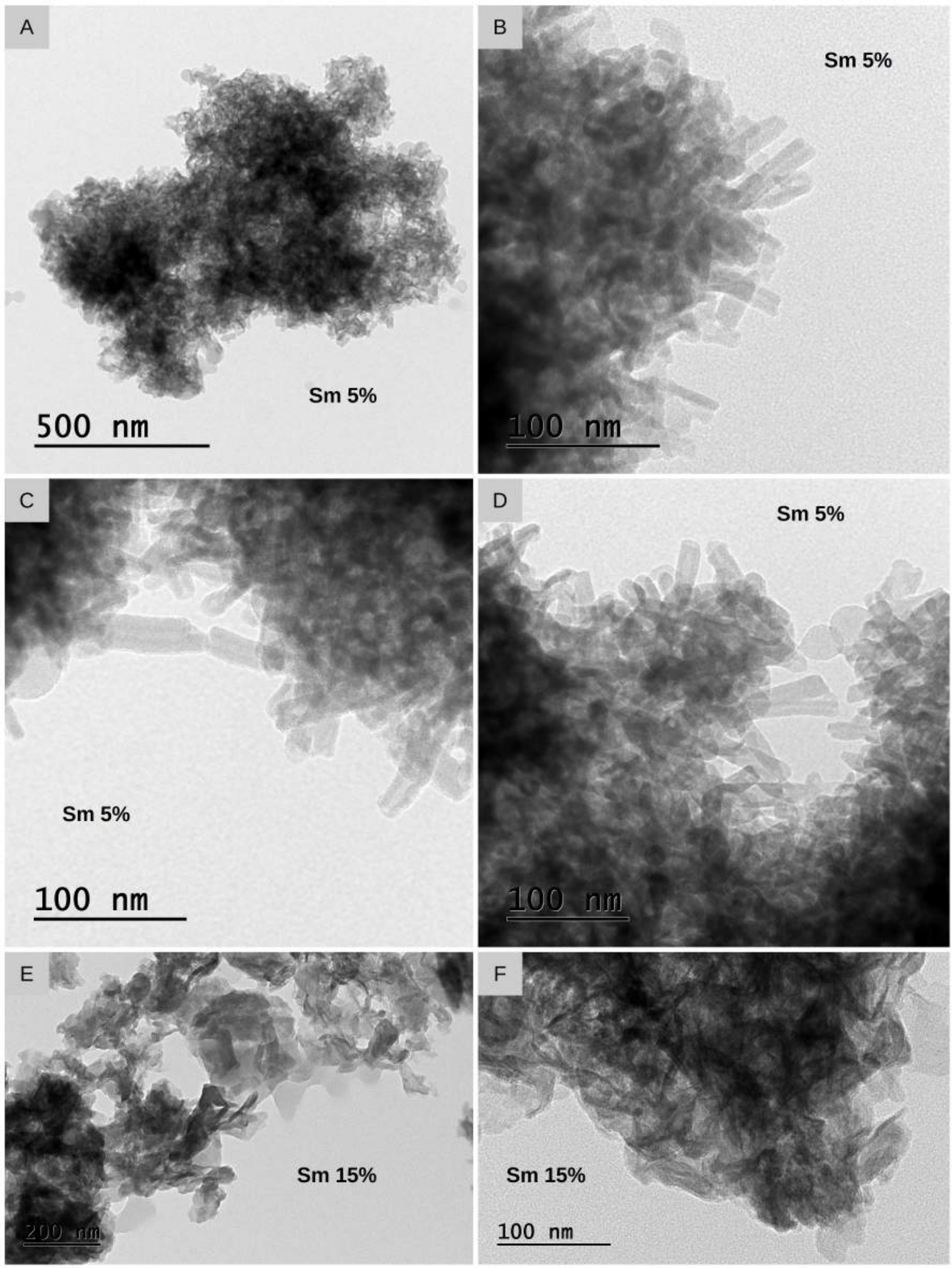

Figura 32 - Microscopia eletrônica de transmissão das amostras ZnAlSmx\%-BTC-P123.

encontrarem majoritariamente aglomerados, a única alternativa a este método para determinação do comprimento dos nanotubos se dá pela existência de estruturas que se posicionam 

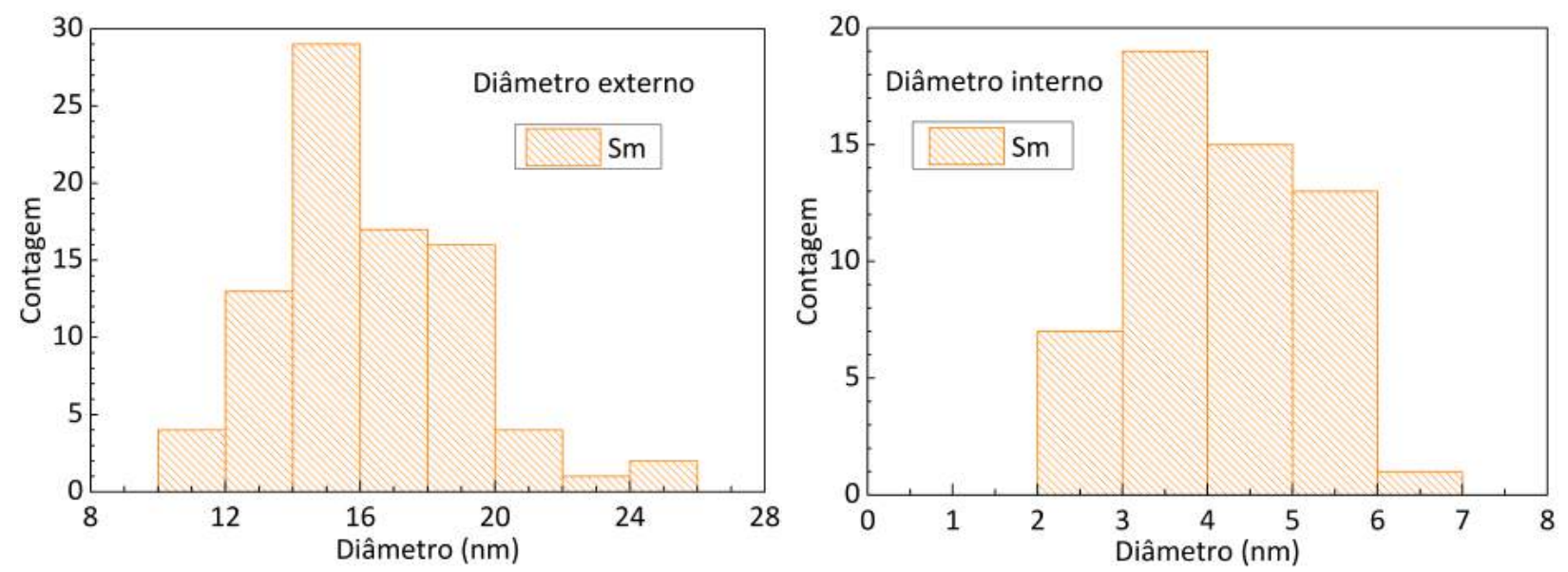

Figura 33 - Diâmetros dos nanotubos presentes na amostra ZnAlSm5\%-BTC-P123.

como na imagem da Figura 34D, ligeiramente destacadas do aglomerado. Para o európio, foram obtidos valores entre 30 e $150 \mathrm{~nm}$, indicando haver ampla distribuição de comprimentos possíveis. Não foi possível, no entanto, obter número suficiente de nanotubos destacados nas micrografias para estudar as características desta distribuição.

Na Figura 35 são apresentados os histogramas relativos aos diâmetros externo e interno dos nanotubos ZnAlEux\%-BTC-P123, que apresentam distribuição normal de dados em torno das médias $\Phi_{E u}=26.8 \pm 0.7 \mathrm{~nm}$ e $\phi_{E u}=7.09 \pm 0.28 \mathrm{~nm}$. O diâmetro externo médio medido para os nanotubos com európio foi o maior observado dentre todas as amostras testadas, em consonância com o tamanho do cristalito obtido nas análises cristalográficas deste lantanídeo.

O quadro E da Figura 34 mostra uma captura bem focalizada da seção transversal de um nanotubo. É possível visualizar o padrão de claros e escuros da estrutura lamelar do material. Cada circunferência corresponde a uma camada de hidróxidos em formato cilíndrico concêntrica às demais, com raio igual ao da camada anterior acrescido de um espaçamento basal. Esta imagem foi convertida em escala de cinza ao longo do eixo amarelo indicado na Figura 36.

Do lado esquerdo do tubo podemos identificar uma parede de largura $8.8 \mathrm{~nm}$ com 8 lamelas, equivalente a 7 espaçamentos basais entre os mínimos do gráfico. Com base neste resultado, o valor obtido como espaçamento basal médio é de 12,6 Å, compatível com os $13,4 \pm 1,1 \AA$ calculados no estudo do difratograma e coerente com o empilhamento mínimo 

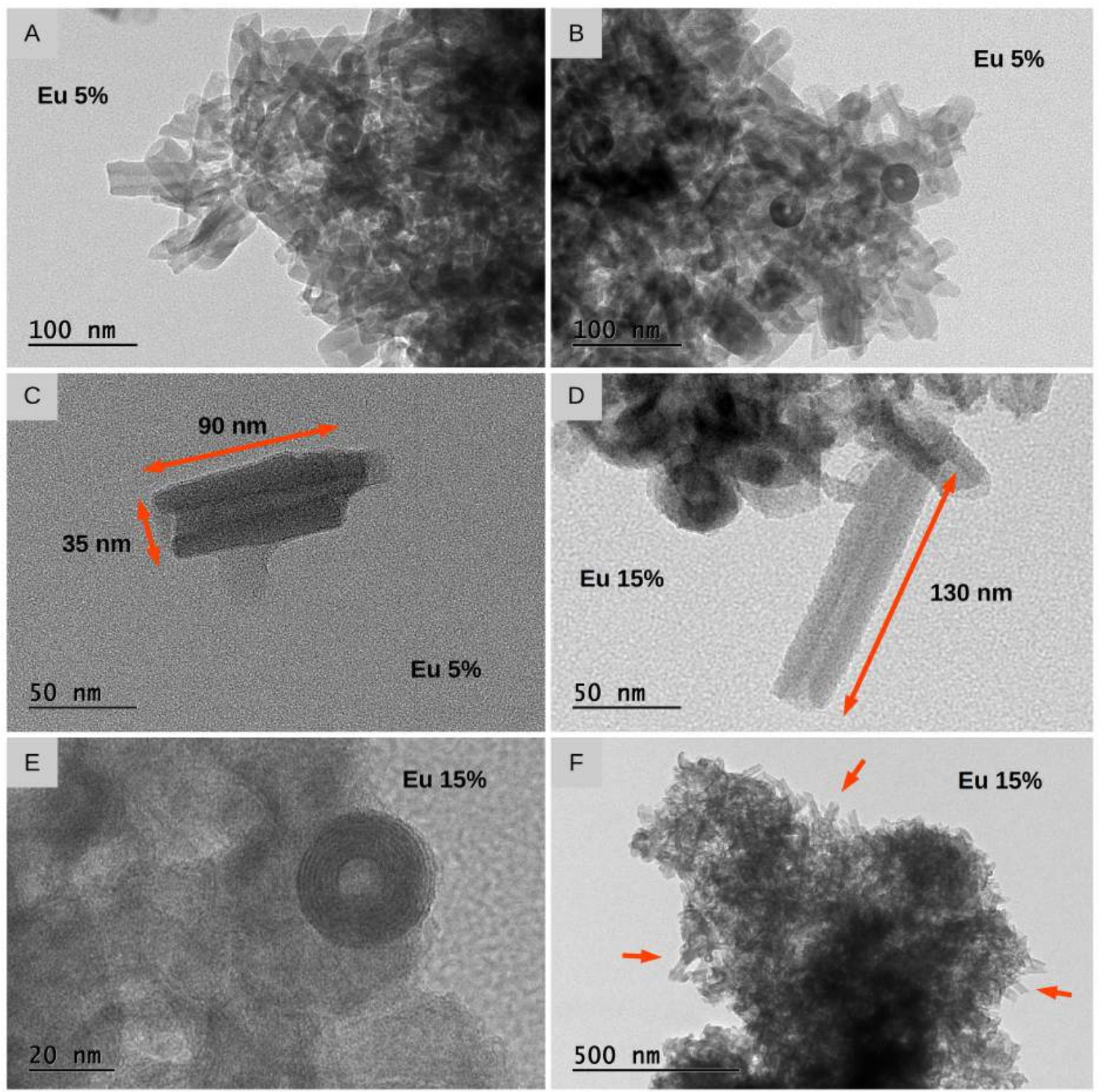

Figura 34 - Microscopia eletrônica de transmissão das amostras ZnAlEux\%-BTC-P123.

de 6 camadas obtido pela equação de Scherrer. A largura da cavidade verificada para este nanotubo em particular foi $11.1 \mathrm{~nm}$. A escala de cinza indica com boa acurácia os vales relativos à posição da camada interna de hidróxidos, possibilitando a separação das regiões internas e externas à cavidade. Por fim, vemos que a parede direita do tubo analisado é mais espessa que a esquerda. Tal característica é repetida em alguns dos tubos presentes nas micrografias. Este efeito indica que os metais e hidroxilas se acomodam em torno das camadas interiores de maneira relativamente desordenada. Não é necessário completar uma 

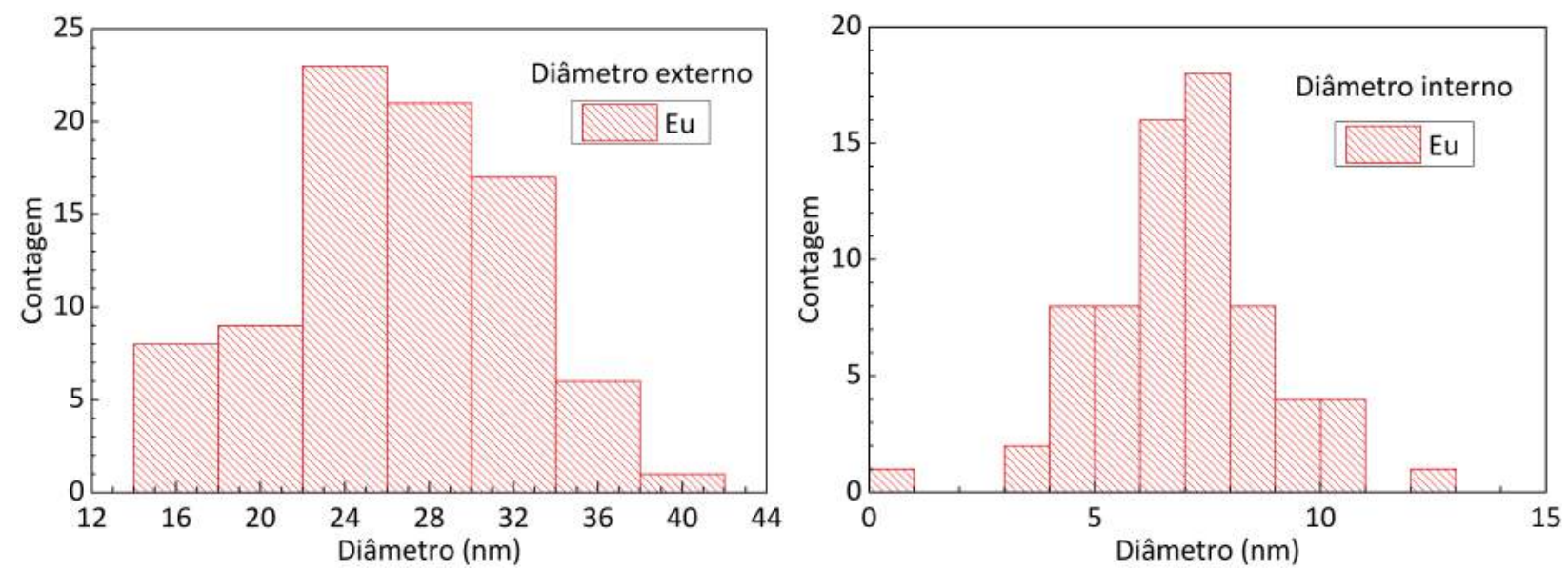

Figura 35 - Diâmetros externo (esq.) e interno (dir.) dos nanotubos presentes nas amostras ZnAlEux\%-BTC-P123.

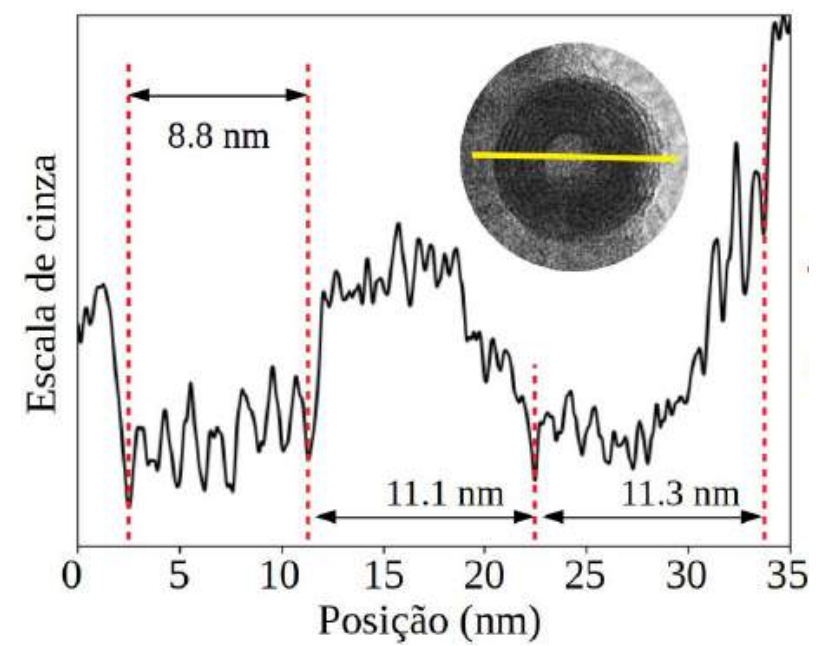

Figura 36 - Perfil em escala de cinza ao longo da linha amarela do nanotubo em destaque. A parede esquerda possui distância $8,8 \mathrm{~nm}$ entre as camadas limite de hidróxidos, correspondendo a um espaçamento basal de 12,6 А.

casca cilíndrica para que a próxima comece a se formar, mas à medida que as diversas porções de uma camada se encontram, forma-se uma casca completa. Neste sentido, só é possível caracterizar cada tubo em termos de seu diâmetro médio. Temos, para o tubo em questão, um diâmetro externo médio estimado em 31,2 nm.

\section{Análise morfológica - ZnAIGdx\%-BTC-P123 e ZnAITbx\%-BTC-P123}

A Figura 37 ilustra as micrografias das amostras contendo gadolínio e térbio. Ao contrário do que foi observado para os lantanídeos de raio atômico maior que o gadolínio, a concentração de $5 \%$ de Gd ou Tb em substituição ao alumínio nas camadas de hidróxidos 
não é suficiente para induzir a formação de nanotubos como morfologia predominante na amostra.

Os pares de imagens $37 \mathrm{~A}-\mathrm{B}$ e $37 \mathrm{C}-\mathrm{D}$ mostram para $\mathrm{x}=5 \%$ o surgimento pontual de nanotubos em meio a regiões compostas por nanofolhas e enrolamentos. Há a formação de aglomerados de nanotubos (Fig. 37E-H) quando a concentração de Gd ou Tb é elevada para 15\%. Para ambas as concentrações testadas desses lantanídeos, a análise de difração de raios $\mathrm{X}$ mostra que não houve a formação de fases laterais cristalinas que pudessem interferir na auto organização dos hidróxidos em torno das micelas surfactantes.

Os histogramas da Figura 38 mostram a distribuição normal das medidas dos diâmetros externos e internos dos nanotubos presentes nas amostras ZnAlGdx\%-BTC-P123. Os valores médios obtidos foram $\Phi_{G d}=16.82 \pm 0.24 \mathrm{~nm} \mathrm{e} \phi_{G d}=5.08 \pm 0.21 \mathrm{~nm}$. As médias $\Phi_{T b}=$ $15.69 \pm 0.29 \mathrm{~nm}$ e $\phi_{T b}=5.6 \pm 0.3 \mathrm{~nm}$ foram obtidas, respectivamente, para os diâmetros externos e internos das amostras ZnAlTbx\%-BTC-P123 (Fig. 39 .

\section{Análise morfológica das amostras ZnAIDyx\%-BTC-P123}

A Figura 40 ilustra micrografias selecionadas das amostras ZnAlDyx\%-BTC-P123 contendo 5, 15 e 20\% de disprósio. Na menor concentração testada, o disprósio incorporado nas camadas de hidróxidos não foi suficiente para permitir o surgimento de nanotubos nas amostras. Foram observadas nanofolhas como no exemplo do quadro 40B, que apresenta uma partícula de formato hexagonal, seguindo o formato da célula unitária dos hidróxidos duplos lamelares de $\mathrm{Zn} / \mathrm{Al}$.

Para a concentração $\mathrm{x}=15 \%$ foi verificado o surgimento de nanotubos. Esta amostra se mostrou especialmente sensível quando exposta ao feixe de elétrons do microscópio, se movendo constantemente durante as medidas e se decompondo em poucos segundos de observação. A melhor resolução obtida (Fig. 40C) sugere grande presença de estruturas em formato cilíndrico, embora não seja possível determinar se o material era composta majoritariamente por aglomerados de nanotubos ou pela presença de nanotubos em meio a outras morfologias. A distribuição dos valores medidos para o diâmetro externo das estruturas (Fig. 41 resultou no valor médio $\Phi_{D y}=14.1 \pm 0.5 \mathrm{~nm}$.

As micrografias inferiores da Figura 40 mostram a presença de folhas de hidróxidos lamelares de ZnAlDy20\%-BTC-P123 em coexistência com a fase lateral Dy(BTC). No qua- 

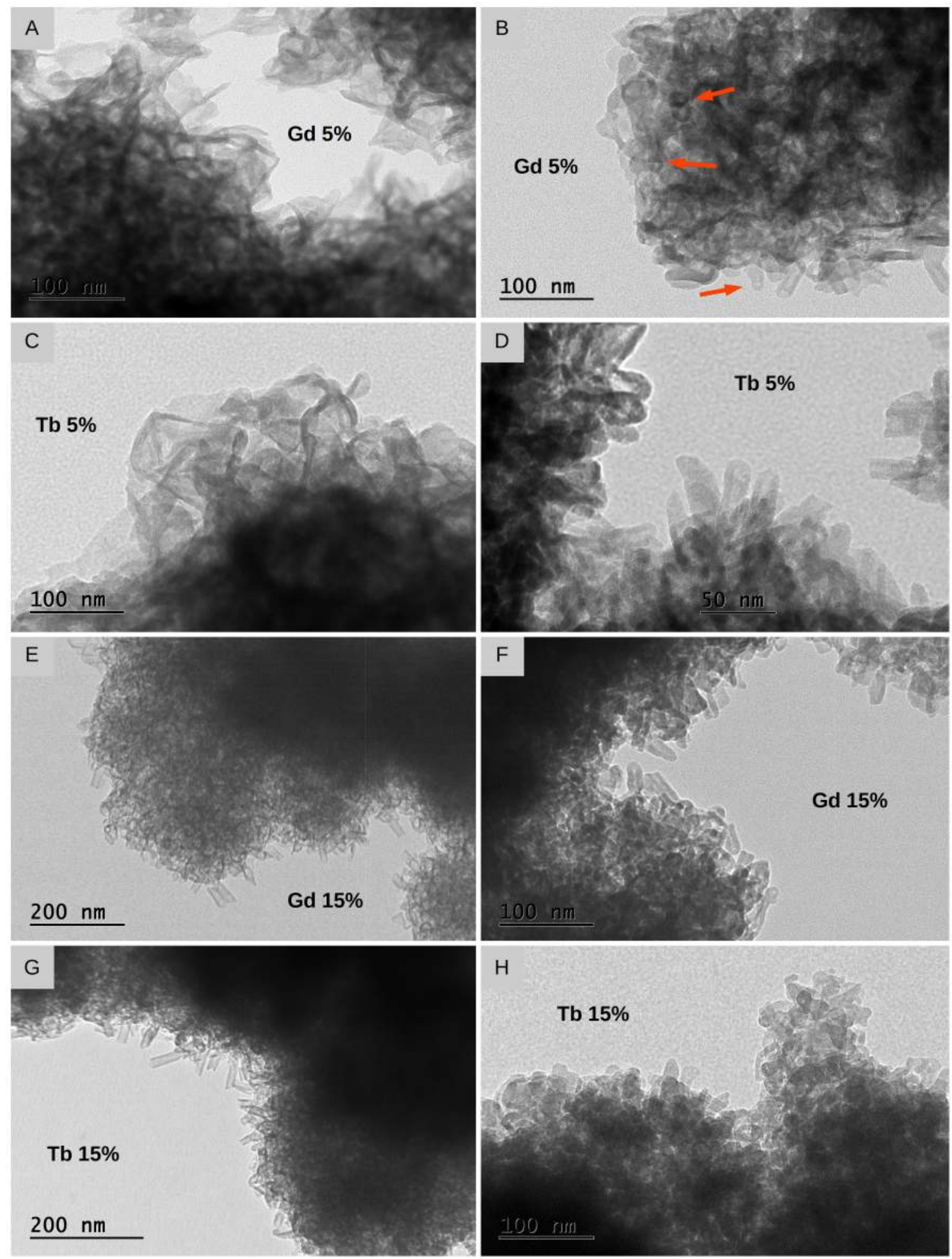

Figura 37 - Microscopia eletrônica de transmissão das amostras ZnAlGdx\%-BTC-P123 e ZnAlTbx\%-BTC-P123. 

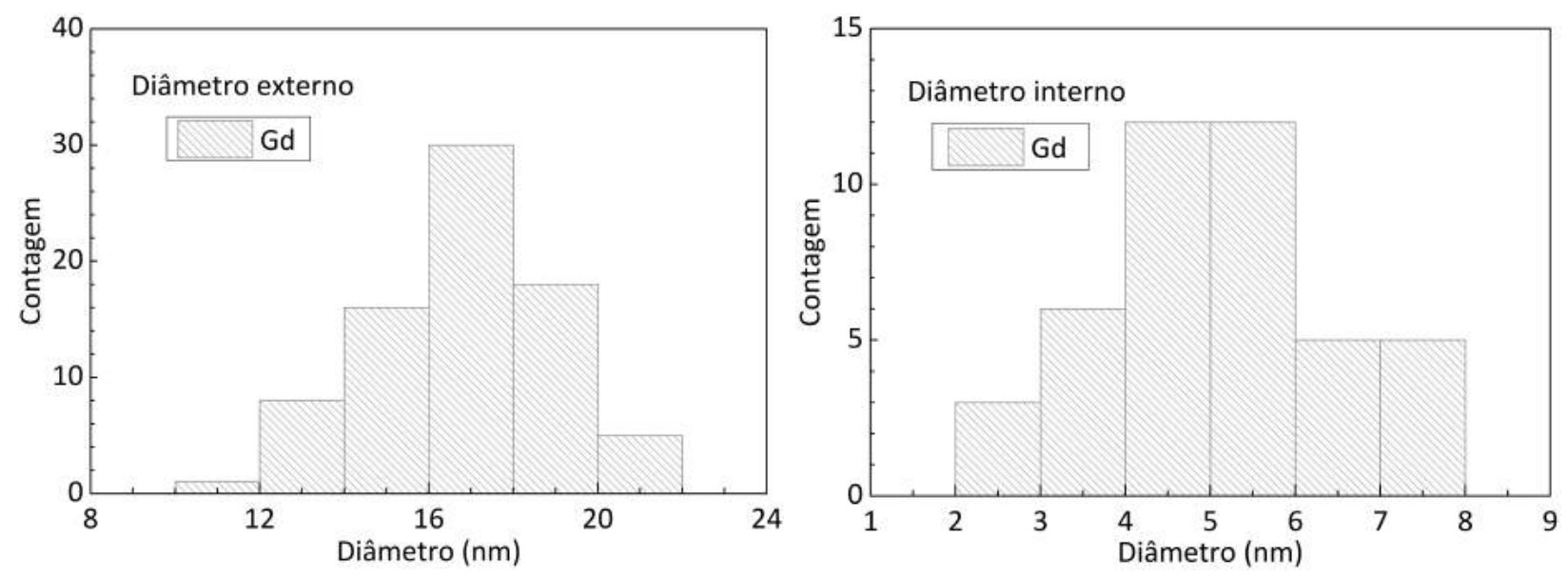

Figura 38 - Diâmetros externo (esq.) e interno (dir.) dos nanotubos presentes nas amostras ZnAlGdx\%-BTC-P123.
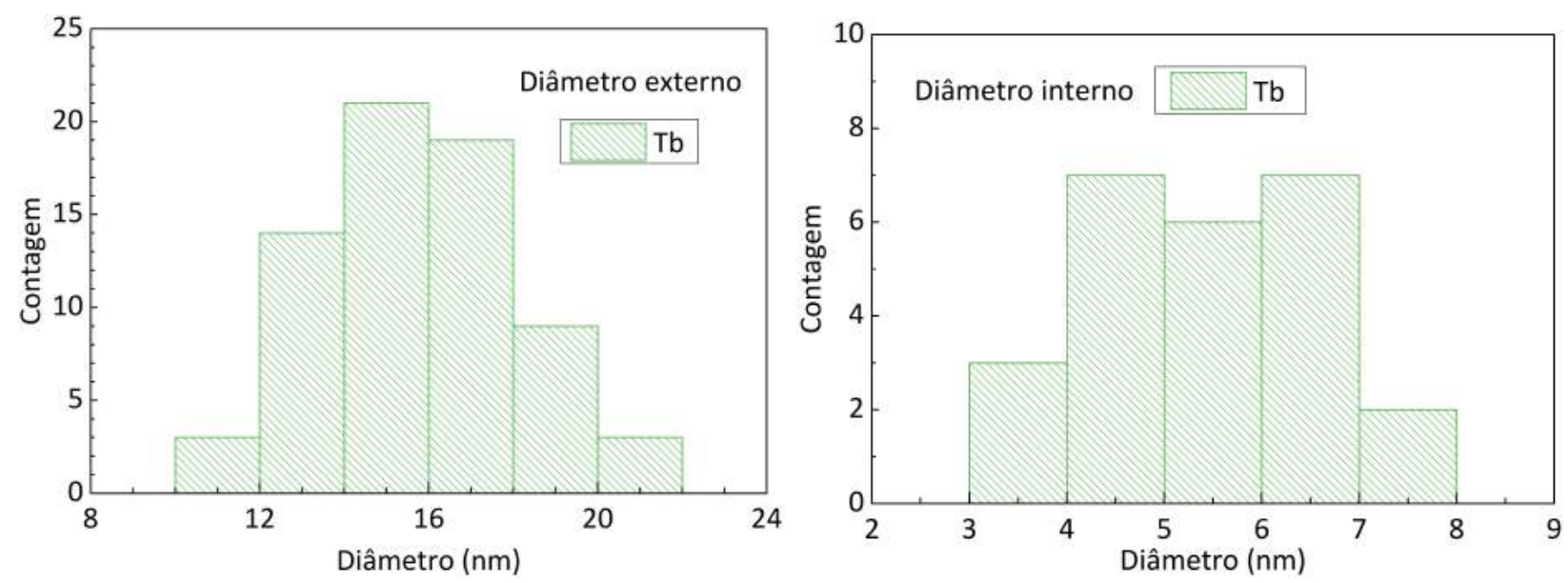

Figura 39 - Diâmetros externo (esq.) e interno (dir.) dos nanotubos presentes nas amostras ZnAlTbx\%-BTC-P123.

dro $40 \mathrm{E}$ é possível observar parte dos bastões micrométricos típicos dos complexos TRbenzenocarboxilatos em primeiro plano, com o hidróxido lamelar ao fundo. Não foi registrada a presença de nanotubos ou estruturas similares para esta concentração.

\section{Análise morfológica - ZnAITRx\%-BTC-P123 - Ho, Er, Tm, Yb, Lu}

As medidas efetuadas para todos os lantanídeos com raio atômico menores que o disprósio mostram comportamentos muito similares quanto a morfologia obtida em cada amostra, como ilustrado nas micrografias selecionadas da Figura 42. Para concentrações de 5\%, todos os hidróxidos ZnAlTRx\%-BTC-P123 (TR = Ho, Er, Tm, Yb ou Lu) possuem morfologia plana, sem a presença de enrolamentos ou nanofolhas com curvaturas apreciáveis. 

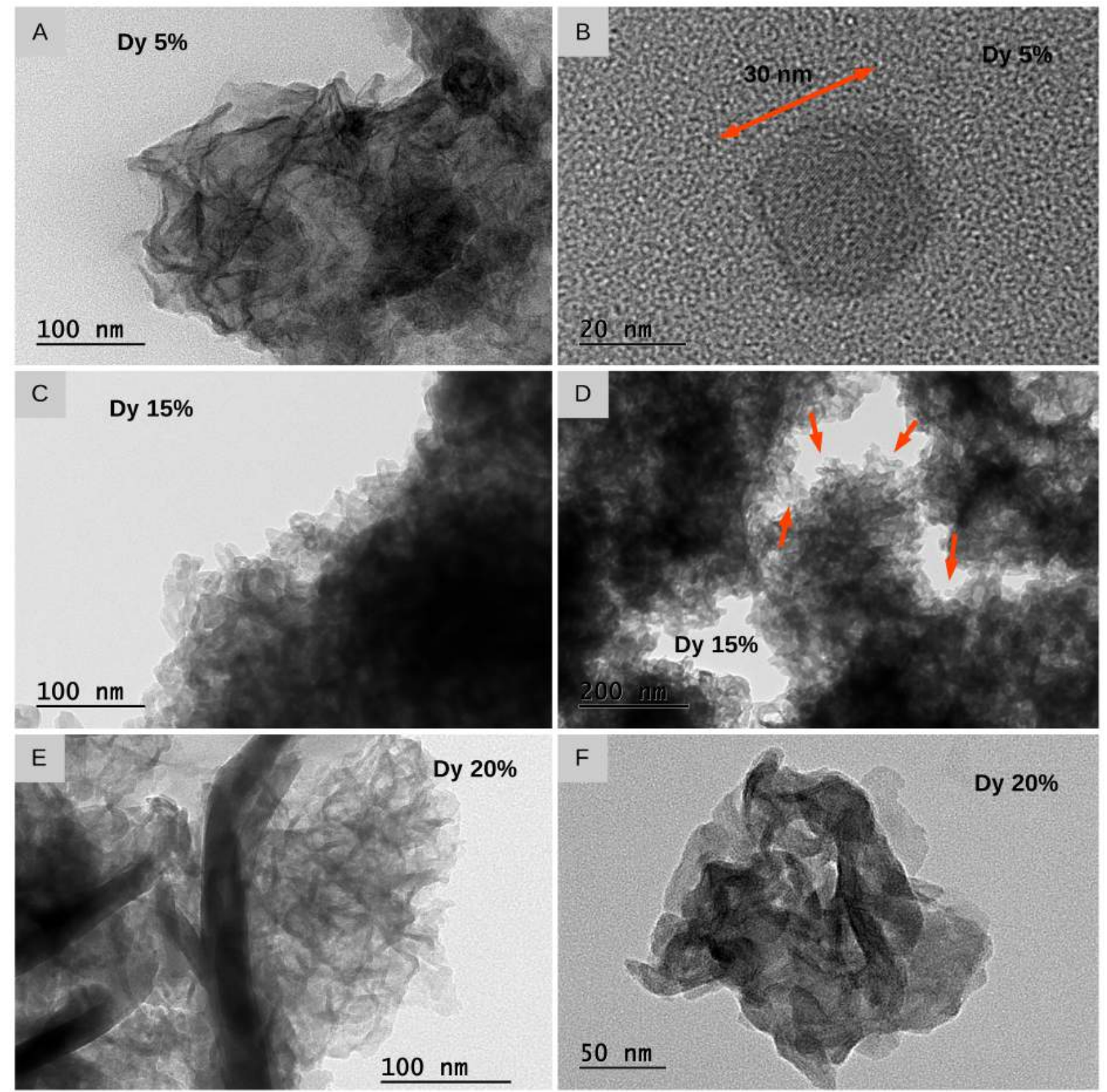

Figura 40 - Microscopia eletrônica de transmissão das amostras ZnAlDyx\%-BTC-P123.

Aumentando a concentração para 15\% de terras raras nas amostras, há o surgimento de estruturas cilíndricas em meio a porções de material com morfologia indefinida. A sensibilidade dos materiais ao feixe do microscópio eletrônico limitou a resolução alcançada, de modo que poucas imagens bem definidas foram obtidas em escala inferior a $100 \mathrm{~nm}$. O quadro 42F mostra a estrutura lamelar da amostra ZnAlEr15\%-BTC-P123, com três camadas de hidróxidos concêntricas formando um nanotubo. O espaçamento basal obtido pela observação direta do tubo foi $\mathrm{d}=1.4 \mathrm{~nm}$, compatível com o valor de $1.27 \pm 0.14$ calculado pela 


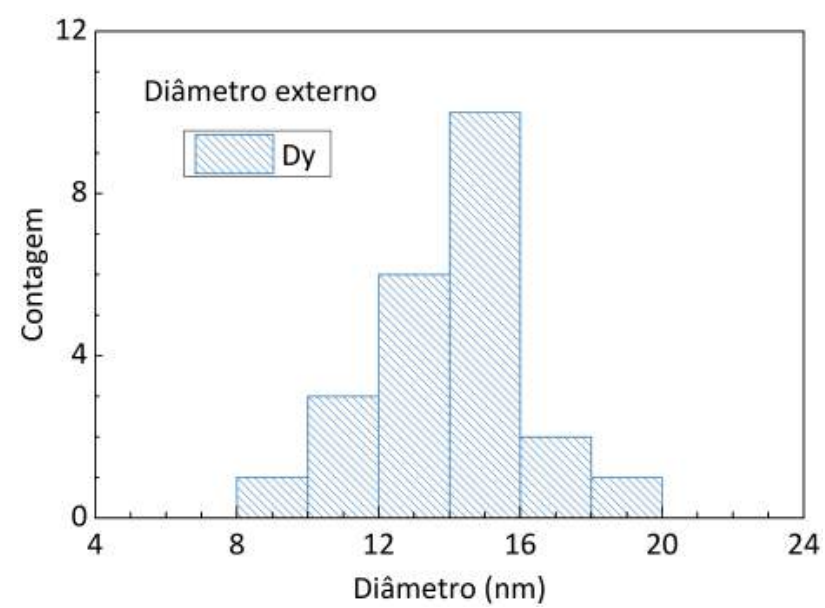

Figura 41 - Diâmetro dos nanotubos presentes na amostra ZnAlDy15\%-BTC-P123.

difração de raios X desta amostra.

Os diâmetros externos dos nanotubos ZnAlTR15\%-BTC-P123 (TR = Ho, Er, Tm, Yb ou Lu) foram similares entre si, com tamanhos médios de $14 \mathrm{~nm}$. Não foi possível medir partículas suficientes para estudar a distribuição de diâmetros externos ou internos nessas amostras.

\section{Análise morfológica - ZnAIYx\%-BTC-P123 e ZnAIPrx\%-BTC-P123}

Embora para a maioria dos casos a morfologia observada em cada composição de hidróxido lamelar dopado com terras raras apresente comportamento correlacionado ao raio iônico do elemento introduzido, duas anomalias são verificadas para a série. O ítrio, com raio iônico entre hólmio e érbio, e o praseodímio, com raio iônico entre lantânio e neodímio, apresentam comportamentos diferentes de seus vizinhos.

Os quadros A-C da Figura 43 mostram as micrografias da amostra ZnAlY5\%-BTC-P123. Enquanto os hidróxidos dopados de hólmio ou érbio nesta concentração apresentam exclusivamente morfologia plana, com a dopagem de ítrio também é possível visualizar enrolamentos e nanotubos. A amostra ZnAlY15\%-BTC-P123 (Fig. 43D-F) apresenta algumas estruturas similares a nanotubos em meio a porções de material com morfologia indefinida, contendo nanofolhas e enrolamentos.

Os hidróxidos lamelares contendo os terras raras de raios maiores que o európio (La, Nd, Sm) exibiram aglomerados de nanotubos para concentrações baixas desses elementos na amostra e morfologia plana para concentrações de 15\%. Embora faça parte deste grupo 


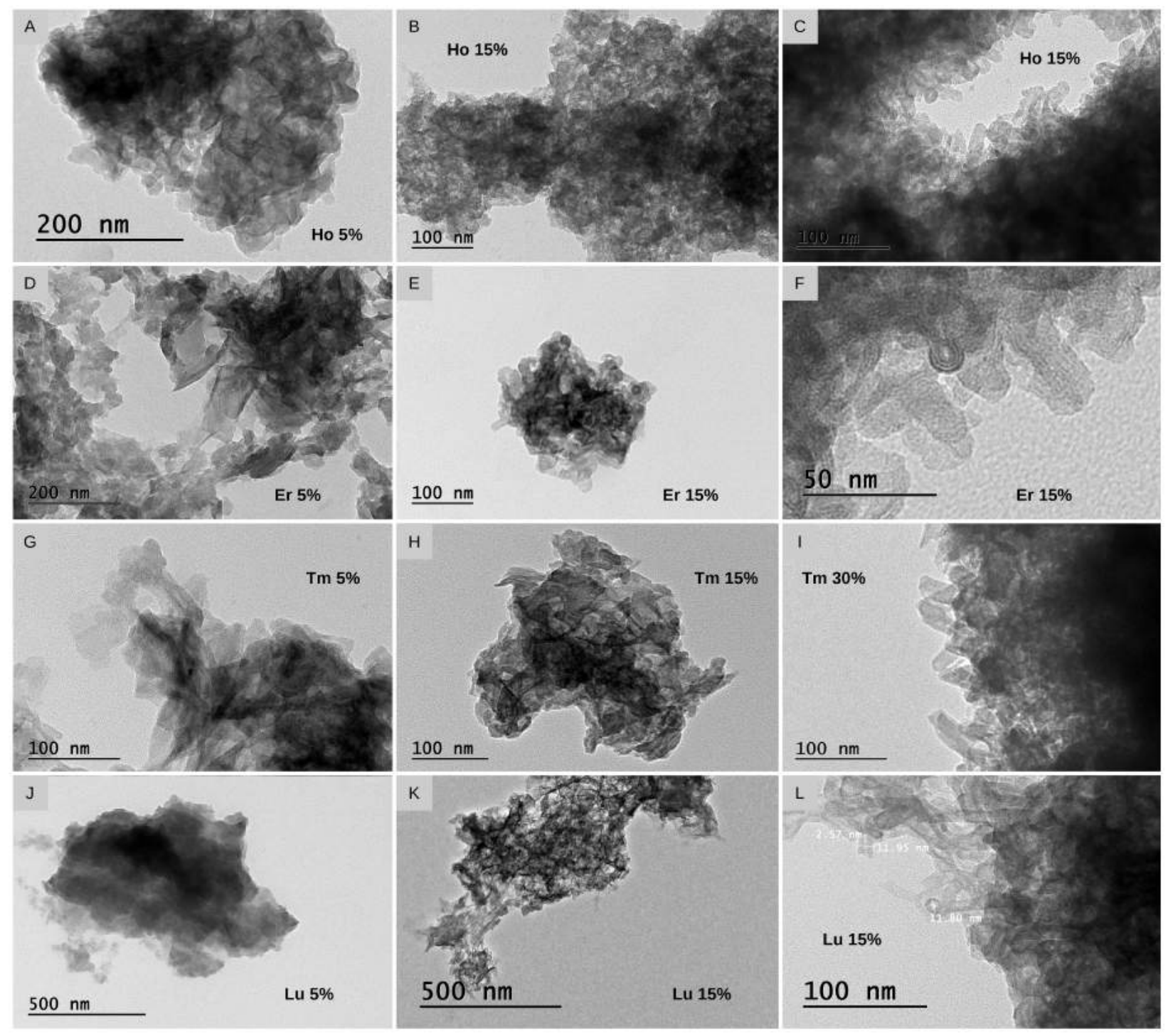

Figura 42 - Microscopia eletrônica de transmissão das amostras ZnAlTRx\%-BTC-P123 (TR $=$ Ho, Er, Tm, Lu).

com respeito a seu raio iônico, as micrografias obtidas para ambas as concentrações de 5 e 15\% testadas de praseodímio (Fig. $43 \mathrm{G}-\mathrm{L}$ ) apresentaram comportamentos similares entre si e diferentes das amostras do mesmo grupo. O que se verificou para os materiais ZnAlPrx\%BTC-P123 foi uma variedade de morfologias coexistentes: planos, nanotubos, pergaminhos, cones e enrolamentos. Nota-se que ambas as concentrações deste lantanídeo permitem o surgimento de curvaturas na camadas de hidróxidos, embora a auto organização dos metais e hidroxilas em torno das micelas cilíndricas não tenha sido efetiva para que a morfologia de nanotubos fosse predominante no sistema.

Os histogramas da Figura 44 mostram a distribuição dos diâmetros externos medidos 


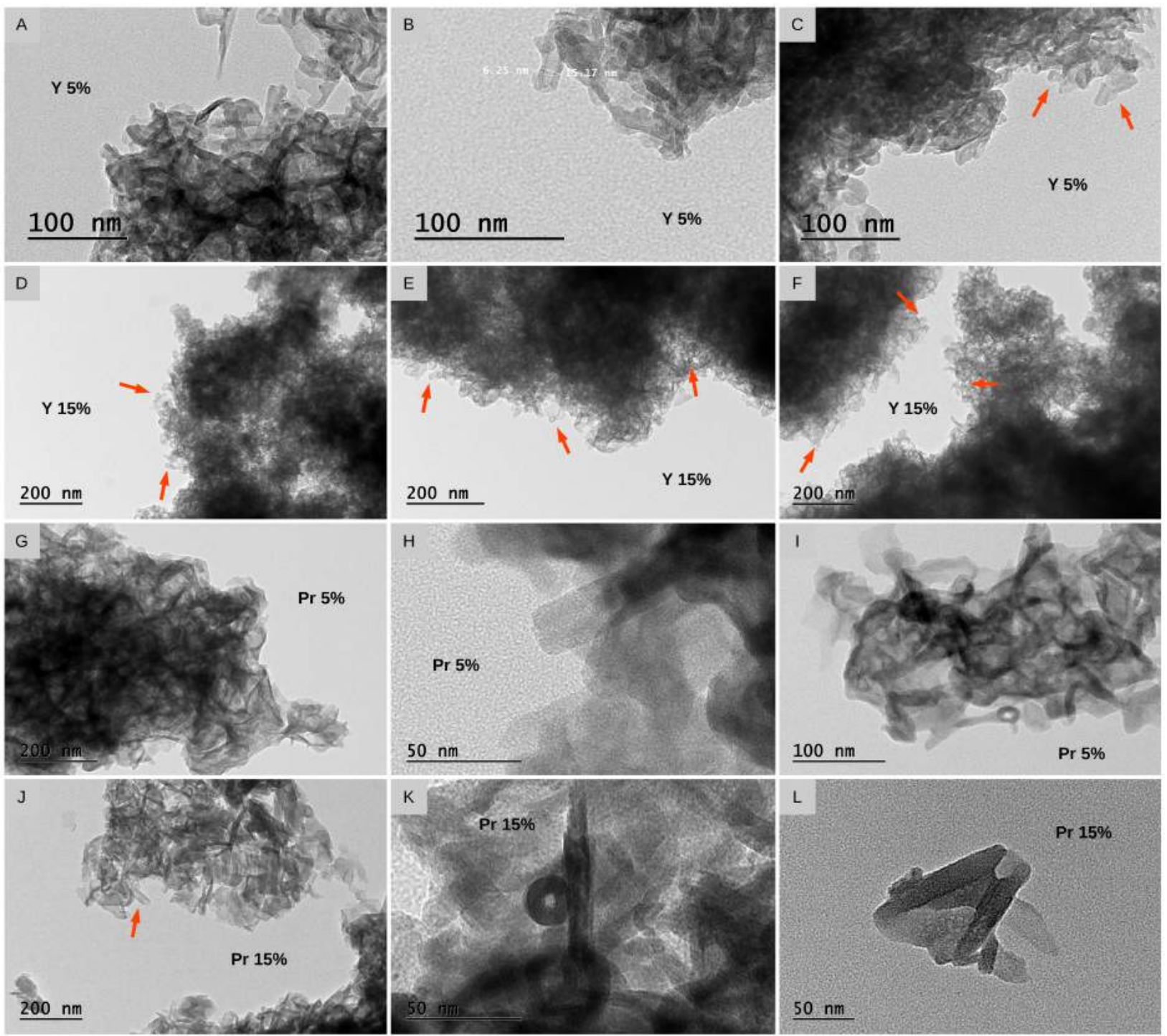

Figura 43 - Microscopia eletrônica de transmissão das amostras ZnAlYx\%-BTC-P123 e ZnAlPrx\%-BTC-P123.

nas estruturas cilíndricas encontradas nas micrografias das amostras contendo ítrio e praseodímio. Embora poucas partículas tenham sido mensuradas, uma distribuição normal de valores foi obtida para as amostras ZnAlYx\%-BTC-P123, com valor médio $\Phi_{Y}=15.7 \pm 0.4$ nm. Os valores de diâmetro medidos nas micrografias de amostras com praseodímio não resultaram em uma distribuição gaussiana.

A amostra ZnAlY14Pr1\%-BTC-P123 foi sintetizada pelo mesmo método descrito anteriormente, na presença de $14 \%$ de ítrio e 1\% de praseodímio em substituição ao alumínio das camadas de hidróxidos. Embora individualmente ambos os terras raras tenham sido ineficientes em induzir a formação de nanotubos, ao doparmos o material com Y e Pr obtivemos 

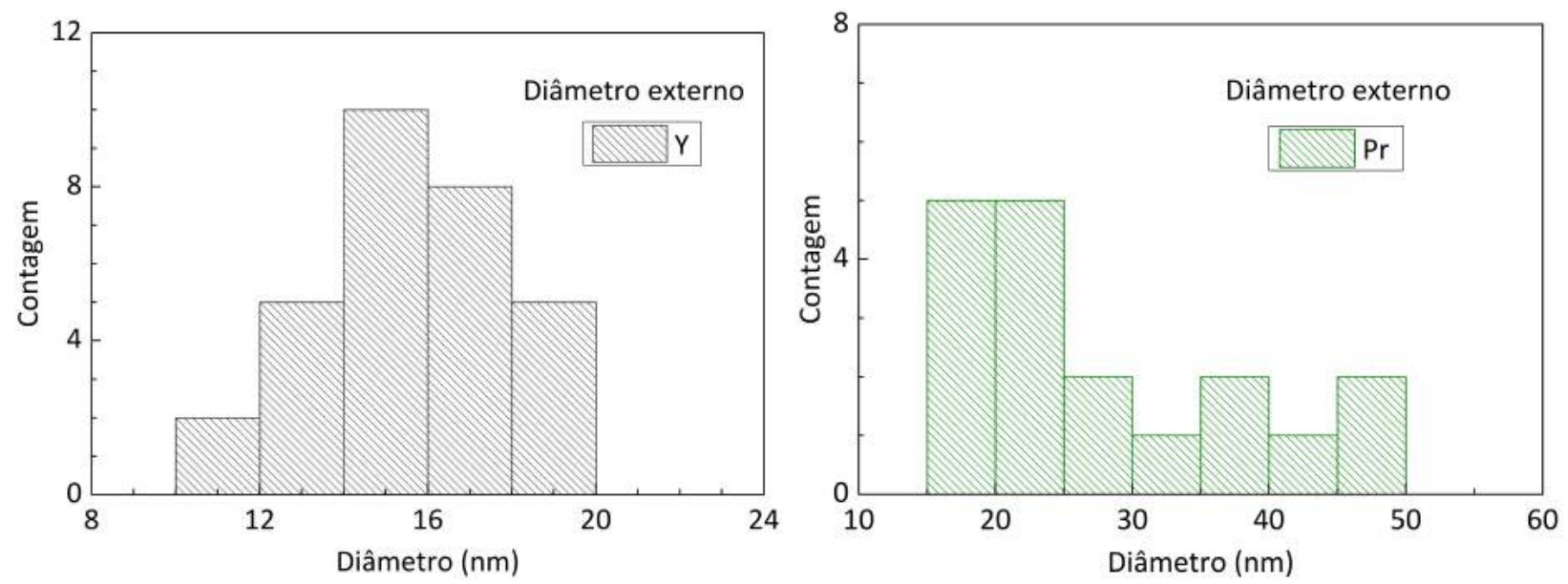

Figura 44 - Diâmetro dos nanotubos presentes nas amostras ZnAlYx\%-BTC-P123 (esq.) e ZnAlPrx\%-BTC-P123 (dir.).

aglomerados de nanotubos bem definidos, como observado na Figura 45.
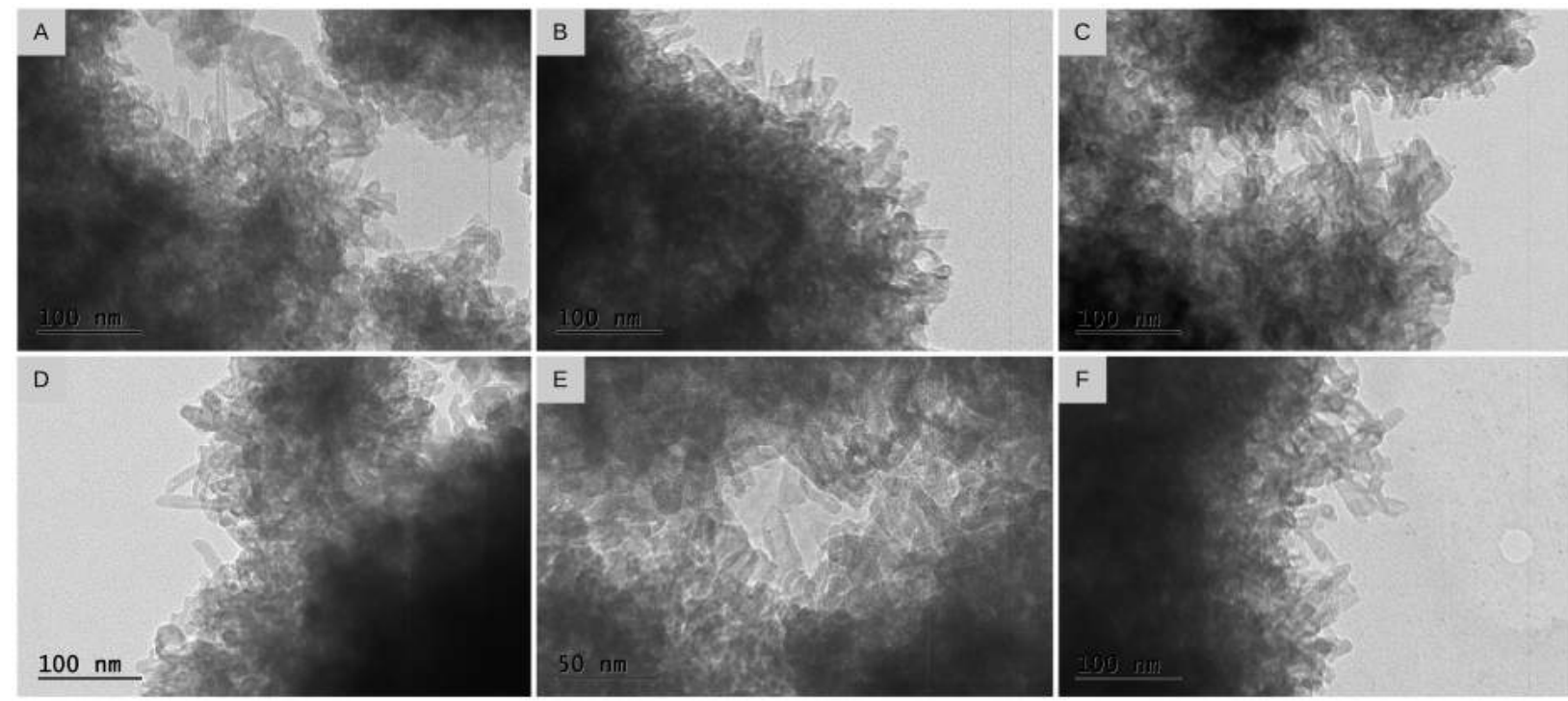

Figura 45 - Microscopia eletrônica de transmissão da amostra ZnAlY14Pr1\%-BTC-P123.

O valor médio dos diâmetros externos medidos nas micrografias da amostra ZnAlY14Pr1\%BTC-P123 foi $\Phi_{Y P r}=13.59 \pm 0.22 \mathrm{~nm}$, conforme a distribuição de dados da Figura 46 .

\section{Considerações gerais sobre as morfologias observadas}

A partir das amostras em que foram produzidos aglomerados de nanotubos, foi possível estabelecer as características médias dessa estrutura para cada terra rara (Tabela 6). A espessura mínima das paredes do nanotubo $\left(\ell_{\min }\right)$ foi estimada como o tamanho do cristalito 


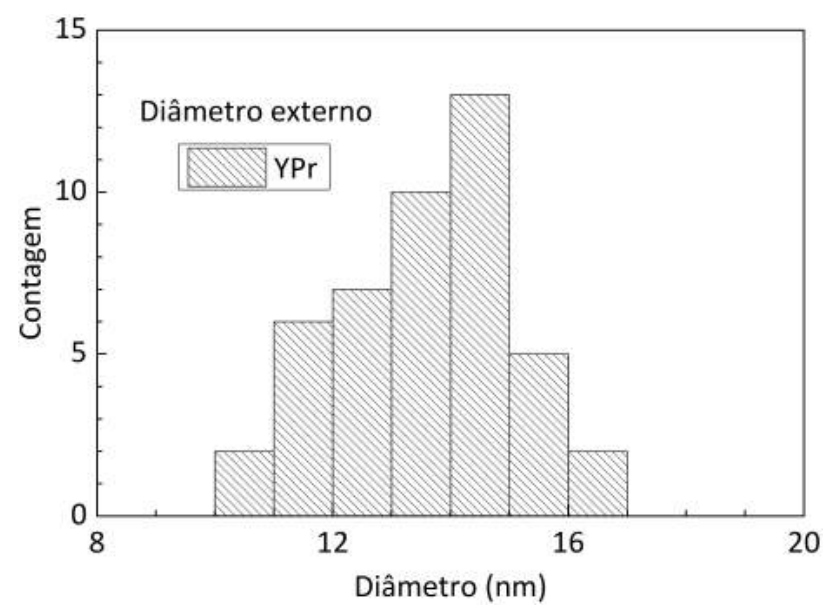

Figura 46 - Diâmetro dos nanotubos presentes na amostra ZnAlY14Pr1\%-BTC-P123.

calculado pela equação de Scherrer. Os diâmetros médios externos $(\Phi)$ foram definidos a partir das distribuições analisadas nas micrografias, enquanto os diâmetros internos $\left(\phi_{\min }\right)$ obtidos nesta técnica foram estimados como o valor mínimo da largura da cavidade. Tais medidas realizadas diretamente pelas micrografias possuem calibração adequada quanto a conversão de pixels para nanômetros, uma vez que os resultados obtidos para o espaçamento basal da amostra foram compatíveis com os valores da análise de difração de raios X (Tab. 4). Uma estimativa do teto atingido para o diâmetro interno médio de cada distribuição de nanotubos $\left(\phi_{\max }\right)$ foi feita subtraindo do diâmetro externo a espessura mínima estimada das paredes dos nanotubos. Por fim, o diâmetro interno médio foi estimado pela relação $\bar{\phi}=\left(\phi_{\min }+\phi_{\max }\right) / 2$. Os valores obtidos para $\bar{\phi}$ foram compatíveis às cavidades medidas nos nanotubos bem focalizados a partir da análise do perfil dessas estruturas em escala de cinza, como nos exemplos das Figuras 27L e 36.

Tabela 6 - Características dos nanotubos analisados para amostras de hidróxidos com diferentes íons terras raras e concentrações. Todas as medidas são apresentadas em nanômetros.

\begin{tabular}{cccccc}
\hline $\mathrm{TR}^{3+}$ & $\begin{array}{c}\text { Espessura da } \\
\text { parede }\left(\ell_{\text {min }}\right)\end{array}$ & $\begin{array}{c}\text { Diâmetro } \\
\text { externo }(\Phi)\end{array}$ & $\begin{array}{c}\text { Diâmetro } \\
\text { interno }\left(\phi_{\text {min }}\right)\end{array}$ & $\begin{array}{c}\text { Diâmetro } \\
\text { interno }\left(\phi_{\text {max }}\right)\end{array}$ & $\begin{array}{c}\text { Diâmetro } \\
\text { interno }(\bar{\phi})\end{array}$ \\
\hline \hline $\mathrm{La}$ & 5.3 & $20.8 \pm 0.5$ & $5.5 \pm 0.4$ & 10.3 & 7.9 \\
$\mathrm{Nd}$ & 4.6 & $15.1 \pm 0.3$ & $4.30 \pm 0.19$ & 6.0 & 5.1 \\
$\mathrm{Sm}$ & 4.6 & $16.2 \pm 0.3$ & $4.13 \pm 0.14$ & 7.1 & 5.6 \\
$\mathrm{Eu}$ & 5.5 & $26.8 \pm 0.7$ & $7.09 \pm 0.28$ & 15.8 & 11.4 \\
$\mathrm{Gd}$ & 4.0 & $16.82 \pm 0.24$ & $5.08 \pm 0.21$ & 8.9 & 7.0 \\
$\mathrm{~Tb}$ & 3.8 & $15.69 \pm 0.29$ & $5.6 \pm 0.3$ & 8.1 & 7.0 \\
$\mathrm{Y}$ & 3.9 & $15.7 \pm 0.4$ & - & 7.8 & - \\
\hline
\end{tabular}


Embora as micelas de P123 utilizadas no processo de síntese para orientar a auto organização dos hidróxidos tenham sido caracterizadas na literatura como bastões de diâmetro $d_{P 123} \approx 20 \mathrm{~nm}$, as cavidades observadas nos nanotubos possuem dimensões inferiores a este valor. Muitas das partículas apresentaram, na realidade, diâmetros externos médios inferiores àqueles esperados para a cavidade, confirmando que não se trata de um resultado devido às limitações em se determinar de forma precisa os limites internos do nanotubo. Deve haver, durante a síntese do material, um processo de contração das micelas à medida que os hidróxidos se depositam em sua superfície, resultando nas dimensões observadas para as partículas. Medidas de adsorção de nitrogênio indicam, para o európio, que a contração das micelas é maior à medida que a concentração deste lantanídeo é aumentada no sistema. [38] Esta contração não se dá de forma uniforme para todos os terras raras. Nota-se que não há correlação entre as dimensões dos nanotubos e características como número atômico, raio iônico ou propriedades termodinâmicas dos terras raras inseridos nas lamelas.

A Figura 47 mostra a correlação dos diâmetros externos com os diâmetros internos e espessuras das paredes dos tubos. À medida que $\bar{\phi}$ e $\ell_{\text {min }}$ aumentam, maiores diâmetros externos $\Phi$ são observados.
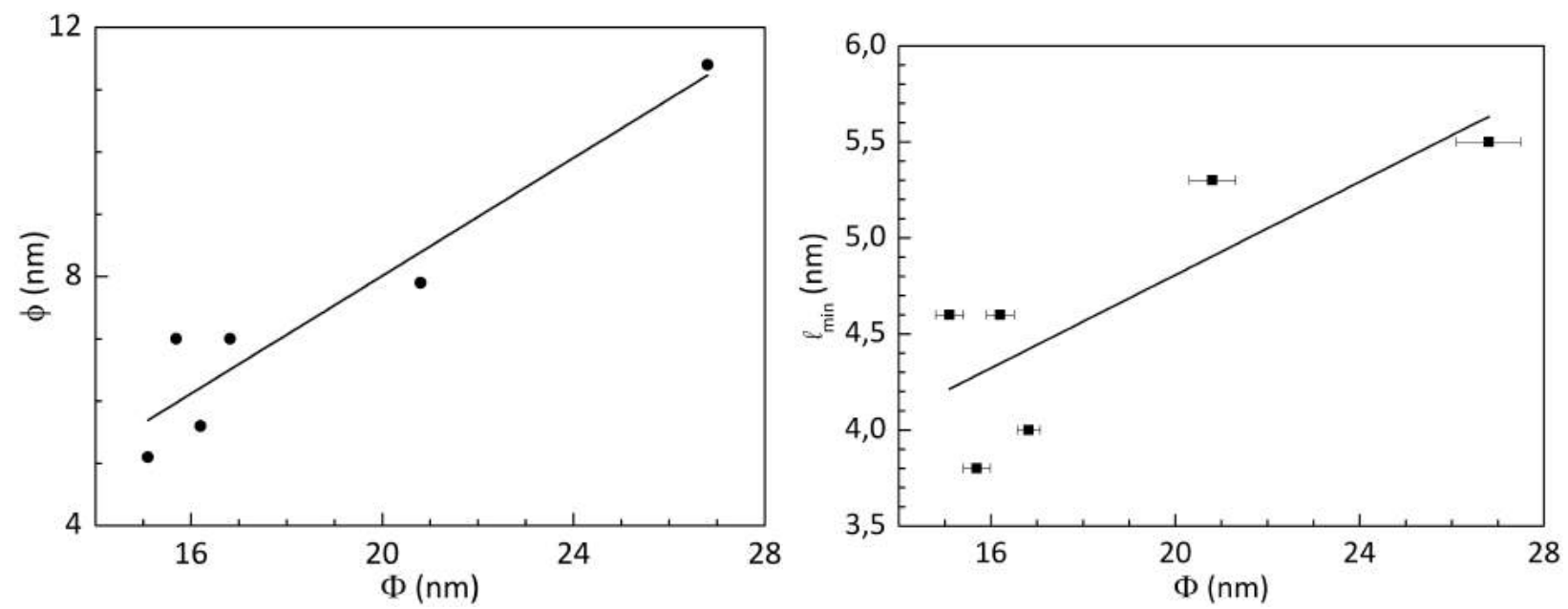

Figura 47 - (esq.) Diâmetro interno médio. (dir.) Espessura mínima das paredes.

A morfologia nanotubular não foi, no entanto, o único resultado obtido neste sistema. Sem a incorporação de terras raras nas amostras, apenas cristais planos de HDL são formados. Em consonância com resultados reportados anteriormente para o európio, 36] somente a adição conjunta de P123, BTC e lantanídeos às composições originais foi capaz de permitir curvaturas no material, induzindo a auto organização do sistema na morfologia pretendida. 
Foi atribuído ao elevado número de coordenação do európio o papel de acomodar ligações adicionais, alterando os ângulos das ligações dos hidróxidos lamelares e permitindo a cristalização de camadas curvas.

Para definir o ambiente químico do európio nas amostras ZnAlEux\%-BTC-P123, nosso grupo submeteu os materiais a espectroscopia de absorção de raios X. As medidas foram realizadas por mim e por colegas do LNA no Laboratório Nacional de Luz Síncrotron do Centro Nacional de Pesquisa em Energia e Materiais (LNLS-CNPEM), e posteriormente analisadas pelo Dr. Alysson F. Morais. Detalhes sobre os procedimentos experimentais e modelos utilizados bem como os resultados completos obtidos podem ser visualizados na referência [38. Para todas as concentrações testadas, o európio apresentou estado de oxidação $\mathrm{Eu}^{3+}$ e número de coordenação compatível com 8, sendo a primeira esfera de coordenação ocupada por oxigênios, com comprimento da ligação $R \approx 2.42 \AA$ (Tabela 7 ). [38] Os oxigênios coordenados fazem parte, principalmente, das hidroxilas que compõem as camadas do material, mas podem ter origem também em moléculas de água ou nos ânions intercalados.

Tabela 7 - Ajuste da primeira esfera de coordenação para os dados de EXAFS da borda LIII do Eu nas amostras ZnAlEux\%-BTC-P123.

\begin{tabular}{cccc}
\hline Concentração & $\mathrm{N}$ & $\mathrm{R}(\AA)$ & $\sigma^{2}\left(\AA^{2}\right)$ \\
\hline \hline $15 \%$ & $7.96(14)$ & $2.4173(18)$ & $0.0120(4)$ \\
$10 \%$ & $8.33(14)$ & $2.4196(18)$ & $0.0114(4)$ \\
$5 \%$ & $8.0(3)$ & $2.419(3)$ & $0.0104(10)$ \\
$3 \%$ & $7.9(7)$ & $2.420(6)$ & $0.0098(21)$ \\
$1 \%$ & $8.0(10)$ & $2.423(10)$ & $0.010(3)$ \\
$0.5 \%$ & $7.9(11)$ & $2.420(10)$ & $0.010(3)$ \\
\hline
\end{tabular}

O número de coordenação e comprimento das ligações obtidos são similares aos relatados para um dos sítios ocupado pelo európio em seu hidróxido puro lamelar $\mathrm{Eu}_{2}(\mathrm{OH})_{5} \mathrm{~A}_{1 / n}^{n-} \cdot n \mathrm{H}_{2} \mathrm{O}$ (HEuL). 82 Nos hidróxidos lamelares de terras raras (HTRL), a existência de moléculas de água coordenadas com os metais é essencial para a estabilização da estrutura. 97. Devido à contração lantanídica, a primeira esfera de coordenação se torna cada vez mais preenchida se tentarmos manter uma mesma configuração ao longo da série dos terras raras. 98. Este efeito induz a redução de ocupação dos sítios onde deveriam ficar as moléculas de água coordenadas, diminuindo a estabilidade da estrutura. Por esta razão, o érbio é o menor terra rara capaz de cristalizar em camadas do tipo $\left\{\left[\mathrm{TR}_{2}(\mathrm{OH})_{5}\left(\mathrm{H}_{2} \mathrm{O}\right)_{2}\right]^{+}\right\}_{\infty}$. 
A Tabela 7 sumariza de forma qualitativa os resultados obtidos pela análise morfológica das amostras estudadas, de forma a facilitar comparações e discutir um panorama geral sobre o sistema. Similarmente ao que ocorre com a cristalização dos HTRLs, à medida que avançamos na série dos lantanídeos a ocorrência de nanotubos é reduzida. 99 Trata-se de um indício que uma possível redução na hidratação daqueles sítios ou, mais genericamente, na capacidade de coordenação do íon terra rara impede a cristalização dos hidróxidos lamelares em torno das micelas de P123.

Com exceção dos hidróxidos dopados de ítrio e praseodímio, o comportamento de cada amostra pode ser separado em grupos de acordo com o raio atômico do lantanídeo incorporado. Amostras ZnAlTRx\%-BTC-P123 sintetizadas com elementos cujos raios atômicos são maiores que o európio (La, Nd, Sm) apresentam formação de aglomerados de nanotubos quando inseridos em baixas concentrações $(\mathrm{x} \leq 5)$ no material. Devido à maior capacidade de coordenação desses elementos, pequenas dopagens são suficientes para flexibilizar a curvatura das lamelas, permitindo sua cristalização em cascas cilíndricas. Para concentrações maiores, há a formação de uma fase lamelar lateral, que inibe a auto organização das amostras ZnAlTR15\%-BTC-P123 em torno das micelas.

Quando dopados com baixa concentração de terras raras (x = 5\%), amostras ZnAlTRx\%BTC-P123 com elementos cujos raios atômicos são menores que o európio e maiores que o hólmio (Gd, Tb, Dy) apresentam morfologia de nanofolhas similar aos HDLs ZnAl-BTCP123, com a presença esparsa de nanotubos em algumas regiões. Com coordenação reduzida em relação ao európio, tais lantanídeos só induzem uma mudança maciça de morfologia quando incorporados em maior concentração. Para $\mathrm{x}=15 \%$ não há formação de fases laterais nas amostras com gadolínio, térbio e disprósio, e são visíveis aglomerados de nanotubos nas micrografias.

Os menores lantanídeos (Ho, Er, Tm, Yb e Lu), por sua vez, embora apresentem pontualmente estruturas cilíndricas em suas micrografias, não cristalizam com morfologia majoritariamente nanotubular para qualquer concentração testada de terra rara em substituição aos alumínios da estrutura.

As amostras ZnAlPrx\%-BTC-P123 e ZnAlYx\%-BTC-P123 apresentaram morfologias similares entre si, mas distintas dos terras raras que apresentam raio atômico próximo de cada um dos elementos. Embora possua para $\mathrm{NC}=8$ raio iônico entre o disprósio e o hólmio, [100 
Tabela 8 - Características das micrografias analisadas para amostras contendo diferentes íons terras raras e concentrações.

\begin{tabular}{|c|c|c|c|c|c|}
\hline $\mathrm{TRx} \%$ & $3 \%$ & $5 \%$ & $15 \%$ & $20 \%$ & $30 \%$ \\
\hline $\mathrm{Y}$ & - & $\begin{array}{c}\text { Nanofolhas, } \\
\text { enrolamentos e } \\
\text { poucos nanotubos }\end{array}$ & $\begin{array}{c}\text { Nanofolhas, } \\
\text { enrolamentos e } \\
\text { poucos nanotubos }\end{array}$ & - & - \\
\hline $\mathrm{La}$ & Nanotubos & Nanotubos & Nanofolhas & - & - \\
\hline $\mathrm{Pr}$ & - & $\begin{array}{c}\text { Nanofolhas, } \\
\text { enrolamentos e } \\
\text { poucos nanotubos }\end{array}$ & $\begin{array}{c}\text { Nanofolhas, } \\
\text { enrolamentos e } \\
\text { poucos nanotubos }\end{array}$ & - & - \\
\hline $\mathrm{Nd}$ & - & Nanotubos & Nanofolhas & - & - \\
\hline $\mathrm{Sm}$ & - & Nanotubos & Nanofolhas & - & - \\
\hline $\mathrm{Eu}$ & $\begin{array}{c}\text { Nanofolhas e } \\
\text { nanotubos }\end{array}$ & Nanotubos & Nanotubos & - & - \\
\hline $\mathrm{Gd}$ & - & $\begin{array}{c}\text { Nanofolhas e } \\
\text { nanotubos }\end{array}$ & Nanotubos & - & - \\
\hline $\mathrm{Tb}$ & - & $\begin{array}{c}\text { Nanofolhas e } \\
\text { nanotubos }\end{array}$ & Nanotubos & - & - \\
\hline Dy & - & Nanofolhas & Nanotubos & $\begin{array}{l}\text { Nanofolhas, } \\
\text { agulhas } \\
\text { (complexo) }\end{array}$ & - \\
\hline Ho & - & Nanofolhas & $\begin{array}{l}\text { Estruturas similares a } \\
\text { nanotubos em meio a } \\
\text { morfologia indefinida }\end{array}$ & - & - \\
\hline Er & - & Nanofolhas & $\begin{array}{l}\text { Estruturas similares a } \\
\text { nanotubos em meio a } \\
\text { morfologia indefinida }\end{array}$ & - & - \\
\hline $\mathrm{Tm}$ & - & Nanofolhas & $\begin{array}{l}\text { Estruturas similares a } \\
\text { nanotubos em meio a } \\
\text { morfologia indefinida }\end{array}$ & - & $\begin{array}{c}\text { Estruturas similares } \\
\text { a nanotubos, com } \\
\text { predominância de } \\
\text { nanofolhas }\end{array}$ \\
\hline $\mathrm{Yb}$ & - & Nanofolhas & $\begin{array}{l}\text { Estruturas similares a } \\
\text { nanotubos em meio a } \\
\text { morfologia indefinida }\end{array}$ & - & - \\
\hline $\mathrm{Lu}$ & - & Nanofolhas & $\begin{array}{l}\text { Estruturas similares a } \\
\text { nanotubos em meio a } \\
\text { morfologia indefinida }\end{array}$ & - & - \\
\hline
\end{tabular}

ao contrário de ambos a substituição de $\mathrm{x}=5 \%$ de ítrio nas amostras permitiu o surgimento pontual de nanotubos nas micrografias. Na direção oposta, apesar de possuir grande raio iônico e apresentar números de coordenação elevados, o praseodímio não forma aglomerados de nanotubos em baixas concentrações, mas também não inibe o surgimento de nanotubos esparsos com a produção de fases laterais. A produção de aglomerados de nanotubos na amostra ZnAlY14Pr1\%-BTC-P123 mostra que a inclusão conjunta de ambos os terras raras é capaz de estabilizar a estrutura, possivelmente por desempenharem papeis complementares quanto a acomodação das ligações, permitindo a auto organização dos hidróxidos em cascas cilíndricas. 


\subsection{Propriedades espectroscópicas}

Além de seu papel na alteração da morfologia da amostra, a substituição do metal trivalente por terras raras produz materiais luminescentes, característica que amplia o campo de aplicações e também se mostra uma poderosa ferramenta para caracterização do ambiente químico dos íons metálicos. A Figura 48 ilustra as amostras ZnAlTR5\%-BTC-P123 quando expostas a radiação ultravioleta pelo feixe do fluorímetro.
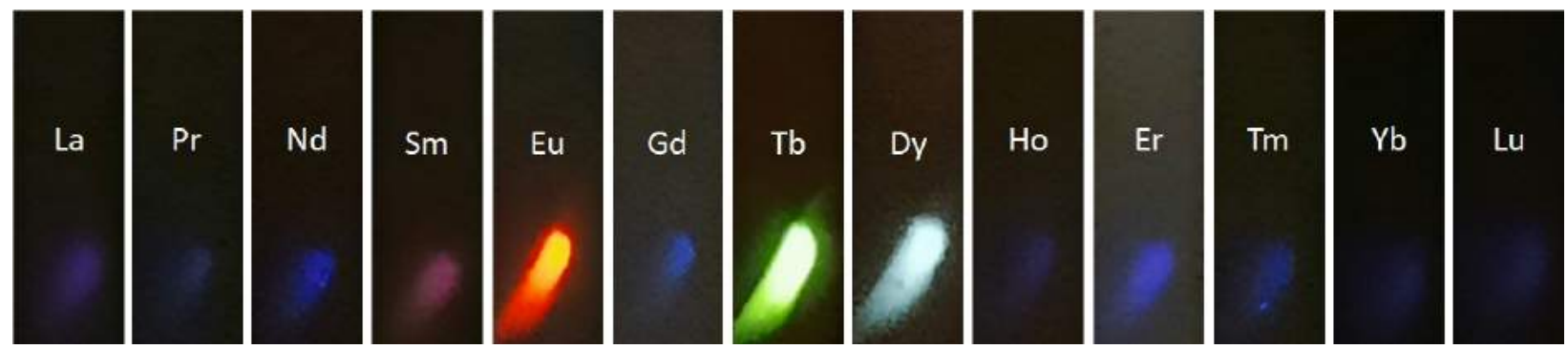

Figura 48 - Amostras $\mathrm{Zn}_{2} \mathrm{Al}_{0.95} \mathrm{TR}_{0.05}$-BTC-P123 expostas a radiação ultravioleta (290 nm) pelo feixe do fluorímetro.

As emissões dos materiais contendo $\mathrm{Sm}^{3+}, \mathrm{Eu}^{3+}, \mathrm{Tb}^{3+}$ e $\mathrm{Dy}^{3+}$ são dominadas pelas transições intraconfiguracionais $4 \mathrm{f}-4 \mathrm{f}$ desses íons, enquanto as demais exibem uma coloração azulada devida aos processos de fluorescência e fosforescência do BTC, ocorridas numa larga região entre o ultravioleta e o azul. Para entender esses dois tipos de comportamento, é necessário discutir como se dá o processo de relaxamento do ligante e a transferência de energia para os lantanídeos, o que será feito na próxima seção. A análise espectroscópica dos íons $\mathrm{Sm}^{3+}, \mathrm{Eu}^{3+}, \mathrm{Tb}^{3+}$ e $\mathrm{Dy}^{3+}$ traz mais informações a respeito do ambiente químico desses metais e será realizada nas seções 6.5.3, 6.5.2, 6.5.4 e 6.5.5, respectivamente.

\subsubsection{BTC: fluorescência, fosforescência e o efeito antena}

Medidas dos espectros de excitação e emissão da amostra ZnAl-BTC-P123 foram realizadas para o estudo dos processos de fluorescência e fosforescência dos benzenocarboxilatos intercalados no material (Fig. 49). Monitorando a excitação no centro da banda de emissão $(\lambda=360 \mathrm{~nm}-\mathrm{UV})$, vemos que a molécula absorve na região do ultravioleta para fluorescer emitindo fótons na região entre 330 e $400 \mathrm{~nm}$. A pequena emissão observada para comprimentos de onda acima de $400 \mathrm{~nm}$ é devida ao processo de fosforescência. 93 

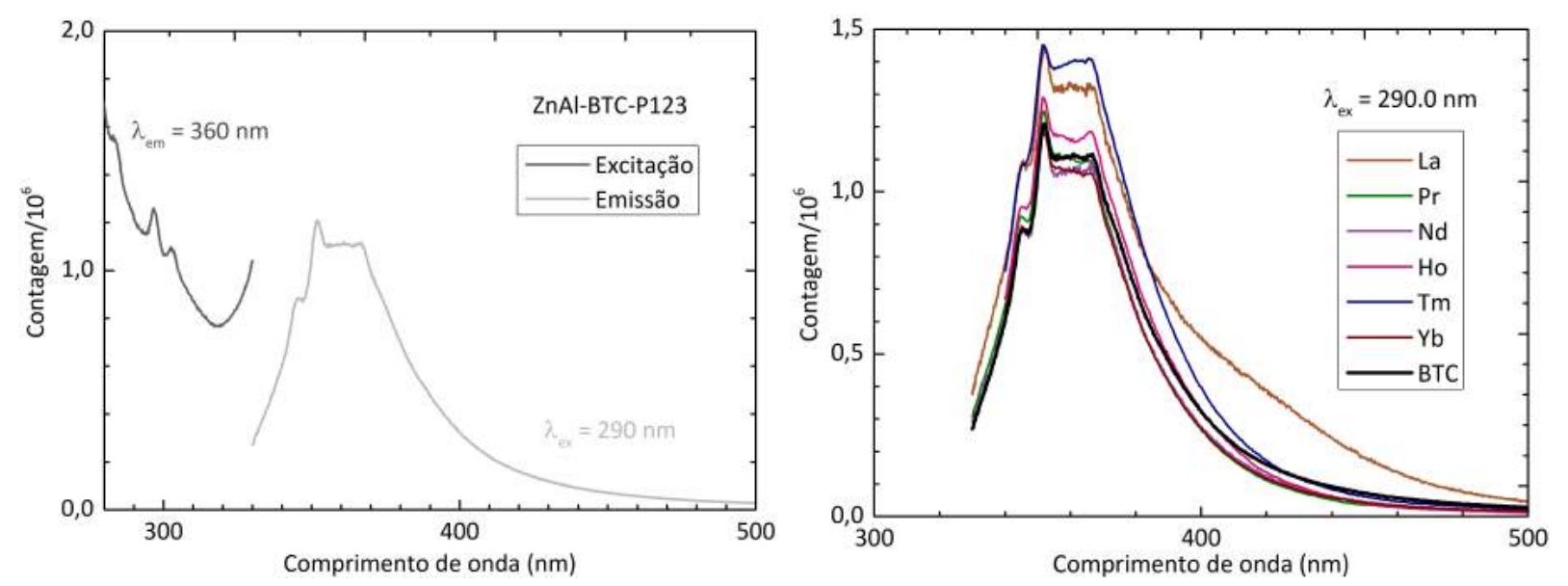

Figura 49 - (esq.) Espectros de excitação e emissão da amostra ZnAl-BTC-P123. (dir.) Emissão das amostras ZnAlTR5\%-BTC-P123.

O gráfico da direita na Figura 49 mostra a emissão dos materiais ZnAlTR5\%-BTC-P123 $(\mathrm{TR}=\mathrm{La}, \mathrm{Pr}, \mathrm{Nd}, \mathrm{Ho}, \mathrm{Tm}, \mathrm{Yb})$ quando excitados em $\lambda_{e x}=290 \mathrm{~nm}$. O espectro dessas amostras é dominado pela fluorescência e fosforescência do BTC, ao invés de apresentar as linhas finas de transição típicas dos íons terras raras. Os materiais dopados possuem esse comportamento por duas razões: 1) a inexistência de uma rota eficiente para transferência de energia do ligante para o íon terra rara; ou 2) a completa dispersão da energia de forma não radiativa devido à presença de hidroxilas no ambiente químico dos terras raras.

Os íons $\mathrm{Y}^{3+}$ e $\mathrm{La}^{3+}$ possuem distribuições $\mathrm{f}^{0}$, isto é, suas camadas com $\ell=3$ mais externas estão vazias, enquanto o $\mathrm{Lu}^{3+}$ possui a camada completamente preenchida $4 \mathrm{f}^{14}$. Para ambos os casos, apenas uma configuração é possível, não havendo estados excitados para uma eventual captação de energia do ligante. O espectro de emissão da amostra ZnAlLa5\%BTC-P123, ilustrado no gráfico da Figura 49(dir.), mostra uma banda de emissão atribuída ao BTC e similar àquela observada na ausência de terras raras.

Por razões distintas, os íons $\mathrm{Ce}^{3+}, \mathrm{Gd}^{3+}$ e $\mathrm{Yb}^{3+}$ também não fornecem rotas eficientes para transferência de energia do BTC para o lantanídeo, como pode ser observado no diagrama da Figura 50. Cério e itérbio possuem seus únicos estados excitados com energias da ordem de $10^{4} \mathrm{~cm}^{-1}$ ou inferior, muito abaixo da base do estado tripleto $\mathrm{T}_{1}\left({ }^{3} \pi^{*}\right)$ do BTC, inviabilizando a transferência. O gadolínio, por sua vez, possui um largo gap de $32200 \mathrm{~cm}^{-1}$, 101] de forma que seu primeiro estado excitado $\left(\mathrm{Gd}^{3+}\right)^{6} \mathrm{P}_{7 / 2}$ se posiciona muito acima da energia do tipleto, localizada entre 18000 e $24000 \mathrm{~cm}^{-1}$. Ainda que seja possível 


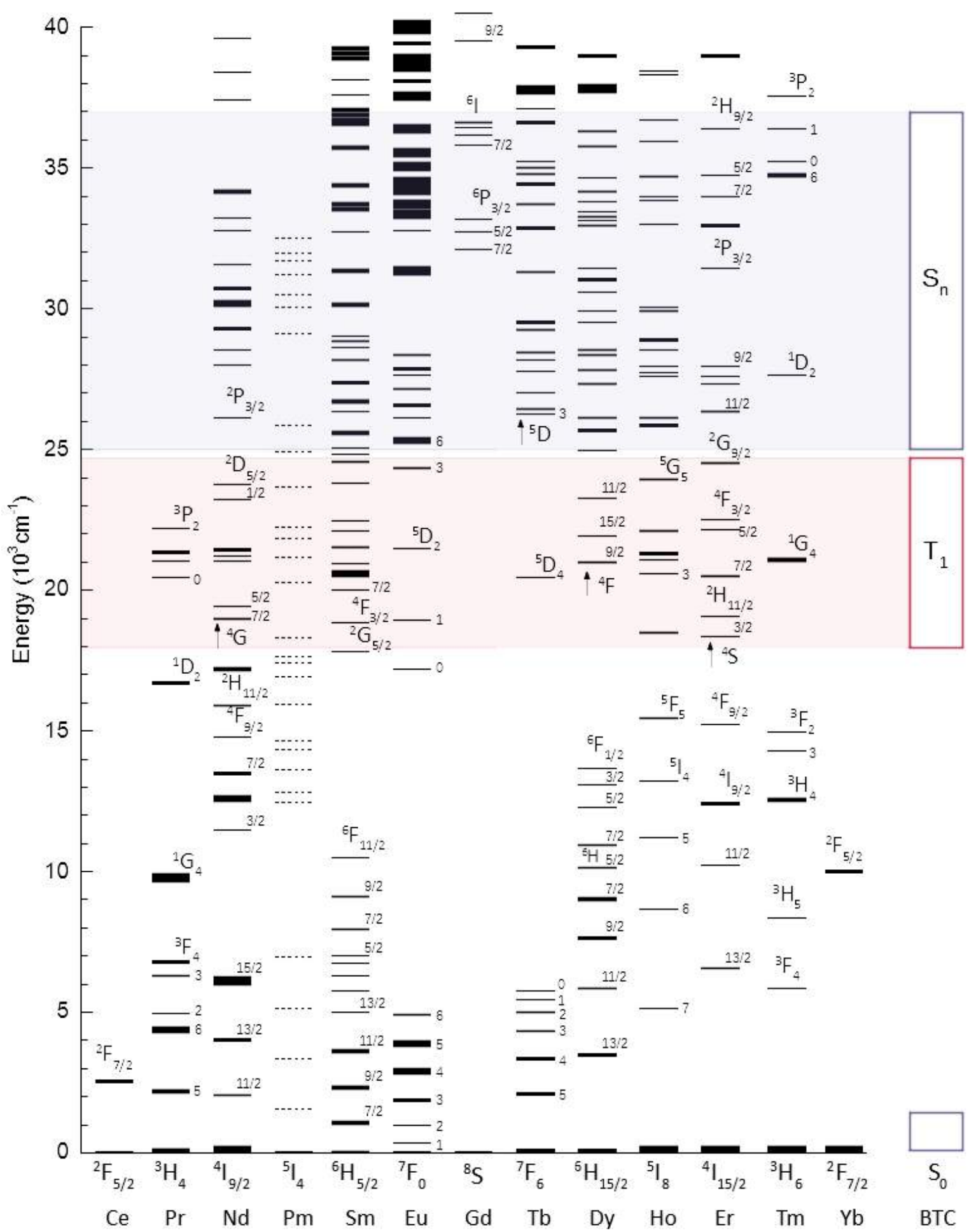

Figura 50 - BTC e Diagrama de Dieke (adaptado de [62]): níveis de energia dos íons lantanídeos $\mathrm{Ln}^{3+}$ ao lado dos níveis moleculares do ligante.

para este íon receber energia dos estados singletos $\mathrm{S}_{n}$ do BTC, trata-se de uma rota menos eficiente, visto que o tempo de vida deste estado é muito menor que do tripleto e os processos 
de fluorescência e cruzamento entre sistemas competem com a transferência ligante-metal como vias de relaxamento da molécula. Eventual transferência ligante-metal bem sucedida resultaria nas emissões características do gadolínio ${ }^{6} \mathrm{P}_{J / 2} \rightarrow{ }^{8} \mathrm{~S}(\mathrm{~J}=3,5$ ou 7$)$ na região do ultravioleta, entre 290 e $310 \mathrm{~nm}$.

No caso dos íons $\mathrm{Pr}^{3+}, \mathrm{Nd}^{3+}, \mathrm{Ho}^{3+}, \mathrm{Er}^{3+}$ e $\mathrm{Tm}^{3+}$, com 2, 3, 10, 11 e 12 elétrons na camada 4f, respectivamente, haveria a princípio níveis candidatos a receber energia numa rota ligante-lantanídeo. O que se observa em seus espectros de emissão, porém, é a ausência das transições finas características desses íons nos limites de detecção do fluorímetro e a presença da banda de fluorescência/fosforescência do BTC (Fig. 49). Esse resultado é atribuído a existência de gaps estreitos entre seus níveis 4f, o que favorece tanto a emissão de fótons na região do infravermelho $(\lambda>850 \mathrm{~nm})$ quanto a extinção da fotoluminescência pela vibração dos osciladores $\mathrm{O}-\mathrm{H}$ presentes nas lamelas, processo conhecido como quenching.

\subsubsection{Európio}

Quando expostas a radiação ultravioleta, as amostras contendo európio apresentam emissão avermelhada, característica de sua transição intraconfiguracional hipersensível. A Figura 51 apresenta em escala logarítmica o espectro de emissão a temperatura ambiente de nanotubos de hidróxidos lamelares com európio, onde são identificados dois níveis emissores no sistema: ${ }^{5} \mathrm{D}_{1}$ e ${ }^{5} \mathrm{D}_{0}$. As transições ${ }^{5} \mathrm{D}_{1} \rightarrow{ }^{7} \mathrm{~F}_{J=0,1,2}$ são observadas na região entre 520 e 570 $\mathrm{nm}$, enquanto aquelas com $\mathrm{J} \geq 3$ se sobrepõem às transições ${ }^{5} \mathrm{D}_{0} \rightarrow{ }^{7} \mathrm{~F}_{J}$ observadas entre 570 e $850 \mathrm{~nm}$.

Transições provenientes dos estados excitados ${ }^{5} \mathrm{D}_{1}$ são mais frequentemente observadas em matrizes inorgânicas medidas a baixas temperaturas. 102 Embora tais transições figurem no espectro da amostra ZnAlEu5\%-BTC-P123, a existência de modos vibracionais à temperatura ambiente e a reabsorção de fótons em grandes concentrações de európio favorecem a extinção desses estados por vias não radiativas. Como consequência, o número de fótons originados dos níveis ${ }^{5} \mathrm{D}_{1}$ é cerca de 200 vezes menor que o observado para os níveis ${ }^{5} \mathrm{D}_{0}$, podendo ser desprezado nas análises quantitativas posteriores. Devido ao aumento da concentração de európio, transições provenientes dos estados excitados ${ }^{5} \mathrm{D}_{1}$ não são observadas na amostra ZnAlEu15\%-BTC-P123.

Os espectros de excitação e emissão da amostra ZnAlEu5\%-BTC-P123 estão ilustrados 


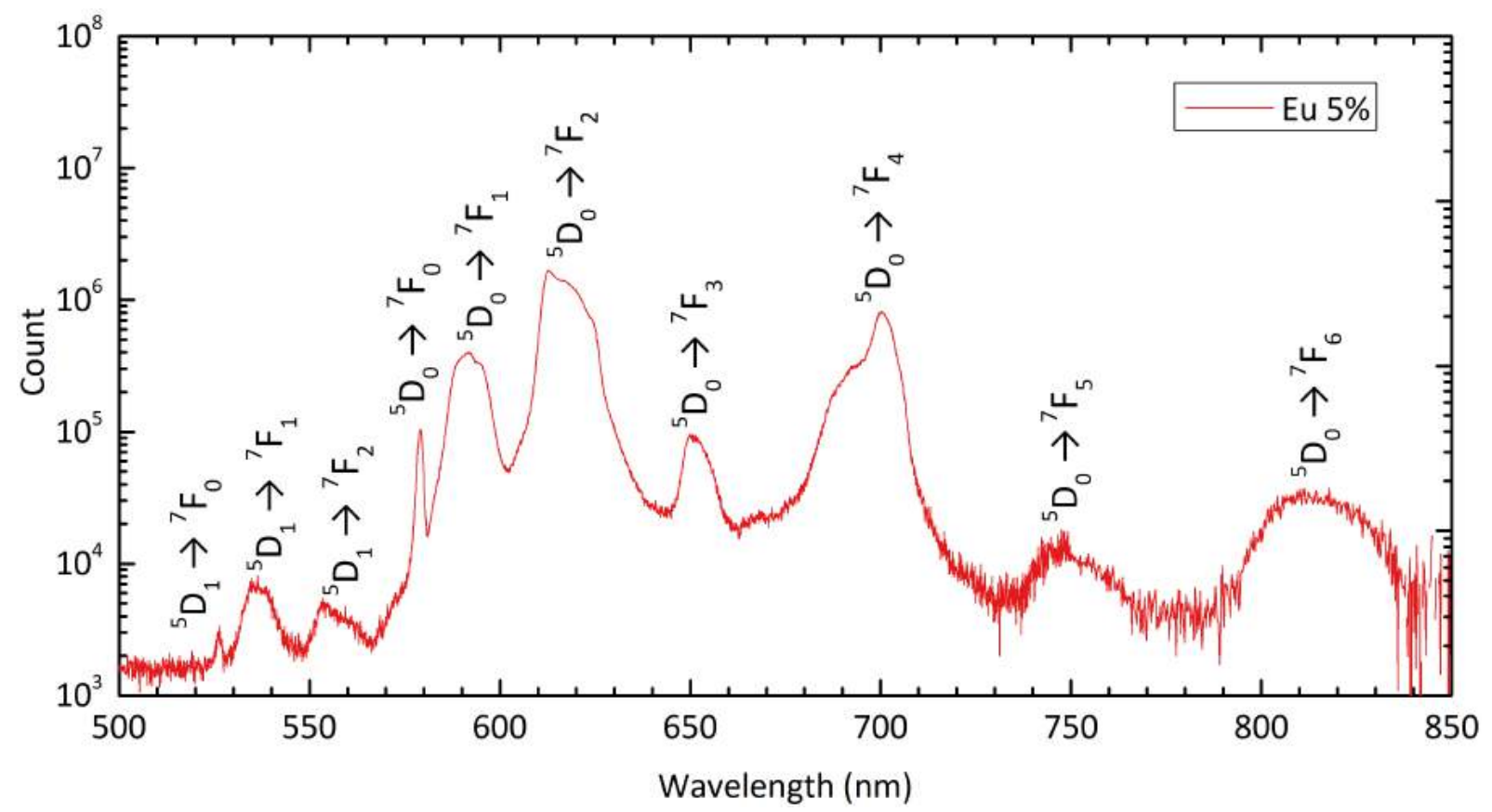

Figura 51 - Espectro de emissão do $\mathrm{Eu}^{3+}$ na amostra ZnAlEu5\%-BTC-P123 em escala logarítmica. Excitação em $\lambda=290 \mathrm{~nm}$.

na Figura 52. A excitação do material, monitorada na transição $\left(\mathrm{Eu}^{3+}\right)^{5} \mathrm{D}_{0} \rightarrow{ }^{7} \mathrm{~F}_{2}$, é dominada pela banda de absorção singleto-singleto $\mathrm{S}_{0}(\pi) \rightarrow \mathrm{S}_{n}\left({ }^{1} \pi^{*}\right)$ do BTC, demonstrando uma eficiente transferência de energia ligante-lantanídeo neste material. As excitações diretas do íon $\mathrm{Eu}^{3+}$ partindo do estado fundamental ${ }^{7} \mathrm{~F}_{0}$ para os níveis excitados (centro em $\mathrm{cm}^{-1}$ ) ${ }^{5} \mathrm{~L}_{6}$ (25381) e ${ }^{5} \mathrm{D}_{2}$ (21526) também estão presentes no espectro, embora menos intensas.

As transições características $\left(\mathrm{Eu}^{3+}\right)^{5} \mathrm{D}_{0} \rightarrow{ }^{7} \mathrm{~F}_{0-6}$ são observadas no espectro de emissão do material, seus centros e respectivas radiâncias estão relacionadas na Tabela 9 . Por ter como nível emissor uma configuração com $\mathrm{J}=0$, pelas regras de seleção de Judd Ofelt apenas transições para os níveis ${ }^{7} \mathrm{~F}_{2},{ }^{7} \mathrm{~F}_{4}$ e ${ }^{7} \mathrm{~F}_{6}$ são permitidas por dipolo elétrico. A transição ${ }^{5} \mathrm{D}_{0}$ $\rightarrow{ }^{7} \mathrm{~F}_{1}$ é puramente magnética, possuindo taxa de emissão espontânea $\mathrm{A}_{M D}=14.37 \mathrm{~s}^{-1}$ calculada na literatura. 67

A presença da transição para o nível ${ }^{7} \mathrm{~F}_{0}$, a princípio proibida tanto por dipolo elétrico quanto magnético, pode indicar a existência de correções de terceira ordem relevantes, a mistura de níveis com diferentes valores de $\mathrm{J}$ na correção dos termos espectroscópicos ou ainda a mistura de estados de transferência de carga com o estado fundamental. A primeira hipótese tem se mostrado pouco viável, visto que possíveis valores de radiância resultantes de transições por correções de terceira ordem teriam intensidades muito inferiores àquelas 

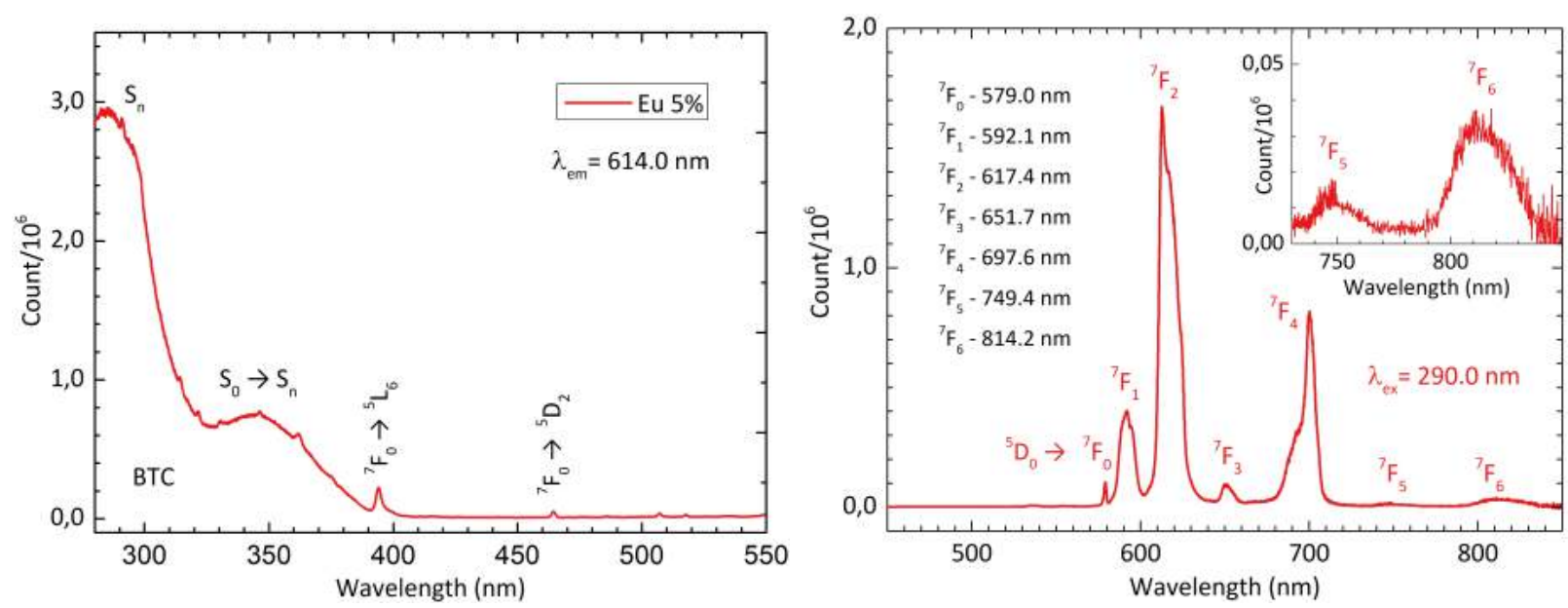

Figura $52-\mathrm{Zn}_{2} \mathrm{Al}_{0.95} \mathrm{Eu}_{0.05}$-BTC-P123 - No gráfico da esquerda, o espectro de excitação é dominado pela banda de absorção $\mathrm{S}_{0} \rightarrow \mathrm{S}_{n}$ do BTC, mas também apresenta as excitações diretas do íon $\mathrm{Eu}^{3+}$ partindo do estado fundamental ${ }^{7} \mathrm{~F}_{0}$ para os níveis excitados (centro em $\mathrm{cm}^{-1}$ ): ${ }^{5} \mathrm{~L}_{6}$ (25381) e ${ }^{5} \mathrm{D}_{2}$ (21526). À direita, o espectro de emissão apresenta todas as transições para os estados ${ }^{7} \mathrm{~F}_{J}$ partindo do emissor ${ }^{5} \mathrm{D}_{0}$.

Tabela 9 - Transições ${ }^{5} \mathrm{D}_{0} \rightarrow{ }^{7} \mathrm{~F}_{J}$ do íon $\mathrm{Eu}^{3+}$ na amostra $\mathrm{Zn}_{2} \mathrm{Al}_{0.95} \mathrm{Eu}_{0.05}$-BTC-P123: radiância de cada transição $\mathrm{I}_{J}$ em \%, centroide $\lambda$ em nanômetros e largura a meia altura (FWHM) em nanômetros.

\begin{tabular}{cccc}
\hline $\mathrm{J}$ & $\mathrm{I}_{J}$ & $\lambda$ & $\mathrm{FWHM}$ \\
\hline 0 & $0.707 \pm 0.028$ & $578.79 \pm 0.07$ & 2.02 \\
1 & $12.72 \pm 0.18$ & $591.86 \pm 0.06$ & 10.02 \\
2 & $58.4 \pm 0.9$ & $617.28 \pm 0.09$ & 12.03 \\
3 & $2.17 \pm 0.13$ & $651.79 \pm 0.20$ & 8.02 \\
4 & $23.7 \pm 0.4$ & $697.23 \pm 0.21$ & 7.51 \\
5 & $0.505 \pm 0.026$ & $750.24 \pm 0.27$ & 4.48 \\
6 & $1.93 \pm 0.03$ & $814.19 \pm 0.09$ & 22.57 \\
\hline
\end{tabular}

medidas, não sendo suficientes para explicar as intensidades observadas. A presença de transição para o níveis ${ }^{7} \mathrm{~F}_{3}$ e ${ }^{7} \mathrm{~F}_{5}$, por sua vez, só pode ser devida a mistura de Js, sugerindo este efeito no espectro medido.

Em particular, a observação da transição ${ }^{5} \mathrm{D}_{0} \rightarrow{ }^{7} \mathrm{~F}_{0}$ é uma indicação que o íon $\mathrm{Eu}^{3+}$ ocupa um sítio com simetria $\mathrm{C}_{n v}, \mathrm{C}_{n}$ ou $\mathrm{C}_{s}$, devido a simetria de estados com $\mathrm{J}=0$. 103 $\mathrm{Na}$ amostra $\mathrm{Zn}_{2} \mathrm{Al}_{0.95} \mathrm{Eu}_{0.05}$-BTC-P123, a largura a meia altura desta transição é de $48.0 \mathrm{~cm}^{-1}$, a menor observada em todo o espectro. Por não possuir subníveis, o alargamento desta linha diz respeito a dois mecanismos: o primeiro deles é de origem térmica, onde o alargamento 
é originado em níveis vibracionais do sistema, e o outro é devido a pequenas diferenças no ambiente químico, como um ligeiro desvio na distância entre metal e ligante ou outro tipo de desordem.

Como $\mathrm{D}_{0} \rightarrow{ }^{7} \mathrm{~F}_{2}$ e $\mathrm{D}_{0} \rightarrow{ }^{7} \mathrm{~F}_{4}$ são mais intensas que o padrão $\mathrm{D}_{0} \rightarrow{ }^{7} \mathrm{~F}_{1}$ (respectivamente 4.7 e 1.9 vezes), é mais provável que $\mathrm{Eu}^{3+}$ esteja localizado em um ambiente químico não centrossimétrico. 66

Para as emissões ${ }^{5} \mathrm{D}_{0} \rightarrow{ }^{7} \mathrm{~F}_{J}$, os termos de matriz reduzida $\mathrm{U}_{\lambda}^{2}$ podem ser escritos na base dos autoestados do Európio como relacionado na Tabela 10. As regras de seleção de Judd-Ofelt para um nível emissor $\mathrm{J}=0$ indicam que transições por dipolo elétrico ocorrem apenas para estados com $\mathrm{J}=2$, 4 ou 6 . A transição ${ }^{5} \mathrm{D}_{0} \rightarrow{ }^{7} \mathrm{~F}_{1}$, por sua vez, é puramente magnética.

Tabela 10 - Termos de matriz reduzida $\mathrm{U}_{\lambda}^{2}[64$ e taxas de emissão espontânea por dipolo magnético $\mathrm{A}_{M D} \mathrm{em} \mathrm{s}^{-1}, 67$, para as transições ${ }^{5} \mathrm{D}_{0} \rightarrow{ }^{7} \mathrm{~F}_{J}$ do íon $\mathrm{Eu}^{3+}$.

\begin{tabular}{ccccc}
\hline $\mathrm{J}$ & $\mathrm{U}_{2}^{2}$ & $\mathrm{U}_{4}^{2}$ & $\mathrm{U}_{6}^{2}$ & $\mathrm{~A}_{M D}$ \\
\hline 0 & 0 & 0 & 0 & 0 \\
1 & 0 & 0 & 0 & 14.37 \\
2 & 0.0032 & 0 & 0 & 0 \\
3 & 0 & 0 & 0 & 0 \\
4 & 0 & 0.0023 & 0 & 0 \\
5 & 0 & 0 & 0 & 0 \\
6 & 0 & 0 & 0.0002 & 0 \\
\hline
\end{tabular}

A equação 3.45 se resume para a transição ${ }^{5} \mathrm{D}_{0} \rightarrow{ }^{7} \mathrm{~F}_{1} \mathrm{em}$

$$
A_{1}=\chi_{M D}^{e m} A_{M D}=\delta \frac{4 \pi \bar{\lambda}_{1}}{h c} I_{1}
$$

A partir desta relação, podemos estimar $\delta$ conhecendo os valores experimentais do centroide $\bar{\lambda}$ da linha de emissão e sua radiância I. Substituindo os termos de matriz reduzida, as equações 3.42 são desacopladas, de modo que as transições ${ }^{5} \mathrm{D}_{0} \rightarrow{ }^{7} \mathrm{~F}_{2},{ }^{5} \mathrm{D}_{0} \rightarrow{ }^{7} \mathrm{~F}_{4}$ e ${ }^{5} \mathrm{D}_{0} \rightarrow{ }^{7} \mathrm{~F}_{6}$ determinam de forma independente os respectivos valores $\Omega_{2}, \Omega_{4}$ e $\Omega_{6}$ :

$$
A_{n}=\chi_{E D}^{e m} A_{E D}^{(n)}=\frac{16 \pi^{3} e^{2}}{3 \varepsilon_{0} h \bar{\lambda}_{n}^{3}} \chi_{E D}^{e m} \Omega_{n} U_{n}^{2}=\delta \frac{4 \pi \lambda}{h c} I_{n}, n=2,4,6
$$

Os parâmetros fenomenológicos de Judd Ofelt foram calculados a partir de 6.5 e 6.6 
para as amostras ZnAlEux\%-BTC-P123 e ZnAlEux\%-NO 3 e os resultados obtidos são descritos na Tabela 11, em comparação com o complexo YBTC:Eu e outros materiais descritos na literatura. Os valores obtidos mostram que há uma alteração no ambiente químico dos íons $\mathrm{Eu}^{3+}$ quando os nitratos intercalados entre as camadas de hidróxidos são substituídos por trimesatos, com o aumento sistemático de todos os parâmetros $\Omega_{\gamma}$.

Tabela 11 - Parâmetros fenomenológicos de Judd Ofelt do íon $\mathrm{Eu}^{3+}$ em diversas matrizes.

\begin{tabular}{|c|c|c|c|}
\hline Matriz & $\Omega_{2}$ & $\Omega_{4}$ & $\Omega_{6}$ \\
\hline 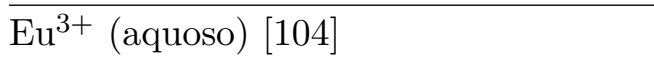 & 1.62 & 5.65 & 5.02 \\
\hline $\mathrm{LaF}_{3}: \mathrm{Eu}^{3+}$ (cristal) 105 & 1.19 & 1.16 & 0.39 \\
\hline YBTC:Eu & $3.21 \pm 0.06$ & $3.50 \pm 0.17$ & $1.14 \pm 0.07$ \\
\hline $\mathrm{ZnAlEu} 5 \%-\mathrm{NO}_{3}$ & $5.03 \pm 0.12$ & $5.56 \pm 0.28$ & $8.05 \pm 0.11$ \\
\hline $\mathrm{ZnAlEu} 15 \%-\mathrm{NO}_{3}$ & $5.62 \pm 0.13$ & $6.2 \pm 0.3$ & $12.31 \pm 0.15$ \\
\hline ZnAlEu5\%-BTC-P123 (exc. 394 nm) & $8.45 \pm 0.20$ & $7.5 \pm 0.5$ & $15.36 \pm 0.19$ \\
\hline ZnAlEu5\%-BTC-P123 (exc. 290 nm) & $7.83 \pm 0.19$ & $7.2 \pm 0.4$ & $12.53 \pm 0.21$ \\
\hline ZnAlEu15\%-BTC-P123 (exc. 394 nm) & $7.67 \pm 0.16$ & $7.0 \pm 0.4$ & $10.80 \pm 0.19$ \\
\hline ZnAlEu15\%-BTC-P123 (exc. $290 \mathrm{~nm}$ ) & $8.41 \pm 0.19$ & $7.1 \pm 0.5$ & $12.37 \pm 0.22$ \\
\hline
\end{tabular}

Este resultado sugere que o BTC induz uma diminuição geral da simetria em torno do európio, alterando os ângulos e comprimentos das ligações e relaxando suas regras de transição - fator que contribui para a luminescência do material. A concentração de európio, no entanto, não influenciou os valores dos parâmetros fenomenológicos calculados para as amostras ZnAlEux\%-BTC-P123, em consonância com as análises estruturais e morfológicas muito similares obtidas para $\mathrm{x}=5$ e $15 \%$.

Medidas do tempo de vida do estado emissor do európio foram realizadas para determinar, juntamente com os parâmetros fenomenológicos, a eficiência quântica do sistema. O ajuste do decaimento exponencial da emissão do estado em função do tempo está ilustrado na Figura 53 , enquanto os resultados de tempo de vida, taxas de transição (total, radiativa e não radiativa) e eficiência quântica obtidos para a amostra ZnAlEu5\%-BTC-P123 estão descritos na Tabela 12 .

Tabela 12 - Taxas de transição e eficiência quântica das amostras contendo európio.

\begin{tabular}{lccccc}
\hline Amostra & $\tau(\mu \mathrm{s})$ & $A\left(\mathrm{~s}^{-1}\right)$ & $A_{\text {rad }}\left(\mathrm{s}^{-1}\right)$ & $A_{n r}\left(\mathrm{~s}^{-1}\right)$ & $\eta(\%)$ \\
\hline ZnAlEu5\%-BTC-P123 & $290 \pm 12$ & 3448 & 397 & 3051 & $11.5 \pm 0.6$ \\
\hline
\end{tabular}




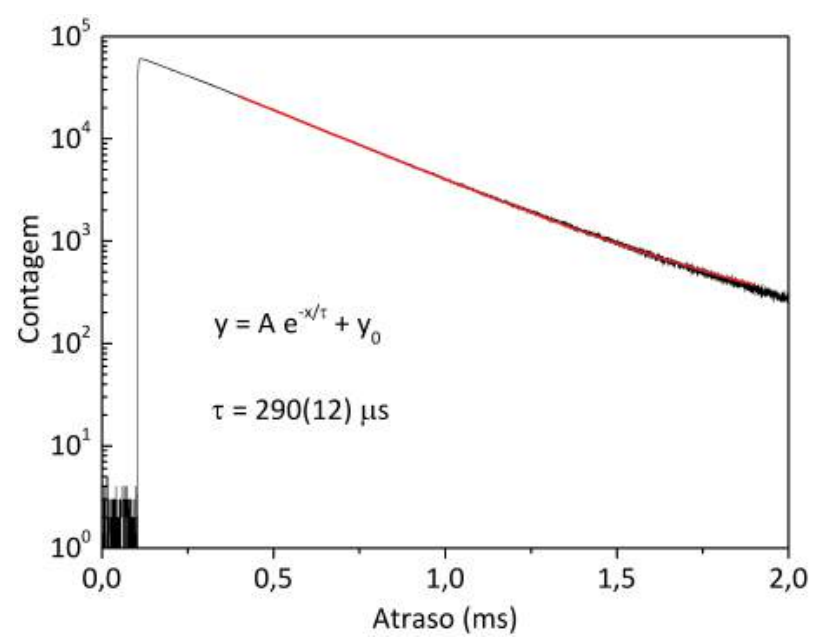

Figura 53 - Ajuste do tempo de vida do estado $\left(\mathrm{Eu}^{3+}\right)^{7} \mathrm{~F}_{0}$ (amostra ZnAlEu5\%-BTC-P123).

A partir da taxa de transição não radiativa apresentada pelo material, é possível estimar pela fórmula empírica de Supkowski e Horrocks o número de osciladores O-H na primeira esfera de coordenação do európio, 106, 107

$$
N_{O H}=2.22 \times\left[A_{n r}-310\right] / 1000
$$

onde $A_{n r}$ está em s${ }^{-1}$.

Obtivemos $N_{O H}=6.085$, coerente com a presença de seis hidroxilas coordenadas com o íon $\mathrm{Eu}^{3+}$. Levando em conta o número de coordenação $\mathrm{NC}=8$ obtido pela análise de absorção de raios X, o európio possui em sua primeira esfera mais dois oxigênios, provenientes dos ligantes BTC. A proximidade entre o BTC e o lantanídeo garante a transferência eficiente de energia pelo processo de Dexter, [108] resultando em materiais mais brilhantes se comparados às amostras $\mathrm{ZnAlEu} 5 \%-\mathrm{NO}_{3}$.

\subsubsection{Samário}

As amostras de hidróxidos lamelares contendo samário exibem emissão característica rosada quando excitadas em radiação UV. Assim como ocorre para o európio, a excitação do samário, monitorada na transição ${ }^{4} \mathrm{G}_{5 / 2} \rightarrow{ }^{6} \mathrm{H}_{7 / 2}$, é dominada pela banda de absorção singleto-singleto $\mathrm{S}_{0}(\pi) \rightarrow \mathrm{S}_{n}\left({ }^{1} \pi^{*}\right)$ do BTC, revelando uma eficiente transferência de energia do ligante para o íon $\mathrm{Sm}^{3+}$. Também estão presentes no espectro algumas linhas de absorção mais finas e menos intensas referentes a transições intraconfiguracionais $4 \mathrm{f}-4 \mathrm{f}$, partindo do 
estado fundamental $\left(\mathrm{Sm}^{3+}\right)^{6} \mathrm{H}_{5 / 2}$ para seus níveis excitados (baricentro em $\mathrm{cm}^{-1}$ ): ${ }^{4} \mathrm{H}_{9 / 2}$ (29041), ${ }^{4} \mathrm{D}_{3 / 2}(27620),{ }^{6} \mathrm{P}_{7 / 2}(26747),{ }^{6} \mathrm{P}_{3 / 2},{ }^{4} \mathrm{~L}_{13 / 2}$ (24876), ${ }^{6} \mathrm{P}_{5 / 2}(24001),{ }^{4} \mathrm{I}_{13 / 2}$ (21569).
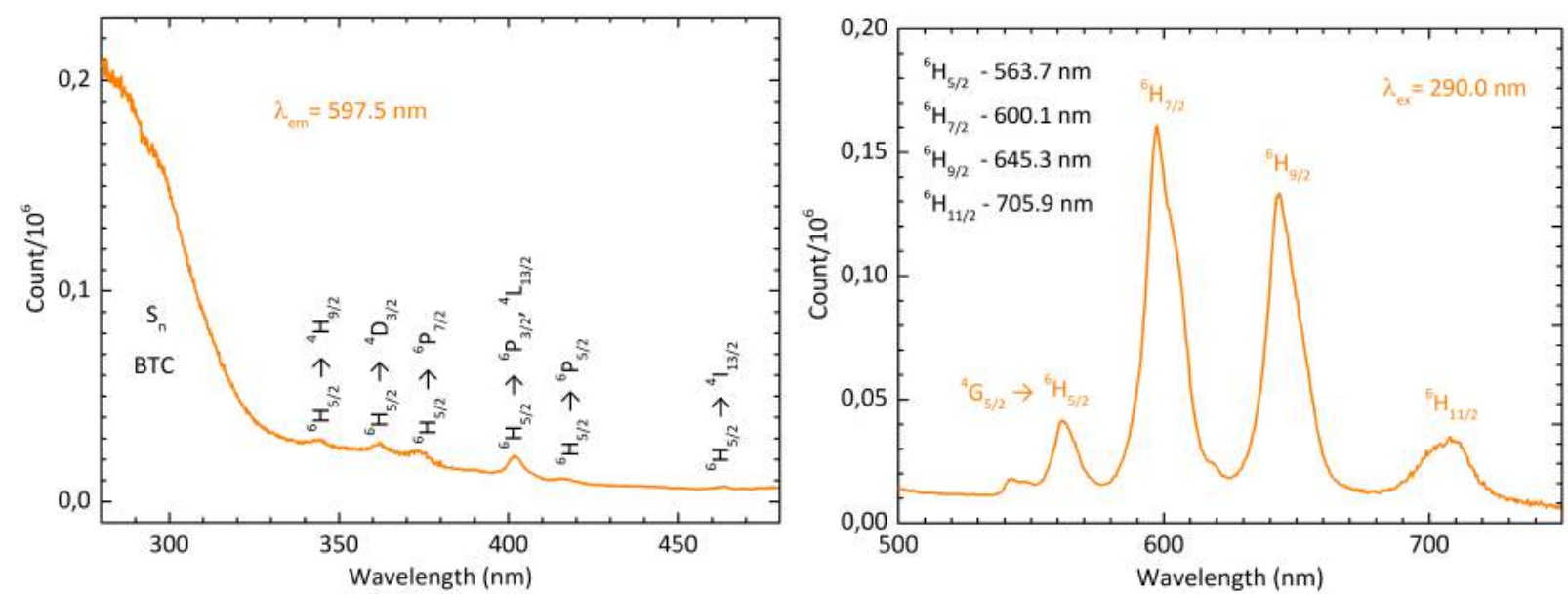

Figura 54 - ZnAlSm5\%-BTC-P123 - No gráfico da esquerda, o espectro de excitação é dominado pela banda de absorção $\mathrm{S}_{0} \rightarrow \mathrm{S}_{n}$ do BTC, mas também apresenta as excitações diretas do íon $\mathrm{Sm}^{3+}$ partindo do estado fundamental ${ }^{4} \mathrm{G}_{5 / 2}$ para os níveis excitados ${ }^{4} \mathrm{H}_{9 / 2},{ }^{4} \mathrm{D}_{3 / 2},{ }^{6} \mathrm{P}_{7 / 2},{ }^{6} \mathrm{P}_{3 / 2},{ }^{4} \mathrm{~L}_{13 / 2},{ }^{6} \mathrm{P}_{5 / 2},{ }^{4} \mathrm{I}_{13 / 2}$. À direita, o espectro de emissão apresenta as transições para os estados ${ }^{6} \mathrm{H}_{J / 2}(\mathrm{~J}=5,7,9$ ou 11) partindo do emissor ${ }^{4} G_{5 / 2}$.

Tabela 13 - Transições ${ }^{4} \mathrm{G}_{5 / 2} \rightarrow{ }^{6} \mathrm{H}_{J}$ do íon $\mathrm{Sm}^{3+}$ na amostra $\mathrm{Zn}_{2} \mathrm{Al}_{0.95} \mathrm{Sm}_{0.05}$-BTC-P123: radiância de cada transição $\mathrm{I}_{J}$ em $\%$, centroide $\lambda$ em nanômetros e largura a meia altura (FWHM) em nanômetros.

\begin{tabular}{cccc}
\hline $\mathrm{J}$ & $\mathrm{I}_{J}$ & $\lambda$ & $\mathrm{FWHM}$ \\
\hline $5 / 2$ & $7.8 \pm 0.4$ & $563.7 \pm 0.3$ & 15.08 \\
$7 / 2$ & $36.4 \pm 0.8$ & $601.0 \pm 0.4$ & 15.77 \\
$9 / 2$ & $26.5 \pm 0.8$ & $646.1 \pm 0.4$ & 15.99 \\
$11 / 2$ & $12.1 \pm 0.6$ & $705.5 \pm 1.0$ & 28.07 \\
\hline
\end{tabular}

As bandas de emissão do $\mathrm{Sm}^{3+}$ na região do espectro visível são devidas às transições do nível emissor ${ }^{2} \mathrm{G}_{5 / 2}$ para os receptores ${ }^{6} \mathrm{H}_{J / 2}(\mathrm{~J}=5,7,9$ ou 11). Os centros dos picos e suas respectivas radiâncias estão relacionados na Tabela 13 . Enquanto a transição mais fraca ${ }^{4} \mathrm{G}_{5 / 2} \rightarrow{ }^{6} \mathrm{H}_{5 / 2}$ é devida puramente a dipolo magnético, as demais são governadas por dipolo elétrico. A transição ${ }^{4} \mathrm{G}_{5 / 2} \rightarrow{ }^{6} \mathrm{H}_{9 / 2}$, conhecida como hipersensível, é a única a contribuir para o valor do parâmetro $\Omega_{2}$. 64 Sua intensidade diz respeito ao grau de simetria angular das ligações ao redor do samário: quanto mais intensa, maiores as deformações angulares e menor a simetria do sítio. Na amostra ZnAlSm5\%-BTC-P123 esta transição sequer apresenta 
a maior radiância entre as linhas do espectro, a despeito do que é comumente observado nas transições pseudo hipersensíveis dos lantanídeos, sugerindo a inexistência de deformações angulares significativas na geometria de coordenação.

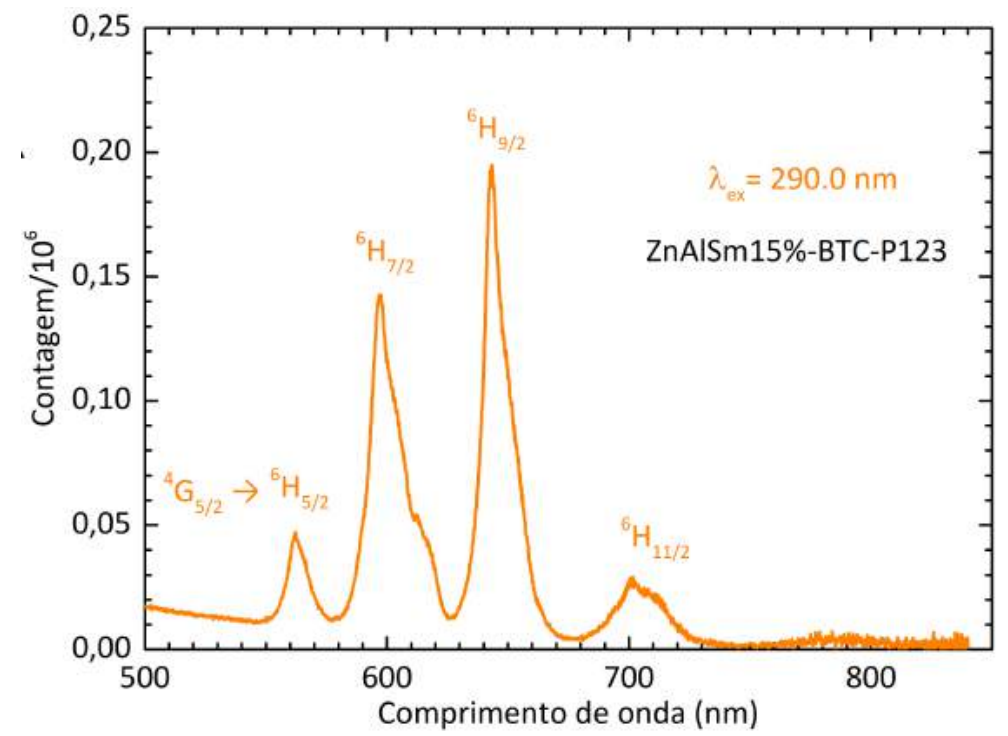

Figura 55 - ZnAlSm15\%-BTC-P123 - O espectro de emissão apresenta as transições para os estados ${ }^{6} \mathrm{H}_{J / 2}\left(\mathrm{~J}=5,7,9\right.$ ou 11) partindo do emissor ${ }^{4} \mathrm{G}_{5 / 2}$.

Ao contrário do que ocorre para amostras contendo európio, o perfil da emissão do material é alterado quando a concentração de samário é elevada (Fig. 55). A intensidade de transição hipersensível aumenta com relação ao padrão ${ }^{4} \mathrm{G}_{5 / 2} \rightarrow{ }^{6} \mathrm{H}_{5 / 2}$, indicando mudanças angulares na coordenação do sistema. Não é possível inferir com as análises realizadas até o momento se este efeito é devido à fase lateral observada nessas amostras ou se é resultado das mudanças estruturais que acarretam na cristalização das amostras com morfologia de nanotubos $(\mathrm{x}=5 \%)$ ou plana $(\mathrm{x}=15 \%)$.

Para as emissões ${ }^{4} \mathrm{G}_{5 / 2} \rightarrow{ }^{6} \mathrm{H}_{J}$, os termos de matriz reduzida $\mathrm{U}_{\lambda}^{2}$ podem ser escritos na base dos autoestados do Samário como relacionado na Tabela 14. Analogamente ao realizado para o Európio, a transição puramente magnética ${ }^{4} \mathrm{G}_{5 / 2} \rightarrow{ }^{6} \mathrm{H}_{5 / 2}$ pode ser utilizada como padrão para estimar o valor do coeficiente empírico $\delta$ :

$$
A_{5 / 2}=\chi_{M D}^{e m} A_{M D}=\delta \frac{4 \pi \bar{\lambda}_{5 / 2}}{h c} I_{5 / 2}
$$

Aplicando as equações (3.42 ao Samário, as linhas de emissão induzidas por dipolo 
Tabela 14 - Termos de matriz reduzida $\mathrm{U}_{\lambda}^{2} 64$ e taxas de emissão espontânea por dipolo magnético $\mathrm{A}_{M D}$ em s${ }^{-1}$, [67] para as transições ${ }^{4} \mathrm{G}_{5 / 2} \rightarrow{ }^{6} \mathrm{H}_{J}$ do íon $\mathrm{Sm}^{3+}$.

\begin{tabular}{ccccc}
\hline $\mathrm{J}$ & $\mathrm{U}_{2}^{2}$ & $\mathrm{U}_{4}^{2}$ & $\mathrm{U}_{6}^{2}$ & $\mathrm{~A}_{M D}$ \\
\hline $5 / 2$ & 0 & 0 & 0 & 3.63 \\
$7 / 2$ & 0 & 0.0078 & 0.0075 & 0 \\
$9 / 2$ & 0.0096 & 0.0061 & 0.0019 & 0 \\
$11 / 2$ & 0 & 0.0045 & 0.0018 & 0 \\
\hline
\end{tabular}

elétrico formam o sistema de equações

$$
\begin{aligned}
& S_{E D}^{\exp }(7 / 2)=U_{\frac{7}{2}, 2}^{2} \Omega_{2}+U_{\frac{7}{2}, 4}^{2} \Omega_{4}+U_{\frac{7}{2}, 6}^{2} \Omega_{6}, \\
& S_{E D}^{\exp }(9 / 2)=U_{\frac{9}{2}, 2}^{2} \Omega_{2}+U_{\frac{9}{2}, 4}^{2} \Omega_{4}+U_{\frac{9}{2}, 6}^{2} \Omega_{6}, \\
& S_{E D}^{e x p}(11 / 2)=U_{\frac{11}{2}, 2}^{2} \Omega_{2}+U_{\frac{11}{2}, 4}^{2} \Omega_{4}+U_{\frac{11}{2}, 6}^{2} \Omega_{6},
\end{aligned}
$$

onde

$$
A_{n}=\frac{8 \pi^{3} e^{2}}{9 \varepsilon_{0} h \bar{\lambda}_{n}^{3}} \chi_{E D}^{e m} S_{E D}^{e x p}(n)=\delta \frac{4 \pi \bar{\lambda}_{n}}{h c} I_{n} .
$$

Conhecido o coeficiente $\delta$, os valores das intensidades de transição de linha $\mathrm{S}_{E D}^{\exp }(\mathrm{n})$ são obtidos pela relação 6.10 a partir da radiância e do comprimento de onda de cada linha de emissão. Desta forma, as equações (6.9) determinam univocamente os parâmetros $\Omega_{2}, \Omega_{4}$ e $\Omega_{6}$ que descrevem o ambiente químico do Samário. A Tabela 15 apresenta os valores obtidos para as amostras ZnAlSmx\%-BTC-P123, em comparação a valores de referência presentes na literatura.

Tabela 15 - Parâmetros fenomenológicos de Judd Ofelt do íon $\mathrm{Sm}^{3+}$ em diversas matrizes.

\begin{tabular}{lccc}
\hline Matriz & $\Omega_{2}$ & $\Omega_{4}$ & $\Omega_{6}$ \\
\hline $\mathrm{Sm}^{3+}$ (aquoso) & $1.08 \pm 0.42$ & $3.67 \pm 0.70$ & $2.87 \pm 0.56$ \\
$\mathrm{LaF}_{3}: \mathrm{Sm}^{3+}$ (cristal) & 1.0 & 0.5 & 1.5 \\
$\mathrm{ZnAlSm} 5 \%-B T C-P 123$ & $0.4 \pm 0.6$ & $5.4 \pm 0.8$ & $-0.7 \pm 0.8$ \\
ZnAlSm15\%-BTC-P123 & $4.5 \pm 0.8$ & $2.4 \pm 1.0$ & $3.9 \pm 1.0$ \\
\hline
\end{tabular}

A alteração em $\Omega_{2}$ reflete a discussão realizada anteriormente acerca da simetria angular no sítio do íon $\mathrm{Sm}^{3+}$. O parâmetro $\Omega_{6}$, mais sensível a mudanças de polarizabilidade do sistema, sugere distorções maiores na amostra com maior concentração de samário. Os valores de $\Omega_{4}$ para ambas as concentrações são compatíveis entre si. Novamente, não é possível 
determinar se este efeito tem origem na fase lateral formada ou em mudanças estruturais nas camadas de hidróxidos. Para calcular a eficiência quântica do sistema, foram realizadas medidas do tempo de vida da amostra ZnAlSm5\%-BTC-P123 (Fig. 56). Os resultados são apresentados na Tabela 16 .

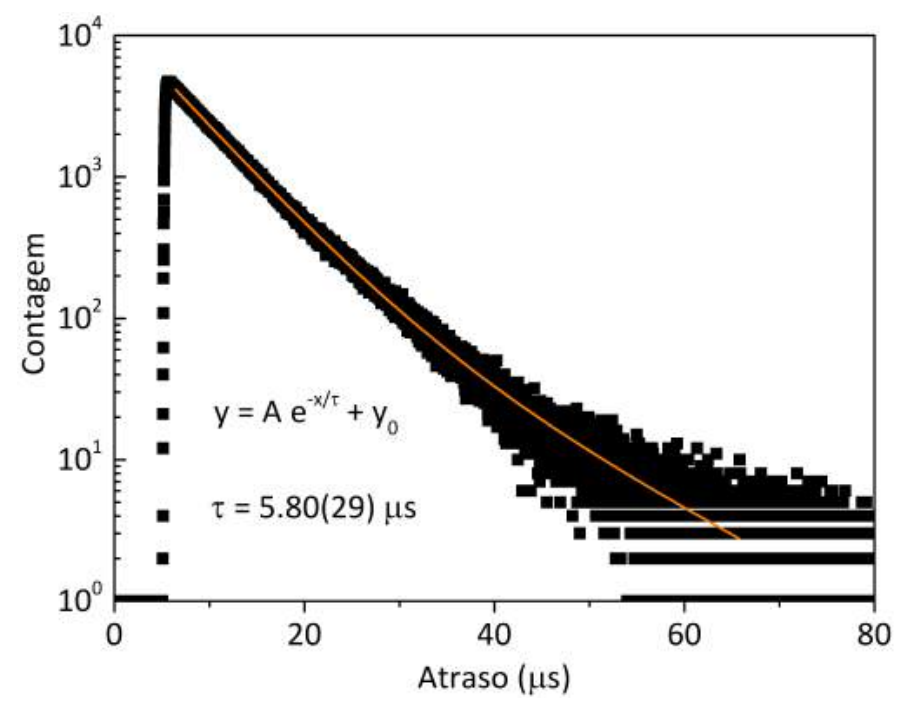

Figura 56 - Ajuste do tempo de vida do estado $\left(\mathrm{Sm}^{3+}\right)^{4} \mathrm{G}_{5 / 2}$ (ZnAlSm5\%-BTC-P123).

A baixa eficiência quântica observada na luminescência do samário, de $0.084 \pm 0.016 \%$, é coerente com o fraco brilho percebido quando a amostra é irradiada no ultravioleta. A existência de muitos estados ressonantes à banda $\mathrm{T}_{1}$ do BTC favorece a extinção dos níveis por vibrações dos osciladores O-H. Diferente do que ocorre com os íons $\mathrm{Nd}^{3+}, \mathrm{Ho}^{3+}$ e $\mathrm{Er}^{3+}$, que não apresentaram luminescência, o gap entre o estado emissor ${ }^{2} \mathrm{G}_{5 / 2}$ e os níveis menos excitados é relativamente alto $\left(7500 \mathrm{~cm}^{-1}\right)$, possibilitando que transições radiativas ocorram, ainda que de forma exígua.

Tabela 16 - Taxas de transição e eficiência quântica das amostras contendo samário.

\begin{tabular}{lccccc}
\hline Amostra & $\tau(\mu \mathrm{s})$ & $A\left(\mathrm{~s}^{-1}\right)$ & $A_{\text {rad }}\left(\mathrm{s}^{-1}\right)$ & $A_{n r}\left(\mathrm{~s}^{-1}\right)$ & $\eta(\%)$ \\
\hline ZnAlSm5\%-BTC-P123 & $5.80 \pm 0.29$ & $172 \cdot 10^{3}$ & 146 & $172 \cdot 10^{3}$ & $0.084 \pm 0.016$ \\
\hline
\end{tabular}

\subsubsection{Térbio}

As amostras ZnAlTbx\%-BTC-P123 exibem fotoluminescência esverdeada, característica da transição pseudo hipersensível do $\mathrm{Tb}^{3+}$. Dentre todos os terras raras testados, os materiais com térbio apresentaram as maiores intensidades de fótons emitidos após a excitação na faixa 
do UV. O espectro de excitação da amostra ZnAlTb5\%-BTC-P123, monitorado em $\lambda_{\text {em }}=$ $542.5 \mathrm{~nm}$, é dominado pela banda de absorção singleto-singleto $\mathrm{S}_{0}(\pi) \rightarrow \mathrm{S}_{n}\left({ }^{1} \pi^{*}\right)$ do BTC (Fig. 57). Adicionalmente, não foram observados fótons emitidos na regiões de fluorescência e fosforescência do ligante, demostrando que o BTC é uma ótima antena para os íons $\mathrm{Tb}^{3+}$. De fato, como evidenciado do diagrama da Figura 50 , o estado emissor $\left(\mathrm{Tb}^{3+}\right)^{5} \mathrm{D}_{4}$ se encontra próximo ao centro da banda $\mathrm{T}_{1}\left({ }^{3} \pi^{*}\right)$ do BTC, sendo a única rota possível para transferência de energia entre ambos.
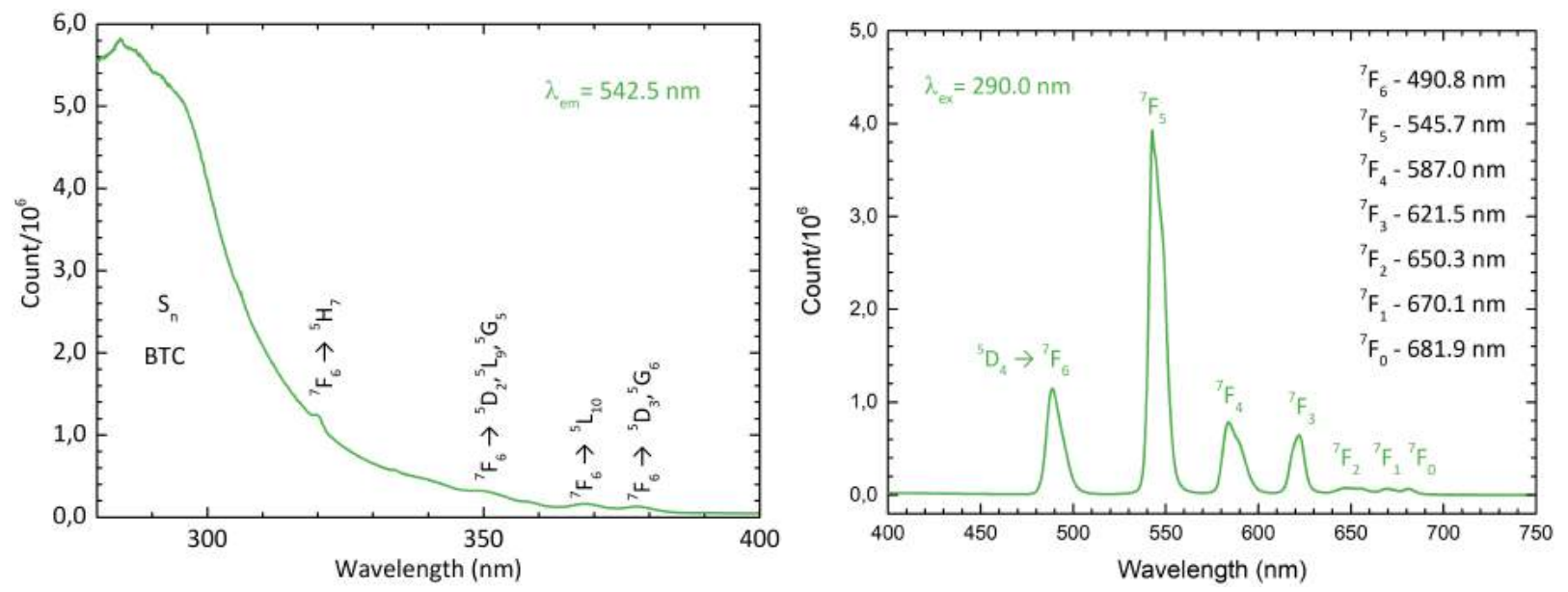

Figura 57 - $\mathrm{Zn}_{2} \mathrm{Al}_{0.95} \mathrm{~Tb}_{0.05}$-BTC-P123 - No gráfico da esquerda, o espectro de excitação é dominado pela banda de absorção $\mathrm{S}_{0} \rightarrow \mathrm{S}_{n}$ do BTC, mas também apresenta as excitações diretas do íon $\mathrm{Tb}^{3+}$ partindo do estado fundamental ${ }^{7} \mathrm{~F}_{6}$ para os níveis excitados (centro em cm ${ }^{-1}$ ): ${ }^{5} \mathrm{H}_{7}$ (31253), ${ }^{5} \mathrm{D}_{2},{ }^{5} \mathrm{~L}_{9},{ }^{5} \mathrm{G}_{5}(28571),{ }^{5} \mathrm{~L}_{10}$ (27155) e ${ }^{5} \mathrm{D}_{3},{ }^{5} \mathrm{G}_{6}$ (26471). À direita, o espectro de emissão apresenta todas as transições para os estados ${ }^{7} \mathrm{~F}_{J}$ partindo do emissor ${ }^{5} \mathrm{D}_{4}$.

O espectro de emissão da amostra ZnAlTb5\%-BTC-P123, excitado em $290 \mathrm{~nm}$ (UV), é constituído pelas transições $\left(\mathrm{Tb}^{3+}\right)^{5} \mathrm{D}_{4} \rightarrow{ }^{7} \mathrm{~F}_{J}, J=0-6$. A transição pseudo hipersensível ${ }^{5} \mathrm{D}_{4} \rightarrow{ }^{7} \mathrm{~F}_{5}$ é induzida tanto por dipolo magnético quanto por dipolo elétrico, enquanto as demais transições são induzidas puramente por DE. A emissão da amostra ZnAlTb15\%BTC-P123 apresentou perfil similar àquela de menor concentração. A Tabela 17 descreve as propriedades das linhas observadas no espectro.

Para as emissões ${ }^{5} \mathrm{D}_{4} \rightarrow{ }^{7} \mathrm{~F}_{J}$, os termos de matriz reduzida $\mathrm{U}_{\lambda}^{2}$ podem ser escritos na base dos autoestados do térbio como relacionado na Tabela 18, Ao contrário dos casos discutidos nas seções anteriores, o térbio não possui uma transição puramente magnética para que o coeficiente empírico $\delta$ seja estimado diretamente. 
Tabela 17 - Transições ${ }^{5} \mathrm{D}_{4} \rightarrow{ }^{7} \mathrm{~F}_{J}$ do íon $\mathrm{Tb}^{3+}$ na amostra $\mathrm{Zn}_{2} \mathrm{Al}_{0.95} \mathrm{~Tb}_{0.05}$-BTC-P123: radiância de cada transição $\mathrm{I}_{J}$ em \%, centroide $\lambda$ em nanômetros e largura a meia altura FWHM em nanômetros.

\begin{tabular}{cccc}
\hline $\mathrm{J}$ & $\mathrm{I}_{J}$ & $\lambda$ & $\mathrm{FWHM}$ \\
\hline 6 & $19.37 \pm 0.12$ & $490.75 \pm 0.07$ & 9.8 \\
5 & $55.04 \pm 0.26$ & $545.71 \pm 0.04$ & 9.6 \\
4 & $12.81 \pm 0.13$ & $586.89 \pm 0.06$ & 12.2 \\
3 & $7.07 \pm 0.11$ & $621.29 \pm 0.07$ & 8.5 \\
2 & $1.48 \pm 0.04$ & $650.36 \pm 0.16$ & 20.0 \\
1 & $0.68 \pm 0.03$ & $670.11 \pm 0.17$ & 13.2 \\
0 & $0.49 \pm 0.03$ & $681.64 \pm 0.22$ & 8.4 \\
\hline
\end{tabular}

Tabela 18 - Termos de matriz reduzida $\mathrm{U}_{\lambda}^{2}[64$ e taxas de emissão espontânea por dipolo magnético $\mathrm{A}_{M D} \mathrm{em} \mathrm{s}^{-1}$, 67] para as transições ${ }^{5} \mathrm{D}_{4} \rightarrow{ }^{7} \mathrm{~F}_{J}$ do íon $\mathrm{Tb}^{3+}$.

\begin{tabular}{ccccc}
\hline $\mathrm{J}$ & $\mathrm{U}_{2}$ & $\mathrm{U}_{4}$ & $\mathrm{U}_{6}$ & $\mathrm{~A}_{M D}$ \\
\hline 6 & 0.0009 & 0.0008 & 0.0013 & 0 \\
5 & 0.0142 & 0.0013 & 0.0022 & 14.32 \\
4 & 0.0002 & 0.0022 & 0.0014 & 0 \\
3 & 0.0022 & 0.0005 & 0.0006 & 0 \\
2 & 0.0011 & 0.0004 & 0.0001 & 0 \\
1 & 0 & 0.0025 & 0 & 0 \\
0 & 0 & 0.0017 & 0 & 0 \\
\hline
\end{tabular}

O nível emissor ${ }^{5} \mathrm{D}_{4}$ possui 7 possíveis rotas de decaimento, sendo a maior parte delas induzida por dipolo elétrico. A transição ${ }^{5} \mathrm{D}_{4} \rightarrow{ }^{7} \mathrm{~F}_{5}$ é a única delas a possuir ambos os termos $\mathrm{A}_{E D}$ e $\mathrm{A}_{M D}$. Para os casos em que a incerteza do coeficiente $\mathrm{A}_{E D}$ é muito menor que o módulo de $\mathrm{A}_{M D}$, é possível usar a taxa de emissão espontânea por dipolo magnético como padrão de calibração do espectro, viabilizando o ajuste dos parâmetros de Judd Ofelt aos dados experimentais de emissão do lantanídeo.

As equações 3.42 e 3.45 podem ser reescritas para as transições puramente elétricas 
do Térbio como o sistema de equações

$$
\begin{aligned}
& \frac{27 \varepsilon_{0} \bar{\lambda}_{0}^{4}}{4 \pi^{2} e^{2} c} \frac{I_{0}}{\chi_{E D}^{e m}}=U_{02}^{2} \frac{\Omega_{2}}{\delta}+U_{04}^{2} \frac{\Omega_{4}}{\delta}+U_{06}^{2} \frac{\Omega_{6}}{\delta}, \\
& \frac{27 \varepsilon_{0} \bar{\lambda}_{1}^{4}}{4 \pi^{2} e^{2} c} \frac{I_{1}}{\chi_{E D}^{e m}}=U_{12}^{2} \frac{\Omega_{2}}{\delta}+U_{14}^{2} \frac{\Omega_{4}}{\delta}+U_{16}^{2} \frac{\Omega_{6}}{\delta}, \\
& \frac{27 \varepsilon_{0} \bar{\lambda}_{2}^{4}}{4 \pi^{2} e^{2} c} \frac{I_{2}}{\chi_{E D}^{e m}}=U_{22}^{2} \frac{\Omega_{2}}{\delta}+U_{24}^{2} \frac{\Omega_{4}}{\delta}+U_{26}^{2} \frac{\Omega_{6}}{\delta}, \\
& \frac{27 \varepsilon_{0} \bar{\lambda}_{3}^{4}}{4 \pi^{2} e^{2} c} \frac{I_{3}}{\chi_{E D}^{e m}}=U_{32}^{2} \frac{\Omega_{2}}{\delta}+U_{34}^{2} \frac{\Omega_{4}}{\delta}+U_{36}^{2} \frac{\Omega_{6}}{\delta}, \\
& \frac{27 \varepsilon_{0} \bar{\lambda}_{4}^{4}}{4 \pi^{2} e^{2} c} \frac{I_{4}}{\chi_{E D}^{e m}}=U_{42}^{2} \frac{\Omega_{2}}{\delta}+U_{44}^{2} \frac{\Omega_{4}}{\delta}+U_{46}^{2} \frac{\Omega_{6}}{\delta}, \\
& \frac{27 \varepsilon_{0} \bar{\lambda}_{6}^{4}}{4 \pi^{2} e^{2} c} \frac{I_{6}}{\chi_{E D}^{e m}}=U_{62}^{2} \frac{\Omega_{2}}{\delta}+U_{64}^{2} \frac{\Omega_{4}}{\delta}+U_{66}^{2} \frac{\Omega_{6}}{\delta} .
\end{aligned}
$$

Definindo as matrizes

$$
I=\left(\begin{array}{c}
\frac{27 \varepsilon_{0} \bar{\lambda}_{0}^{4}}{4 \pi^{2} e^{2} c} \frac{I_{0}}{\chi_{E D}^{e m}} \\
\vdots \\
\frac{27 \varepsilon_{0} \bar{\lambda}_{4}^{4}}{4 \pi^{2} e^{2} c} \frac{I_{4}}{\chi_{E D}^{e m}} \\
\frac{27 \varepsilon_{0} \bar{\lambda}_{6}^{4}}{4 \pi^{2} e^{2} c} \frac{I_{6}}{\chi_{E D}^{e m}}
\end{array}\right), \quad U=\left(\begin{array}{ccc}
U_{02}^{2} & U_{04}^{2} & U_{06}^{2} \\
U_{12}^{2} & U_{14}^{2} & U_{16}^{2} \\
U_{22}^{2} & U_{24}^{2} & U_{26}^{2} \\
U_{32}^{2} & U_{34}^{2} & U_{36}^{2} \\
U_{42}^{2} & U_{44}^{2} & U_{46}^{2} \\
U_{62}^{2} & U_{64}^{2} & U_{66}^{2}
\end{array}\right), W=\left(\begin{array}{cccccc}
\frac{1}{\sigma I[0]} & 0 & 0 & 0 & 0 & 0 \\
0 & \frac{1}{\sigma I[1]} & 0 & 0 & 0 & 0 \\
0 & 0 & \frac{1}{\sigma I[2]} & 0 & 0 & 0 \\
0 & 0 & 0 & \frac{1}{\sigma I[3]} & 0 & 0 \\
0 & 0 & 0 & 0 & \frac{1}{\sigma I[4]} & 0 \\
0 & 0 & 0 & 0 & 0 & \frac{1}{\sigma I[6]}
\end{array}\right),
$$

onde $\sigma \mathrm{I}[\mathrm{n}]$ é a incerteza experimental propagada do n-ésimo elemento da matriz I, os parâmetros modificados $\bar{\Omega}=\left(\begin{array}{ccc}\frac{\Omega_{2}}{\delta} & \frac{\Omega_{4}}{\delta} & \frac{\Omega_{6}}{\delta}\end{array}\right)$ minimizam o erro quando satisfazem a relação

$$
\bar{\Omega}=\left(U^{T} W U\right)^{-1} U^{T} W I .
$$

Para a transição ${ }^{5} \mathrm{D}_{4} \rightarrow{ }^{7} \mathrm{~F}_{5}$, as taxas de emissão espontânea se relacionam à radiância do espectro como

$$
A_{5}=\chi_{E D}^{e m} A_{E D}^{(5)}+\chi_{M D}^{e m} A_{M D}^{(5)}=\delta \frac{4 \pi \bar{\lambda}_{5}}{h c} I_{5} \Longrightarrow
$$




$$
\frac{A_{M D}^{(5)}}{\delta}=\frac{4 \pi \bar{\lambda}_{5} I_{5}}{h c \chi_{M D}^{e m}}-\frac{4 \pi^{3} e^{2}}{27 \varepsilon_{0} h \bar{\lambda}_{n}^{3}} \frac{\chi_{E D}^{e m}}{\chi_{M D}^{e m}}\left(U_{52}^{2} \frac{\Omega_{2}}{\delta}+U_{54}^{2} \frac{\Omega_{4}}{\delta}+U_{56}^{2} \frac{\Omega_{6}}{\delta}\right)
$$

Substituindo nesta equação os valores ajustados em 6.12 para $\bar{\Omega}=\left(\begin{array}{lll}\frac{\Omega_{2}}{\delta} & \frac{\Omega_{4}}{\delta} \quad \frac{\Omega_{6}}{\delta}\end{array}\right)$, é possível obter uma estimativa para o coeficiente $\delta$. Temos, então:

$$
\Omega=\delta \cdot \bar{\Omega}
$$

Emissões de outros lantanídeos podem ser analisadas à luz da teoria de Judd Ofelt por esse mesmo procedimento, desde que haja pelo menos uma transição mista induzida pelos dipolos elétrico e magnético e que seja respeitada a condição de que a incerteza do coeficiente $\mathrm{A}_{E D}$ seja muito menor que o módulo da taxa de emissão espontânea $\mathrm{A}_{M D}$.

A partir deste modelo, foi possível calcular os coeficientes fenomenológicos $\Omega_{\gamma}$ para a amostra ZnAlTb5\%-BTC-P123. A condição de que a incerteza do coeficiente $A_{E D}$ seja muito menor que o módulo de $A_{M D}$ não é plenamente satisfeita neste material, acarretando nos valores altos de incertezas apresentados na Tabela 19.

Tabela 19 - Parâmetros fenomenológicos de Judd Ofelt do íon $\mathrm{Tb}^{3+}$ em diversas matrizes.

\begin{tabular}{lccc}
\hline Matriz & $\Omega_{2}$ & $\Omega_{4}$ & $\Omega_{6}$ \\
\hline $\mathrm{Tb}^{3+}$ (aquoso) & 2.76 & 7.95 & 2.87 \\
$\mathrm{LaF}_{3}: \mathrm{Tb}^{3+}$ (cristal) & 1.1 & 1.4 & 0.9 \\
YTMA:Tb & $12 \pm 4$ & $2.5 \pm 0.8$ & $57 \pm 18$ \\
ZnAlTb5\%-BTC-P123 & $10 \pm 3$ & $3.6 \pm 1.3$ & $49 \pm 17$ \\
\hline
\end{tabular}

O tempo de vida do estado $\left(\mathrm{Tb}^{3+}\right)^{7} \mathrm{~F}_{5}$ foi medido para uma estimativa dos parâmetros ópticos do material. O ajuste realizado e os resultados obtidos são ilustrados na Figura 58 e Tabela 20, respectivamente.

As elevadas incertezas obtidas para os parâmetros fenomenológicos e para o tempo de vida da amostra acarretam em uma incerteza grande também na eficiência calculada, de 77 $\pm 17 \%$. Como esperado, devido à existência de um único nível ressonante do térbio com a molécula antena e um grande gap entre esse estado emissor e seus receptores, a eficiência quântica observada na amostra ZnAlTb5\%-BTC-P123 é a maior dentre todos os terras raras testados. 


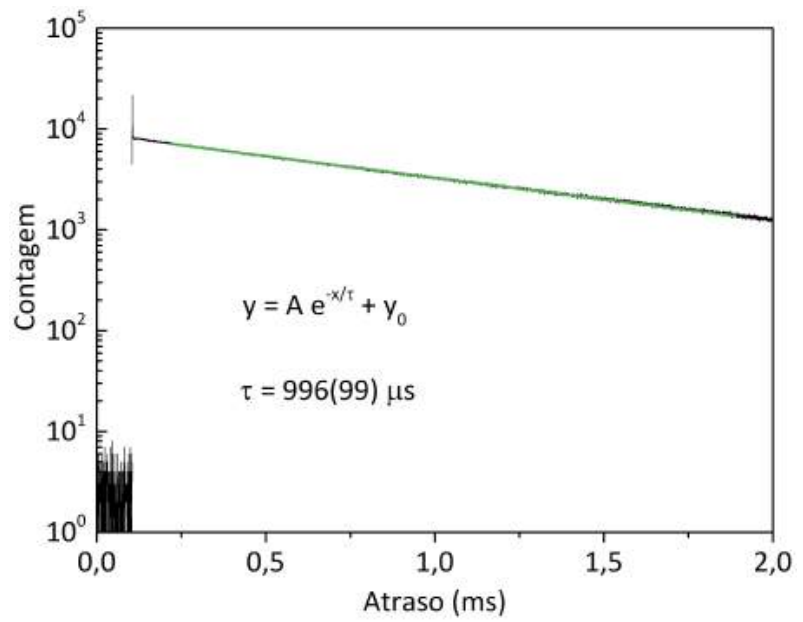

Figura 58 - Ajuste do tempo de vida do estado $\left(\mathrm{Tb}^{3+}\right)^{7} \mathrm{~F}_{5}$ (ZnAlTb5\%-BTC-P123).

Tabela 20 - Tempo de vida, taxas de transição e eficiência quântica das amostras contendo térbio.

\begin{tabular}{lccccc}
\hline Amostra & $\tau(\mu \mathrm{s})$ & $\mathrm{A}\left(\mathrm{s}^{-1}\right)$ & $\mathrm{A}_{\text {rad }}\left(\mathrm{s}^{-1}\right)$ & $\mathrm{A}_{n r}\left(\mathrm{~s}^{-1}\right)$ & $\eta(\%)$ \\
\hline ZnAlTb5\%-BTC-P123 & $996 \pm 99$ & 1004 & 170 & 227 & $77 \pm 17$ \\
\hline
\end{tabular}

\subsubsection{Disprósio}

Embora dominado pela banda de absorção singleto-singleto do BTC, o espectro de excitação das amostras ZnAlDyx\%-BTC-P123 apresentou também a absorção direta do estado fundamental $\left(\mathrm{Dy}^{3+}\right){ }^{6} \mathrm{H}_{15 / 2}$ para os níveis ${ }^{4} \mathrm{M}_{15 / 2},{ }^{6} \mathrm{P}_{7 / 2},{ }^{6} \mathrm{P}_{5 / 2},{ }^{6} \mathrm{P}_{3 / 2},{ }^{4} \mathrm{M}_{19 / 2},{ }^{4} \mathrm{M}_{21 / 2},{ }^{4} \mathrm{I}_{13 / 2}$, ${ }^{4} \mathrm{~K}_{17 / 2},{ }^{4} \mathrm{~F}_{7 / 2},{ }^{4} \mathrm{G}_{11 / 2}$ e ${ }^{4} \mathrm{H}_{15 / 2}$, como ilustrado na Figura 59 .

Apresentando fotoluminescência ciano quando excitadas na região do ultravioleta $\left(\lambda_{e x}=\right.$ $290 \mathrm{~nm})$, as amostras contendo disprósio emitiram fótons do emissor ${ }^{4} \mathrm{~F}_{9 / 2}$, relaxando para os níveis ${ }^{6} \mathrm{H}_{J}(\mathrm{~J}=15 / 2,13 / 2,11 / 2,9 / 2$ e $7 / 2)$. O quarto e o quinto picos mais intensos do espectro são constituídos pela superposição dos níveis ${ }^{6} \mathrm{H}_{9 / 2}+{ }^{6} \mathrm{~F}_{11 / 2}$ e ${ }^{6} \mathrm{~F}_{9 / 2}+{ }^{6} \mathrm{H}_{7 / 2}$, respectivamente. As propriedades das linhas de emissão estão descritas na Tabela 21.

Enquanto as demais linhas são induzidas exclusivamente por dipolo elétrico, a transição ${ }^{4} \mathrm{~F}_{9 / 2} \rightarrow{ }^{6} \mathrm{~F}_{11 / 2}$ é induzida por uma composição dos dipolos elétrico e magnético. 64 Utilizando um procedimento análogo ao realizado para os cálculos do térbio, é possível calcular os parâmetros fenomenológicos de Judd-Ofelt para as amostras contendo disprósio. Neste caso, alguns cuidados devem ser tomados: os ômegas são muito sensíveis a pequenas variações na área dos picos 3, 4 e 5 (Tab. 21). É necessário que as correções nesta região, 

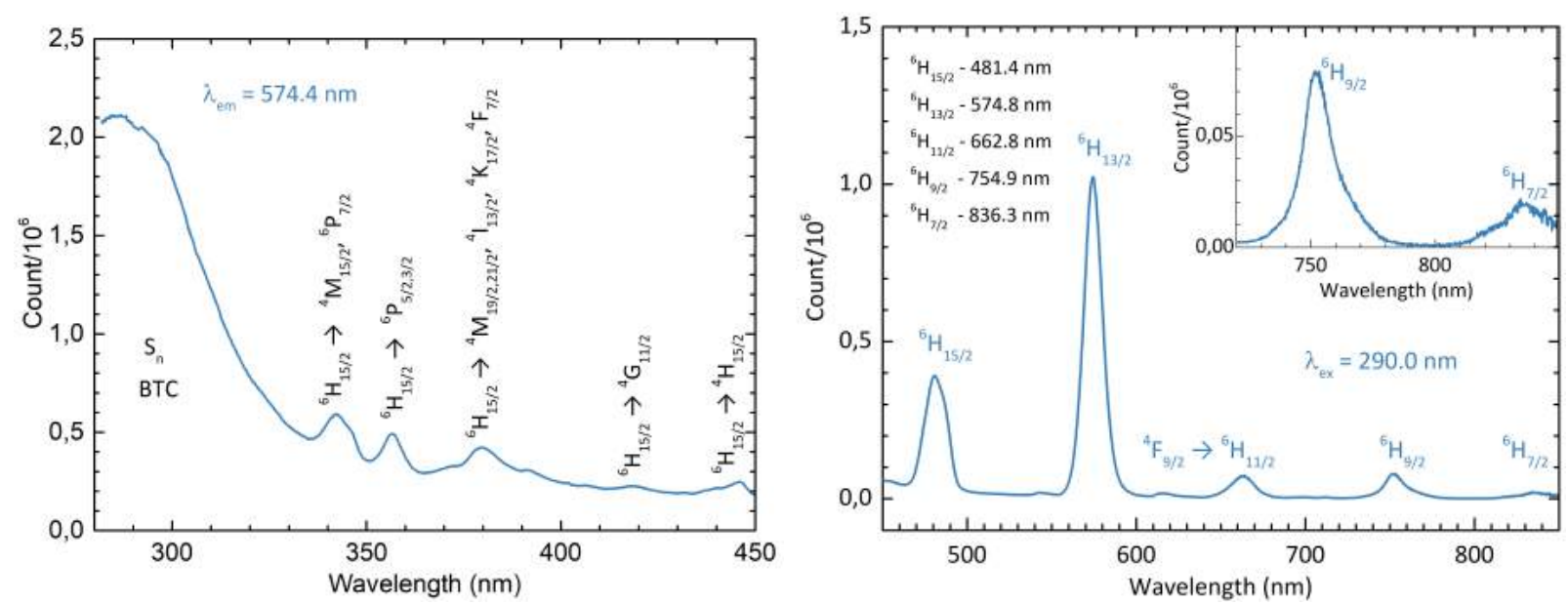

Figura 59 - ZnAlDy5\%-BTC-P123 - (esq.) Espectro de excitação constituído pela banda de absorção $\mathrm{S}_{0} \rightarrow \mathrm{S}_{n}$ do BTCe excitações diretas do íon $\mathrm{Dy}^{3+}$ partindo do estado fundamental ${ }^{6} \mathrm{H}_{15 / 2}$ para os níveis excitados (centro em $\mathrm{cm}^{-1}$ ): ${ }^{4} \mathrm{M}_{15 / 2}$, ${ }^{6} \mathrm{P}_{7 / 2}(29210),{ }^{6} \mathrm{P}_{5 / 2},{ }^{6} \mathrm{P}_{3 / 2}(28046),{ }^{4} \mathrm{M}_{19 / 2},{ }^{4} \mathrm{M}_{21 / 2},{ }^{4} \mathrm{I}_{13 / 2},{ }^{4} \mathrm{~K}_{17 / 2},{ }^{4} \mathrm{~F}_{7 / 2}$ (26332), ${ }^{4} \mathrm{G}_{11 / 2}$ (23890) e ${ }^{4} \mathrm{H}_{15 / 2}$ (22429).(dir.) Espectro de emissão: transições para os estados ${ }^{6} \mathrm{H}_{J}(\mathrm{~J}=15 / 2,13 / 2,11 / 2,9 / 2$ e $7 / 2)$ partindo do emissor ${ }^{4} \mathrm{~F}_{9 / 2}$.

Tabela 21 - Transições ${ }^{4} \mathrm{~F}_{9 / 2} \rightarrow{ }^{2 S+1} \mathrm{~L}_{J}$ do íon $\mathrm{Dy}^{3+}$ na amostra $\mathrm{Zn}_{2} \mathrm{Al}_{0.95} \mathrm{Dy}_{0.05}$-BTC-P123: radiância $\mathrm{I}_{i}$ de cada transição em \%, centroide $\lambda$ em nanômetros e largura a meia altura FWHM em nanômetros.

\begin{tabular}{ccccc}
\hline $\mathrm{i}$ & ${ }^{2 S+1} \mathrm{~L}_{J}$ & $\mathrm{I}_{i}$ & $\lambda$ & FWHM \\
\hline 1 & ${ }^{6} \mathrm{H}_{15 / 2}$ & $7.99 \pm 0.21$ & $481.08 \pm 0.18$ & 15.7 \\
2 & ${ }^{6} \mathrm{H}_{13 / 2}$ & $17.48 \pm 0.09$ & $574.85 \pm 0.06$ & 12.7 \\
3 & ${ }^{6} \mathrm{H}_{11 / 2}$ & $1.71 \pm 0.05$ & $662.8 \pm 0.3$ & 14.9 \\
4 & ${ }^{6} \mathrm{H}_{9 / 2},{ }^{6} \mathrm{~F}_{11 / 2}$ & $1.70 \pm 0.06$ & $753.9 \pm 0.4$ & 13.6 \\
5 & ${ }^{6} \mathrm{~F}_{9 / 2},{ }^{6} \mathrm{H}_{7 / 2}$ & $0.62 \pm 0.06$ & $834.7 \pm 1.4$ & 16.0 \\
\hline
\end{tabular}

tanto no que se refere aos procedimentos experimentais quando a subtração de eventuais backgrounds, sejam muito bem feitas. Após diversos testes e estudos numéricos, verificouse que os valores calculados para $\Omega_{4}$ do disprósio são mais confiáveis quando a transição ${ }^{4} \mathrm{~F}_{9 / 2} \rightarrow{ }^{6} \mathrm{H}_{7 / 2},{ }^{6} \mathrm{~F}_{9 / 2}$ é medida. A Tabela 22 mostra os resultados obtidos para os parâmetros fenomenológicos das amostras ZnAlDyx\%-BTC-P123 em comparação com valores relatados na literatura.

O tempo de vida da amostra ZnAlDy5\%-BTC-P123 foi medido para o cálculo dos parâmetros ópticos do sistema. O ajuste e os resultados obtidos são apresentados na Figura 60 e na Tabela 23, respectivamente. 
Tabela 22 - Parâmetros fenomenológicos de Judd Ofelt do íon Dy ${ }^{3+}$ em diversas matrizes.

\begin{tabular}{|c|c|c|c|}
\hline Matriz & $\Omega_{2}$ & $\Omega_{4}$ & $\Omega_{6}$ \\
\hline $\mathrm{Dy}^{3+}$ (aquoso) & 0.58 & 3.54 & 3.90 \\
\hline $\mathrm{LaF}_{3}: \mathrm{Dy}^{3+}$ (cristal) & 1.10 & 1.40 & 0.90 \\
\hline ZnAlDy5\%-BTC-P123 & $6.1 \pm 0.4$ & $3.5 \pm 0.6$ & $3.15 \pm 0.26$ \\
\hline ZnAlDy15\%-BTC-P123 & $6.3 \pm 0.4$ & $-0.63 \pm 0.29$ & $4.9 \pm 0.4$ \\
\hline
\end{tabular}

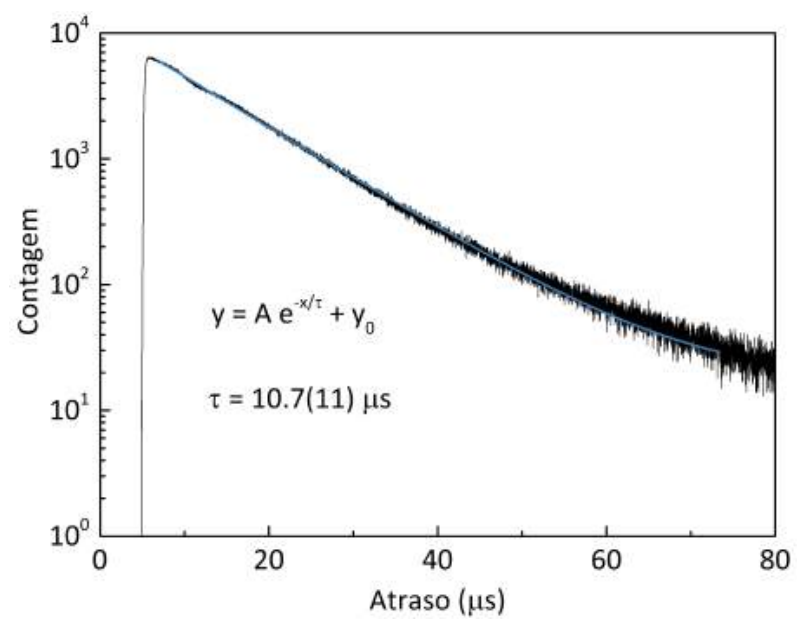

Figura 60 - Ajuste do tempo de vida do estado $\left(\mathrm{Dy}^{3+}\right)^{6} \mathrm{H}_{13 / 2}$ (ZnAlDy5\%-BTC-P123).

Tabela 23 - Taxas de transição e eficiência quântica das amostras contendo disprósio.

\begin{tabular}{lccccc}
\hline Amostra & $\tau(\mu \mathrm{s})$ & $\mathrm{A}\left(\mathrm{s}^{-1}\right)$ & $\mathrm{A}_{\text {rad }}\left(\mathrm{s}^{-1}\right)$ & $\mathrm{A}_{n r}\left(\mathrm{~s}^{-1}\right)$ & $\eta(\%)$ \\
\hline ZnAlDy5\%-BTC-P123 & $10.7 \pm 1.1$ & $93 \cdot 10^{3}$ & 8734 & $92 \cdot 10^{3}$ & $1.04 \pm 0.11$ \\
\hline
\end{tabular}

\subsubsection{Considerações gerais sobre a luminescência das amostras estudadas}

A intercalação de benzenocarboxilatos nos hidróxidos lamelares se mostrou eficiente como forma de sensibilizar os íons $\mathrm{Eu}^{3+}$ e $\mathrm{Tb}^{3+}$, e efetiva para os íons $\mathrm{Sm}^{3+}$ e $\mathrm{Dy}^{3+}$, como evidenciado pelo espectro de excitação dos quatro lantanídeos. A melhor eficiência observada para os casos do európio e do térbio se deve à existência de poucos níveis ressonantes entre os terras raras e a banda $\mathrm{T}_{1}$ do $\mathrm{BTC}$ - o que reduz o número de rotas de transferência de energia entre ambos -, além dos elevados gaps observados entre os estados emissores e seus níveis receptores, favorecendo o relaxamento do sistema por vias radiativas.

A transferência de energia entre lantanídeos e moléculas sensibilizadoras atuando como antena se dá usualmente pelos processos de Dexter ou de Förster. 109 No processo de Förster, há um acoplamento dipolo-dipolo entre os sistemas, que permite a transferência de energia de forma não radiativa. Para que esse acoplamento seja efetivo, há uma dependência 
com o inverso da distância entre o doador e o receptor de energia $\left(1 / \mathrm{d}^{6}\right)$, tornando a eficiência muito sensível à distância entre ambos. [110] No processo de Dexter, a distância entre doador e receptor é ainda mais importante, ocorrendo apenas para ligações inferiores a $10 \AA$. 108 Neste caso, há uma troca de elétrons entre o doador e o receptor de energia, onde o doador transfere um elétron em seu estado excitado e recebe um elétron em seu estado fundamental. Este processo mantém a carga e o spin globalmente conservados.

Similarmente ao térbio, o íon $\mathrm{Tm}^{3+}$ apresenta apenas uma rota de transferência de energia no sistema estudado, entre seu estado ${ }^{1} \mathrm{G}_{4}$ e a banda $\mathrm{T}_{1}$ do BTC, além de gaps para potenciais níveis receptores da mesma ordem de grandeza que disprósio. Não se verifica, no entanto, a emissão azul característica do túlio no espectro de emissão das amostras ZnAlTmx\%-BTCP123, onde o relaxamento do sistema se dá pelos processos de fluorescência e fosforescência do ligante. 


\section{Conclusão}

A partir do método de coprecipitação apresentado, foi possível sintetizar hidróxidos triplos lamelares de zinco, alumínio e terras raras de composição $\mathrm{Zn}_{2} \mathrm{Al}_{1-x} \mathrm{TR}_{x}(\mathrm{OH})_{6} \mathrm{~A}_{1 / n}^{n-} \cdot \mathrm{yH}_{2} \mathrm{O}$, com concentrações variando entre $\mathrm{x}=0$ e 15\%, chegando a $30 \%$ para os lantanídeos de menor raio atômico. Devido à diminuição da constante de solubilidade dos hidróxidos de terras raras ao longo da série lantanídica, os elementos de menor número atômico apresentaram tendência à formação de fases laterais. Fases puras dos hidróxidos lamelares pretendidos apenas foram obtidas para os metais com raio atômico menor que o samário. A estratégia de indução da auto-organização dos hidróxidos lamelares ao redor de micelas surfactantes cilíndricas se mostrou eficiente, gerando, com a inclusão de uma concentração ótima de $\mathrm{TR}^{3+}$ na amostra, aglomerados de nanotubos de hidróxidos lamelares com os íons $\mathrm{La}^{3+}, \mathrm{Nd}^{3+}$,

$\mathrm{Sm}^{3+}, \mathrm{Eu}^{3+}, \mathrm{Gd}^{3+}, \mathrm{Tb}^{3+}$ ou $\mathrm{Dy}^{3+}$. Os nanotubos produzidos apresentaram larga distribuição de comprimentos, entre 30 e 150 nm, e diâmetros médios entre 15 e 30 nm, dependentes dos metais inseridos na estrutura.

Os íons TR desempenharam um papel fundamental na determinação da morfologia do material: devido ao número de coordenação elevado desses elementos, há a possibilidade de ocorrerem distorções locais na estrutura cristalina da amostra, viabilizando que cada camada originalmente plana e rígida seja cristalizada com curvatura suficiente para a formação de cascas cilíndricas. Neste sentido, os terras raras com maior raio atômico possuem maior capacidade de coordenação, causando maiores deformações locais e possibilitando o surgimento de aglomerados de nanotubos em concentrações menores.

Concentrações de $\mathrm{x}=3$ a $5 \%$ se mostraram ideais para a formação de nanotubos nas amostras ZnAlTRx\%-BTC-P123 com TR = La, Nd ou Sm. As fases laterais presentes em concentrações maiores tendem a inibir a morfologia de nanotubos com esses metais. O európio se revelou um caso limite, onde o surgimento de fases laterais em concentrações maiores, da ordem de 15\%, não são importantes e a capacidade de coordenação é alta o suficiente para deformar a estrutura mesmo em menores concentrações. Desta forma, aglomerados de nanotubos foram observados para amostras com $3 \% \leq \mathrm{x} \leq 15 \%$ de $\mathrm{Eu}^{3+}$. A concentração de $\mathrm{x}=15 \%$ se mostrou ideal para a formação de nanotubos nas amostras ZnAlTRx\%-BTC- 
P123 com TR = Gd, Tb ou Dy. Concentrações menores não foram suficientes para induzir a mudança de morfologia, enquanto maiores já apresentaram a formação de fases laterais. A reduzida capacidade de coordenação dos lantanídeos menores que o disprósio impossibilitou o surgimento de aglomerados de nanotubos na presença desses metais, embora tenha sido notada a formação pontual de nanotubos em meio a amostras com morfologia predominantemente plana.

Além de seu papel na estrutura e morfologia dos hidróxidos lamelares, a inclusão de lantanídeos foi capaz de produzir materiais luminescentes. A intercalação de benzeno-1,3,5tricarboxilatos nos hidróxidos lamelares se mostrou eficiente como forma de sensibilizar os íons $\mathrm{Eu}^{3+}, \mathrm{Tb}^{3+}, \mathrm{Sm}^{3+}$ e $\mathrm{Dy}^{3+}$, possibilitando a formação de nanotubos com fotoluminescência vermelha, verde, rosa e ciano quando expostos à radiação ultravioleta. Os parâmetros fenomenológicos de Judd Ofelt ajustados aos dados experimentais indicaram, para os materiais que luminesceram, que os sítios ocupados pelos lantanídeos nas amostras ZnAlTRx\%-BTCP123 possuem baixa simetria, provavelmente devido a deformidades causadas pela presença do BTC em sua primeira esfera de coordenação.

Este trabalho demonstrou que o método desenvolvido no LNA para a síntese de nanotubos de hidróxidos lamelares com európio pode ser estendido para a produção de uma classe de nanotubos luminescentes contendo diferentes lantanídeos, como divulgado em nosso artigo recentemente publicado no periódico RSC Advances. [99] Em parte por conta das desordens locais geradas com a inclusão de terras raras, em parte pela limitação intrínseca dada pelas dimensões das nanopartículas, os materiais analisados apresentam baixa cristalinidade, o que torna difícil as tarefas de controlar e caracterizar esse novo sistema. O papel dos ânions intercalados na morfologia dos nanotubos ainda é um tema que merece ser estudado em pesquisas futuras. A inclusão de novas moléculas sensibilizadoras, capazes de transferir energia a outros terras raras, também é um assunto de interesse. Para o futuro, acreditamos que devem ser testadas aplicações promissoras para esta classe de materiais, como a fotocatálise, já prevista em projetos submetidos recentemente à CAPES e à FAPESP pelo nosso grupo. 


\section{Bibliografia}

[1] Carl Hochstetter. "Untersuchung Über Die Zusammensetzung Einiger Mineralien". Em: J. Prakt. Chem. 27 (1842), 375-378.

[2] E. Manasse. Em: Proc. Verb. 24.92 (1915).

[3] W Feitknecht e M Gerber. "Zur Kenntnis der Doppelhydroxyde und basisehen Doppelsalze III Uber Magnesium-Aluminiumdoppelhydroxyd". Em: Helv. Chim. Acta 25 (1942), pp. 131-137.

[4] D. G. Evans e R. C. T. Slade. Layered Double Hydroxides: structure and bonding Structural aspects of layered double hydroxides. Springer, 2006.

[5] V. Rives. Layered Double Hydroxides: Present and Future. Nova Science Publishers, 2001.

[6] Aamir I Khan e Dermot O'Hare. "Intercalation chemistry of layered double hydroxides: recent developments and applications". Em: Journal of Materials Chemistry 12.11 (2002), pp. 3191-3198.

[7] Guoli Fan, Feng Li, David G Evans e Xue Duan. "Catalytic applications of layered double hydroxides: recent advances and perspectives". Em: Chemical Society Reviews 43.20 (2014), pp. 7040-7066.

[8] RMM Santos, J Tronto, Valérie Briois e CV Santilli. "Thermal decomposition and recovery properties of $\mathrm{ZnAl}-\mathrm{CO} 3$ layered double hydroxide for anionic dye adsorption: insight into the aggregative nucleation and growth mechanism of the LDH memory effect." Em: Journal of Materials Chemistry A 5.20 (2017), pp. 9998-10009.

[9] Shilin Zhang, Feng Yao, Lan Yang, Fazhi Zhang e Sailong Xu. "Sulfur-doped mesoporous carbon from surfactant-intercalated layered double hydroxide precursor as high-performance anode nanomaterials for both Li-ion and Na-ion batteries". Em: Carbon 93 (2015), pp. 143-150.

[10] Lagnamayee Mohapatra e Kulamani Parida. "A review on the recent progress, challenges and perspective of layered double hydroxides as promising photocatalysts". Em: Journal of Materials Chemistry A 4.28 (2016), pp. 10744-10766.

[11] A Khenifi, Z Derriche, C Mousty, V Prévot e C Forano. "Adsorption of glyphosate and glufosinate by Ni2AlNO3 layered double hydroxide". Em: Applied Clay Science 47.3-4 (2010), pp. 362-371.

[12] Katharina Ladewig, Zhi Ping Xu e Gao Qing Max Lu. "Layered double hydroxide nanoparticles in gene and drug delivery". Em: Expert Opin Drug Deliv 6.9 (2009), pp. 907-922. DOI: 10.1517/17425240903130585.

[13] Siyu He, Li Wu, Xue Li, Hongyu Sun, Ting Xiong, Jie Liu, Chengxi Huang, Huipeng Xu, Huimin Sun, Weidong Chen, Ruxandra Gref e Jiwen Zhang. "Metal-organic frameworks for advanced drug delivery". Em: Acta Pharmaceutica Sinica B (2021). DoI: 10.1016/j.apsb.2021.03.019. 
[14] Xue Bi, Hui Zhang e Liguang Dou. "Layered Double Hydroxide-Based Nanocarriers for Drug Delivery". Em: Pharmaceutics 6.2 (2014), 298-332. DOI: 10 . 3390 / pharmaceutics6020298.

[15] Jing Hu, Xiaomin Tang, Qing Dai, Zhiqiang Liu, Huamin Zhang, Anmin Zheng, Zhizhang Yuan e Xianfeng Li. "Layered double hydroxide membrane with high hydroxide conductivity and ion selectivity for energy storage device". Em: Nature Communications 12.3409 (2021). DOI: 10.1038/s41467-021-23721-9.

[16] Xiao-Yu Yang, Li-Hua Chen, Yu Li, Joanna Claire Rooke, Clément Sanchez e BaoLian Su. "Hierarchically porous materials: synthesis strategies and structure design". Em: Chem. Soc. Rev. 46.2 (2017), pp. 481-558. DOI: 10.1039/C6CS00829A. URL: http://dx.doi.org/10.1039/C6CS00829A.

[17] Ming-Hui Sun, Shao-Zhuan Huang, Li-Hua Chen, Yu Li, Xiao-Yu Yang, Zhong-Yong Yuan e Bao-Lian Su. "Applications of hierarchically structured porous materials from energy storage and conversion, catalysis, photocatalysis, adsorption, separation, and sensing to biomedicine". Em: Chem. Soc. Rev. 45.3479 (2016), pp. 3479-3563. DOI: $10.1039 / \mathrm{c} 6 \mathrm{cs} 00135 \mathrm{a}$

[18] Lorenzo Vigna, Arianna Nigro, Alessio Verna, Ivan Vito Ferrari, Simone Luigi Marasso, Sergio Bocchini, Marco Fontana, Angelica Chiodoni, Candido Fabrizio Pirri e Matteo Cocuzza. "Layered Double Hydroxide-Based Gas Sensors for VOC Detection at Room Temperature". Em: ACS Omega (2021).

[19] Yishun Zhong, Gen Chen, Xiaohe Liu, Dan Zhang, Ning Zhang, Junhui Li, Shuquan Liang, Renzhi Ma e Guanzhou Qiu. "Layered rare-earth hydroxide nanocones with facile host composition modification and anion-exchange feature: topotactic transformation into oxide nanocones for upconversion". Em: Nanoscale 9.24 (2017), pp. 81858191. DOI: 10.1039/C7NR02001E.

[20] Huan Wang, Zhonghua Sun, Xiaoran Zou, Jianhai Rena e Chun yang Zhang. "Controllable synthesis of $\mathrm{CoFe} 2 \mathrm{Se} 4 / \mathrm{NiCo} 2 \mathrm{Se} 4$ hybrid nanotubes with heterointerfaces and improved oxygen evolution reaction performance". Em: Nanoscale (2021), Advance Article. DOI: 10.1039/D1NR00406A.

[21] Carlo Perego e Roberto Millini. "Porous materials in catalysis: challenges for mesoporous materials". Em: Chem. Soc. Rev. 42.9 (2014), pp. 3956-3976. DOI: 10.1039/ C2CS35244C

[22] R. Tian, R. Liang, M. Wei, D. G. Evans e X. Duan. "Applications of Layered Double Hydroxide Materials: Recent Advances and Perspective. 50 Years of Structure and Bonding - The Anniversary Volume". Em: (2016), pp. 65-84. DOI: 10.1007/430_ 2015_205.

[23] Shadpour Mallakpoura, Masoud Hatamia e Chaudhery Mustansar Hussainb. "Recent innovations in functionalized layered double hydroxides: Fabrication, characterization, and industrial applications". Em: Advances in Colloid and Interface Science 283.102216 (2020). DOI: $10.1016 /$ j.cis. 2020.102216.

[24] T. J. Pinnavaia. Encycl. Mater. Sci. Technol. Elsevier, 2001, 7011-7012. 
[25] Yufei Zhao, Guangbo Chen, Tong Bian, Chao Zhou, Geoffrey I. N. Waterhouse, Li-Zhu Wu, Chen-Ho Tung, Lorna J. Smith, Dermot O'Hare e Tierui Zhang. "Defect-Rich Ultrathin ZnAl-Layered Double Hydroxide Nanosheets for Efficient Photoreduction of CO2 to CO with Water". Em: Advanced Materials 27.47 (2015), pp. 7824-7831. DOI: $10.1002 /$ adma.201503730.

[26] Xitao Chen, Fei Mi, Hui Zhang e Huaiqian Zhang. "Facile synthesis of a novel magnetic core-shell hierarchical composite submicrospheres Fe3O4@ CuNiAl-LDH under ambient conditions". Em: Materials Letters 69 (2012), pp. 48-51.

[27] Liang Li, Yingjun Feng, Yongsheng Li, Wenru Zhao e Jianlin Shi. "Fe3O4 core/layered double hydroxide shell nanocomposite: versatile magnetic matrix for anionic functional materials". Em: Angewandte Chemie International Edition 48.32 (2009), pp. 5888-5892.

[28] Liang Huang, Dongchang Chen, Yong Ding, Shi Feng, Zhong Lin Wang e Meilin Liu. "Nickel-cobalt hydroxide nanosheets coated on NiCo2O4 nanowires grown on carbon fiber paper for high-performance pseudocapacitors". Em: Nano letters 13.7 (2013), pp. 3135-3139.

[29] Jingwen Zhao, Jiale Chen, Simin Xu, Mingfei Shao, Qiang Zhang, Fei Wei, Jing Ma, Min Wei, David G Evans e Xue Duan. "Hierarchical NiMn layered double hydroxide/carbon nanotubes architecture with superb energy density for flexible supercapacitors". Em: Advanced Functional Materials 24.20 (2014), pp. 2938-2946.

[30] J. Zhang, Z. Li, Y. Chen, S. Gao e X. W. D. Lou. "Nickel-Iron Layered Double Hydroxide Hollow Polyhedrons as a Superior Sulfur Host for Lithium-Sulfur Batteries". Em: Angewandte Chemie International Edition 57.34 (2018), pp. 10944-10948. DOI: 10.1002/anie.201805972.

[31] Mingfei Shao, Fanyu Ning, Yufei Zhao, Jingwen Zhao, Min Wei, David G Evans e Xue Duan. "Core-shell layered double hydroxide microspheres with tunable interior architecture for supercapacitors". Em: Chemistry of Materials 24.6 (2012), pp. 11921197.

[32] Xiaohe Liu, Renzhi Ma, Yoshio Bando e Takayoshi Sasaki. "A General Strategy to Layered Transition-Metal Hydroxide Nanocones: Tuning the Composition for High Electrochemical Performance". Em: Advanced Materials 24.16 (2012), pp. 2148-2153. DOI: 10.1002 /adma.201104753.

[33] Qian Wang, Xiaofei Wang e Chunlei Shi. "LDH Nanoflower Lantern Derived from ZIF67 and Its Application for Adsorptive Removal of Organics from Water". Em: Ind. Eng. Chem. Res. 57.37 (2018), pp. 12478-12484. DOI: 10.1021/acs.iecr.8b01324.

[34] M. A. Rocha, P. A. D. Petersen, E. Teixeira-Neto, H. M. Petrilli, F. Leroux, C. TaviotGueho e V. R. L. Constantino. "Layered double hydroxide and sulindac coiled and scrolled nanoassemblies for storage and drug release". Em: RSC Adv. 6.20 (2016), 16419-16436. DOI: 10.1039/C5RA25814F

[35] A. F. Morais et al. "Hierarchical self-supported ZnAlEu LDH nanotubes hosting luminescent CdTe quantum dots". Em: Chem. Commun. 53.53 (2017), pp. 7341-7344. 
[36] Alysson Ferreira Morais. "Preparação e estudo de nanotubos luminescentes de hidróxidos duplos lamelares (LDH) contendo íons terras raras". Em: Tese de doutorado (2018).

[37] Danilo Mustafa, Eric Breynaert, Alysson Ferreira Morais e Ivan Guide Nunes da Silva. "Processo para síntese de nanotubos de hidróxidos duplos lamelares, nanotubos de hidróxidos duplos lamelares e seus usos". Em: Patente: Privilégio de Inovação, Registro BR1020180092669 (2018).

[38] Alysson F. Morais, Dimy Nanclares, Ivan G. N. Silva, Alfredo Duarte, Fernando A. Garcia, Eric Breynaert e Danilo Mustafa. "Mesostructuring layered materials: selfsupported mesoporous layered double hydroxide nanotubes". Em: Nanoscale 13 (), pp. 11781-11792. DOI: 10.1039/D1NR02477A.

[39] K. Momma e F. Izumi. "VESTA 3 for three-dimensional visualization of crystal, volumetric and morphology data". Em: J. Appl. Crystallogr. 44 (2011), pp. 12721276.

[40] P. J. Sideris, U. G. Nielsen, Z. Gan e C. P. Grey. "Mg/Al ordering in layered double hydroxides revealed by multinuclear NMR spectroscopy". Em: Science 321 (2008), pp. 113-7.

[41] A. Di Bitetto, E. André, C. Carteret, P. Durand e G. Kervern. "Probing the Dynamics of Layered Double Hydroxides by Solid-State 27 Al NMR Spectroscopy". Em: The Journal of Physical Chemistry C 121 (2017), pp. 7276-7281.

[42] M. Vucelic, W. Jones e G. D. Moggridge. "Cation ordering in synthetic layered double hydroxides". Em: Clays and Clay Minerals 45 (1997), pp. 803-813.

[43] Sonia Jaśkaniec, Christopher Hobbs, Andrés Seral-Ascaso, João Coelho, Michelle P. Browne, Daire Tyndall, Takayoshi Sasaki e Valeria Nicolosi. "Low-temperature synthesis of high quality Ni-Fe layered double hydroxides hexagonal platelet". Em: Scientific Reports 8 (2018).

[44] Xiaohe Liu, Renzhi Ma, Yoshio Bando e Takayoshi Sasaki. "A general strategy to layered transition-metal hydroxide nanocones: tuning the composition for high electrochemical performance". Em: Advanced Materials 24.16 (2012), pp. 2148-2153.

[45] Paschalis Alexandridis, Vassiliki Athanassiou, Shinya Fukuda e T. Alan Hatton. "Surface Activity of Poly(ethylene oxide)-block-Poly(propylene oxide)-block-Poly(ethylene oxide) Copolymers". Em: Langmuir 10.8 (1994), pp. 2604-2612. DOI: 10 . $1021 /$ 1a00020a019.

[46] Feng Yan e John Texter. "Advances in Colloid and Interface Science". Em: Advances in Colloid and Interface Science 128-130 (2006), pp. 27-35. DOI: $10.1016 /$ j.cis . 2006.11 .014 .

[47] R. Ma e T. Sasaki. "Nanosheets of oxides and hydroxides: ultimate 2D charge-bearing functional crystallites". Em: Advanced Materials 22.45 (2010), pp. 5082-104.

[48] Tian Zhong et al. "Nanophotonic rare-earth quantum memory with optically controlled retrieval". Em: Science 31 (2017).

[49] Jonathan R. Everts, Matthew C. Berrington, Rose L. Ahlefeldt e Jevon J. Longdell. "Microwave to optical photon conversion via fully concentrated rare-earth ion crystals". Em: Phys. Rev. A 99 (2019). 
[50] Francine Bettio Costa. "Investigação espectroscópica e estudo do mecanismo de conversão descendente de energia em vidros $\mathrm{TeO}_{2}-\mathrm{WO}_{3}$ co-dopados com íons $\mathrm{Nd}^{3+} \mathrm{e}$ $\mathrm{Yb}^{3+}$. Em: Tese de doutorado (2016).

[51] F. Auzel. "Upconversion and anti-stokes processes with $\mathrm{f}$ and d ions in solids". Em: Chem. Rev. (2004).

[52] M. Ylihrsil, T. Valta, M. Karp e L. Hattara. "Oligonucleotide array-in-well platform for detection and genotyping human adenoviruses by utilizing upconverting phosphor label technology". Em: Analytical (2011).

[53] E. Van der Kolk, P. Dorenbos, K. Kr mer e D. Biner. "High-resolution luminescence spectroscopy study of down-conversion routes in $\mathrm{Na} \mathrm{Gd} \mathrm{F} \mathrm{4:} \mathrm{Nd}^{3+}$ and $\mathrm{Na}$ Gd F 4: $\mathrm{Tm}^{3+}$ using synchrotron radiation". Em: Phys. Rev. B (2008).

[54] J. De Wild, A. Meijerink, J. Rath e W. Van Sark. "Upconverter solar cells: materials and applications". Em: Energy and Environmental Science (2011).

[55] K. Binnemans. "Interpretation of europium(III) spectra". Em: Coordination Chemistry Reviews 295 (2015).

[56] J. Michael Hollas. Modern Spectroscopy. Wiley, 2004.

[57] P.S. Peijzel, A. Meijerink, R.T. Wegh, M.F. Reid e G.W. Burdick. "A complete $4 \mathrm{f}^{n}$ energy level diagram for all trivalent lanthanide ions". Em: Journal of Solid State Chemistry 178 (2005).

[58] B. R. Judd. "Optical absorption intensities of rare-earth ions". Em: Physical Review 127 (1962).

[59] Robert C. Hilborn. "Einstein coefficients, cross sections, f values, dipole moments, and all that". Em: Am. J. Phys. 50 (1982), pp. 982-986.

[60] L. J. F. Broer, C. J. Gorter e J. Hoogschagen. "On the intensities and the multipole carachter in the spectra of rare earth ions". Em: Physica XI 4 (1945).

[61] B. M. Walsh. "Judd-Ofelt theory: principles and practices". Em: International school of atomic and molecular spectroscopy (2006).

[62] G. H. Dieke. "Spectra and Energy Levels of Rare-Earth Ions in Crystals". Em: (1968).

[63] G. S. Ofelt. "Intensities of crystal spectra of rare-earth ions". Em: The Journal of Chemical Physics 37 (1962).

[64] W. T. Carnall e H. Crosswhite. "Energy level structure and transition probabilities in the spectra of trivalent lanthanides in $\mathrm{LaF}_{3}$ ". Em: Argone, IL, USA: Technical Report $A N L-78-X X-9549$ (1978).

[65] Jeffrey M. Lemm. Handbook On The Physics And Chemistry Of Rare Earths. Vol. 9. North Holland, 1987. ISBN: 9780444870452.

[66] Renaldo T. Moura, Albano N. Carneiro Neto, Ricardo L. Longo e Oscar L. Malta. "On the Calculation and Interpretation of Covalency in the Intensity Parameters of $4 \mathrm{f}-4 \mathrm{f}$ Transitions in Eu3+ Complexes Based on the Chemical Bond Overlap Polarizability". Em: Journal of Luminescence 170 (), pp. 420-430. DOI: 10.1016/j · jlumin. 2015. 08.016 . 
[67] Christopher M. Dodson e Rashid Zia. "Magnetic dipole and electric quadrupole transitions in the trivalent lanthanide series: Calculated emission rates and oscillator strengths". Em: Physical Review B 86 (2012).

[68] TAInstruments. TGA Brochure. http://www.tainstruments . com/pdf/brochure/ 2011\%20TGA\%20Brochure.pdf. 2011 (acessado 4 de julho de 2021).

[69] TAInstruments. TGA Brochure. http : / / www . tainstruments . com / pdf / TGA \% 20Brochure.pdf. Acessado 4 de julho de 2021.

[70] PerkinElmer. 2400 Series II CHNS/O Elemental Analysis. https: //resources. perkinelmer.com/lab-solutions/resources/docs/BRO_2400_SeriesII_CHNSO_ Elemental_Analysis.pdf. Acessado 4 de julho de 2021.

[71] AMETEK. SpectroArcos brochure. http://www.potencialzero.com/media/33905/ br_arcosen082011.pdf. Acessado 5 de julho de 2021.

[72] Linda E. Franken, Kay Grünewald, Egbert J. Boekema e Marc C. A. Stuart. "A Technical Introduction to Transmission Electron Microscopy for Soft-Matter: Imaging, Possibilities, Choices, and Technical Developments". Em: Small 16.14 (2020).

[73] P. Petrov, J. Yuan, K. Yoncheva, A. H. E. Müller e C. B. Tsvetanov. "Wormlike morphology formation and stabilization of pluronic P123 micelles by solubilization of pentaerythritol tetraacrylate". Em: Journal of Physical Chemistry B 112 (2008).

[74] S. Velu, V. Ramkumar, A. Narayanan e C. S. Swamy. "Effect of interlayer anions on the physicochemical properties of zinc-aluminium hydrotalcite-like compounds". Em: JOURNAL OF MATERIALS SCIENCE 32 (1997), pp. 957-964.

[75] Fredy Rodriguez-Rivas, Adrián Pastor, Cristobalina Barriga, Manuel Cruz-Yusta, Luis Sánchez e Ivana Pavlovic. "Effect of interlayer anions on the physicochemical properties of zinc-aluminium hydrotalcite-like compounds". Em: Chemical Engineering Journal 346 (2018), pp. 151-158.

[76] S. Marappa, S. Radha e P. V. Kamath. "Nitrate-intercalated layered double hydroxides - Structure model, order, and disorder". Em: European Journal of Inorganic Chemistry 12 (2013), pp. 2122-2128.

[77] Baiyi Shao, Pingping Feng, Xinying Wang, Fangming Cui e Xiaojing Yang. "Orientation of (Hetero) Aromatic Anions in the LEuH Interlayer and Enhanced Photoluminescence". Em: The Journal of Physical Chemistry C 123.12 (2019), pp. 74677474 .

[78] V. A. Drits e A. S. Bookin. Layered Double Hydroxides: Present and Future - Chapter 2. Nova Science Publishers, 2001.

[79] Christophe Vaysse, Liliane Guerlou-Demourgues, Alain Demourgues, Florian Lazartigues, David Fertier e Claude Delmas. "New (Ni, Co)-based layered double hydroxides with intercalated oxometalate (Mo, W) species, obtained by chimie douce reactions". Em: J. Mater. Chem. 12.4 (2002), pp. 1035-1043. DOI: 10.1039/B107791K.

[80] Anthony W Musumeci, Zhi Ping Xu, Suzanne V Smith, Rodney F Minchin e Darren J Martin. "Layered double hydroxide nanoparticles incorporating terbium: applicability as a fluorescent probe and morphology modifier". Em: Journal of Nanoparticle Research 12.1 (2010), pp. 111-120. 
[81] Sandra Gago, Martyn Pillinger, Rute A. Sá Ferreira, Luís D. Carlos, Teresa M. Santos e Isabel S. Gonçalves. "Immobilization of Lanthanide Ions in a Pillared Layered Double Hydroxide". Em: Chem. Mater. 17.23 (2005), pp. 5803-5809. Dor: 10.1021/ cm051431p.

[82] Fengxia Geng, Hao Xin, Yoshitaka Matsushita, Renzhi Ma, Masahiko Tanaka, Fujio Izumi, Nobuo Iyi e Takayoshi Sasaki. "New Layered Rare-Earth Hydroxides with Anion-Exchange Properties". Em: Chem. Eur. J. 14 (2008), pp. 9255-9260. DOI: 10. 1002/chem. 200800127.

[83] Christian Serre, Franck Millange, Christelle Thouvenot, Nicole Gardant, Fabienne Pellé e Gérard Férey. "Synthesis, characterisation and luminescent properties of a new three-dimensional lanthanide trimesate: M ((C 6 H 3)-(CO 2) 3) (M= Y, Ln) or MIL-78". Em: Journal of Materials Chemistry 14.10 (2004), pp. 1540-1543.

[84] C. Daiguebonne, O. Guilloa, Y. Gérault, A. Lecerf e K. Boubekeur. "Synthesis and crystal structure of two new rare earth trimesate complexes: ErTMA(H2O) $5 \cdot 3.5 \mathrm{H} 2 \mathrm{O}$ and YTMA(H2O)6". Em: Inorganica Chimica Acta 284.1 (1999), pp. 139-145. ISSN: 0020-1693. DOI: https : / / doi . org/10 . 1016/S0020-1693(98) 00283-7. URL: https://www.sciencedirect.com/science/article/pii/S0020169398002837.

[85] Ivan GN Silva, Danilo Mustafa, Bruno Andreoli, Maria CFC Felinto, Oscar L Malta e Hermi F Brito. "Highly luminescent Eu3+-doped benzenetricarboxylate based materials". Em: Journal of Luminescence 170 (2016), pp. 364-368.

[86] G. R. Choppin, P. A. Bertrand, Y. Hasegawa e E. N. Rizkalla. "Thermodynamics of complexation of lanthanides by benzoic and isophthalic acids". Em: Inorg. Chem. 21.10 (1982), pp. 3722-3724. DOI: 10.1021/ic00140a025.

[87] Paul L. Brown e Christian Ekberg. Hydrolysis of Metal Ions - Chap 6: Scandium, Ytrium and the Lanthanide Metals. Wiley, 2016.

[88] Shivanna Marappa e P. Vishnu Kamath. "Structure of the Carbonate-Intercalated Layered Double Hydroxides: A Reappraisal". Em: Industrial and Engineering Chemistry Research 54 (2015), 11075-11079.

[89] Hong-Gu Jeon, Hyunsub Kim, Hyunjin Jung e Song-Ho Byeon. "Phosphate uptake behavior of layered rare earth hydroxides l-RE(OH)3 ( $\mathrm{RE}=\mathrm{Sm}, \mathrm{Gd}, \mathrm{Er}$, and Y) from water". Em: Solid State Sciences 81 (2018), pp. 1-7. DOI: 10.1016/j . solidstatesciences.2018.04.008.

[90] T. Stumpf, H. Curtius, C. Walther, K. Dardenne, K. Ufer e T. Fanghanel. "Incorporation of $\mathrm{Eu}(\mathrm{III})$ into Hydrotalcite: A TRLFS and EXAFS Study". Em: Environ. Sci. Technol. 41 (2007), pp. 3186-3191. DOI: 10.1021/es0624873.

[91] Vera R. L. Constantino e Thomas J. Pinnavaia. "Basic Properties of Mg2+i-jAl3+x Layered Double Hydroxides Intercalated by Carbonate, Hydroxide, Chloride, and Sulfate Anions". Em: Inorg. Chem. 34 (1995), pp. 883-892.

[92] Alexandre A. S. Goncalves, Maria J. F. Costa, Liping Zhang, Filip Ciesielczyk e Mietek Jaroniec. "One-Pot Synthesis of MeAl2O4 $(\mathrm{Me}=\mathrm{Ni}$, Co, or $\mathrm{Cu}$ ) Supported on $\gamma$-Al2O3 with Ultralarge Mesopores: Enhancing Interfacial Defects in $\gamma$-Al2O 3 To Facilitate the Formation of Spinel Structures at Lower Temperatures". Em: Chem. Mater. 30 (2018), 436-446. 
[93] Ernesto Rezende Souza, Ivan G.N. Silva, Ercules E.S. Teotonio, Maria C.F.C. Felinto e Hermi F. Brito. "Optical properties of red, green and blue emitting rare earth benzenetricarboxylate compounds". Em: Journal of Luminescence 130 (2010), 283291.

[94] Vanessa Prevot, Claude Forano e Jean Pierre Besse. "Hybrid derivatives of layered double hydroxides". Em: Appl. Clay Sci. 18 (2001), pp. 3-15. DoI: 10.1016/S0169$1317(00) 00025-9$.

[95] Geetanjali Mishra, Barsha Dash, Sony Pandey e Prangya Paramita Mohanty. "Antibacterial actions of silver nanoparticles incorporated Zn-Al layered double hydroxide and its spinel". Em: Journal of Environmental Chemical Engineering 1.4 (2013), pp. 1124-1130.

[96] Zhongzhu Yang, Fenghua Wanga, Chang Zhang, Guangming Zeng, Xiaofei Tan, Zhigang Yu, Yu Zhong, Hou Wangab e Fang Cuiab. "Utilization of LDH-based materials as potential adsorbents and photocatalysts for the decontamination of dyes wastewater: a review". Em: RSC Advances 6 (2016), pp. 79415-36.

[97] Jianbo Liang, Renzhi Ma e Takayoshi Sasaki. "Layered rare earth hydroxides (LREHs): synthesis and structure characterization towards multifunctionality". Em: Dalton Trans. 43.27 (2014), pp. 10355-10364. DOI: 10.1039/C4DT00425F

[98] Xuejiao Wang, Ji-Guang Li, Maxim S. Molokeev, Xiaojun Wang, Weigang Liu, Qi Zhu, Hidehiko Tanaka, Keiko Suzuta, Byung-Nam Kimc e Yoshio Sakkac. "Hydrothermal crystallization of a $\mathrm{Ln} 2(\mathrm{OH}) 4 \mathrm{SO} 4 \mathrm{nH} 2 \mathrm{O}$ layered compound for a wide range of $\mathrm{Ln}(\mathrm{Ln}=\mathrm{La}-\mathrm{Dy})$, thermolysis, and facile transformation into oxysulfate and oxysulfide phosphors". Em: RSC Adv. 7 (2017), p. 13331. DOI: 10.1039/c7ra00645d.

[99] Dimy Nanclares, Alysson F. Morais, Thainá Calaça, Ivan G. N. Silva e Danilo Mustafa. "A class of novel luminescent layered double hydroxide nanotubes". Em: $R S C$ Advances 11.40 (2021), pp. 24747-24751. DOI: 10.1039/D1RA03948B.

[100] R. D. Shannon. "Revised effective ionic radii and systematic studies of interatomic distances in halides and chalcogenides". Em: Acta Crystallographica Section A 32.5 (1976), pp. 751-767. DOI: 10.1107/S0567739476001551.

[101] P. S. Peijzel, P. Vermeulen, W. J. M. Schrama, A. Meijerink, M. F. Reid e G. W. Burdick. "High-resolution measurements of the vacuum ultraviolet energy levels of trivalent gadolinium by excited state excitation". Em: Phys. Rev. B 71 (2005). DoI: 10.1103/PhysRevB.71.125126.

[102] Koen Binnemans. "Interpretation of europium (III) spectra". Em: Coordination Chemistry Reviews 295 (2015), pp. 1-45.

[103] Koen Binnemans e Christiane Görller-Walrand. "Application of the Eu3+ ion for site symmetry determination". Em: Journal of Rare Earths 14.3 (1996), pp. 173-180.

[104] K.Binnemans, K. van Herck e C. Görller-Walrand. "Influence of dipicolinate ligands on the spectroscopic properties of europium(III) in solution". Em: Wiley-Interscience (1967).

[105] M. J. Weber. "Optical properties of ions in crystals". Em: Chem. Phys. Lett. 266.297 (1997). 
[106] R. M. Supkowski e W. D. W. Horrocks. "On the determination of the number of water molecules, q, coordinated to europium(III) ions in solution from luminescence decay lifetimes". Em: Inorg. Chim. Acta 340 (2002), pp. 44-48. DOI: 10.1016/S00201693(02) 01022-8.

[107] W. D. Horrocks e D. R. Sudnick. "Lanthanide Ion Luminescence Probes of the Structure of Biological Macromolecules". Em: Acc. Chem. Res. 14.12 (1981), pp. 384-392. DOI: doi.org/10.1021/ar00072a004.

[108] D. L. Dexter. "A Theory of Sensitized Luminescence in Solids". Em: J. Chem. Phys. 21 (1953), p. 836. DOI: 10.1063/1.1699044.

[109] Shiori Miyazaki, Kiyoshi Miyata, Haruna Sakamoto, Fumiya Suzue, Yuichi Kitagawa, Yasuchika Hasegawa e Ken Onda. "Dual Energy Transfer Pathways from an Antenna Ligand to Lanthanide Ion in Trivalent Europium Complexes with Phosphine-Oxide Bridges". Em: J. Phys. Chem. A 124.33 (2020), pp. 6601-6606. DOI: 10.1021/acs. jpca.0c02224.

[110] Daniel C. Harris. Applications of Spectrophotometry - Quantitative Chemical Analysis. W. H. Freeman e Co., 2010. ISBN: 978-1-4292-1815-3. 



\section{ANEXO A - Medidas complementares de PXRD}

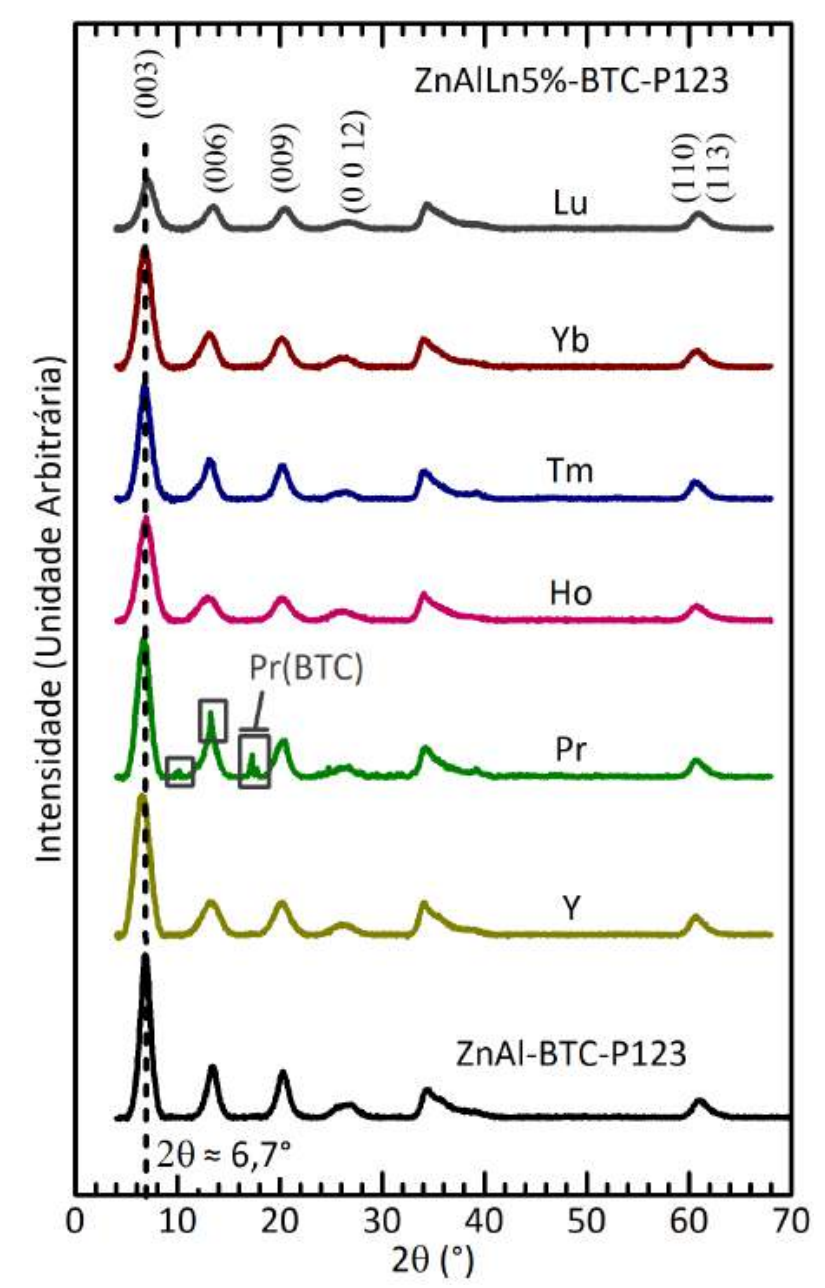

Figura A.1 - XRD das amostras contendo 5\% de Y, Pr, Ho, Tm, Yb e Lu. 

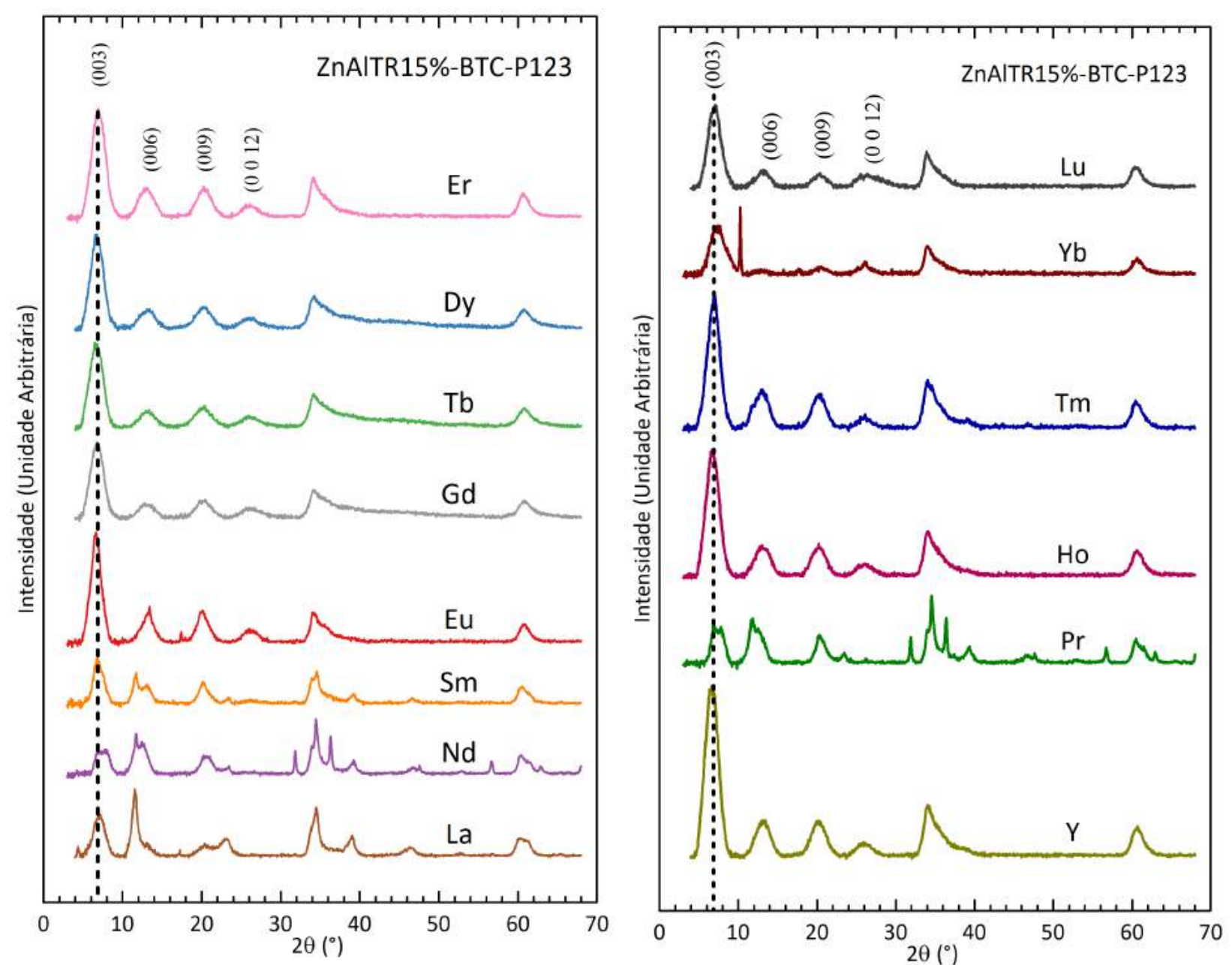

Figura A.2 - XRD das amostras contendo 15\% de TRs. 


\section{ANEXO B - Medidas complementares de estabilidade térmica}
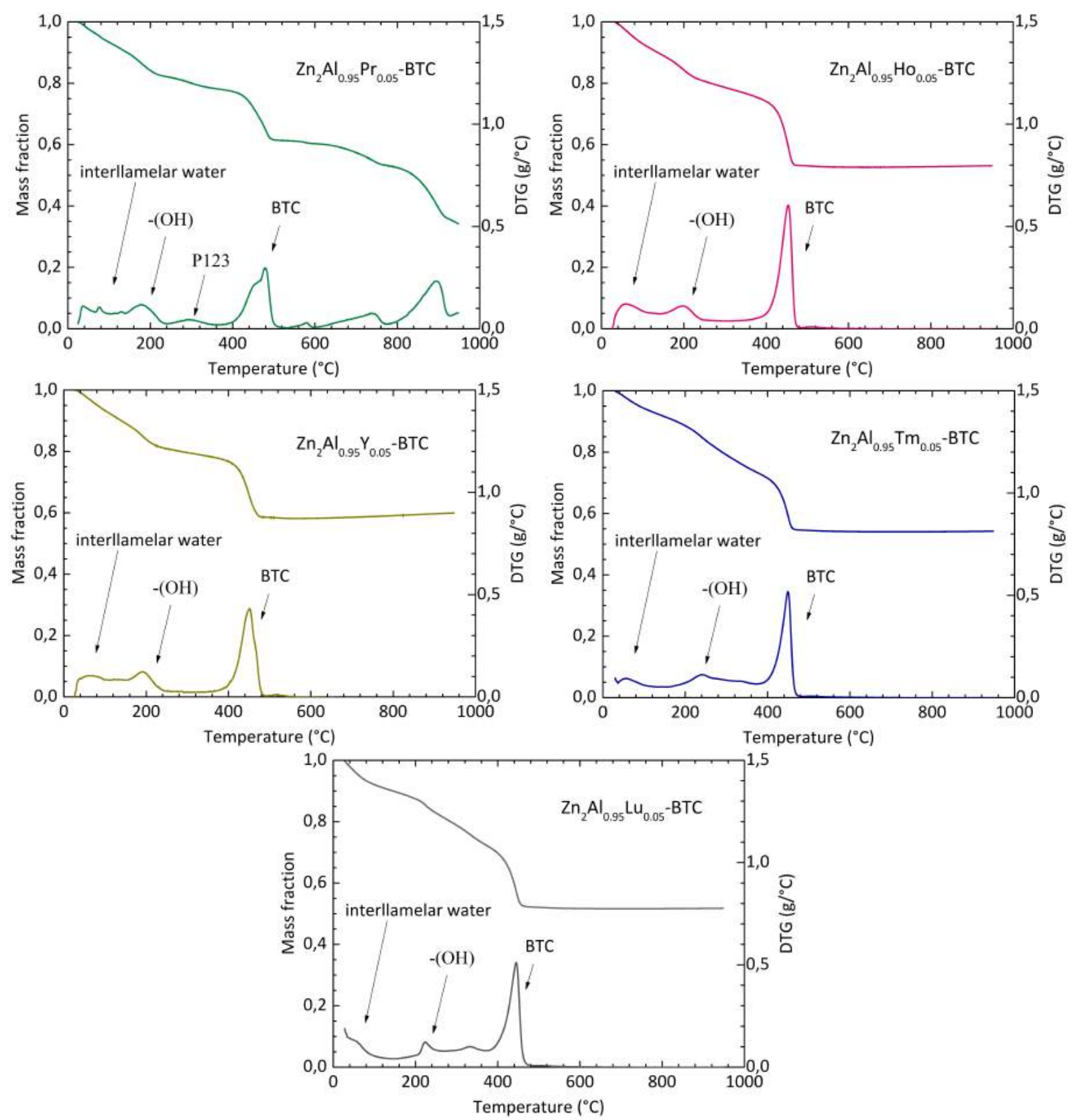

Figura B.1 - Termogravimetria das amostras contendo Y, Pr, Ho, Tm e Lu. 



\section{ANEXO C - Código para cálculo dos parâmetros fenomenológicos de Judd Ofelt}

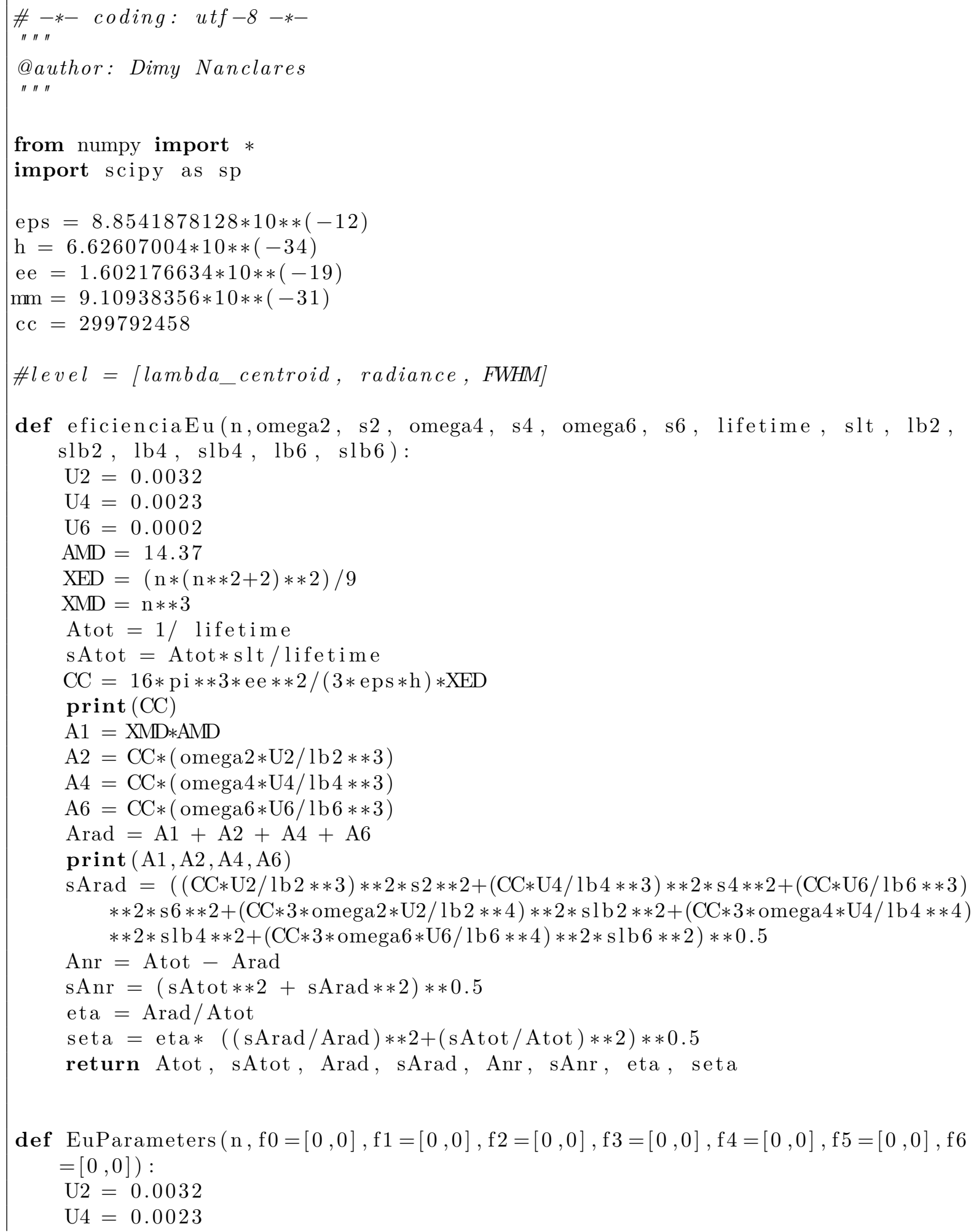


$\mathrm{U} 6=0.0002$

$\mathrm{AMD}=14.37$

const $=9.6 \mathrm{e}-42 / 4.803 \mathrm{e}-10 * * 2$

$\mathrm{X}=9 * \mathrm{n} * * 3 /(\mathrm{n} *(\mathrm{n} * * 2+2) * * 2)$

omega $2=$ const $*(\mathrm{f} 2 \exp [0] * 100) * * 4 * \mathrm{X} * \mathrm{f} 2[1] /((\mathrm{f} 1 \exp [0] * 100) * * 4 * \mathrm{f} 1[1]$ $* \mathrm{U} 2)$

omega $4=\mathrm{const} *(\mathrm{f} 4 \exp [0] * 100) * * 4 * \mathrm{X} * \mathrm{f} 4[1] /((\mathrm{f} 1 \exp [0] * 100) * * 4 * \mathrm{f} 1[1]$ $* \mathrm{U} 4)$

omega $6=\mathrm{const} *(\mathrm{f} 6 \exp [0] * 100) * * 4 * \mathrm{X} * \mathrm{f} 6[1] /((\mathrm{f} 1 \exp [0] * 100) * * 4 * \mathrm{f} 1[1]$ *U6)

return omega 2 , omega4, omega6

def EuParametersSI $(\mathrm{n}, \mathrm{f} 0=[0,0,0], \mathrm{f} 1=[0,0,0], \mathrm{f} 2=[0,0,0], \mathrm{f} 3=[0,0,0], \mathrm{f} 4=[0,0,0], \mathrm{f} 5$ $=[0,0,0], \mathrm{f} 6=[0,0,0])$ :

$\mathrm{U} 2=0.0032$

$\mathrm{U} 4=0.0023$

$\mathrm{U} 6=0.0002$

$\mathrm{AMD}=14.37$

$\mathrm{sF} 0=0.04171$

$\mathrm{sF} 1=0.01369$

$\mathrm{sF} 2=0.01439$

$\mathrm{sF} 3=0.06237$

$\mathrm{sF} 4=0.05151$

$\mathrm{sF} 6=0.01532$

const $=3 * \mathrm{eps} * \mathrm{~h} /(16 * \mathrm{pi} * * 3 * \mathrm{ee} * * 2)$

$\mathrm{X}=9 * \mathrm{n} * * 3 /(\mathrm{n} *(\mathrm{n} * * 2+2) * * 2)$

$\mathrm{XMD}=\mathrm{n} * * 3$

$\mathrm{CC}=4 * \mathrm{pi} * \mathrm{f} 1[1] * \mathrm{f} 1[0] /(\mathrm{h} * \mathrm{cc} * \mathrm{XMD} * \mathrm{AMD})$

print $(\mathrm{CC})$

omega $2=$ const $* \mathrm{AMD} *(\mathrm{f} 2[0]) * * 4 * \mathrm{X} * \mathrm{f} 2[1] /((\mathrm{f} 1[0]) * \mathrm{f} 1[1] * \mathrm{U} 2)$

omega4 $=$ const $* \mathrm{AMD} *(\mathrm{f} 4[0]) * * 4 * \mathrm{X} * \mathrm{f} 4[1] /((\mathrm{f} 1[0]) * \mathrm{f} 1[1] * \mathrm{U} 4)$

omega $6=$ const $* \mathrm{AMD} *(\mathrm{f} 6[0]) * * 4 * \mathrm{X} * \mathrm{f} 6[1] /((\mathrm{f} 1[0]) * \mathrm{f} 1[1] * \mathrm{U} 6)$

$\mathrm{s} 2=\operatorname{omega} 2 *((\mathrm{f} 2[2] / 2) * * 2 / \mathrm{f} 2[0] * * 2+(\mathrm{f} 1[2] / 2) * * 2 / \mathrm{f} 1[0] * * 2+\mathrm{sF} 2 * * 2+\mathrm{sF} 1$ $* * 2) * * 0.5$

$\mathrm{s} 4=\operatorname{omega} 2 *((\mathrm{f} 4[2] / 2) * * 2 / \mathrm{f} 4[0] * * 2+(\mathrm{f} 1[2] / 2) * * 2 / \mathrm{f} 1[0] * * 2+\mathrm{sF} 4 * * 2+\mathrm{sF} 1$ $* * 2) * * 0.5$

$\mathrm{s} 6=\operatorname{omega} 2 *((\mathrm{f} 6[2] / 2) * * 2 / \mathrm{f} 6[0] * * 2+(\mathrm{f} 1[2] / 2) * * 2 / \mathrm{f} 1[0] * * 2+\mathrm{sF} 6 * * 2+\mathrm{sF} 1$ $* * 2) * * 0.5$

return omega $2, \mathrm{~s} 2$, omega4, s4, omega6, s6

def eficienciaSm (n, omega2, s2, omega4, s4, omega6, s6, lifetime, slt, trans): $\mathrm{U} 22, \mathrm{U} 24, \mathrm{U} 26=0.0000,0.0078,0.0075$

$\mathrm{U} 32, \mathrm{U} 34, \mathrm{U} 36=0.0096,0.0061,0.0019$

$\mathrm{U} 42, \mathrm{U} 44, \mathrm{U} 46=0.0000,0.0045,0.0018$

$\operatorname{lb} 2, \operatorname{slb} 2=\operatorname{trans}[1][0], \operatorname{trans}[1][2] / 2$

lb3, slb3 = trans [2][0], trans [2][2]/2

$\operatorname{lb} 4, \operatorname{slb} 4=\operatorname{trans}[3][0], \operatorname{trans}[3][2] / 2$

$\mathrm{AMD}=2 * \mathrm{pi} * \mathrm{ee} * * 2 * 1.73 \mathrm{e}-8 /(\operatorname{eps} * \mathrm{~mm} * \mathrm{cc} * \operatorname{trans}[0][0] * * 2)$

$\mathrm{XED}=(\mathrm{n} *(\mathrm{n} * * 2+2) * * 2) / 9$

$\mathrm{XMD}=\mathrm{n} * * 3$

Atot $=1 /$ lifetime

sAtot $=$ Atot $*$ slt $/$ lifetime

$\mathrm{CC}=16 * \mathrm{pi} * * 3 * \mathrm{ee} * * 2 /(6 * 3 * \mathrm{eps} * \mathrm{~h}) * \mathrm{XED}$

print $(\mathrm{AMD}, \mathrm{CC})$

$\mathrm{A} 1=\mathrm{XMD} * \mathrm{AMD}$

$\mathrm{A} 2=\mathrm{CC} *($ omega $2 * \mathrm{U} 22+\mathrm{omega} 4 * \mathrm{U} 24+\mathrm{omega} 6 * \mathrm{U} 26) / \mathrm{lb} 2 * * 3$ 


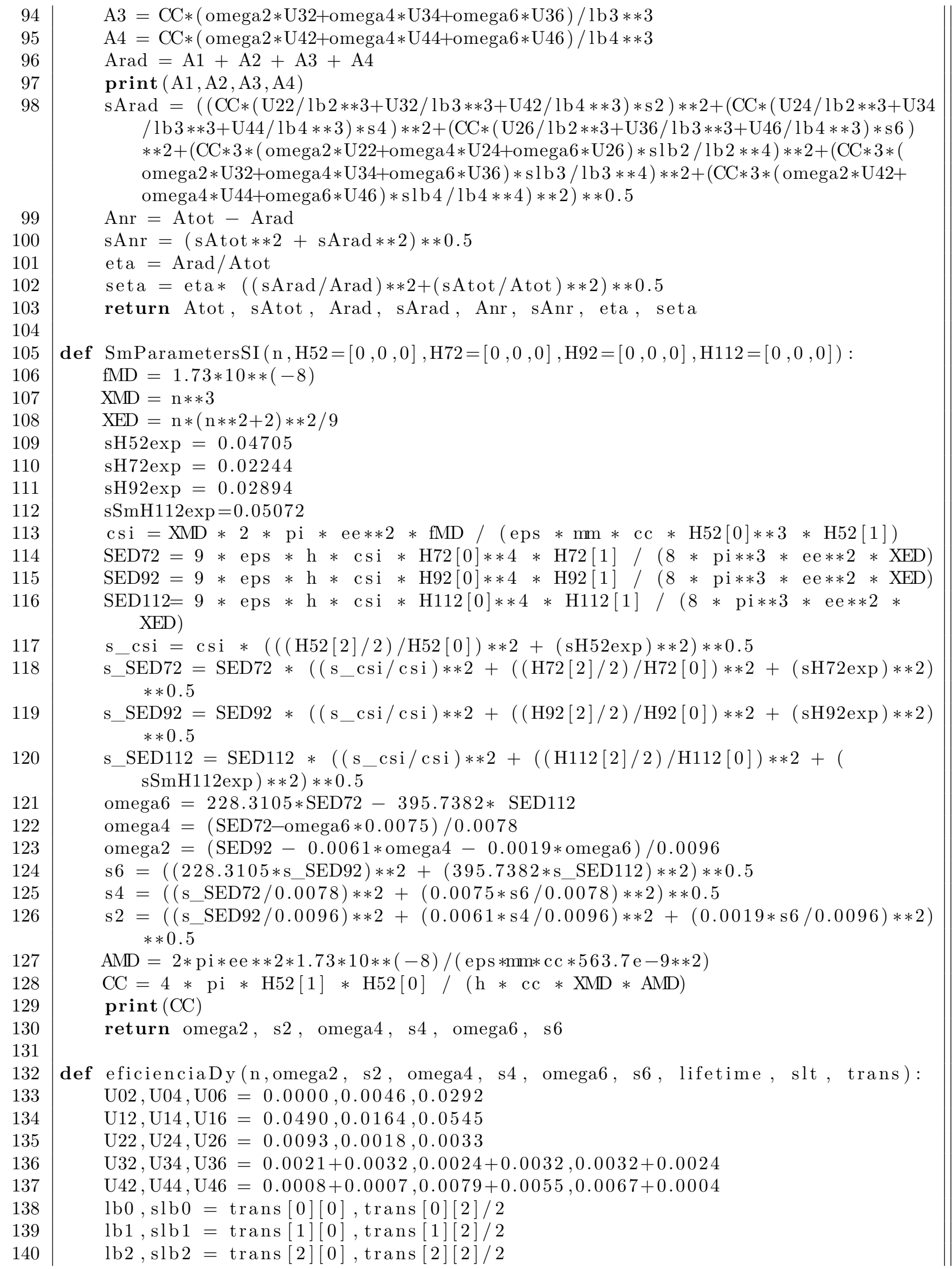


lb3, slb3 $=\operatorname{trans}[3][0], \operatorname{trans}[3][2] / 2$

$\operatorname{lb} 4, \operatorname{slb} 4=\operatorname{trans}[4][0], \operatorname{trans}[4][2] / 2$

$\mathrm{AMD}=11.72$

$\mathrm{XED}=(\mathrm{n} *(\mathrm{n} * * 2+2) * * 2) / 9$

$\mathrm{XMD}=\mathrm{n} * * 3$

Atot $=1 /$ lifetime

sAtot $=$ Atot $*$ slt $/$ lifetime

$\mathrm{CC}=16 *$ pi $* * 3 *$ ee $* * 2 /(10 * 3 * \operatorname{eps} * \mathrm{~h}) * \mathrm{XED}$

print $(\mathrm{AMD}, \mathrm{CC})$

$\mathrm{A} 0=\mathrm{CC} *($ omega $2 * \mathrm{U} 02+$ omega $4 * \mathrm{U} 04+\mathrm{omega} 6 * \mathrm{U} 06) / \mathrm{lb} 0 * * 3$

$\mathrm{A} 1=\mathrm{CC} *($ omega $2 * \mathrm{U} 12+\mathrm{omega} 4 * \mathrm{U} 14+\mathrm{omega} 6 * \mathrm{U} 16) / \mathrm{lb} 1 * * 3$

$\mathrm{A} 2=\mathrm{CC} *($ omega $2 * \mathrm{U} 22+$ omega $4 * \mathrm{U} 24+\mathrm{omega} 6 * \mathrm{U} 26) / \mathrm{lb} 2 * * 3$

$\mathrm{A} 3=\mathrm{CC} *($ omega $2 * \mathrm{U} 32+$ omega $4 * \mathrm{U} 34+\mathrm{omega} 6 * \mathrm{U} 36) / \mathrm{lb} 3 * * 3+\mathrm{XMD} * \mathrm{AMD}$

$\mathrm{A} 4=\mathrm{CC} *($ omega $2 * \mathrm{U} 42+$ omega $4 * \mathrm{U} 44+$ omega $6 * \mathrm{U} 46) / \mathrm{lb} 4 * * 3$

$\mathrm{Arad}=\mathrm{A} 0+\mathrm{A} 1+\mathrm{A} 2+\mathrm{A} 3+\mathrm{A} 4$

print $(\mathrm{A} 0, \mathrm{~A} 1, \mathrm{~A} 2, \mathrm{~A} 3, \mathrm{~A} 4)$

$\mathrm{sArad}=((\mathrm{CC} *(\mathrm{U} 02 / \mathrm{lb} 0 * * 3+\mathrm{U} 12 / \mathrm{lb} 1 * * 3+\mathrm{U} 22 / \mathrm{lb} 2 * * 3+\mathrm{U} 32 / \mathrm{lb} 3 * * 3+\mathrm{U} 42 / \mathrm{lb} 4 * * 3) * \mathrm{~s} 2)$ $* * 2+(\mathrm{CC} *(\mathrm{U} 04 / \mathrm{lb} 0 * * 3+\mathrm{U} 14 / \mathrm{lb} 1 * * 3+\mathrm{U} 24 / \mathrm{lb} 2 * * 3+\mathrm{U} 34 / \mathrm{lb} 3 * * 3+\mathrm{U} 44 / \mathrm{lb} 4 * * 3) * \mathrm{~s} 4)$ $* * 2+(\mathrm{CC} *(\mathrm{U} 06 / \mathrm{lb} 0 * * 3+\mathrm{U} 16 / \mathrm{lb} 1 * * 3+\mathrm{U} 26 / \mathrm{lb} 2 * * 3+\mathrm{U} 36 / \mathrm{lb} 3 * * 3+\mathrm{U} 46 / \mathrm{lb} 4 * * 3) * \mathrm{~s} 6)$ $* * 2+(\mathrm{CC} * 3 *($ omega $2 * \mathrm{U} 02+$ omega $4 * \mathrm{U} 04+\mathrm{omega} 6 * \mathrm{U} 06) * \mathrm{~s} 1 \mathrm{~b} 0 / \mathrm{lb} 0 * * 4) * * 2+(\mathrm{CC} * 3 *($ omega $2 * \mathrm{U} 12+$ omega $4 * \mathrm{U} 14+$ omega $6 * \mathrm{U} 16) * \mathrm{slb} 1 / \mathrm{lb} 1 * * 4) * * 2+(\mathrm{CC} * 3 *($ omega $2 * \mathrm{U} 22+$ omega $4 * \mathrm{U} 24+$ omega $6 * \mathrm{U} 26) * \operatorname{slb} 2 / \mathrm{lb} 2 * * 4) * * 2+(\mathrm{CC} * 3 *($ omega $2 * \mathrm{U} 32+$ omega $4 * \mathrm{U} 34+$ omega $6 * \mathrm{U} 36) * \operatorname{slb} 3 / \mathrm{lb} 3 * * 4) * * 2+(\mathrm{CC} * 3 *($ omega $2 * \mathrm{U} 42+$ omega $4 * \mathrm{U} 44+$ omega $6 * \mathrm{U} 46) *$ $\operatorname{slb} 4 / \operatorname{lb} 4 * * 4) * * 2) * * 0.5$

Anr $=$ Atot - Arad

$\operatorname{sAnr}=(\operatorname{sAtot} * * 2+\operatorname{sArad} * * 2) * * 0.5$

eta $=$ Arad $/$ Atot

seta $=\operatorname{eta} *((\operatorname{sArad} / \operatorname{Arad}) * * 2+(\operatorname{sAtot} /$ Atot $) * * 2) * * 0.5$

return Atot, sAtot, Arad, sArad, Anr, sAnr, eta, seta

def DyParametersSI $(\mathrm{n}, \mathrm{H} 152=[0,0,0], \mathrm{H} 132=[0,0,0], \mathrm{H} 112=[0,0,0], \mathrm{H} 92 \mathrm{~F} 112=[0,0,0]$, $\mathrm{H} 72 \mathrm{~F} 92=[0,0,0]$, sigma $=$ 'on ') :

if $\mathrm{H} 72 \mathrm{~F} 92[1] !=0$ :

$\mathrm{U}=\mathrm{z} \operatorname{eros}((4,3))$

$\mathrm{b}=\mathrm{zeros}(4)$

$\mathrm{U}[0][0], \mathrm{U}[0][1], \mathrm{U}[0][2]=0.0000,0.0046,0.0292$

$\mathrm{U}[1][0], \mathrm{U}[1][1], \mathrm{U}[1][2]=0.0490,0.0164,0.0545$

$\mathrm{U}[2][0], \mathrm{U}[2][1], \mathrm{U}[2][2]=0.0093,0.0018,0.0033$

$\mathrm{U}[3][0], \mathrm{U}[3][1], \mathrm{U}[3][2]=0.0008+0.0007,0.0079+0.0055,0.0067+0.0004$

$\mathrm{AMD}=11.72$

$\mathrm{XMD}=\mathrm{n} * * 3$

$\mathrm{XED}=\mathrm{n} *(\mathrm{n} * * 2+2) * * 2 / 9$

const $=3 * \operatorname{eps} * 10 /(4 *$ pi $* * 2 *$ ee $* * 2 * \mathrm{XED} * \mathrm{cc})$

$\mathrm{b}[0]=\mathrm{const} * \mathrm{H} 152[0] * * 4 * \mathrm{H} 152[1]$

$\mathrm{b}[1]=$ const $* \mathrm{H} 132[0] * * 4 * \mathrm{H} 132[1]$

$\mathrm{b}[2]=$ const $* \mathrm{H} 112[0] * * 4 * \mathrm{H} 112[1]$

$\mathrm{b}[3]=\mathrm{const} * \mathrm{H} 72 \mathrm{~F} 92[0] * * 4 * \mathrm{H} 72 \mathrm{~F} 92[1]$

else :

$\mathrm{U}=\mathrm{z} \operatorname{eros}((3,3))$

$\mathrm{b}=\mathrm{z} \operatorname{eros}(3)$

$\mathrm{U}[0][0], \mathrm{U}[0][1], \mathrm{U}[0][2]=0.0000,0.0046,0.0292$

$\mathrm{U}[1][0], \mathrm{U}[1][1], \mathrm{U}[1][2]=0.0490,0.0164,0.0545$

$\mathrm{U}[2][0], \mathrm{U}[2][1], \mathrm{U}[2][2]=0.0093,0.0018,0.0033$

$\mathrm{AMD}=11.72$ 


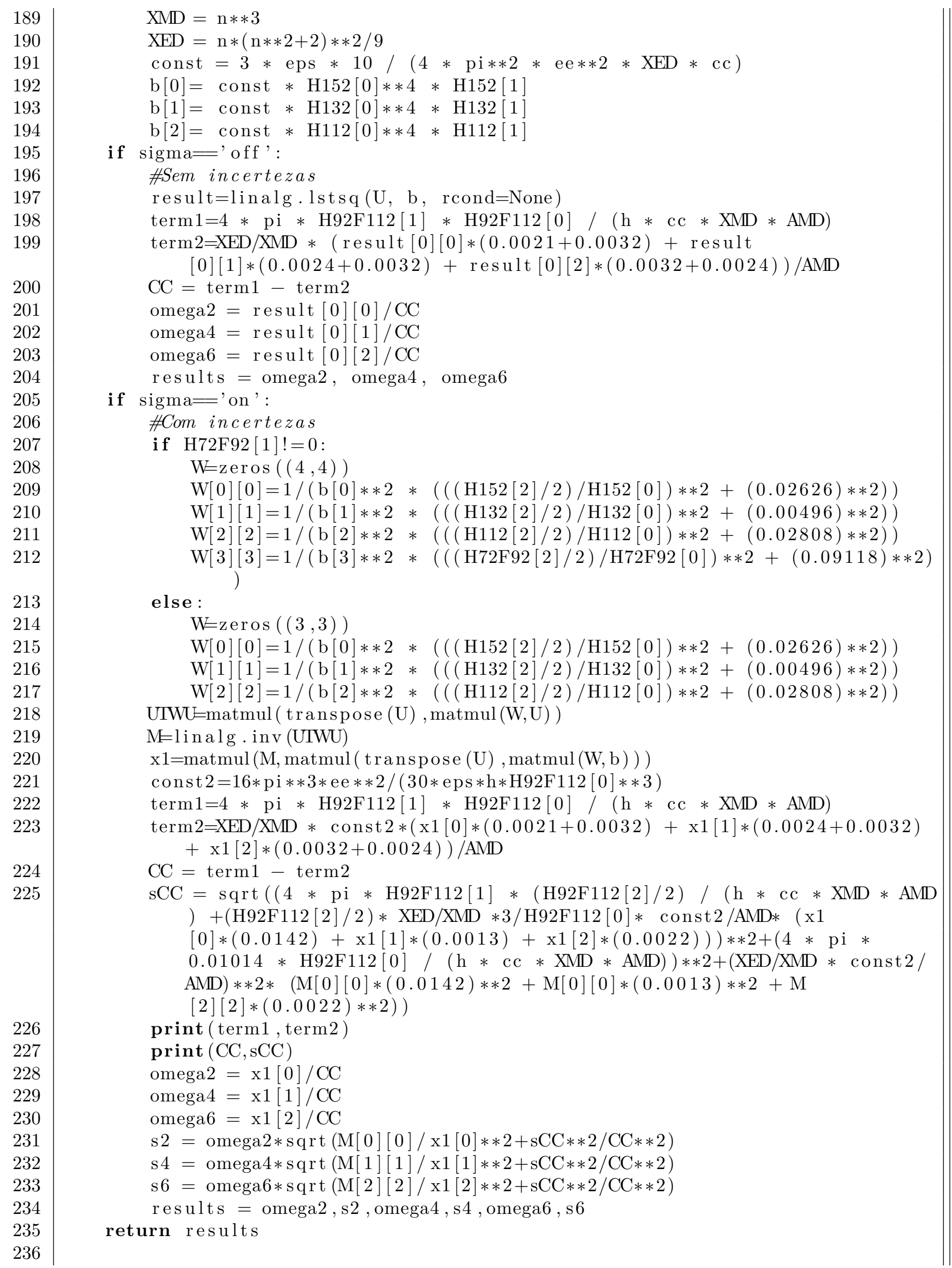


def DyParametersSI4peaks $(\mathrm{n}, \mathrm{H} 152=[0,0], \mathrm{H} 132=[0,0], \mathrm{H} 112=[0,0], \mathrm{H} 92 \mathrm{~F} 112=[0,0])$ :

$\mathrm{U}=\mathrm{zeros}((3,3))$

$\mathrm{b}=\operatorname{zeros}(3)$

$\mathrm{U}[0][0], \mathrm{U}[0][1], \mathrm{U}[0][2]=0.0000,0.0046,0.0292$

$\mathrm{U}[1][0], \mathrm{U}[1][1], \mathrm{U}[1][2]=0.0490,0.0164,0.0545$

$\mathrm{U}[2][0], \mathrm{U}[2][1], \mathrm{U}[2][2]=0.0093,0.0018,0.0033$

$\mathrm{AMD}=11.72$

$\mathrm{XMD}=\mathrm{n} * * 3$

$\mathrm{XED}=\mathrm{n} *(\mathrm{n} * * 2+2) * * 2 / 9$

const $=3 * \operatorname{eps} * 10 /(4 *$ pi $* * 2 *$ ee $* * 2 * \mathrm{XED} * \mathrm{cc})$

$\mathrm{b}[0]=$ const $* \mathrm{H} 152[0] * * 4 * \mathrm{H} 152[1]$

$\mathrm{b}[1]=$ const $* \mathrm{H} 132[0] * * 4 * \mathrm{H} 132[1]$

$\mathrm{b}[2]=$ const $* \mathrm{H} 112[0] * * 4 * \mathrm{H} 112[1]$

result=linalg. $\operatorname{solve}(U, b)$

print $(\mathrm{U}, \mathrm{b}$, result)

const $2=16 *$ pi $* * 3 *$ ee $* * 2 /(30 * \operatorname{eps} * \mathrm{~h} * \mathrm{H} 92 \mathrm{~F} 112[0] * * 3)$

$\operatorname{term} 1=4 *$ pi $* \mathrm{H} 92 \mathrm{~F} 112[1] * \mathrm{H} 92 \mathrm{~F} 112[0] /(\mathrm{h} * \mathrm{cc} * \mathrm{XMD} * \mathrm{AMD})$

term $2=\mathrm{XED} / \mathrm{XMD} * \operatorname{const} 2 * \quad($ result $[0] *(0.0021+0.0032)+$ result $[1] *(0.0024+0.0032)+$ result $[2] *(0.0032+0.0024)) / \mathrm{AMD}$

$\mathrm{CC}=\operatorname{term} 1-$ term 2

print $(\mathrm{CC})$

omega $2=\operatorname{result}[0] / \mathrm{CC}$

omega4 $=$ result $[1] / \mathrm{CC}$

omega 6 result $[2] / \mathrm{CC}$

return omega 2 , omega4, omega6

def eficienciaTb (n, omega2, s2, omega4, s4, omega6, s6, lifetime, slt, trans): $\mathrm{U} 02, \mathrm{U} 04, \mathrm{U} 06=0.0000,0.0017,0.0000$

$\mathrm{U} 12, \mathrm{U} 14, \mathrm{U} 16=0.0000,0.0025,0.0000$

$\mathrm{U} 22, \mathrm{U} 24, \mathrm{U} 26=0.0011,0.0004,0.0001$

$\mathrm{U} 32, \mathrm{U} 34, \mathrm{U} 36=0.0022,0.0005,0.0006$

$\mathrm{U} 42, \mathrm{U} 44, \mathrm{U} 46=0.0002,0.0022,0.0014$

$\mathrm{U} 52, \mathrm{U} 54, \mathrm{U} 56=0.0142,0.0013,0.0022$

$\mathrm{U} 62, \mathrm{U} 64, \mathrm{U} 66=0.0009,0.0008,0.0013$

lb0, slb0 = trans $[0][0], \operatorname{trans}[0][2] / 2$

$\operatorname{lb} 1, \operatorname{slb} 1=\operatorname{trans}[1][0], \operatorname{trans}[1][2] / 2$

$\operatorname{lb} 2, \operatorname{slb} 2=\operatorname{trans}[2][0], \operatorname{trans}[2][2] / 2$

lb3, slb3 $=\operatorname{trans}[3][0], \operatorname{trans}[3][2] / 2$

$\operatorname{lb} 4, \operatorname{slb} 4=\operatorname{trans}[4][0], \operatorname{trans}[4][2] / 2$

$\operatorname{lb} 5, \operatorname{slb} 5=\operatorname{trans}[5][0], \operatorname{trans}[5][2] / 2$

$\operatorname{lb} 6, \operatorname{slb} 6=\operatorname{trans}[6][0], \operatorname{trans}[6][2] / 2$

$\mathrm{AMD}=14.32$

$\mathrm{XED}=(\mathrm{n} *(\mathrm{n} * * 2+2) * * 2) / 9$

$\mathrm{XMD}=\mathrm{n} * * 3$

Atot $=1 /$ lifetime

sAtot $=$ Atot $*$ slt $/$ lifetime

$\mathrm{CC}=16 *$ pi $* * 3 *$ ee $* * 2 /(9 * 3 *$ eps $* \mathrm{~h}) * \mathrm{XED}$

print $(\mathrm{AMD}, \mathrm{CC})$

$\mathrm{A} 0=\mathrm{CC} *($ omega $2 * \mathrm{U} 02+$ omega $4 * \mathrm{U} 04+\mathrm{omega} 6 * \mathrm{U} 06) / \mathrm{lb} 0 * * 3$

$\mathrm{A} 1=\mathrm{CC} *($ omega $2 * \mathrm{U} 12+$ omega $4 * \mathrm{U} 14+\mathrm{omega} 6 * \mathrm{U} 16) / \mathrm{lb} 1 * * 3$

$\mathrm{A} 2=\mathrm{CC} *($ omega $2 * \mathrm{U} 22+$ omega $4 * \mathrm{U} 24+\mathrm{omega} 6 * \mathrm{U} 26) / \mathrm{lb} 2 * * 3$

$\mathrm{A} 3=\mathrm{CC} *($ omega $2 * \mathrm{U} 32+$ omega $4 * \mathrm{U} 34+$ omega $6 * \mathrm{U} 36) / \mathrm{lb} 3 * * 3$

$\mathrm{A} 4=\mathrm{CC} *($ omega $2 * \mathrm{U} 42+$ omega $4 * \mathrm{U} 44+$ omega $6 * \mathrm{U} 46) / \mathrm{lb} 4 * * 3$

$\mathrm{A} 5=\mathrm{CC} *($ omega $2 * \mathrm{U} 52+$ omega $4 * \mathrm{U} 54+$ omega $6 * \mathrm{U} 56) / 1 \mathrm{~b} 5 * * 3+\mathrm{XMD} * \mathrm{AMD}$

$\mathrm{A} 6=\mathrm{CC} *($ omega $2 * \mathrm{U} 62+$ omega $4 * \mathrm{U} 64+\mathrm{omega} 6 * \mathrm{U} 66) / \mathrm{lb} 6 * * 3$ 
292

301

302

303

304

305

306

307

308

309

310

311

312

313

314

315

316

317

318

319

320

321

322

323

324

325

326

327

328

329

330

331

332

333

334

print ( $\mathrm{A} 5 \_\mathrm{ED}=$ " , CC $*($ omega $2 * \mathrm{U} 52+\mathrm{omega} 4 * \mathrm{U} 54+\mathrm{omega} 6 * \mathrm{U} 56) / \mathrm{lb} 5 * * 3$, "s=" , CC $*($ $\mathrm{U} 52 * * 2 * \mathrm{~s} 2 * * 2 / \mathrm{lb} 5 * * 6+\mathrm{U} 54 * * 2 * \mathrm{~s} 4 * * 2 / \mathrm{lb} 5 * * 6+\mathrm{U} 56 * * 2 * \mathrm{~s} 6 * * 2 / \mathrm{lb} 5 * * 6+(\mathrm{omega} 2 *$ $\mathrm{U} 52+$ omega $4 * \mathrm{U} 54+$ omega $6 * \mathrm{U} 56) * * 2 * \operatorname{slb} 5 * * 2 / \operatorname{lb} 5 * * 8) * * 0.5)$

$\mathrm{Arad}=\mathrm{A} 0+\mathrm{A} 1+\mathrm{A} 2+\mathrm{A} 3+\mathrm{A} 4+\mathrm{A} 5+\mathrm{A} 6$

print $(\mathrm{A} 0, \mathrm{~A} 1, \mathrm{~A} 2, \mathrm{~A} 3, \mathrm{~A} 4, \mathrm{~A} 5, \mathrm{~A} 6)$

$\mathrm{sArad}=((\mathrm{CC} *(\mathrm{U} 02 / \mathrm{lb} 0 * * 3+\mathrm{U} 12 / \mathrm{lb} 1 * * 3+\mathrm{U} 22 / \mathrm{lb} 2 * * 3+\mathrm{U} 32 / \mathrm{lb} 3 * * 3+\mathrm{U} 42 / \mathrm{lb} 4 * * 3+\mathrm{U} 52 /$ lb $5 * * 3+\mathrm{U} 62 / \mathrm{lb} 6 * * 3) * \mathrm{~s} 2) * * 2+(\mathrm{CC} *(\mathrm{U} 04 / \mathrm{lb} 0 * * 3+\mathrm{U} 14 / \mathrm{lb} 1 * * 3+\mathrm{U} 24 / \mathrm{lb} 2 * * 3+\mathrm{U} 34 /$ $\mathrm{lb} 3 * * 3+\mathrm{U} 44 / \mathrm{lb} 4 * * 3+\mathrm{U} 54 / \mathrm{lb} 5 * * 3+\mathrm{U} 64 / \mathrm{lb} 6 * * 3) * \mathrm{~s} 4) * * 2+(\mathrm{CC} *(\mathrm{U} 06 / \mathrm{lb} 0 * * 3+\mathrm{U} 16 /$ $\mathrm{lb} 1 * * 3+\mathrm{U} 26 / \mathrm{lb} 2 * * 3+\mathrm{U} 36 / \mathrm{lb} 3 * * 3+\mathrm{U} 46 / \mathrm{lb} 4 * * 3+\mathrm{U} 56 / \mathrm{lb} 5 * * 3+\mathrm{U} 66 / \mathrm{lb} 6 * * 3) * \mathrm{~s} 6)$ $* * 2+(\mathrm{CC} * 3 *($ omega $2 * \mathrm{U} 02+$ omega $4 * \mathrm{U} 04+$ omega $6 * \mathrm{U} 06) * \mathrm{~s} 1 \mathrm{~b} 0 / \mathrm{lb} 0 * * 4) * * 2+(\mathrm{CC} * 3 *($ omega $2 * \mathrm{U} 12+$ omega $4 * \mathrm{U} 14+$ omega $6 * \mathrm{U} 16) * \mathrm{slb} 1 / \mathrm{lb} 1 * * 4) * * 2+(\mathrm{CC} * 3 *($ omega $2 * \mathrm{U} 22+$ omega $4 * \mathrm{U} 24+$ omega $6 * \mathrm{U} 26) * \operatorname{slb} 2 / \mathrm{lb} 2 * * 4) * * 2+(\mathrm{CC} * 3 *($ omega $2 * \mathrm{U} 32+$ omega $4 * \mathrm{U} 34+$ omega $6 * \mathrm{U} 36) * \operatorname{slb} 3 / \mathrm{lb} 3 * * 4) * * 2+(\mathrm{CC} * 3 *($ omega $2 * \mathrm{U} 42+\mathrm{omega} 4 * \mathrm{U} 44+\mathrm{omega} 6 * \mathrm{U} 46) *$ $\operatorname{slb} 4 / \operatorname{lb} 4 * * 4) * * 2+(\mathrm{CC} * 3 *($ omega $2 * \mathrm{U} 52+$ omega $4 * \mathrm{U} 54+\mathrm{omega} 6 * \mathrm{U} 56) * \mathrm{slb} 5 / \mathrm{lb} 5 * * 4)$ $* * 2+(\mathrm{CC} * 3 *($ omega $2 * \mathrm{U} 62+$ omega $4 * \mathrm{U} 64+$ omega $6 * \mathrm{U} 66) * \mathrm{~s} \operatorname{lb} 6 / \mathrm{lb} 6 * * 4) * * 2) * * 0.5$

Anr $=$ Atot - Arad

$\mathrm{sAnr}=(\operatorname{sAtot} * * 2+\operatorname{sArad} * * 2) * * 0.5$

eta $=$ Arad $/$ Atot

seta $=\operatorname{eta} *((\operatorname{sArad} / \operatorname{Arad}) * * 2+(\operatorname{sAtot} /$ Atot $) * * 2) * * 0.5$

return Atot, sAtot, Arad, sArad, Anr, sAnr, eta, seta

def $\operatorname{TbParametersSI}(\mathrm{n}, \mathrm{F} 6=[0,0], \mathrm{F} 5=[0,0], \mathrm{F} 4=[0,0], \mathrm{F} 3=[0,0], \mathrm{F} 2=[0,0], \mathrm{F} 1=[0,0], \mathrm{F} 0$ $=[0,0], \operatorname{sigma}=$ 'on' $)$ :

$\mathrm{U}=\mathrm{zeros}((6,3))$

$\mathrm{b}=\mathrm{z} \operatorname{eros}(6)$

$\mathrm{U}[0][0], \mathrm{U}[0][1], \mathrm{U}[0][2]=0.0009,0.0008,0.0013$

$\mathrm{U}[1][0], \mathrm{U}[1][1], \mathrm{U}[1][2]=0.0002,0.0022,0.0014$

$\mathrm{U}[2][0], \mathrm{U}[2][1], \mathrm{U}[2][2]=0.0022,0.0005,0.0006$

$\mathrm{U}[3][0], \mathrm{U}[3][1], \mathrm{U}[3][2]=0.0011,0.0004,0.0001$

$\mathrm{U}[4][0], \mathrm{U}[4][1], \mathrm{U}[4][2]=0.0000,0.0025,0.0000$

$\mathrm{U}[5][0], \mathrm{U}[5][1], \mathrm{U}[5][2]=0.0000,0.0017,0.0000$

$\mathrm{AMD}=14.32$

$\mathrm{XMD}=\mathrm{n} * * 3$

$\mathrm{XED}=\mathrm{n} *(\mathrm{n} * * 2+2) * * 2 / 9$

const $=3 * \operatorname{eps} * 9 /(4 *$ pi $* * 2 *$ ee $* * 2 *$ XED $*$ cc $)$

$\mathrm{b}[0]=$ const $* \mathrm{~F} 6[0] * * 4 * \mathrm{~F} 6[1]$

$\mathrm{b}[1]=$ const $* \mathrm{~F} 4[0] * * 4 * \mathrm{~F} 4[1]$

$\mathrm{b}[2]=\mathrm{const} * \mathrm{~F} 3[0] * * 4 * \mathrm{~F} 3[1]$

$\mathrm{b}[3]=\mathrm{const} * \mathrm{~F} 2[0] * * 4 * \mathrm{~F} 2[1]$

$\mathrm{b}[4]=$ const $* \mathrm{~F} 1[0] * * 4 * \mathrm{~F} 1[1]$

$\mathrm{b}[5]=\mathrm{const} * \mathrm{~F} 0[0] * * 4 * \mathrm{~F} 0[1]$

if $\operatorname{sigma}=$ ' off':

\#Sem incertezas

result=linalg. lstsq (U, b, rcond=None)

$\operatorname{term} 1=4 * \mathrm{pi} * \mathrm{~F} 5[1] * \mathrm{~F} 5[0] /(\mathrm{h} * \mathrm{cc} * \mathrm{XMD} * \mathrm{AMD})$

term $2=\mathrm{XED} / \mathrm{XMD} *($ result $[0][0] *(0.0142)+$ result $[0][1] *(0.0013)+$ result $[0][2] *(0.0022)) / \mathrm{AMD}$

$\mathrm{CC}=\operatorname{term} 1-\operatorname{term} 2$

print ( result $[0], \mathrm{CC})$

omega $2=$ result $[0][0] / \mathrm{CC}$

omega4 = result $[0][1] / \mathrm{CC}$

omega $6=$ result $[0][2] / \mathrm{CC}$

results $=$ omega 2, omega 4, omega 6

if $\operatorname{sigma}=$ ' on':

\#Com incertezas

$\mathrm{W}=\mathrm{zeros}((6,6))$ 
$\mathrm{W}[0][0]=1 /(\mathrm{b}[0] * * 2 *(((\mathrm{~F} 6[2] / 2) / \mathrm{F} 6[0]) * * 2+(0.00626) * * 2))$

$\mathrm{W}[1][1]=1 /(\mathrm{b}[1] * * 2 *(((\mathrm{~F} 4[2] / 2) / \mathrm{F} 4[0]) * * 2+(0.01014) * * 2))$

$\mathrm{W}[2][2]=1 /(\mathrm{b}[2] * * 2 *(((\mathrm{~F} 3[2] / 2) / \mathrm{F} 3[0]) * * 2+(0.01511) * * 2))$

$\mathrm{W}[3][3]=1 /(\mathrm{b}[3] * * 2 *(((\mathrm{~F} 2[2] / 2) / \mathrm{F} 2[0]) * * 2+(0.02617) * * 2))$

$\mathrm{W}[4][4]=1 /(\mathrm{b}[4] * * 2 *(((\mathrm{~F} 1[2] / 2) / \mathrm{F} 1[0]) * * 2+(0.04849) * * 2))$

$\mathrm{W}[5][5]=1 /(\mathrm{b}[5] * * 2 *(((\mathrm{~F} 0[2] / 2) / \mathrm{F} 0[0]) * * 2+(0.06628) * * 2))$

UTWU $=$ matmul $(\operatorname{transpose}(\mathrm{U}), \operatorname{matmul}(\mathrm{W}, \mathrm{U}))$

$\mathrm{M}=$ lin a $\mathrm{lg}$. inv (UTWU)

$\mathrm{x} 1=\operatorname{matmul}(\mathrm{M}, \operatorname{matmul}(\operatorname{transpose}(\mathrm{U}), \operatorname{matmul}(\mathrm{W}, \mathrm{b})))$

print $(\mathrm{x} 1)$

const $2=16 * \mathrm{pi} * * 3 *$ ee $* * 2 /(27 * \operatorname{eps} * \mathrm{~h} * \mathrm{~F} 5[0] * * 3)$

$\operatorname{term} 1=4 * \mathrm{pi} * \mathrm{~F} 5[1] * \mathrm{~F} 5[0] /(\mathrm{h} * \mathrm{cc} * \mathrm{XMD} * \mathrm{AMD})$

term $2=\mathrm{XED} / \mathrm{XMD} * \operatorname{const} 2 / \mathrm{AMD} *(\mathrm{x} 1[0] *(0.0142)+\mathrm{x} 1[1] *(0.0013)+\mathrm{x} 1$

$$
[2] *(0.0022))
$$

print (term 1 , term 2$)$

$\mathrm{CC}=\operatorname{term} 1-\operatorname{term} 2$

$\mathrm{sCC}=\operatorname{sqrt}((4 * \mathrm{pi} * \mathrm{~F} 5[1] *(\mathrm{~F} 5[2] / 2) /(\mathrm{h} * \mathrm{cc} * \mathrm{XMD} * \mathrm{AMD})+(\mathrm{F} 5$ $[2] / 2) * \mathrm{XED} / \mathrm{XMD} * 3 / \mathrm{F} 5[0] * \operatorname{const} 2 / \mathrm{AMD} *(\mathrm{x} 1[0] *(0.0142)+\mathrm{x} 1$ $[1] *(0.0013)+\mathrm{x} 1[2] *(0.0022))) * * 2+(4 * \mathrm{pi} * 0.01014 * \mathrm{~F} 5[0] /(\mathrm{h}$ $* \mathrm{cc} * \mathrm{XMD} * \mathrm{AMD})) * * 2+(\mathrm{XED} / \mathrm{XMD} * \operatorname{const} 2 / \mathrm{AMD}) * * 2 *(\mathrm{M}[0][0] *(0.0142)$ $* * 2+\mathrm{M}[0][0] *(0.0013) * * 2+\mathrm{M}[2][2] *(0.0022) * * 2))$

print $(\mathrm{CC}, \mathrm{sCC})$

omega $2=\mathrm{x} 1[0] / \mathrm{CC}$

omega $4=\mathrm{x} 1[1] / \mathrm{CC}$

omega $6=\mathrm{x} 1[2] / \mathrm{CC}$

$\mathrm{s} 2=$ omega $2 * \mathrm{sqrt}(\mathrm{M}[0][0] / \mathrm{x} 1[0] * * 2+\mathrm{sCC} * * 2 / \mathrm{CC} * * 2)$

$\mathrm{s} 4=$ omega $4 * \operatorname{sqrt}(\mathrm{M}[1][1] / \mathrm{x} 1[1] * * 2+\mathrm{sCC} * * 2 / \mathrm{CC} * * 2)$

$\mathrm{s} 6=$ omega $6 * \operatorname{sqrt}(\mathrm{M}[2][2] / \mathrm{x} 1[2] * * 2+\mathrm{sCC} * * 2 / \mathrm{CC} * * 2)$

results $=$ omega $2, \mathrm{~s} 2$, omega $4, \mathrm{~s} 4$, omega $6, \mathrm{~s} 6$ 